\title{
Desert Dust Outbreak in the Canary Islands (February 2020): Assessment and Impacts
}
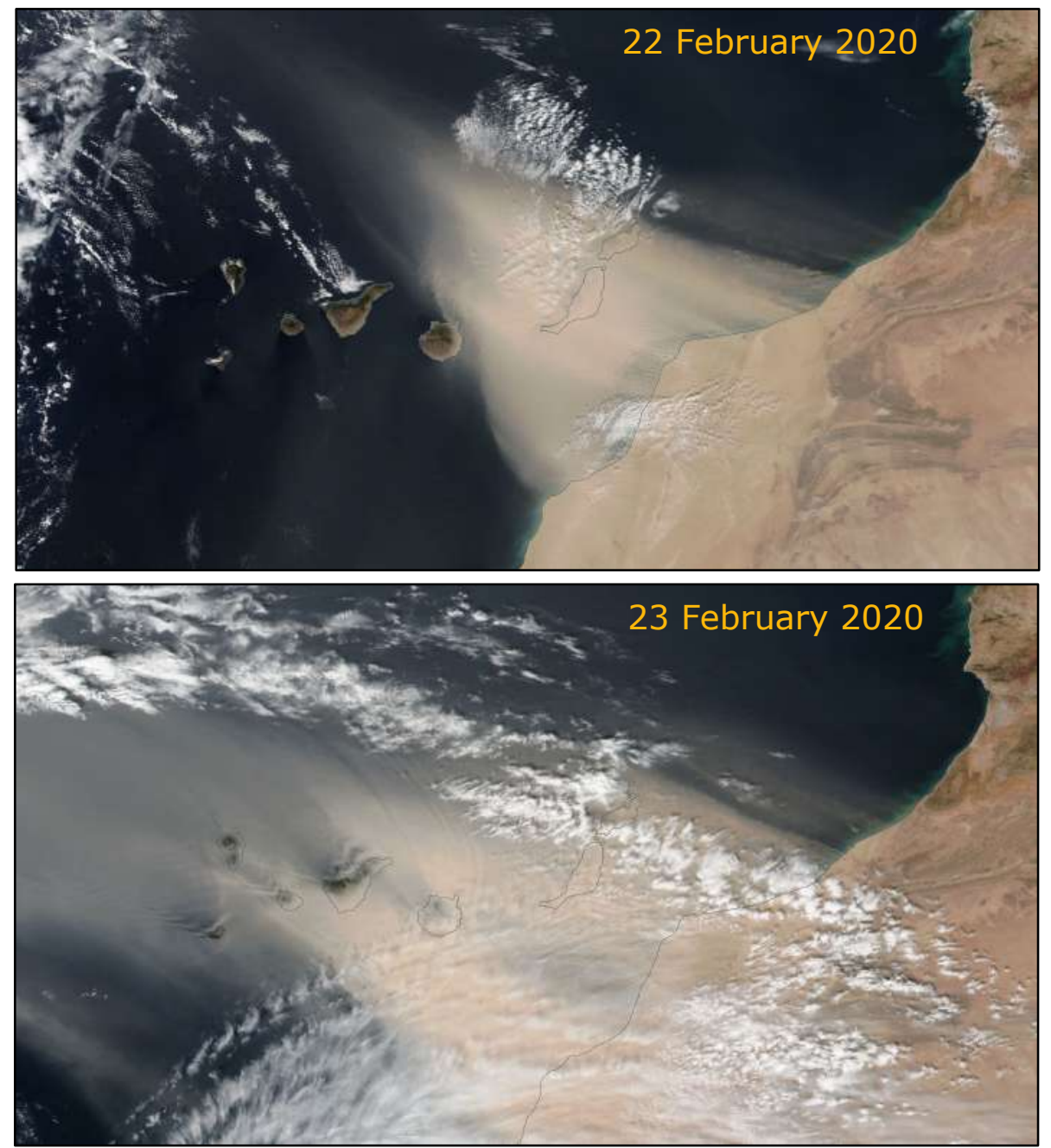

Joint publication of State Meteorological Agency (AEMET) and World Meteorological Organization (WMO)

WMO GAW Report No. 259

WWRP 2021-1 

Cover images: Images for 22-23 February 2020 obtained by the Visible Infrared I maging Radiometer Suite (VIIRS) sensor abord the Suomi polar satellite. We acknowledge the use of imagery provided by services from NASA's Global Imagery Browse Services (GIBS), part of NASA's Earth Observing System Data and Information System (EOSDIS).

\section{Citations:}

Cuevas, E., Milford, C., Barreto, A., Bustos, J. J., García, R. D., Marrero, C. L., Prats, N., Bayo, C., Ramos, R., Terradellas, E., Suárez, D., Rodríguez, S., de la Rosa, J., Vilches, J., Basart, S., Werner, E., López-Villarrubia, E., Rodríguez-Mireles, S., Pita Toledo, M. L., González, O., Belmonte, J., Puigdemunt, R., Lorenzo, J.A., Oromí, P., and del Campo-Hernández, R.: Desert Dust Outbreak in the Canary I slands (February 2020): Assessment and Impacts. (Eds. Cuevas, E., Milford, C. and Basart, S.), State Meteorological Agency (AEMET), Madrid, Spain and World Meteorological Organization, Geneva, Switzerland, WMO Global Atmosphere Watch (GAW) Report No. 259, WWRP 2021-1, 2021.

For more information, please contact: I zaña Atmospheric Research Centre

Headquarters: Calle La Marina, 20

Santa Cruz de Tenerife

Tenerife, 38001, Spain

Tel: +34922151718

Fax: +34922574 475

Email: ciai@aemet.es

http://izana.aemet.es

State Meteorological Agency (AEMET)

Headquarters: Calle Leonardo Prieto Castro, 8

Ciudad Universitaria

28071, Madrid, Spain

www. aemet.es

World Meteorological Organization (WMO)

7 bis, avenue de la Paix

P.O. Box 2300

$\mathrm{CH}-1211$ Geneva 2, Switzerland

www.wmo.int

WMO

GAW Report No. 259

WWRP 2021-1

Disclaimer: The contents of this publication may be reused, citing the source and date. 


\section{(c) World Meteorological Organization, 2019}

The right of publication in print, electronic and any other form and in any language is reserved by WMO. Short extracts from WMO publications may be reproduced without authorization, provided that the complete source is clearly indicated. Editorial correspondence and requests to publish, reproduce or translate this publication in part or in whole should be addressed to:

Chair, Publications Board

World Meteorological Organization (WMO)

7 bis, avenue de la Paix

Tel.: $+41(0) 227308403$

P.O. Box 2300

Fax: $+41(0) 227308040$

$\mathrm{CH}-1211$ Geneva 2, Switzerland

Email: Publications@wmo.int

\section{NOTE}

The designations employed in WMO publications and the presentation of material in this publication do not imply the expression of any opinion whatsoever on the part of WMO concerning the legal status of any country, territory, city or area, or of its authorities, or concerning the delimitation of its frontiers or boundaries.

The mention of specific companies or products does not imply that they are endorsed or recommended by WMO in preference to others of a similar nature which are not mentioned or advertised.

The findings, interpretations and conclusions expressed in WMO publications with named authors are those of the authors alone and do not necessarily reflect those of WMO or its Members.

This publication has been issued without formal editing. 


\title{
Desert Dust Outbreak in the Canary I slands (February 2020): Assessment and I mpacts
}

\author{
E. Cuevas ${ }^{1}$, C. Milford ${ }^{1}$, A. Barreto ${ }^{1,2}$, J. J. Bustos ${ }^{1}$, R. D. García ${ }^{1,3}$, C. L. Marrero ${ }^{1}$, \\ N. Prats ${ }^{1}$, C. Bayo ${ }^{1}$, R. Ramos ${ }^{1}$, E. Terradellas ${ }^{4 *}$, D. Suárez ${ }^{5}$, S. Rodríguez ${ }^{6,7}$, \\ J. de la Rosa ${ }^{8}$, J. Vilches ${ }^{9}$, S. Basart ${ }^{10}$, E. Werner ${ }^{4}$, E. López-Villarrubia ${ }^{11}$, \\ S. Rodríguez-Mireles ${ }^{12}$, M. L Pita Toledo ${ }^{11}$, O. González ${ }^{13}$, J. Belmonte ${ }^{14,15}$, \\ R. Puigdemunt ${ }^{14,15}$, J.A. Lorenzo ${ }^{16}, \mathrm{P}$. Oromí ${ }^{17}$ and R. del Campo-Hernández ${ }^{5}$
}

\section{Editors:}

Emilio Cuevas $^{1}$, Celia Milford ${ }^{1}$ and Sara Basart ${ }^{10}$

1 Izaña Atmospheric Research Centre, State Meteorological Agency (AEMET), Tenerife, Spain

2 Cimel Electronique, Paris, France

3 Air Liquide, Tenerife, Spain

4 Sand and Dust Storm Warning Advisory and Assessment Regional Centre, AEMET, Spain

5 State Meteorological Agency (AEMET), Madrid, Spain

6 Experimental Station of Arid Zones, EEZA CSIC, Almería, Spain

7 Institute of Natural Products and Agrobiology, IPNA CSIC, Tenerife, Spain

8 Universidad de Huelva. Earth Sciences. Huelva, Spain

9 Environment Vice-Ministry, Canary Islands Government, Gran Canaria, Spain

10 Barcelona Supercomputing Centre, Barcelona, Spain

11 Public Health Directorate, Canary I slands Government, Gran Canaria, Spain

12 Hospital Universitario de Gran Canaria, Canary Islands Government, Gran Canaria, Spain

13 Institute of Technology and Renewable Energies (ITER), Tenerife, Spain

14 Institute of Environmental Sciences and Technology, Universitat Autònoma de Barcelona

15 Dept. of Animal Biology, Plant Biology and Ecology, Universitat Autònoma de Barcelona

16 Spanish Ornithological Society (SEO/BirdLife) Canary Islands, Spain

17 Dept. of Animal Biology, Universidad de La laguna (ULL), Tenerife, Spain

${ }^{*}$ Now retired

\section{Joint publication of State Meteorological Agency (AEMET) and World Meteorological Organization (WMO)}

\author{
November 2020
}

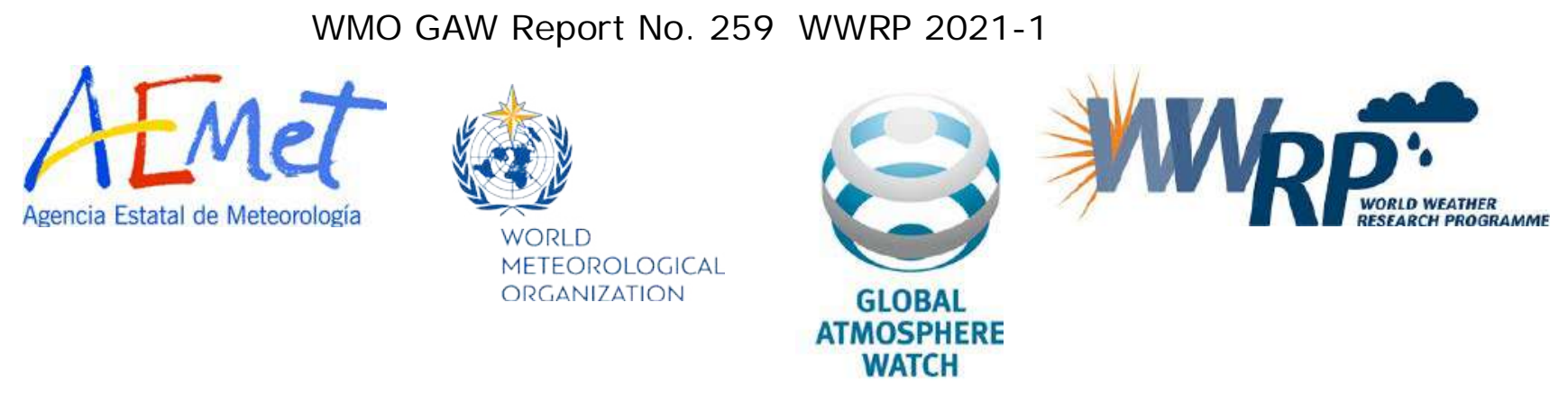





\section{Contents}

1 INTRODUCTION

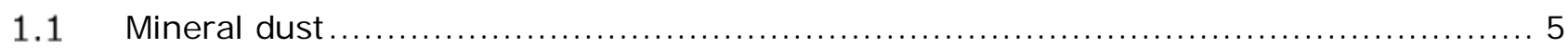

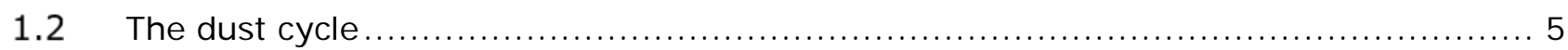

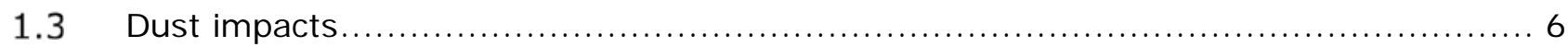

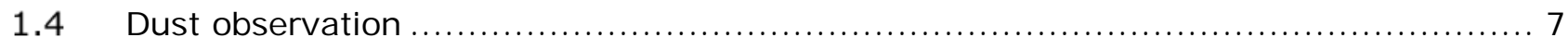

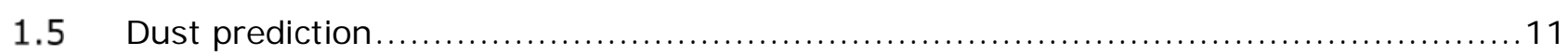

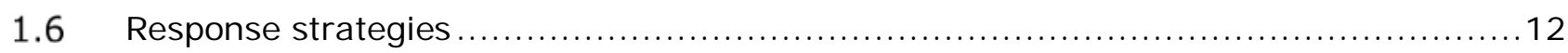

1.7 Saharan mineral dust in the Canary Islands: current and previous research............12

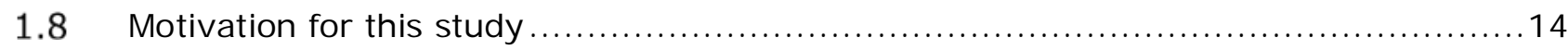

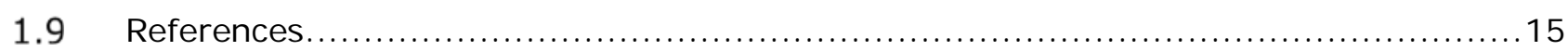

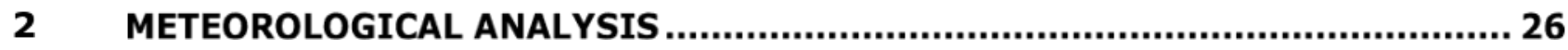

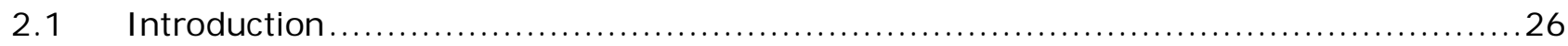

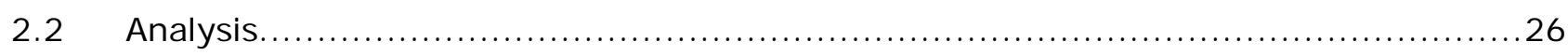

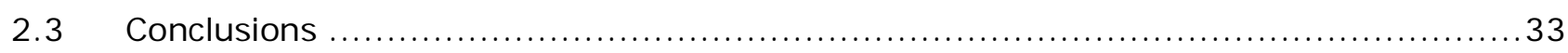

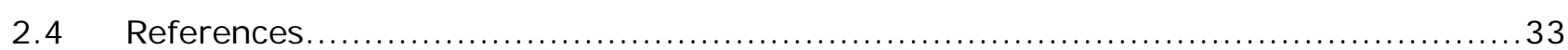

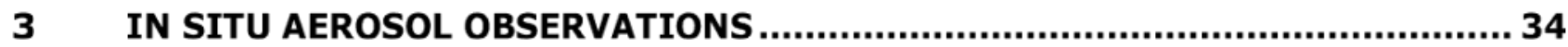

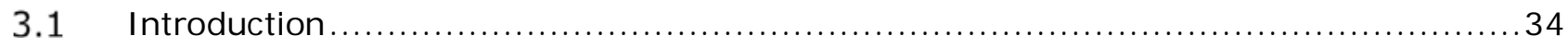

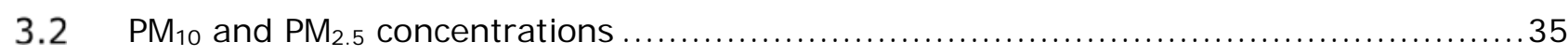

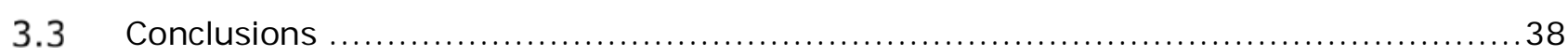

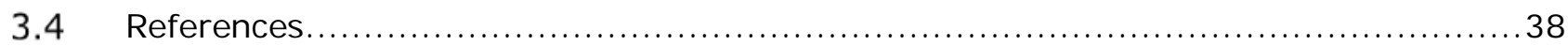

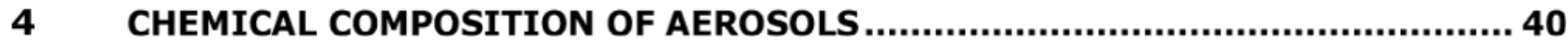

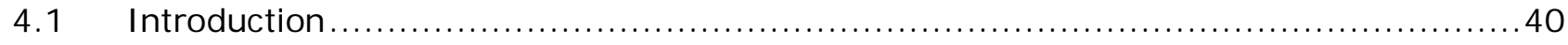

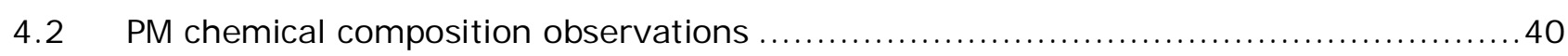

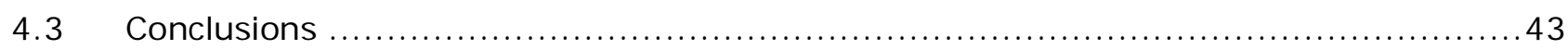

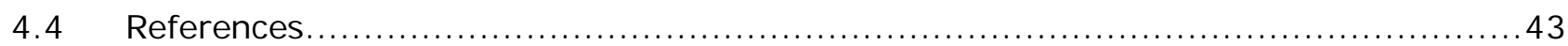

5 COLUMN AEROSOL OBSERVATIONS AND RADIATIVE FORCING ...................... 45

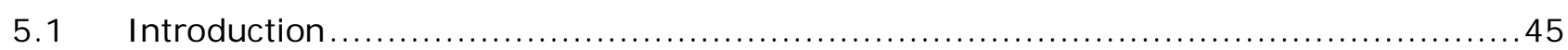

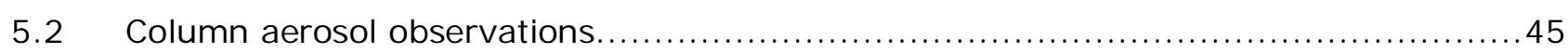

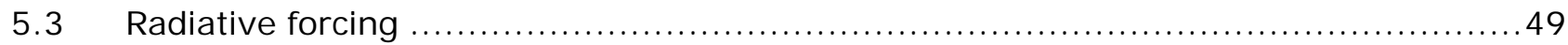

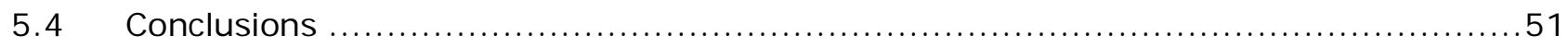

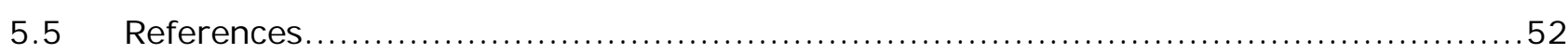

6 LONG-TERM OBSERVATION RECORDS IN THE CANARY ISLANDS...................54

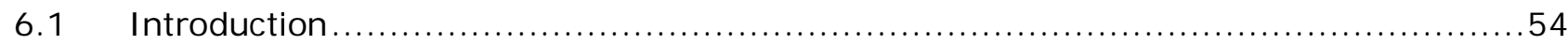

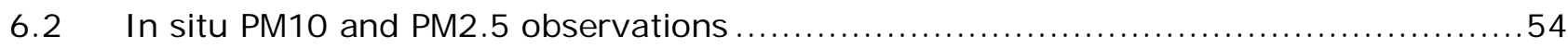

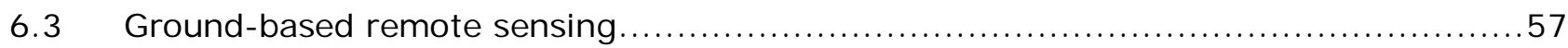




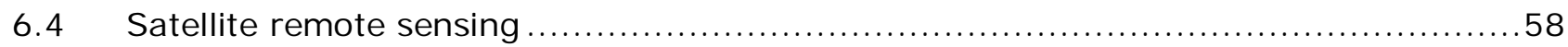

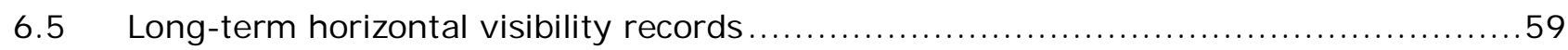

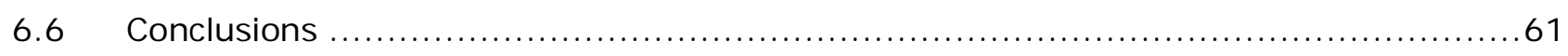

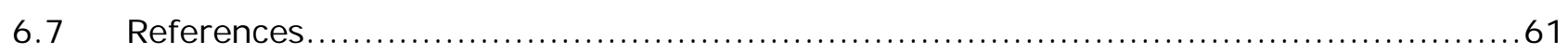

7 NUMERICAL MODELLING OF THE FEBRUARY 2020 DUST EVENT .................... 62

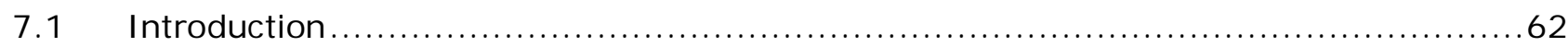

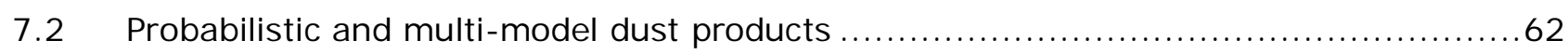

7.3 Operational model performance during the 22-24 February 2020 dust event ..........64

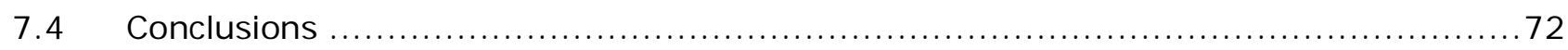

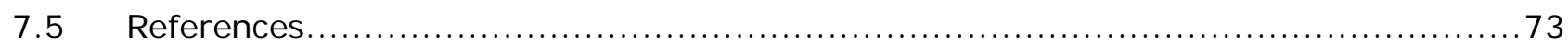

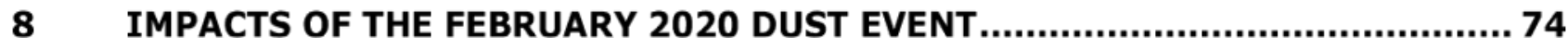

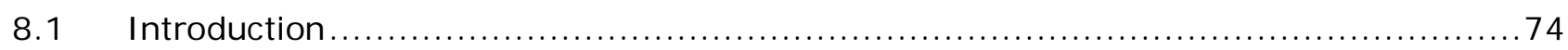

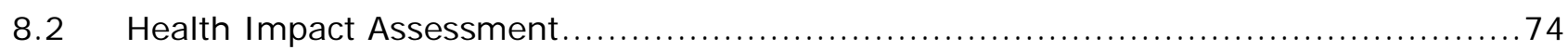

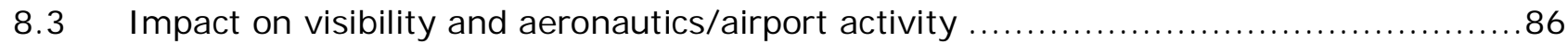

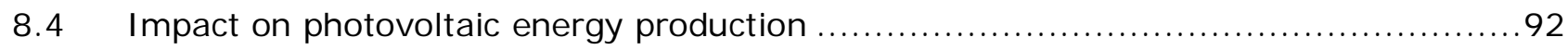

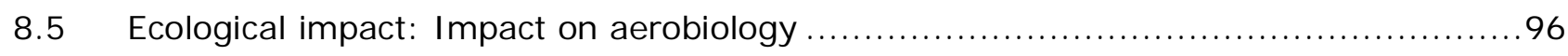

8.6 Ecological impact: Impact on migratory birds in the Canary Islands .................... 101

8.7 Ecological impact: Arrival of invertebrates to the Canary Islands during the February

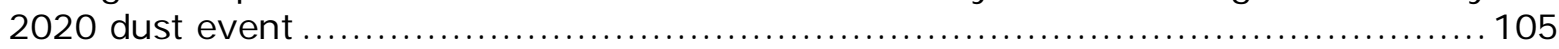

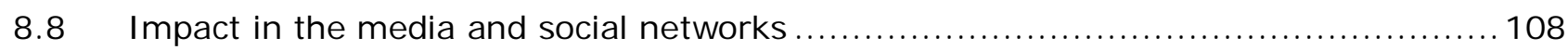

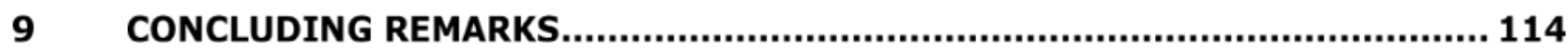

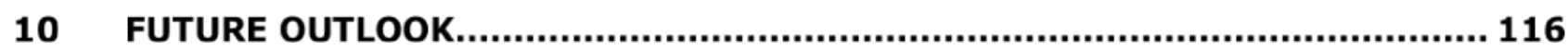

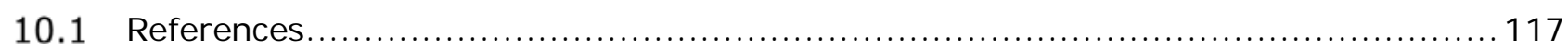

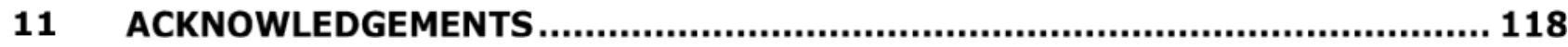


E. Terradellas, E. Cuevas and S. Basart

\section{$1.1 \quad$ Mineral dust}

The World Meteorological Organization (WMO) and the World Health Organization (WHO) both highlight the growing concern about the impact of solid or liquid particles suspended in the air on human health and the environment. These particles, whose sizes range from about 0.001 to 100 microns, can come from very different sources. Some are anthropogenic and consist mainly of sulphates, nitrates and carbon compounds associated with the use of fossil fuels. Others, in contrast, are of natural origin, such as those from biogenic or volcanic emissions, sea salt particles and mineral dust resulting from erosion of soils by wind. On average, this mineral dust accounts for about $40 \%$ of the mass of suspended particles in the atmosphere, although the percentage is extremely variable both geographically and on different timescales. It is sometimes responsible for very severe episodes of pollution, where the concentration of suspended particles can reach levels 10 and even 100 times higher than the maximum value recommended by WHO.

\subsection{The dust cycle}

To understand the variability in concentrations and the occurrence of extreme situations, one must keep in mind the dust cycle, which is one more element of the terrestrial system. In the arid regions of the Earth, when strong wind blows on dry and unvegetated soils, huge amounts of particles are lifted from the surface. Once in the air, these particles - mineral dust - can be incorporated into the atmospheric circulation and transported over great distances before depositing again on the land or ocean surface by effect, largely, of gravity and precipitation.

As can be seen from the annual airborne dust bulletins published by WMO (Figure 1.1), most of the dust is concentrated around the main sources: the belt of tropical and subtropical deserts of the northern hemisphere, which extends from the Sahara, through the Arabic and Syrian deserts, to the Thar, located between India and Pakistan, as well as through the deserts of Central Asia and China-Mongolia (Taklamakan and Gobi).

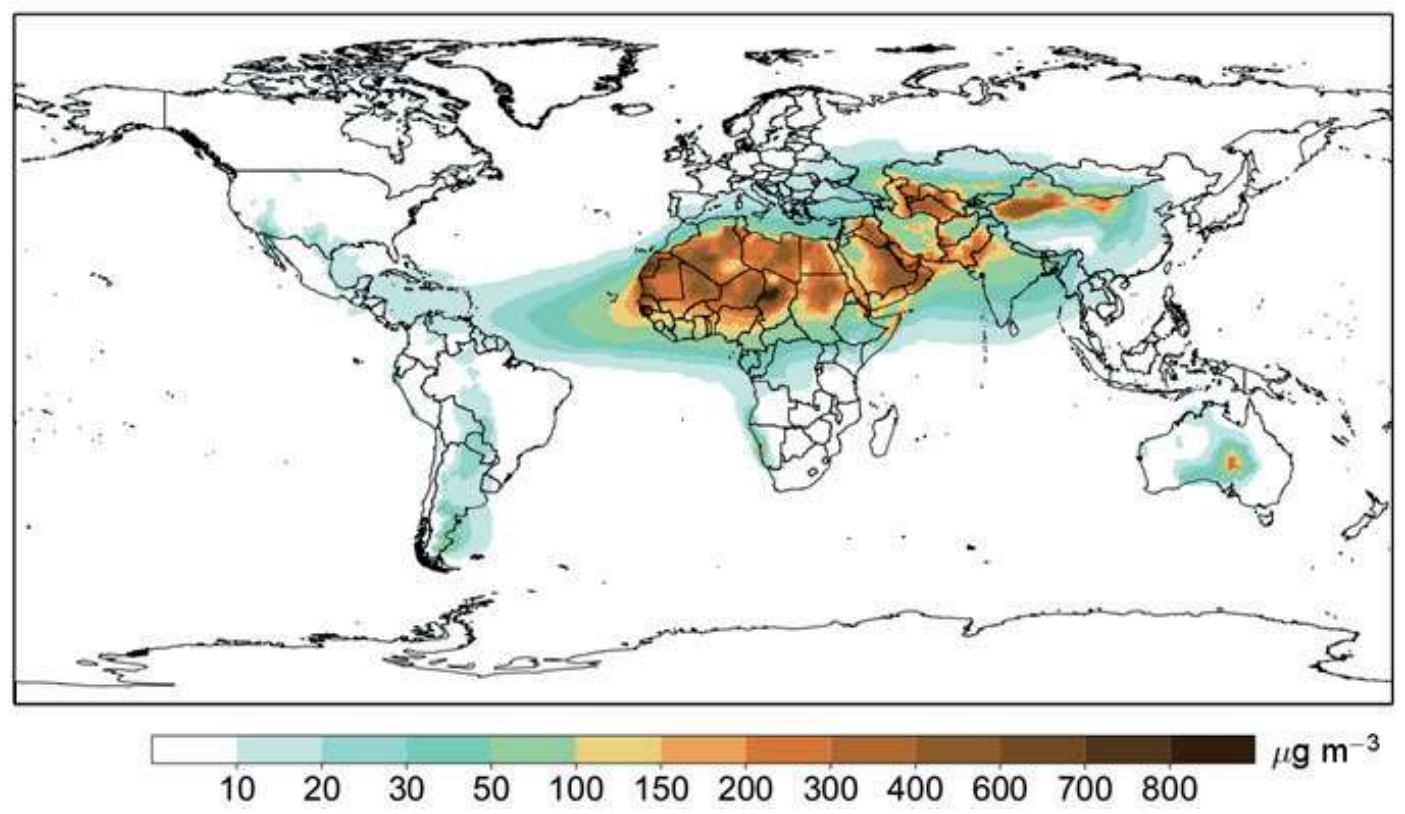

Figure 1.1. Average surface dust concentration during 2018 provided by the NASA MERRA-2 model

(Source: WMO bulletin No. 3, 2019) 
From these sources, dust is transported to the surrounding regions, some heavily populated, such as the Mediterranean basin, Equatorial Africa, northern India or the eastern provinces of China. It is also worth noting the transport of Saharan dust across the Atlantic, which sometimes reaches the Americas and the Caribbean (Prospero \& Lamb, 2003).

\section{$1.3 \quad$ Dust impacts}

In both the source regions and the regions where the particles arrive transported by the wind, the concentration of mineral dust is strongly linked to the evolution of the meteorological situation, but in turn the mineral dust itself affects atmospheric processes, as well as the global and regional climate. The particles absorb, and above all disperse, a part of the solar radiation that reaches the Earth's atmosphere, reducing the proportion of this radiation reaching the surface. Furthermore, the dust also absorbs and re-emits a part of the long-wave radiation from the surface and from the atmosphere itself (Tegen and Lacis, 1996). These interactions are very complex and their net result, in terms of heating or cooling, will depend on the size, shape and chemical and mineralogical composition of the particles, their vertical distribution and the nature and state of the underlying surface.

Dust particles also play an important role in cloud microphysics and precipitation formation processes. They can act as condensation nuclei that facilitate the formation of liquid water clouds and also as freezing nuclei that favour the formation of clouds ice crystals. The changes thus induced alter the life cycle of the clouds and indirectly change again the amount of solar radiation that reaches the surface (Boucher et al., 2013) and affect the amount and location of precipitation.

Suspended dust is an important risk factor for human health, with particle size being the main determinant of the type of problems it can cause. Particles over 10 microns are not inhaled and can only cause damage to external organs of the body: skin or eye irritations, conjunctivitis or increased susceptibility to eye infections. Inhalable particles, i.e. those less than 10 microns, often become trapped in the nose, mouth and upper airways, causing respiratory problems such as asthma, tracheitis, pneumonia, rhinitis or silicosis, or, more commonly, complicating previous pathologies of this nature. Finer particles can penetrate the lower airways and access blood flow, from where they can cause cardiovascular problems and affect any organ in the body. Finally, some infectious diseases, such as bacterial meningitis in the Sahel (Molesworth et al., 2003) or valley fever in the southwestern United States and northwestern Mexico (Sprigg et al., 2014), have also been associated with mineral dust.

High dust concentration episodes also have important immediate and long-term consequences in various economic sectors, including solar energy generation, transport - especially aviation - and agriculture. The presence of dust is a fundamental factor in the design and operation of solar power generation plants. On the one hand, dust deposition soils photovoltaic plant panels and thermosolar mirrors, reducing the power generated and increasing cleaning costs and water consumption, which is a major problem in arid regions. On the other hand, the suspended dust reduces the solar radiation that reaches the surface and, in particular, the fraction of direct radiation, which is practically the only one that can be harnessed in thermosolar plants. Finally, in these latter plants, high concentrations of dust near the earth surface also cause losses in energy transmission from the heliostat field to the receiving tower.

Dust has a significant impact on air traffic due to the reduced visibility it causes. Low visibility conditions pose a danger to airport operations and in particular to aircraft take-offs and landings. They require the activation of protocols that reduce the operational capacity of the airports concerned, which can lead to delays, diversions and cancellations of flights both locally and regionally. Furthermore, continuous exposure to high concentrations of dust causes damage to different aircraft components. In particular, it reduces the lifetime of the motors and increases the frequency of maintenance work. 
The effects of dust on agriculture are multiple. In a dust storm there is an immediate loss in the plant tissue from the impact of the particles. Leaf damage reduces photosynthetic activity and therefore decreases the energy available for plant growth and development. In less severe cases, direct damage is minor, but the deposition of dust on the leaves is also an obstacle for optimal use of the sun's energy. In the longer term, the upper layer of soil is lost, which can lead to increased erosion, land degradation and desertification (Sivakumar, 2005).

Finally, the sedimentation and deposition of dust on the Earth's surface is a source of micronutrients for both terrestrial and marine ecosystems (Jickells et al., 2005). It has been shown that the Amazon rainforest is fertilized by Saharan dust and also that the contribution of phosphorus and iron favours the production of biomass in ocean regions that suffer shortage of these elements (Bristow et al., 2010).

\subsection{Dust observation}

Tracking adverse situations and implementing early warning and prediction systems that enable effective mitigation measures require continuous, reliable observation systems with good spatial and temporal coverage, and near real-time data available. It exists in three groups of observation systems. They are complementary, because they inform us of different aspects of the suspended dust content and its nature and properties. These are in situ observation systems, ground-based remote sensing and satellite teledetection.

\subsubsection{In situ observation}

Rodríguez et al. (2012) present a summary of the methods available for in situ observation of mineral dust. The most commonly used parameters to continuously estimate the particulate concentration near the surface are $\mathrm{PM}_{10}$ and $\mathrm{PM}_{2.5}$ (concentration of particles with aerodynamic diameter less than 10 and 2.5 microns, respectively) supplied by air quality control networks. The gravimetric method, consisting of forcing the passage of ambient air through a filter where the particles are deposited, is the reference method for performing these measurements. However, it is more common to use automatic meters that provide somewhat less accurate measurements, but cheaper, with a higher time resolution and available in a more immediate time frame. It is important to note that PM measurements integrate the contribution of all types of particles, not just mineral dust. In order to obtain estimates of the specific concentration of dust, statistical methods, such as that described in Escudero et al. (2007) will have to be used, or methods based on chemical filter analysis. However, the most important problem for the operational use of these measurements in the monitoring and prediction of dust episodes is the lack of international protocols for the homogenization of observation methods, quality control and real-time data exchange.

Air quality measurements are systematic and with good spatial density in the most developed countries, but dispersed, discontinuous and often not available in real-time near the main sources of dust, usually located in desert areas. In contrast, weather observations records have good spatial and temporal coverage. Since horizontal visibility is reduced by the presence of suspended particles in the atmosphere, visibility data contained in weather reports can be used as an alternative, indirect way to track dust episodes. There is no physical relationship between reduced visibility and particle concentration. However, in the scientific literature you can find various empirical formulas that relate both two quantities (e.g. Camino et al., 2015), and these are usually only applicable in specific geographical areas. It is important to note that visibility is reduced both by the presence of particles and water droplets in the atmosphere. Therefore, the visibility data must be supplemented with present-weather information to rule out cases where visibility is reduced by the presence of hydrometeors (fog, rain, etc.). Since October 2015, the WMO Regional Centre for northern Africa, the Middle East and Europe of the WMO Sand and Dust Storm Warning Advisory and Assessment System (SDS-WAS) publishes every six hours a map of its geographic domain showing all meteorological observatories where visibility has been reduced to less than $5 \mathrm{~km}$ by the presence of dust (Figure 1.2). 

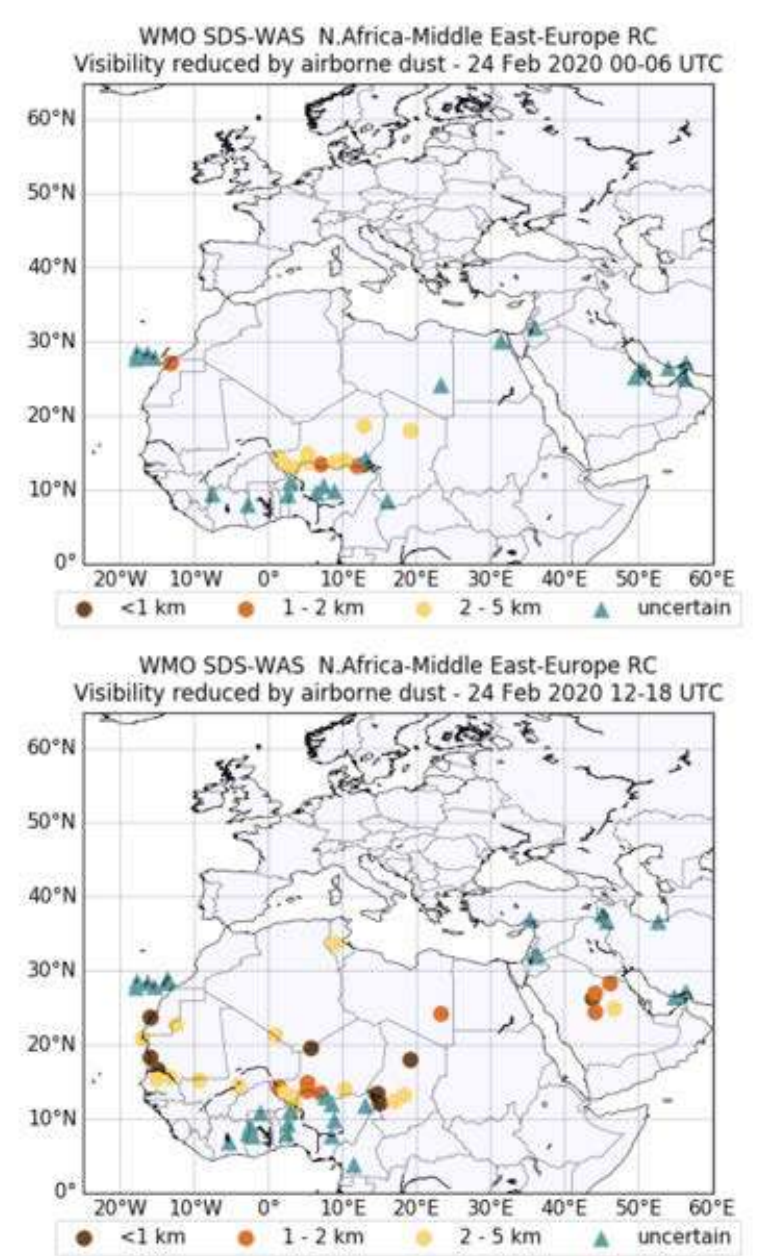

WMO SDS-WAS N.Africa-Middle East-Europe RC

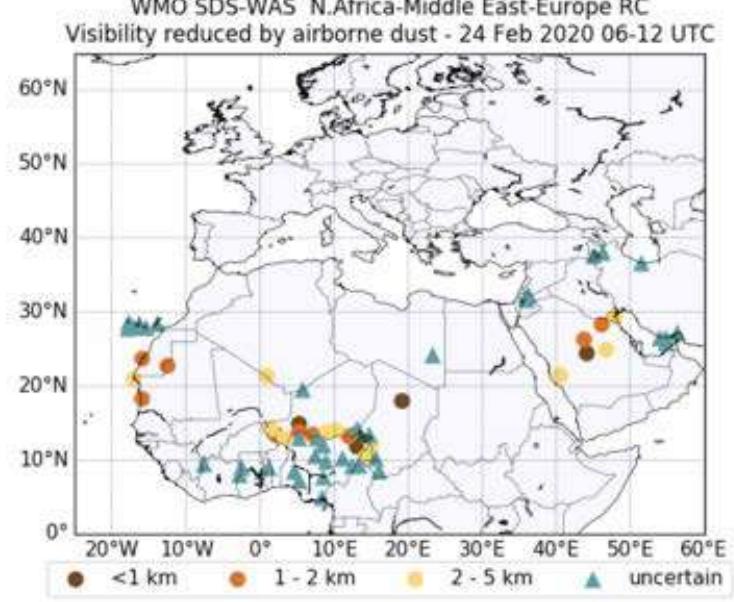

WMO SDS-WAS N.Africa-Middle East-Europe RC

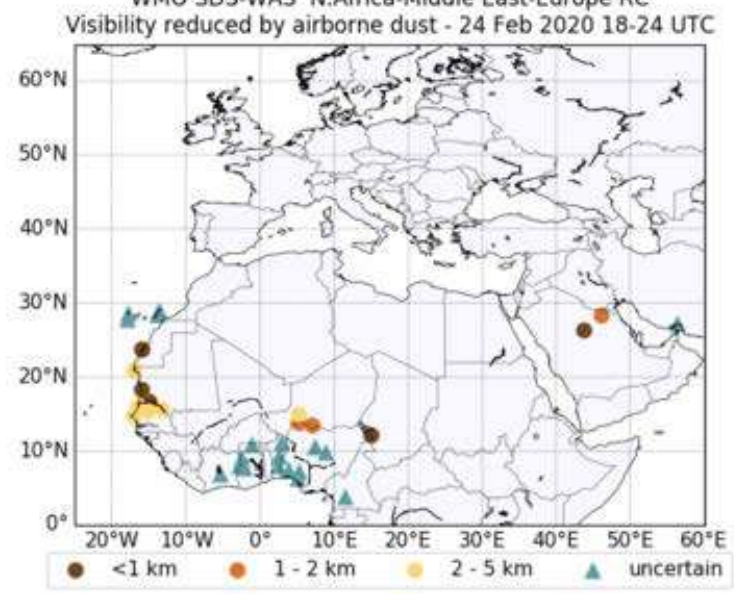

Figure 1.2. Meteorological observatories where on 24 February 2020 visibility was reduced to less than $5 \mathrm{~km}$ by the presence of dust

(Source: https://sds-was. aemet.es/forecast-products/ dust-observations/visibility).

\subsubsection{Ground-based remote sensing}

Photometers and lidars are the most commonly used ground-based remote sensing systems for measuring the content and properties of suspended particles. The former belongs to the category of passive remote sensing, because they are based on the measurement of radiation received from an external source. The lidar, on the other hand, emits pulses of radiation and measures the fraction returned by the atmosphere, so they are called active remote sensing systems.

Solar photometers intended for the observation of suspended particles, automatically and continuously measure direct solar irradiance at different wavelengths. Considering that the radiation emitted by the sun is known, algorithms (Dubovik \& King, 2000) have been developed to calculate the so-called aerosol optical depth (AOD), a dimensionless variable indicating the power of suspended particles to attenuate radiation of a certain wavelength as it passes through the atmosphere. Indirectly, AOD serves to estimate the total load of aerosols in an atmospheric column. In addition, the Ångstrom exponent ( $\mathrm{AE}$ ), which is the variation of AOD with wavelength, gives us information on the dominant size of the particles.

In the world there are several solar photometers networks, the Aerosol Robotic NETwork (AERONET, Holben et al., 1998), SKYNET (Takamura and Nakajima, 2004), and the GAW Precision Filter Radiometer (GAW-PFR) network (Kazadzis et al., 2018). AERONET (Holben et al., 1998) is the most extensive network (i.e. with a global coverage and longest-term records). The Maritime Aerosol Network (MAN), the marine component of AERONET, 
complements the networks on the land (Smirnov et al., 2009). In addition to direct solar irradiance measurements, the photometers in this network perform diffuse radiation measurements that provide additional information on the size and optical properties of the suspended particles. Solar photometers have a limitation that they do not allow measurements with a cloud covered or night sky. For this reason, equipment has been developed, already incorporated into the AERONET network, capable of obtaining AOD and AE from the measurement of solar radiation reflected by the moon (Barreto et al., 2013). Finally, different procedures have been tested to estimate the contribution of mineral dust to total AOD. They all use particle size distribution or $\mathrm{AE}$, which is an indicator of dominant size, and rely on assumption that mineral dust particles are the largest, which is usually true far from the oceans, where particles of sea salt abound, of a similar size to mineral dust.

A lidar consists of an emitting unit, equipped with a source of luminous pulses that are sent vertically into the atmosphere, and a telescope, which measures the portion of energy backscattered by the atmosphere to the surface. Based on this information and using inversion algorithms, these instruments provide information on the vertical distribution of suspended particles. Mona et al. (2012) present a detailed review of this technique. There are lidar equipment with different levels of complexity, from automatic elastic backscatter systems, that measure the energy that has not undergone a frequency change, to the more complex Raman lidar, with multiple frequencies and capable of measuring energy that has undergone a change of frequency when backscattered.

The basic product of lidar systems is the vertical backscatter profile which, through additional hypotheses can be converted into a vertical extinction profile and, usually with the additional use of a solar photometer, a vertical particle mass concentration profile (Bovchaliuk et al., 2016), although this last step introduces quite a bit of uncertainty. More complex systems also allow us to infer microphysical properties such as refractive index and particle size distribution (Müller et al., 2019).

For specific information on mineral dust, polarized light lidar systems must be used. Indeed, the fraction of depolarized light depends on the shape of the particles; it is higher in those that are less spherical, such as dust. Another element that adds significant information about the specific dust content is a channel that measures the inelastic backscatter (Raman) produced by silicon dioxide, a very abundant compound in dust particles (Tatarov et al., 2011).

There are currently several lidar networks in operation. WMO promotes collaboration between them and the harmonization of their products through GALION (Bösenberg and Hoff, 2007), a network of networks established under the GAW Programme.

Ceilometers are simple, automatic, single-wavelength equipment that works continuously using lidar technology. They have been used preferably in aeronautical meteorology to measure the height of the base of the clouds. However, they can also be used to obtain backscatter profiles (Thomas, 2012). In Europe, these teams have been integrated into the E- PROFILE operational network, within the framework of EUMETNET, which is an association of 31 national meteorological services in Europe.

\subsubsection{Satellite remote sensing}

Satellite products, because of their wide spatial coverage and rapid availability, are a basic tool for observing the spatio-temporal distribution of dust. In particular, they allow us to identify dust sources and transport routes, so they are very useful for monitoring adverse situations. In addition, some products are applicable for the initialization of numerical prediction models. Many operational aerosol products are nowadays available from both polar Low Earth Orbiting and geostationary satellites. The retrieval of desert dust from space observations does largely rely on an interpretation step of the measured optical properties which differs depending on the capabilities of different instruments onboard of the considered satellite. 
Polar satellites are at relatively low altitudes (between 500 and $800 \mathrm{~km}$ ), covering a global domain at high spatial resolution with a consistent sensor. However, the polar sensors provide few measurements per day over the same point. Conversely, geostationary satellites are situated at a set point over the Equator, at $36000 \mathrm{~km}$ height, and provide measurements over a given disk. For instance, Meteosat Second Generation (MSG) sharing the advantages of a geostationary orbit and the geometric, radiometric and spectroscopic capabilities of the Spinning Enhanced Visible and InfraRed Imager (SEVIRI) radiometer, is an essential tool for Near Real-Time (NRT) monitoring in Europe and Africa (Figure 1.3).

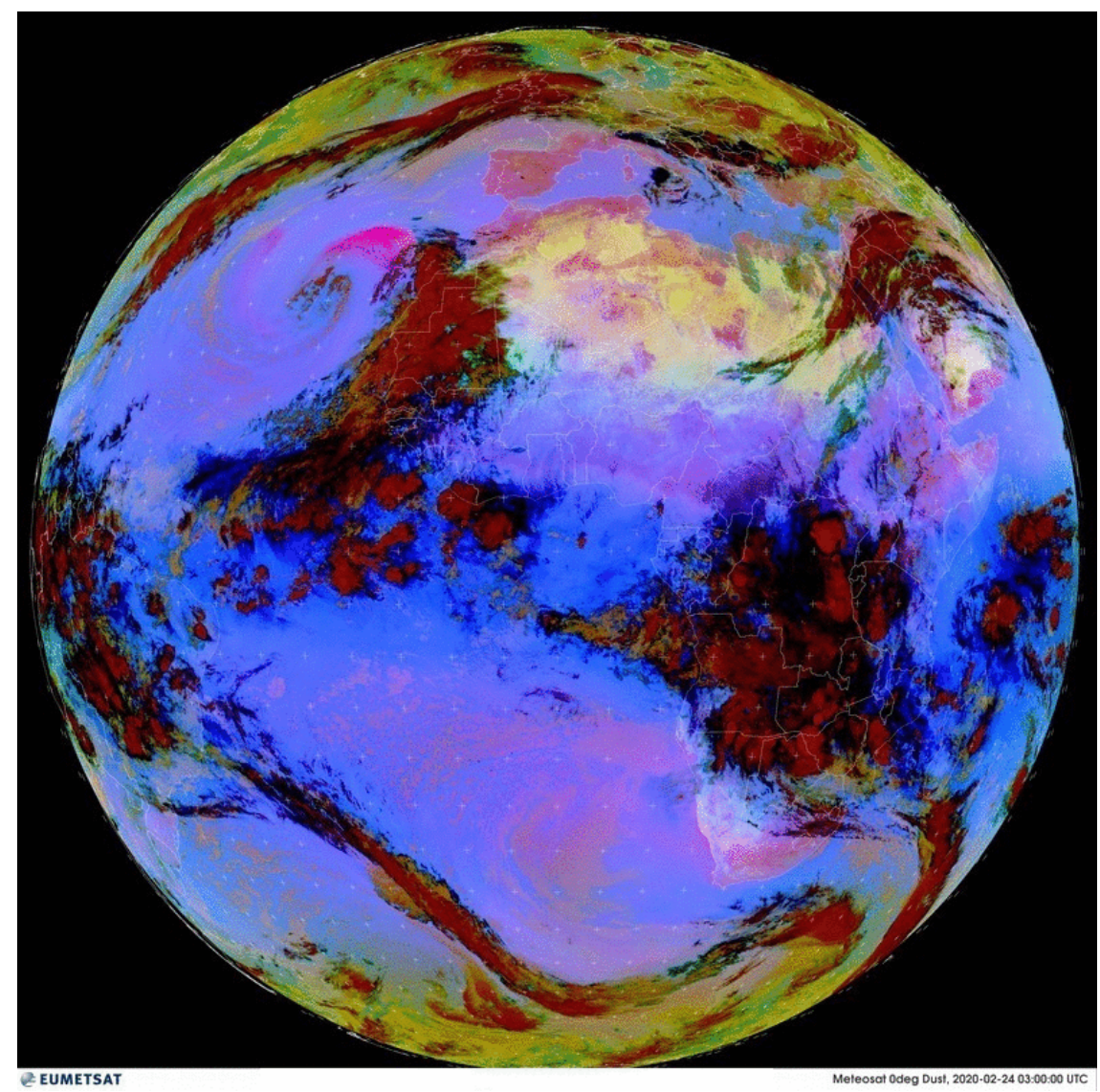

Figure 1.3. EUMETSAT RGB-Dust Product from 24 February 2020 at 03 UTC where the Saharan dust plume covering the Canary I slands is observed in pink.

There has been a series of significant satellite system developments to provide desert dust products (Cuevas et al., 2015). In the 1990s, the community utilized the Advanced Very-HighResolution Radiometer (AVHRR) and the Total Ozone Mapping Spectrometer (TOMS) sensors for desert dust detection. In 2000, with the launch of the polar NASA Terra satellite with the Moderate Resolution Imaging Spectroradiometer (MODIS), a significant advancement in desert dust observations started. Some of these instruments already provided information about the nature and properties of atmospheric particles:

- The Moderate Resolution I maging Spectroradiometer (MODI S), installed on board the Terra and Aqua satellites, provides AOD values that are most commonly assimilated by prediction models. It also provides some information on the type and size of airborne particles.

- The Multi-angle I maging SpectroRadiometer (MISR), which travels aboard the Terra satellite, provides, in addition to basic products such as AOD, properties of particles such as their size and shape. Due to its small viewing angle, it has a limitation with a global coverage that can be reached only in 9 days. 
- The Ozone Monitoring I nstrument (OMI), on board Aura satellite, is especially useful for distinguishing between sulphates, dust and smoke, but also allows to obtain total AOD.

- The Cloud-Aerosol Lidar with Orthogonal Polarization (CALIOP), an elastic lidar with two wavelengths and polarized light, is the main instrument on board the CALIPSO satellite. It provides vertical profiles of backscatter and dominant particle type.

- The POLarization and Directionality of the Earth's Reflectances (POLDER) is a passive optical imaging radiometer and polarimeter instrument on board of PARASOL (Polarization \& Anisotropy of Reflectances for Atmospheric Sciences coupled with Observations from a Lidar) which is a French-built Earth observing research satellite. It provides AOD and dominant particle type.

- The I nfrared Atmospheric Sounding I nterferometer (IASI), a Fourier Transform Spectrometer, on board the European Space Agency (ESA) MetOp satellite. It provides vertical profiles of backscatter and dominant particle type.

- The Advanced Along-Track Scanning Radiometer (AATSR) is a multi-channel imaging radiometer on board the ESA satellite ENVISAT. It provides some information on the type and size of particles.

In 2017, the Sentinel-5P satellite was launched, specifically aimed at observing atmospheric composition. It is expected that in the coming years, new and important advances will be made with the provision of more sophisticated instruments, some already in orbit, such as the Sea and Land Surface Temperature Radiometer (SLSTR) aboard Sentinel-3 or the Visible Infrared I maging Radiometer Suite (VIIRS) aboard the NASA Suomi NPP polar satellite. It is important to mention that there are several follow-up sensors that will continue these dustrelated observations. In some cases, the successor instruments are already in orbit, such as VIIRS replacing MODIS and AATSR, while in other cases they are scheduled for launch within the next few years. Some examples of successor instruments are: the Multi-viewing Multichannel Multi-polarization I maging (3MI) replacing POLDER; the Infrared Atmospheric Sounder Interferometer - New Generation (IASI-NG) replacing IASI; the InfraRed Spectrograph (IRS) replacing SEVIRI and the Atmospheric lidar (ATLID) on board the EarthCARE satellite replacing CALIOP.

\section{$1.5 \quad$ Dust prediction}

For about 25 years, the dust concentration forecast has been addressed by Numerical Weather Prediction (NWP) models in which this concentration is included in the forecast equations of the model itself (Nickovic and Dobricic, 1996). Benedetti et al. (2018) detail how this approach to the dust forecasting has provided good results, although it still faces several challenges. As there is the wide variety of scales of the processes involved in the dust cycle, models with high resolution and extensive geographic domain are needed, requiring enormous computing capacity. In addition, dust production is a function of the strength of the wind on the surface and the conditions of the ground, but the wind has a very variable magnitude, in space and in time, and the soil conditions are sometimes very heterogeneous and are not always well characterized. In addition, the dust emission is approximately proportional to the third power of the wind speed. Therefore, quantitative prediction of dust concentration requires a high accuracy in wind forecasting, which is conditioned by the capacity of current NWP models.

A significant problem in dust prediction is the lack of observational data suitable for the data assimilation process and for the verification of the predictions themselves. Most observational systems provide information on the total particle content and it is not easy to discriminate the specific contribution of mineral dust. In addition, remote sensing methods often integrate the signal from the entire atmospheric column and provide little information about the height at which the dust cloud is located. Under these circumstances, the AOD obtained from MODIS 
was the first product used in data assimilation (Zhang and Reid, 2006), although before the Deep Blue algorithm (Hsu et al., 2004) was operationally introduced, information on the most reflective surfaces, such as deserts, was lacking. The assimilation of AOD by models that do not simulate other types of particles besides dust is particularly complex.

Despite the difficulties, during the last 25 years the number of predictions made by national meteorological services and research centres around the world has increased steadily. Many of them are currently available through the WMO Sand and Dust Storm Warning Advisory and Assessment System (Terradellas et al., 2015; Basart et al., 2019), which will be described in the following section.

Ensemble Prediction System (EPS) attempt to describe the future state of the atmosphere from a probabilistic point of view. Multiple simulations are performed with one or more models to take into account the uncertainty in the initial state or inaccuracy of the models and mathematical methods used to solve their equations (Palmer et al., 2005). So far, three multimodel dust prediction initiatives have been launched. These aim to mitigate the deficiencies of individual models and evaluate the uncertainty associated with the prediction made with a single model. One of the systems is based on global models (Sessions et al. 2015), while the other two, developed in the framework of SDS-WAS, are regional in nature, for northern Africa, the Middle East and Europe (Terradellas et al., 2016) and for Asia.

\section{$1.6 \quad$ Response strategies}

In response to society's need to follow and predict episodes with high dust concentrations, as well as for the assessment and mitigation of their negative impacts, in May 2007, WMO launched the SDS-WAS, with the mission of improving the capacity of countries to provide predictions, observations, information and knowledge to users. It is an international consortium involving research institutes and operational centres around the world, especially meteorological services (Terradellas et al., 2015). It is organized into three regional nodes:

- $\quad$ Regional Node for northern Africa, the Middle East and Europe (SDS-WAS NAMEE RC) coordinated by a Regional Centre located in Barcelona, managed by the State Meteorological Agency of Spain (AEMET) and the Barcelona Supercomputing Centre (BSC);

- $\quad$ Regional Node for Asia, coordinated by a Regional Centre in Beijing, managed by the Chinese Meteorological Administration;

- $\quad$ Regional Node for the American continent, coordinated by a Regional Centre in Barbados, managed by the Caribbean Institute for Meteorology and Hydrology.

In May 2013, faced with the demand for many national meteorological services and the good results obtained by SDS-WAS, which demonstrated the feasibility and the need to convert R\&D initiatives into operational services, WMO appointed the AEMET and BSC consortium to create in Barcelona the first Regional Meteorological Centre specialized in Dust and Sand Storm Prediction. The Centre began operating in February 2014 under the name Barcelona Dust Forecast Centre. Every day it generates and distributes predictions for northern Africa (north of the Equator), Middle East and Europe (Terradellas et al., 2016). Subsequently, in 2018, a second operating Centre was created in Beijing, which makes daily predictions for Asia.

\subsection{Saharan mineral dust in the Canary I slands: current and previous research}

The Canary Islands form an archipelago located in the eastern part of the subtropical North Atlantic, near the coasts of southern Morocco and northern western Sahara, between coordinates $27^{\circ} 37^{\prime} \mathrm{N}$ and $29^{\circ} 25^{\prime} \mathrm{N}$, and $13^{\circ} 20^{\prime} \mathrm{W}$ and $18^{\circ} 10^{\prime} \mathrm{W}$. The archipelago is an ideal place for the study of the transport of mineral dust from the Sahara to the subtropical North Atlantic. 
The Izaña Observatory situated on the island of Tenerife at $2373 \mathrm{~m}$ a.s.I., is a meteorological and climatological station that was inaugurated in 1916. In addition, it is also one of the 31 WMO GAW stations with a comprehensive programme for the measurement of atmospheric aerosols, and specifically for mineral dust. This station is complemented by another station in Santa Cruz de Tenerife, at sea level, and with a station at very high altitude in the terminal of the Teide Cable Car (3555 m a.s.I.) (Cuevas et al., 2019). Substantial number of research studies on Saharan mineral dust were conducted in the Canary I slands by research groups working either directly with the Izaña Observatory GAW programme, or with data obtained at this observatory and other stations located in the archipelago.

The relationship of the island of Tenerife with dust observations goes back many years. The first indirect reference can be found in an article by Charles Darwin himself (1846) in which he groups and analyses numerous scattered accounts of dust that has fallen in considerable quantities on ships sailing the Atlantic Ocean near the African coast. Darwin himself made dust observations aboard the ship H.M.S. Beagle during his voyages near the Cabo Verde archipelago, south of the Canary Islands. In fact, Darwin had planned a thorough exploration of the island of Tenerife with his friend Ramsay, but just as they anchored in the port of Santa Cruz de Tenerife on 6 January 1832, the captain of the Beagle, Robert Fitzroy, was informed that they could not disembark. News had arrived that there had been an outbreak of cholera in England and therefore as a precautionary measure, the crew and passengers aboard the H.M.S. Beagle would have to quarantine before setting foot in Tenerife. The Beagle left Tenerife without Darwin being able to realize his wish to visit Pico del Teide and analyse the characteristic features of the island of Tenerife.

The distinguished Prof. Christian Junge, considered the father of modern atmospheric chemistry, and the first driving force for the Izaña Observatory to become what it is today, a measurement and monitoring station of atmospheric composition of global importance, discovered that dust from the Sahara could cross the entire Atlantic and reach the Caribbean (J unge, 1954). Junge himself, together with other eminent German scientists from the Max- Planck-Institut für Chemie (Otto-Hahn-Institut) in Mainz (Germany) conducted the first trace gas measurements at the Izaña Observatory. Their results showed that the observatory offered excellent conditions for the study of subtropical air masses of maritime and continental origin. They obtained results on the size distribution and composition of aerosols and the concentration of trace gases such as $\mathrm{CO}_{2}, \mathrm{~N}_{2} \mathrm{O}$ and $\mathrm{SO}_{2}$ measured in extremely pure air conditions (Abel et al., 1968). However, paradoxically, there was no Saharan dust outbreak in the period of time in which they were measuring at the Izaña Observatory. Instead it was Prof. Joseph M. Prospero from the University of Miami, who studied the transoceanic transport of mineral dust and began the first systematic measurements of dust from the Sahara at the I zaña Observatory in 1974 in the framework of the Global Atmospheric Research Programme (GARP) Atlantic Tropical Experiment (GATE) (Prospero et al., 1976 a; 1976b; Prospero, 1979).

Subsequently, the Sahara dust measurement program at the Izaña Observatory continued within the framework of the Atmosphere-Ocean Chemistry Experiment (AEROCE), a wideranging multidisciplinary and multi-institutional research programme that focused on aspects of atmospheric chemistry of the North Atlantic Ocean (Prospero, 1997). The I zaña Observatory paid a tribute to Prof. Prospero in March 2016, the year in which the Izaña Observatory was celebrating its centenary, by renaming the laboratory that performs aerosol and atmospheric dust measurements as the Joseph M. Prospero Aerosols Research Laboratory. Professor Prospero continues, to this day, collaborating with researchers from the Izaña Observatory, launching continuous initiatives to study the changes that occur in the dust transported by the Saharan Air Layer (SAL) in its transit from Africa to the Caribbean.

In 1995, the first articles on aerosols, mineral dust and other atmospheric components measured in Izaña and on the island of Tenerife began to be published with the active participation of researchers from the National Institute of Meteorology (INM) (now AEMET) (Prospero et al., 1995; Raes et al., 1997). In 2000, the first articles involving Izaña were published in which the impact of mineral dust was modelled (Díaz et al., 2000; Expósito et al., 2000), and in which satellite data were used (Díaz et al., 2001). In 2002, the first major intensive measurement campaign was carried out to characterize the chemical composition of 
mineral dust in Tenerife (Querol et al., 2003), which would be followed by others (Kandler et al., 2007), publishing the first article on the impact of dust on air quality in the Canary I slands (Viana et al., 2002). Other articles have also been published in this last line of work (Alastuey et al., 2005; Alonso-Pérez et al., 2007; Rodríguez et al., 2008; Querol et al., 2008; Milford et al., 2020).

Due to the tests that France carried out with atomic bombs in southern Algeria between 1960 and 1966, one research area has been to confirm the relationship between the concentration of mineral dust in the Sahara and the levels of certain radiotracers (Hernández et al, 2005; Karlsson et al., 2008; Hernández et al., 2008). Characterization studies of the chemical composition and optical properties of mineral dust have also been carried out in different desert areas of North Africa, the Middle East, the Iberian Peninsula and the Canary Islands (Moreno et al., 2006; Castillo et al., 2008 ; Basart et al., 2009; Delgado et al., 2010; Guirado et al., 2011; 2014; Andrews et al., 2011; Ravelo-Pérez et al., 2016; García et al., 2017 a; 2017b; Pandolfi et al., 2018, Rodríguez et al., 2019; Laj et al., 2020). The presence of pollutants, produced in North Africa, in the mineral dust was analysed at the Izaña Observatory (Rodríguez et al., 2011).

Studies have also been carried out on the radiative forcing exercised by desert mineral dust (García et al., 2008; 2011 a; 2011b; 2012; 2014; 2018; Collaud Coen et al., 2020), and its impact on satellite measurements (Bassani et al., 2016). Another set of studies have been focused on studying the processes of generation and transport of mineral dust, such as the analysis of weather patterns that favour dust intrusions into the Marine Boundary Layer (MBL) of the North Atlantic (Alonso-Pérez et al., 2011), dry and wet deposition (Castillo et al., 2017) or the study of trends in the MBL (Alonso-Pérez et al., 2010). The determination of dust source regions (Alonso-Pérez et al., 2012; Salvador et al., 2014) and atmospheric processes that modulate large-scale dust transport in the free troposphere to the North Atlantic and the Mediterranean (Rodríguez et al., 2015; Cuevas et al., 2017) have also been the subject of research.

The characterization of the vertical structure of the Saharan Air Layer over the subtropical North Atlantic (Córdoba-J abonero et al., 2011; 2016; Andrey et al., 2014; Berjón et al., 2019) has also been addressed, including the studies of the nucleation processes of mineral dust in the SAL (Boose et al., 2016). The extensive experience in aerosol observation at the Izaña Observatory has resulted in the publication of a series of scientific articles on methodologies and instrumentation specifically designed for aerosol measurements, and their quality assurance (Rodríguez et al., 2012; Guirado et al., 2012; Barreto et al., 2013; 2014; 2016; 2017; 2019; 2020; Torres et al., 2014; 2017; Camino et al., 2015; García et al., 2016; Almansa et al., 2017; 2020; López-Solano et al., 2018; Toledano et al., 2018, Benavent-Oltra et al., 2019; Cuevas et al., 2019; García-Cabrera et al., 2020).

Numerical modelling of mineral dust and evaluation of dust models has been addressed within the framework of the activities of the two SDS-WAS WMO regional centres coordinated by AEMET in collaboration with the BSC (Basart et al., 2012; Cuevas et al., 2015; Huneeus et al., 2016; Pérez García-Pando et al., 2016) and within the framework of ECMWF and Copernicus activities (Eskes et al., 2015; Benedetti et al., 2018). The impact of mineral dust on different aspects of human health in regions of Africa and the Canary Islands has also been the subject of research (López-Villarrubia et al., 2012; Pérez García-Pando et al., 2014; Baez-Ferrer et al., 2019; Domínguez-Rodríguez et al., 2019; 2020).

\section{$1.8 \quad$ Motivation for this study}

The Izaña Observatory is world-renowned as a pioneer in the studies of mineral dust and its impact on the environment. It is ideally located to serve as a Centre of excellence in future aerosol research and continue to lead research on mineral dust and its role in climate change.

Due to the extensive experience available in the Canary Islands and specifically in the Izaña Observatory, in undertaking studies on Sahara mineral dust, it was considered appropriate to 
carry out a comprehensive multidisciplinary study of the 22-24 February 2020 dust outbreak that severely affected the archipelago. The 22-24 February 2020 dust outbreak, the most intense since there are records in the Canary Islands, is the ideal candidate for this type of study. The increase in the frequency and intensity of adverse meteorological phenomena as a consequence of climate change and global warming requires atmospheric researchers to work together with specialists from other disciplines to be able to assess the impact that adverse meteorological events, such as dust outbreaks, can have on numerous socio-economic activities, and to estimate if possible, their economic cost.

1.9 References

Abel, N., R. Jaenicke, C. Junge, H. Kanter, P. Rodríguez García Prieto, W. Seiler, 1969: Luftchemische Studien am Observatorium Izaña (Teneriffa). Met. Rdsch., 22.

Alastuey, A., X. Querol, S. Castillo, M. Escudero, A. Avila, E. Cuevas, C. Torres, P.M. Romero, F. Exposito, O. García, J.P. Diaz, R.V. Dingenen, J.P. Putaud, July 2002: Characterization of total suspended particles (TSP) and PM2.5 at Izana and Sta. Cruz de Tenerife (Canary Islands, Spain) during a Saharan dust Episode, Atmos. Environ., 39, 26,4,715-4.728, 2005.

Almansa, A. F., E. Cuevas, B. Torres, Á. Barreto, R.D. García, V.E. Cachorro, Á.M. de Frutos, C. López, and R. Ramos, 2017: A new zenith-looking narrow-band radiometer-based system (ZEN) for dust AOD monitoring, Atmos. Meas. Tech., 10, 565-579, https: //amt.copernicus.org/articles/10/565/2017/.

Almansa, A.F., E. Cuevas, Á. Barreto, B. Torres, O.E. García, R. Delia García, C. VelascoMerino, V.E. Cachorro, A. Berjón, M. Mallorquín, C. López, R. Ramos, C. Guirado-Fuentes, R. Negrillo, Á.M. de Frutos, 2020: Column Integrated Water Vapor and Aerosol Load Characterization with the New ZEN-R52 Radiometer, Remote Sens., 12, 1424.

Alonso-Pérez, S., E. Cuevas, X. Querol, J.C. Guerra, C. Pérez, 2012: African dust source regions for observed dust outbreaks over the Subtropical Eastern North Atlantic region, above 25N. Journal of Arid Environments, 78, 100-109, https:// www.sciencedirect.com/journal/journal-of-arid-environments/vol/78

Alonso-Pérez, S., E. Cuevas, C. Pérez, X. Querol, J.M. Baldasano, R. Draxler, and J.J. de Bustos, 2010: Trend changes of African Airmass intrusions in the marine boundary layer over the subtropical Eastern North Atlantic region in winter. Tellus B, https://onlinelibrary.wiley.com/doi/abs/10.1111/j.1600-0889.2010.00524.x

Alonso-Pérez, S., E. Cuevas, X. Querol, 2011: Objective identification of synoptic meteorological patterns favouring African dust intrusions into the marine boundary layer of the subtropical eastern north Atlantic region. Meteorol. Atmos. Phys. 113:109-124.

Alonso-Pérez, S., E. Cuevas, X. Querol, M. Viana, J.C. Guerra, 2007: Impact of the Saharan dust outbreaks on the ambient levels of total suspended particles (TSP) in the Marine Boundary Layer (MBL) of the Subtropical Eastern North Atlantic Ocean, Atmos. Environ.,41/40, 9468-9480. https://www.sciencedirect.com/science/article/abs/pii/S1352231007007674

Andrews, E., J.A. Ogren, P. Bonasoni, A. Marinoni, E. Cuevas, S. Rodríguez, J.Y. Sun, D.A. Jaffe, E.V. Fischer, U. Baltensperger, E. Weingartner, M. Collaud Coen, S. Sharma, A.M. Macdonald, W.R. Leaitch, N.-H. Lin, P. Laj, T. Arsov, I. Kalapov, A. Jefferson, P. Sheridan, 2011: Climatology of aerosol radiative properties in the free troposphere, Atmospheric Research, 102, 365-393.

Andrey, J., E. Cuevas, M.C. Parrondo, S. Alonso-Pérez, A. Redondas, M. Gil-Ojeda, 2014: Quantification of ozone reductions within the Saharan air layer through a 13-year climatologic analysis of ozone profiles, Atmospheric Environment, 84, 28-34. 
Baez-Ferrer, N., A. Domínguez-Rodríguez, D. Hernandez-Vaquero, S. Rodríguez, P. Avanzas, P. Abreu-Gonzalez, and E. Cuevas, 2019: P3420 Is there an association between Saharan dust events and acute coronary syndrome incidence?, European Heart Journal, 40 (Supplement_1), ehz745-0294.

Barreto, A., E. Cuevas, B. Damiri, C. Guirado, T. Berkoff, A.J. Berjón, Y. Hernández, F. Almansa, and M. Gil, 2013: A new method for nocturnal aerosol measurements with a lunar photometer prototype, Atmos. Meas. Tech., 6, 585-598, https: //amt.copernicus.org/articles/6/585/2013/ .

Barreto, A., E. Cuevas, M.J. Granados-Muñoz, L. Alados-Arboledas, P.M. Romero, J. Gröbner, N. Kouremeti, A.F. Almansa, T. Stone, T., M. Sorokin, B. Holben, M. Canini, and M. Yela, 2016: The new sun-sky-lunar Cimel CE318-T multiband photometer - a comprehensive performance evaluation, Atmos. Meas. Tech., 9, 631-654, https://amt.copernicus.org/articles/9/631/2016/.

Barreto, A., E. Cuevas, P. Pallé, P.M. Romero, C. Guirado, C. Wehrli, and F. Almasa, 2014: Recovering Long-term Aerosol Optical Depth Series (1976-2012) from an Astronomical Potassium-based Resonance Scattering Spectrometer, Atmospheric Measurement Techniques, 7, 4103-4116, https://amt.copernicus.org/articles/7/4103/2014/

Barreto, A., R. Román, E. Cuevas, D. Pérez-Ramírez, A.J. Berjón, N. Kouremeti, S. Kazadzis, J. Gröbner, M. Mazzola, C. Toledano, J.A. Benavent-Oltra, L. Doppler, J. Juryšek, A.F. Almansa, S. Victori, F. Maupin, C. Guirado-Fuentes, R. González, V. Vitale, P. Goloub, L. Blarel, L. Alados-Arboledas, E. Woolliams, S. Taylor, J.C. Antuña, M. Yela, 2019: Evaluation of night-time aerosols measurements and lunar irradiance models in the frame of the first multi-instrument nocturnal intercomparison campaign, Atmospheric Environment, Volume 202, Pages 190-211, ISSN 1352-2310, https: //www.sciencedirect.com/science/article/pii/S1352231019300287?via\% 3Dihub.

Barreto, Á., R. Román, E. Cuevas, A.J. Berjón, A.F. Almansa, C. Toledano, R. González, Y. Hernández, L. Blarel, P. Goloub, C. Guirado, and M. Yela, 2017: Assessment of nocturnal aerosol optical depth from lunar photometry at the Izaña high mountain observatory, Atmos. Meas. Tech., 10, 3007-3019, https://amt. copernicus.org/articles/10/3007/2017/

Barreto, A., O.E. García, M. Schneider, R.D. García, F. Hase, E. Sepúlveda, A.F. Almansa, E. Cuevas, T. Blumenstock, 2020: Spectral Aerosol Optical Depth Retrievals by GroundBased Fourier Transform Infrared Spectrometry. Remote Sens., 12 (19), 3148.

Basart, S., S. Nickovic, E. Terradellas, E. Cuevas Agulló, C. Pérez García-Pando, G. GarcíaCastrillo, . E. Werner \& F. Benincasa, 2019: The WMO SDS-WAS Regional Centre for Northern Africa, Middle East and Europe, E3S Web Conf., Volume 99, 2019, doi: https: //www.e3sconferences.org/articles/e3sconf/abs/2019/25/e3sconf_caduc2019_04008/e3sconf_cadu c2019_04008.html

Basart, S., C. Pérez, S. Nickovic, S., E. Cuevas \& J. Baldasano, 2012: Development and evaluation of the BSC-DREAM8b dust regional model over Northern Africa, the Mediterranean and the Middle East. Tellus B, 64. https://www.tandfonline.com/doi/full/10.3402/tellusb.v64i0.18539.

Bassani, C., C. Manzo, A. Zakey, E. Cuevas Agulló, 2016: Effect of the Aerosol Type Selection for the Retrieval of Shortwave Ground Net Radiation: Case Study Using Landsat eight Data, Atmosphere, 7, 111.

Benavent-Oltra, J. A., R. Román, J.A. Casquero-Vera, D. Pérez-Ramírez, H. Lyamani, P. OrtizAmezcua, A.E. Bedoya-Velásquez, G. de Arruda Moreira, Á. Barreto, A. Lopatin, D. Fuertes, M. Herrera, B. Torres, B., O. Dubovik, J.L. Guerrero-Rascado, P. Goloub, 
F.J . Olmo-Reyes, and L. Alados-Arboledas, 2019: Different strategies to retrieve aerosol properties at night-time with the GRASP algorithm, Atmos. Chem. Phys., 19, 1414914171, https://doi.org/10.5194/acp-19-14149-2019.

Benedetti, A., J.S. Reid, P. Knippertz, J.H. Marsham, F. Di Giuseppe, S. Rémy, S. Basart, O. Boucher, I.M. Brooks, L. Menut, L. Mona, P. Laj, G. Pappalardo, A. Wiedensohler, A. Baklanov, M. Brooks, P.R. Colarco, E. Cuevas, A. da Silva, J. Escribano, J. Flemming, N. Huneeus, O. Jorba, S. Kazadzis, S. Kinne, T. Popp, P.K. Quinn, T.T. Sekiyama, T. Tanaka, and E. Terradellas, 2018: Status and future of numerical atmospheric aerosol prediction with a focus on data requirements, Atmos. Chem. Phys., 18, 10615-10643, https: //doi.org/10.5194/acp-18-10615-2018.

Berjón, A., A. Barreto, Y. Hernández, M. Yela, C. Toledano, and E. Cuevas, 2019: A 10-year characterization of the Saharan Air Layer lidar ratio in the subtropical North Atlantic, Atmos. Chem. Phys., 19, 6331-6349, https://doi.org/10.5194/acp-19-6331-2019.

Boose, Y., B. Sierau, M.I. García, S. Rodríguez, A. Alastuey, C. Linke, M. Schnaiter, P. Kupiszewski, Z.A. Kanji, and U. Lohmann, 2016: Ice nucleating particles in the Saharan Air Layer, Atmos. Chem. Phys. Discuss., https://acp.copernicus.org/articles/16/9067/2016/

Boucher, O., D. Randall, P. Artaxo, C. Bretherton, G. Feingold, P. Forster, V.-M. Kerminen, Y. Kondo, H. Liao, U. Lohmann, P. Rasch, S.K. Satheesh, S. Sherwood, B. Stevens, and X.Y. Zhang, 2013: Clouds and aerosols. In Climate Change 2013: The Physical Science Basis. Contribution of Working Group I to the Fifth Assessment Report of the Intergovernmental Panel on Climate Change. T.F. Stocker, D. Qin, G.-K. Plattner, M. Tignor, S.K. Allen, J. Doschung, A. Nauels, Y. Xia, V. Bex, and P.M. Midgley, Eds. Cambridge University Press, pp. 571-657,

https: //www.cambridge. org/core/ books/climate-change-2013-the-physical-sciencebasis/clouds-and-aerosols/11F2D995DB0981610675738B72E7AECA.

Bovchaliuk, V., P. Goloub, T. Podvin, I. Veselovskii, D. Tanre, A. Chaikovsky, O. Dubovik, A. Mortier, A. Lopatin, M. Korenskiy, and S. Victori, 2016: Comparison of aerosol properties retrieved using GARRLiC, LIRIC, and Raman algorithms applied to multiwavelength lidar and sun/sky-photometer data, Atmos. Meas. Tech., 9, 3391-3405, https: //doi. org/10.5194/amt-9-3391-2016.

Bristow, C. S., K.A. Hudson-Edwards, \& A. Chappell, 2010: Fertilizing the Amazon and equatorial Atlantic with West African dust. Geophysical Research Letters, 37(14).

Bösenberg, J., and R. Hoff, 2007: Plan for the Implementation of the GAW Aerosol Lidar Observation Network GALION, (Hamburg, Germany, 27-29 March 2007).WMO.

Camino, C., E. Cuevas, S. Basart, S. Alonso-Pérez, J.M. Baldasano, E. Terradellas, B. Marticorena, S. Rodríguez, A. Berjón, March 2015: An empirical equation to estimate mineral dust concentrations from visibility observations in Northern Africa, Aeolian Research, 16, 55-68.

Castillo, S., A. Alastuey, E. Cuevas, X. Querol, A. Avila, 2017: Quantifying Dry and Wet Deposition Fluxes in Two Regions of Contrasting African Influence: The NE Iberian Peninsula and the Canary Islands, Atmosphere 2017, 8, 5, 86; https://www. mdpi.com/2073-4433/8/5/86.

Castillo, S., T. Moreno, X. Querol, A. Alastuey, E. Cuevas, L. Herrmann, M. Mounkaila, W. Gibbons, 2008: Trace element variation in size-fractionated African desert dusts, J ournal of Arid Environments 72, 1.034-1.045.

Collaud Coen, M., E. Andrews, A. Alastuey, T.P. Arsov, J. Backman, B.T. Brem, , N. Bukowiecki, C. Couret, K. Eleftheriadis, H. Flentje, M. Fiebig, M. Gysel-Beer, J.L. Hand, 
A. Hoffer, R. Hooda, C. Hueglin, W. Joubert, M. Keywood, J.E. Kim, S.W. Kim, C. Labuschagne, N.H. Lin, Y. Lin, C. Lund Myhre, K. Luoma, H. Lyamani, A. Marinoni, O.L. Mayol-Bracero, N. Mihalopoulos, M. Pandolfi, N. Prats, A.J. Prenni, J.P. Putaud, L. Ries, F. Reisen, K. Sellegri, S. Sharma, P. Sheridan, J.P. Sherman, J. Sun, G. Titos, E. Torres, T. Tuch, R. Weller, A. Wiedensohler, P. Zieger, and P. Laj, 2020: Multidecadal trend analysis of in situ aerosol radiative properties around the world, Atmos. Chem. Phys., 20, 8867-8908, https://acp.copernicus.org/articles/20/8867/2020/.

Córdoba-Jabonero, C., J. Andrey-Andrés, L. Gómez, J.A. Adame, M. Sorribas, M. NavarroComas, O. Puentedura, E. Cuevas, M. Gil-Ojeda, 2016: Vertical mass impact and features of Saharan dust intrusions derived from ground-based remote sensing in synergy with airborne in situ measurements, Atmospheric Environment, 142, 420-429, ISSN 13522310, https://www.sciencedirect. com/science/article/ pii/S1352231016305957.

Córdoba-J abonero, C., M. Sorribas, J.L. Guerrero-Rascado, J.A. Adame, Y. Hernández, H. Lyamani, V. Cachorro, M. Gil, L. Alados-Arboledas, E. Cuevas, and B. de la Morena, 2011: Synergetic monitoring of Saharan dust plumes and potential impact on surface: a case study of dust transport from Canary Islands to Iberian Peninsula, Atmos. Chem. Phys., 11, 3067-3091, https://acp.copernicus.org/articles/11/3067/2011/.

Cuevas, E., A.J. Gómez-Peláez, S. Rodríguez, E. Terradellas, S. Basart, R.D. García, O.E. García, S. Alonso-Pérez, 2017: The pulsating nature of large-scale Saharan dust transport as a result of interplays between mid-latitude Rossby waves and the North African Dipole Intensity , Atmospheric Environment, 167, 586-602, ISSN 1352-2310, https: //doi.org/10.1016/j. atmosenv.2017.08.059.

Cuevas, E., C. Camino, A. Benedetti, S. Basart, E. Terradellas, J.M. Baldasano, J.J. Morcrette, B. Marticorena, P. Goloub, A. Mortier, A. Berjón, Y. Hernández, M. Gil-Ojeda, and M. Schulz, 2015: The MACC-II 2007-2008 reanalysis: atmospheric dust evaluation and characterization over northern Africa and the Middle East, Atmos. Chem. Phys., 15, 3991-4024, https://acp. copernicus.org/articles/15/3991/2015/.

Cuevas, E., C. Milford, J.J. Bustos, O.E. García, R.D. García, A.J . Gómez-Peláez, C. GuiradoFuentes, C. Marrero, N. Prats, R. Ramos, A. Redondas, E. Reyes, P.P. Rivas-Soriano, S. Rodríguez, P.M. Romero-Campos, C.J. Torres, M. Schneider, ,M. Yela, J. Belmonte, R. del Campo-Hernández, F. Almansa, A. Barreto, C. López-Solano, S. Basart, E. Terradellas, E. Werner, S. Afonso, C. Bayo, A. Berjón, V. Carreño, N.J. Castro, N. Chinea, A.M. Cruz, , M. Damas, F. De Ory-Ajamil, M.I. García, V. Gómez-Trueba, C. Hernández Y. Hernández, B. Hernández-Cruz, S.F. León-Luís, R. López-Fernández, J.López-Solano, F. Parra, E. Rodríguez, M. Rodríguez-Valido, C. Sálamo, E. Sanromá, D.Santana, F. Santo Tomás, E. Sepúlveda, and E. Sosa, 2019: Izaña Atmospheric Research Centre Activity Report 2017-2018. (Eds. E. Cuevas, C. Milford, and O. Tarasova), State Meteorological Agency (AEMET), Madrid, Spain and World Meteorological Organization, Geneva, Switzerland, WMO/GAW Report No. 247.

Cuevas, E., P.M. Romero-Campos, N. Kouremeti, S. Kazadzis, P. Räisänen, R.D. García, A. Barreto, C. Guirado-Fuentes, R. Ramos, C. Toledano, F. Almansa, and J. Gröbner, 2019: Aerosol optical depth comparison between GAW-PFR and AERONET-Cimel radiometers from long-term (2005-2015) 1 min synchronous measurements, Atmos. Meas. Tech., 12, 4309-4337, https://amt. copernicus.org/articles/12/4309/2019/.

Darwin, C., An account of the Fine Dust which often falls on Vessels in the Atlantic Ocean, 1846: Quarterly Journal of the Geological Society, 2, 26-30, 1 February 1846.

Delgado, J.D., O. E. García, A. M. Díaz, J.P. Díaz, F.J. Expósito, E. Cuevas, X. Querol, A. Alastuey, S. Castillo, 2010: Origin and SEM analysis of aerosols in the high mountain of Tenerife (Canary Islands), Natural Science, Vol.2, No.10, 1119-1129; https://www.researchgate. net/publication/229046438_Origin_and_SEM_analysis_of_aer osols_in_the_high_mountain_of_Tenerife_Canary_Islands. 
Díaz, J. P., F. Expósito, C.J. Torres, F. Herrera, J.M. Prospero, M.C. Romero, 2001: Radiative properties of aerosols in Saharan dust outbreaks using ground-based and satellite data: Applications to radiative forcing, J. Geophys. Res., Vol. 106 , No. D16 , p. 18.403..

Diaz, J.P., F.J . Expósito, C.J. Torres, V. Carreño, A. Redondas, ,2000: Simulations of the UV Levels with the Presence of Mineral Aerosols, J. Geophys. Res., Vol 105, No. D4, pp. 4.979-4.991, February 27.

Domínguez-Rodríguez, A., N. Baez-Ferrer, S. Rodríguez, P. Abreu-González, M. GonzálezColaço Harmand, V. Amarnani-Amarnani, E. Cuevas, L. Consuegra-Sánchez, S. AlonsoPérez, P. Avanzas, G. Burillo Putze, 2019: Impacto de la exposición a la calima del polvo del Sáhara en los pacientes con insuficiencia cardiaca aguda atendidos en un servicio de urgencias, Emergencias, 31, 161-166.

Domínguez-Rodríguez, A., N. Baez-Ferrer, S. Rodríguez, P. Avanzas, P. Abreu-Gonzalez, E. Terradellas, E. Cuevas, S. Basart, E. Werner, 2020: Saharan dust Events in the Dust Belt - Canary Islands- and the Observed Association within Hospital Mortality of Patients with Heart Failure. J. Clin. Med., 9, 376.

Dubovik, O. \& M.D. King, 2000: A flexible investment algorithm for retrieval of aerosol optical properties from Sun and sky radiance measurements. Journal of Geophysical Research: Atmospheres, 105(D16), 20673-20696.

Escudero, M., X. Querol, J. Pey, A. Alastuey, N. Pérez, F. Ferreira, S. Alonso, , S. Rodríguez, and E. Cuevas, 2007: A methodology for the quantification of the net African dust load in air quality monitoring networks. Atmospheric Environment, 41(26), 5516- 5524.

Eskes, H., V. Huijnen, A. Arola, A. Benedictow, A.-M. Blechschmidt, , E. Botek, O. Boucher, I. Bouarar, S. Chabrillat, E. Cuevas, R. Engelen, H. Flentje, A. Gaudel, J. Griesfeller, L. Jones, J. Kapsomenakis, E. Katragkou, S. Kinne, B. Langerock, M. Razinger, A. Richter, M. Schultz, N. Sudarchikova, V. Thouret, M. Vrekoussis, A. Wagner, and C. Zerefos, 2015: Validation of reactive gases and aerosols in the MACC global analysis and forecast system, Geosci. Model Dev., 8, 3523-3543, https: //gmd.copernicus.org/articles/8/3523/2015/.

Expósito, F.J., J. P. Diaz, P. A. Hernandez-Leal, M. Arbelo, F. Herrera, C. Torres and V. Carreño, Aerosol phase function modelling in Saharan dust invasions using the ratio AVHRR/NOAA Ch1/Ch2, Advances in Space Research, Vol. 26, Issue 6, 2000, Pages 1.013-1.016.

García, M. I., S. Rodríguez, and A. Alastuey : Impact of North America on the aerosol composition in the North Atlantic free troposphere, Atmos. Chem. Phys., 17, 7387-7404, https://acp.copernicus.org/articles/17/7387/2017/.

García, M. I., B.L. van Drooge, S. Rodríguez, and A. Alastuey, 2017: Speciation of organic aerosols in the Saharan Air Layer and in the free troposphere westerlies, Atmos. Chem. Phys., 17, 8939-8958, https://acp.copernicus.org/articles/17/8939/2017/.

García, O. E., A. M. Díaz, F. J. Expósito, J. P. Díaz, A. Redondas, and T. Sasaki, 2008: Aerosol radiative forcing and forcing efficiency in the UVB for regions affected by Saharan and Asian mineral dust, J. Atmos. Sci., 66, 1033-1040, https: //journals.ametsoc.org/view/journals/atsc/66/4/2008jas2816.1.xml

García, O. E., J.P. Díaz, F.J. Expósito, A.M. Díaz, O. Dubovik, Y. Derimian, P. Dubuisson, and J.-C. Roger, 2012: Shortwave radiative forcing and efficiency of key aerosol types using AERONET data, Atmos. Chem. Phys., 12, 5129-5145, https: //acp.copernicus.org/articles/12/5129/2012/ 
García, O. E., F. J. Expósito, J. P. Díaz, and A. M. Díaz (2011), Radiative forcing under mixed aerosol conditions, J. Geophys. Res., 116, D01201,

https: //core.ac.uk/download/pdf/217341695. pdf.

García, O. E., F. J. Expósito, J. P. Díaz, and A. M. Díaz, O. Dubovik, Y. Derimian, Aerosol Radiative Forcing: AERONET-based estimates, Climate Models, ISBN 979-953-307-3384, Book edited by Dr Leonard M. Druyan, Columbia University, Dept. of Applied Physics and Applied Mathematics, USA; InTech (www.intechweb.org).

García, R. D., A. Barreto, E. Cuevas, J. Gröbner, O.E. García, A. Gómez-Peláez, P.M. RomeroCampos, A. Redondas, V.E. Cachorro, and R. Ramos, 2018: Comparison of observed and modelled cloud-free long-wave downward radiation (2010-2016) at the high mountain BSRN Izaña station, Geosci. Model Dev., 11, 2139-2152, https://gmd.copernicus. org/articles/11/2139/2018/.

García, R. D., O.E. García, E. Cuevas, V.E. Cachorro, A. Barreto, C. Guirado-Fuentes, N. Kouremeti, J.J. Bustos, P.M. Romero-Campos, and A.M. de Frutos, 2016: Aerosol optical depth retrievals at the Izaña Atmospheric Observatory from 1941 to 2013 by using artificial neural networks, Atmos. Meas. Tech., 9, 53-62, https://amt. copernicus.org/articles/9/53/2016/

García, R.D., O.E, García, E. Cuevas, V.E. Cachorro, P.M. Romero-Campos, R. Ramos and A.M. de Frutos, 2014: Solar radiation measurements compared to simulations at the BSRN I zaña station. Mineral dust radiative forcing and efficiency study, JGRAtmospheres, Vol 119, 1-16, https://agupubs.onlinelibrary.wiley.com/doi/full/10.1002/2013J D020301.

García-Cabrera, R. D., E. Cuevas Agulló, Á. Barreto, V.E. Cachorro, M. Pó, R. Ramos, and K. Hoogendijk, 2020: Aerosol retrievals from the EKO MS-711 spectral direct irradiance measurements and corrections of the circumsolar radiation, Atmos. Meas. Tech., 13, 2601-2621, https://amt.copernicus.org/articles/13/2601/2020/.

Guirado, C., E. Cuevas, V.E. Cachorro, C. Toledano, S. Alonso-Pérez, J.J. Bustos, S. Basart, P.M. Romero, C. Camino, M. Mimouni, L. Zeudmi, P. Goloub, J.M. Baldasano, and A.M. de Frutos, 2014: Aerosol characterization at the Saharan AERONET site Tamanrasset, Atmos. Chem. Phys., 14, 11753-11773, https://acp.copernicus.org/articles/14/11753/2014/acp-14-11753-2014.html.

Guirado, C., E. Cuevas, V. Cachorro), M. Mimouni, L. Zeudmi, C. Toledano, 2011: Preliminary characterization of columnar aerosol properties (AOD-AE) at the Saharan Tamanrasset (Algeria) station, Opt. Pura Apl., 44 (4) 635-639, Special Section: thirty-seventh AMASOM Instrumentation and Techniques.

Guirado, C., R. Ramos, A. de Frutos, A. Berjón, A. Redondas, C López, V. Cachorro, E. Cuevas, R. González, S. González, M. Hernánez, 2012: Optical calibration facility at the Izaña Atmospheric Research Centre, Opt. Pura Apl., 45 (1) 57-62, Special Section: thirtyseventh AMASOM Instrumentation and Techniques.

Hernández, F., S. Alonso-Pérez, J. Hernández-Armas, E. Cuevas, L. Karlsson, P.M. RomeroCampos, 2005: Influence of major African dust intrusions on the 137Cs and 40K activities as well as PM10 concentrations in the lower atmosphere at the island of Tenerife, Atmos. Environ., 39, 4.111-4.118.

Hernández, S. Rodríguez, L. Karlsson, S. Alonso-Pérez, M. López-Pérez, J., Hernández-Armas, E. Cuevas, 2008: Origin of observed high 7Be and mineral dust concentrations in ambient air on the island of Tenerife, Atmos. Environ. 42 (18), 4.247-4.256. 
Holben, B. N., T.F. Eck, I.A. Slutsker, D. Tanre, J.P. Buis, A. Setzer, E. Vermote, J.A. Reagan, Y.J. Kaufman, T. Nakajima, F. Lavenu, I. Jankowiak, \& A. Smirnov, 1998: . AERONET-A federated instrument network and data archive for aerosol characterization. Remote sensing of environment, 66(1), 1-16.

Hsu, N.C., Tsay, S.C., King, M. D., \& Herman, J. R. (2004). Aerosol properties over brightreflecting source regions. IEEE Transactions on Geoscience and Remote Sensing, 42(3), 557-569.

Huneeus, N., S. Basart, S. Fiedler, J.-J. Morcrette, A. Benedetti, J. Mulcahy, E. Terradellas, C. Pérez García-Pando, G. Pejanovic, S. Nickovic, P. Arsenovic, M. Schulz, E. Cuevas, J.M. Baldasano, J. Pey, S. Remy, and B. Cvetkovic, 2016: Forecasting the northern African dust outbreak towards Europe in April 2011: a model intercomparison, Atmos. Chem. Phys., 16, 4967-4986, https://acp.copernicus.org/articles/16/4967/2016/.

J ickells, T. D., Z.S. An, K.K. Andersen, A.R. Baker, G. Bergametti, N. Brooks, J J Cao, P. W. Boyd, R.A. Duce, K. A. Hunter, H. Kawahata, N. Kubilay, J. laRoche, P.S. Liss, N. Mahowald, J.M. Prospero, A.J. Ridgwell, I. Tegen, R. Torres, 2005: Global iron connections between desert dust, ocean biogeochemistry, and climate. Science, 308(5718), 67-71.

Junge, C.E., 1956: Recent Investigations in Air Chemistry, Tellus, 8, 2, 127 - 139, https://www.tandfonline.com/doi/abs/10.3402/tellusa.v8i2.8971.

Kandler, K., N. Benker, E. Cuevas, M. Ebert, P. Knippertz, S. Rodríguez, L. Schütz, S. Weinbruch, 2007: Chemical composition and complex refractive index of Saharan Mineral Dust at Izaña, Tenerife (Spain) derived by electron microscopy, Atmos. Environ., $41,8.058-8.074$.

Karlsson, L., F. Hernandez, S. Rodríguez, M. López-Pérez, J. Hernandez-Armas, S. AlonsoPérez, and E. Cuevas, 2008: Using $137 \mathrm{Cs}$ and $40 \mathrm{~K}$ to identify natural Saharan dust contributions to PM10 concentrations and air quality impairment in the Canary Islands, $42,7.034-7.042$.

Kazadzis, S., N. Kouremeti, H. Diémoz, J. Gröbner, B.W. Forgan, M. Campanelli, V. Estellés, K. Lantz, J. Michalsky, T. Carlund, E. Cuevas, C. Toledano, R. Becker, S. Nyeki,

P.G. Kosmopoulos, V. Tatsiankou, L. Vuilleumier, F.M. Denn, N. Ohkawara, O. Ijima, P. Goloub, P.I. Raptis, M. Milner, K. Behrens, A. Barreto, G. Martucci, E. Hall, J. Wendell, B.E. Fabbri, and C. Wehrli. Results from the Fourth WMO Filter Radiometer Comparison for AOD measurements. Atmospheric Chemistry and Physics, 18(5), 3185-3201.

Laj, P., A. Bigi, C. Rose, E. Andrews, C. Lund Myhre, M. Collaud Coen, Y. Lin, Y.,

A. Wiedensohler, M. Schulz, J.A. Ogren, M. Fiebig, J. Gliß, A. Mortier, M. Pandolfi,

T. Petäja, S.W. Kim, W. Aas, J.P. Putaud, O. Mayol-Bracero, M. Keywood, L. Labrador,

P. AaltoE. Ahlberg, L. Alados-Arboledas, A. Alastuey, M. Andrade, B. Artíñano,

S. Ausmeel, T. Arsov, E. Asmi, J. Backman, U. Baltensperger, S. Bastian, O. Bath, J.P. Beukes, B.T. Brem, N. Bukowiecki, S. Conil, C. Couret, D. Day, W. Dayantolis, A. Degorska, K. Eleftheriadis, P. Fetfatzis, O. Favez, H. Flentje, M.I. Gini, A. Gregorič, M. Gysel-Beer, A.G. Hallar, J. Hand, A. Hoffer, C. Hueglin, R.K. Hooda, A. Hyvärinen, I. Kalapov, N. Kalivitis, A. Kasper-Giebl, J.E. Kim, G. Kouvarakis, I. Kranjc, R. Krejci, M. Kulmala, C. Labuschagne, H.-J.Lee, H. Lihavainen, N.H. Lin, G. Löschau, K. Luoma, A. Marinoni, S. Martins Dos Santos, F. Meinhardt, M. Merkel, J.M. Metzger,

N. Mihalopoulos, N.A. Nguyen, J. Ondracek, N. Pérez, M.R. Perrone, J.-E. Petit, D. Picard, J.-M. Pichon, V. Pont, N. Prats, A. Prenni, F. Reisen, S. Romano, K. Sellegri, S. Sharma,

G. Schauer, P. Sheridan, J.P. Sherman, M. Schütze, A. Schwerin, R. Sohmer, M. Sorribas, M. Steinbacher, J. Sun, G. Titos, B. Toczko, T. Tuch, P. Tulet, P. Tunved, V. Vakkari, F. Velarde, P. Velasquez, P. Villani, S. Vratolis, S.-H. Wang, K. Weinhold, R. Weller, M. Yela, J. Yus-Diez, V. Zdimal, P. Zieger, and N. Zikova, 2020: A global analysis of climate-relevant aerosol properties retrieved from the network of Global Atmosphere 
Watch (GAW) near-surface observatories, Atmos. Meas. Tech., 13, 4353-4392, https://doi.org/10.5194/amt-13-4353-2020, J. López-Solano, A. Redondas, T. Carlund, J.J. Rodríguez-Franco, H. Diémoz, S.F. León-Luis, B. Hernández-Cruz, C. GuiradoFuentes, N. Kouremeti, J. Gröbner, S. Kazadzis, V. Carreño, A. Berjón, D. Santana-Díaz, M. Rodríguez-Valido, V. De Bock, J.R. Moreta, J. Rimmer, A.R.D. Smedley, L. Boulkelia, N. Jepsen, P. Eriksen, A.F. Bais, V. Shirotov, J.M. Vilaplana, K.M. Wilson, and T. Karppinen, 2018: Aerosol optical depth in the European Brewer Network, Atmos. Chem. Phys., https://acp.copernicus.org/articles/18/3885/2018/

López-Villarubia, E., C. Íñiguez, N. Peral, M.D. García, F. Ballester, 2012: Characterizing mortality effects of particulate matter size fractions in the two capital cities of the Canary Islands, Environmental Research, 112, 129-138.

Milford, C., E. Cuevas, C.L. Marrero, J. Bustos, V. Gallo, S. Rodríguez, S.P.M. Romero-Campos, C. Torres, 2020: Impacts of Desert Dust Outbreaks on Air Quality in Urban Areas, Atmosphere, 11, 23. https://www.mdpi.com/2073-4433/11/1/23.

Molesworth, A. M., E. Cuevas, S.J . Connor, A.P. Morse, \& M.C. Thomson, 2003: Environmental risk and meningitis epidemics in Africa. Emerging infectious diseases, 9(10), 1287.

Mona, L., Z. Liu, D. Muller, A. Omar, A. Papayannis,G. Pappalardo, N. Sugimoto, and M. Vaughan, 2012: Lidar measurements for desert dust characterization: an overview. Advances in Meteorology.

Moreno T., X. Querol, S. Castillo, A. Alastuey, L. Herrmann, M. Mounkaila, E. Cuevas, J. Elvira, W. Gibbons, Geochemical variations in mineral aerosols within the Sahara-Sahel Dust, Chemosphere, 65 (2006) 261-270.

Muller, D., E. Chemyakin, A. Kolgotin, R.A. Ferrare, C.A. Hostetler, \& A. Romanov, 2019: Automated, unsupervised investment of multiwavelength lidar data with TiARA: assessment of retrieval performance of microphysical parameters using simulated data. Applied Optics, 58(18), 4981-5008.

Ničković, S., and S. Dobričić, 1996: A model for long-range transport of desert dust. Monthly Weather Review, 124, 2537-2544.

Palmer, T. N., G.J. Shutts, R. Hagedorn, F.J . Doblas-Reyes, T. Jung, T. \& M. Leutbecher, 2005: . Representing model uncertainty in weather and climate prediction. Annu. Rev. Earth Planet. It is sci. , 33, 163-193.

Pandolfi, M., L. Alados-Arboledas, A. Alastuey, M. Andrade, C. Angelov, B. Artiñano, J. Backman, U. Baltensperger, P. Bonasoni, N. Bukowiecki, M. Collaud Coen, S. Conil, E. Coz, V. Crenn, V. Dudoitis, M. Ealo, K. Eleftheriadis, O. Favez, P. Fetfatzis, M. Fiebig, H. Flentje, P. Ginot, M. Gysel, B. Henzing, A. Hoffer, A. Holubova Smejkalova, I. Kalapov, N. Kalivitis, G. Kouvarakis, A. Kristensson, M. Kulmala, H. Lihavainen, C. Lunder, K. Luoma, H. Lyamani, A. Marinoni, N. Mihalopoulos, M. Moerman, J. Nicolas, C. O'Dowd, T. Petäjä, J.-E. Petit, J.M. Pichon, N. Prokopciuk, J.-P. Putaud, S. Rodríguez, J. Sciare, K. Sellegri, E. Swietlicki, G. Titos, T. Tuch, P. Tunved, V. Ulevicius, A. Vaishya, M. Vana, A. Virkkula, S. Vratolis, E. Weingartner, A. Wiedensohler, and P.A. Laj, 2018: European aerosol phenomenology - 6: scattering properties of atmospheric aerosol particles from 28 ACTRIS sites, Atmos. Chem. Phys., 18, 7877-7911, https://acp.copernicus.org/articles/18/7877/2018/

Pérez García-Pando, C., M.C. Stanton, P.J . Diggle, S. Trzaska, R.L. Miller, J.P. Perlwitz, J.M. Baldasano, E. Cuevas, P. Ceccato, P. Yaka, and M.C. Thomson, 2014: Soil Dust Aerosols and Wind as Predictors of Seasonal Meningitis Incidence in Niger, Environmental Health Perspectives https://ehp. niehs.nih.gov/doi/full/10.1289/ehp.1306640. 
Pérez García-Pando, C., R. L. Miller, J.P. Perlwitz, S. Rodríguez, and J.M. Prospero, 2016: Predicting the mineral composition of dust aerosols: Insights from elemental composition measured at the Izaña Observatory, Geophys. Res. Lett., 43, https://agupubs.onlinelibrary. wiley.com/doi/full/10.1002/2016GL069873.

Prospero, J. M., \& P.J. Lamb, 2003: African droughts and dust transport to the Caribbean: Climate change implications. Science, 302(5647), 1024- 1027.

Prospero, J., 1979: Mineral and sea salt aerosol concentrations in various ocean regions. J. Geophys. Res., 84:726-732.

Prospero, J., T. Carlson, D. Savoie, and R. Nees, 1976b: Atmospheric turbidity measurements during GATE, RSMS, Univ. of Miami Technical Report TR76-6. Univ. of Miami, Miami, Fla.

Prospero, J., R. Nees, and D. Savoie, 1976 a: Atmospheric aerosol measurements during GATE. RSMAS, Univ. of Miami Technical Report TR76-5. Univ. of Miami, Miami, Fla.

Prospero, J.M., R. Schmitt, E. Cuevas, D. Savoie, W. Graustein, K. Turekian, A. Volz-Thomas, A. Diaz, S. Oltmans, H. Levy-II, 1995: Temporal Variability of Summertime Ozone and Aerosols in the Free Troposphere over the Eastern North Atlantic, Geophys. Res. Lett., $22,21,2.925-2.928$.

Prospero, J.M., 1997: The Atmosphere/Ocean Chemistry Experiment (AEROCE): An overview, (abstract), Eos Trans. AGU, 78, Fall Meet Suppl., F122-123

Querol X., A. Alastuey, S. Castillo, A. Avila, M. Escudero, E. Cuevas, C. Estarellas, P.M. Romero, C.J. Torres, J.M. Sancho, F.J. Expósito, O.E. García, J.P. Díaz, J.C Guerra, J.P. Putaud, R. Van Dingenen, 2003: Characterization of particulate matter from an African air mass intrusion over Tenerife during MINATROC campaign (July 2002), European Aerosol Conference, Madrid, 1-5 September 2003. J ournal of Aerosol Science, II, 1353-1354.

Querol, X., A. Alastuey, T. Moreno, M. M. Viana, S. Castillo, J. Pey, S. Rodríguez, B. Artiñano, P. Salvador, S. García Dos Santos, M.D. Herce Garraleta, R. Fernandez Patier, M.J. Sanz, M.C. Minguillón, E. Monfort, R. Palomo, E.R. Pinilla, E. Cuevas, 2008: Spatial and Temporal variations in airborne particulate matter (pm10 and pm2.5) across Spain 1999-2005, Atmospheric Environment 42 3964-3979.

Raes, F., R. Van Dingenen, E. Cuevas, P. Van Velthoven, J. M. Prospero, September 1997: Observations of aerosols in the free troposphere and marine boundary layer of the subtropical NE Atlantic: discussion of the processes determining their size distribution, J. Geophys. Res., Vol 102, D17, 21.315-21.328.

Ravelo-Pérez, L.M., S. Rodríguez, L. Galindo, M.I. García, A. Alastuey, J. López-Solano, 2016: Soluble iron dust export in the high altitude Saharan Air Layer, Atmospheric Environment, 133, 49-59, https://www.sciencedirect.com/science/article/pii/S135223101630200X.

Rodríguez, S., A. Alastuey, and X. Querol, 2012: A review of methods for long-term in situ characterization of aerosol dust. Aeolian Research, 6, 55-74.

Rodríguez, S., A. Alastuey, S. Alonso-Pérez, X. Querol, E. Cuevas, E., J. Abreu-Afonso, M.Viana, N. Pérez, M. Pandolfi, and J. de la Rosa, 2011: Transport of desert dust mixed with North African industrial pollutants in the subtropical Saharan Air Layer, Atmos. Chem. Phys., 11, 6663-6685, https://acp.copernicus.org/articles/11/6663/2011/. 
Rodríguez, S., G. Calzolai, M. Chiari, S. Nava, M.I. García, J. López-Solano, C. Marrero, J. López-Darias, E. Cuevas, S. Alonso-Pérez, N. Prats, A. Amato, F. Lucarelli, and X. Querol, 2019: Rapid changes of dust geochemistry in the Saharan Air Layer linked to sources and meteorology, in press,

https://www. sciencedirect.com/science/article/abs/pii/S1352231019308258?via\% 3Dihub

Rodríguez, S., E. Cuevas, Y. González, R. Ramos, P.M. Romero, N. Pérez, X. Querol, A. Alastuey, 2008: Influence of sea breeze circulation and road traffic emissions on the relationship between particle number, black carbon, PM1, PM2.5 and PM2.5-10 concentrations in a coastal city, Atmos. Environ., 42, 523-6534.

Rodríguez, S., E. Cuevas, J.M. Prospero, A. Alastuey, X. Querol, J. López-Solano, M.I. García, and S. Alonso-Pérez, 2015: Modulation of Saharan dust export by the North African dipole, Atmos. Chem. Phys., 15, 7471-7486,

https://acp. copernicus.org/articles/15/7471/2015/acp-15-7471-2015-metrics.html.

Salvador, P., S. Alonso-Pérez, J. Pey , B. Artíñano , J. J. de Bustos , A. Alastuey , and X. Querol, 2014: African dust outbreaks over the western Mediterranean Basin: 11-year characterization of atmospheric circulation patterns and dust source areas, Atmos. Chem. Phys., 14, 6759-6775, 2014, https://acp.copernicus.org/articles/14/6759/2014/.

Sessions, W. R., J.S. Reid, A. Benedetti, P.R. Colarco,A. da Silva, S. Lu, T. Sekiyama, T.Y. Tanaka, J.M. Baldasano, S. Basart, M.E. Brooks, T.F. Eck, M. I redell, J.A. Hansen, O.C. J orba, H.-M.H. Juang, P. Lynch, J.-J. Morcrette, S. Moorthi, J. Mulcahy, Y. Pradhan, M. Razinger, C.B. Sampson, J. Wang, and D.L. Westphal, 2015: Development towards a global operational aerosol consensus: basic climatological characteristics of the International Cooperative for Aerosol Prediction Multi-Model Ensemble (ICAP-MME), Atmos. Chem. Phys., 15, 335-362, https://acp.copernicus.org/articles/15/335/2015/.

Sivakumar, M. V., 2005: Impacts of sand storms/dust storms on agriculture. In Natural disasters and extreme events in agriculture (pp. 159-177). Springer, Berlin, Heidelberg.

Smirnov, A., B.N. Holben, I. Slutsker, D.M. Giles, C.R. McClain, T.F. Eck, S. M. Sakerin, A. Macke, P. Croot, G. Zibordi, P. K. Quinn, J. Sciare, S. Kinne, M. Harvey, T. J. Smyth, S. Piketh, T. Zielinski, A. Proshutinsky, J. I. Goes, N. B. Nelson, P. Larouche, V. F. Radionov, P. Goloub, K. Krishna Moorthy, R. Matarrese, E. J. Robertson, and F. Jourdin , 2009: Maritime aerosol network as a component of aerosol robotic network. J ournal of Geophysical Research: Atmospheres, 114(D6).

Sprigg, W. A., S. Nickovic, J.N. Galgiani, G. Pejanovic, S. Petkovic, M. Vujadinovic, A. Vukovic, M. Dacic, S. DiBiase, A.Prasad, \& H. El-Askary, 2014: Regional dust storm modelling for health services: the case of valley fever. Aeolian Research, 14, 53-73.

Takamura, T., \& T. Nakajima, 2004: . Overview of SKYNET and its activities. Proceedings of AERONET workshop, El Arenosillo. Opt. Pura Apl., 37, 3303-3308.

Tatarov, B., D. Muller, D.H. Shin, S.K. Shin, I. Mattis, P. Seifert, Young Min Noh, Y. J. Kim, and \& N. Sugimoto, 2011: Lidar measurements of Raman scattering at ultraviolet wavelength from mineral dust over East Asia. Optics express, 19(2), 1569-1581.

Tegen, I., \& A.A. Lacis, 1996:. Modelling of particle size distribution and its influence on the radiative properties of mineral dust aerosol. Journal of Geophysical Research: Atmospheres, 101(D14), 19237-19244.

Terradellas, E., S. Basart, \& E. Cuevas, 2016: Airborne Dust: From R\&D to Operational Forecast. AEMET NIPO 281-16-007-3, WMO/GAW Report No. 230, WMO/WWRP No. 2016-2. 
Terradellas, E., S. Nickovic, \& X.Y. Zhang, 2015: Airborne dust: a hazard to human health, environment and society. World Meteorological Organization Bulletin, 64(2), 42-46.

Thomas, W., 2012: Transitioning to Operations: Lidars and Ceilometers. In WMO Technical Conference on Meteorological and Environmental Instruments and Methods of Observation, TECO-2012 (pp. 16-18)

Toledano, C., R. González, D. Fuertes, E. Cuevas, T.F. Eck, S. Kazadzis, N. Kouremeti, J. Gröbner, P. Goloub, L. Blarel, R. Román, Á. Barreto, A. Berjón, B. N. Holben, and V.E. Cachorro, 2018: Assessment of Sun photometer Langley calibration at the highelevation sites Mauna Loa and Izaña, Atmos. Chem. Phys., 18, 14555-14567, https://amt.copernicus.org/articles/10/3743/2017/.

Torres, B., O. Dubovik, D. Fuertes, G. Schuster, V.E. Cachorro, T. Lapionok, P. Goloub, L. Blarel, A. Barreto, M. Mallet, C. Toledano, and D. Tanré, 2017: Advanced characterization of aerosol properties from measurements of spectral optical depth using the GRASP algorithm. Atmos. Meas. Tech., 10, 3743-3781. https://www.atmos-meastech.net/10/3743/2017/.

Torres, B., O. Dubovik, C. Toledano, A. Berjon, V.E. Cachorro, T. Lapyonok, P. Litvinov, P. and Goloub, 2014: Sensitivity of aerosol retrieval to geometrical configuration of groundbased sun/sky radiometer observations, Atmos. Chem. Phys., 14, 847-875,. https: //acp.copernicus.org/articles/14/847/2014/.

Viana, M., X. Querol, A. Alastuey, E. Cuevas, and S. Rodríguez, 2002: Influence of African dust on the levels of atmospheric particulates in the Canary Islands air quality network, Atmos. Environ., 36, 5.861-5.875.

Weinzierl, B., A. Ansmann, J.M. Prospero, D. Althausen, N. Benker, F. Chouza, F., M. Dollner, D. Farrell, W. K. Fomba, V. Freudenthaler, J. Gasteiger, S. Groß, M. Haarig, B. Heinold, K. Kandler, T. B. Kristensen, O. L. Mayol-Bracero, T. Müller, O. Reitebuch, D. Sauer, A. Schäfler, K. Schepanski, A. Spanu, I. Tegen, C. Toledano, and A. Walser, 2017: The Saharan aerosol long-range transport and aerosol-cloud-interaction experiment: overview and selected highlights. Bulletin of the American Meteorological Society, 98(7), 1427-1451.

Yu, H., M. Chin, T. Yuan, H. Bian, L.A. Remer, J.M. Prospero, A. Omar, D. Winker, Y. Yang, Y. Zhang, Z. Zhang \& C. Zhao2015: The fertilizing role of African dust in the Amazon rainforest: A first multiyear assessment based on data from Cloud-Aerosol Lidar and Infrared Pathfinder Satellite Observations. Geophysical Research Letters, 42(6), $1984-$ 1991.

Zhang, J., \& J.S. Reid, 2006: MODIS aerosol product analysis for data assimilation: Assessment of over ocean level 2 aerosol optical thickness retrievals. Journal of Geophysical Research: Atmospheres, 111(D22). 


\title{
2 METEOROLOGI CAL ANALYSIS
}

\author{
J.J de Bustos, D. Suárez, C. L. Marrero and E. Cuevas
}

\section{$2.1 \quad$ Introduction}

The impact of Saharan dust outbreaks on the marine boundary layer of the Subtropical North Atlantic, and more specifically on the Canary Islands, as well as the temporal trends of these outbreaks was analysed by Alonso-Pérez et al. (2007) and Alonso-Perez et al.(2011 a). AlonsoPerez et al. (2011b) objectively identified synoptic weather patterns that favour Saharan dust outbreaks into the MBL of the subtropical eastern North Atlantic region in winter. In this section, the synoptic situation associated with the unprecedented 22-24 February 2020 dust event is analysed in detail.

\section{$2.2 \quad$ Analysis}

Several meteorological structures of different spatio-temporal scales were involved in the 22- 24 February 2020 dust outbreak. The meteorological situation of this event caused a very intense dust episode from the desert areas of western Sahara towards the Canary Islands that was produced by the evolution of a cut-off low, which became detached from the general circulation (Figure 2.1) and initiated a retrograde movement towards the SW as an isolated low, remaining at the end of the process as a deep low centred near the $W$ of the Canary Islands.

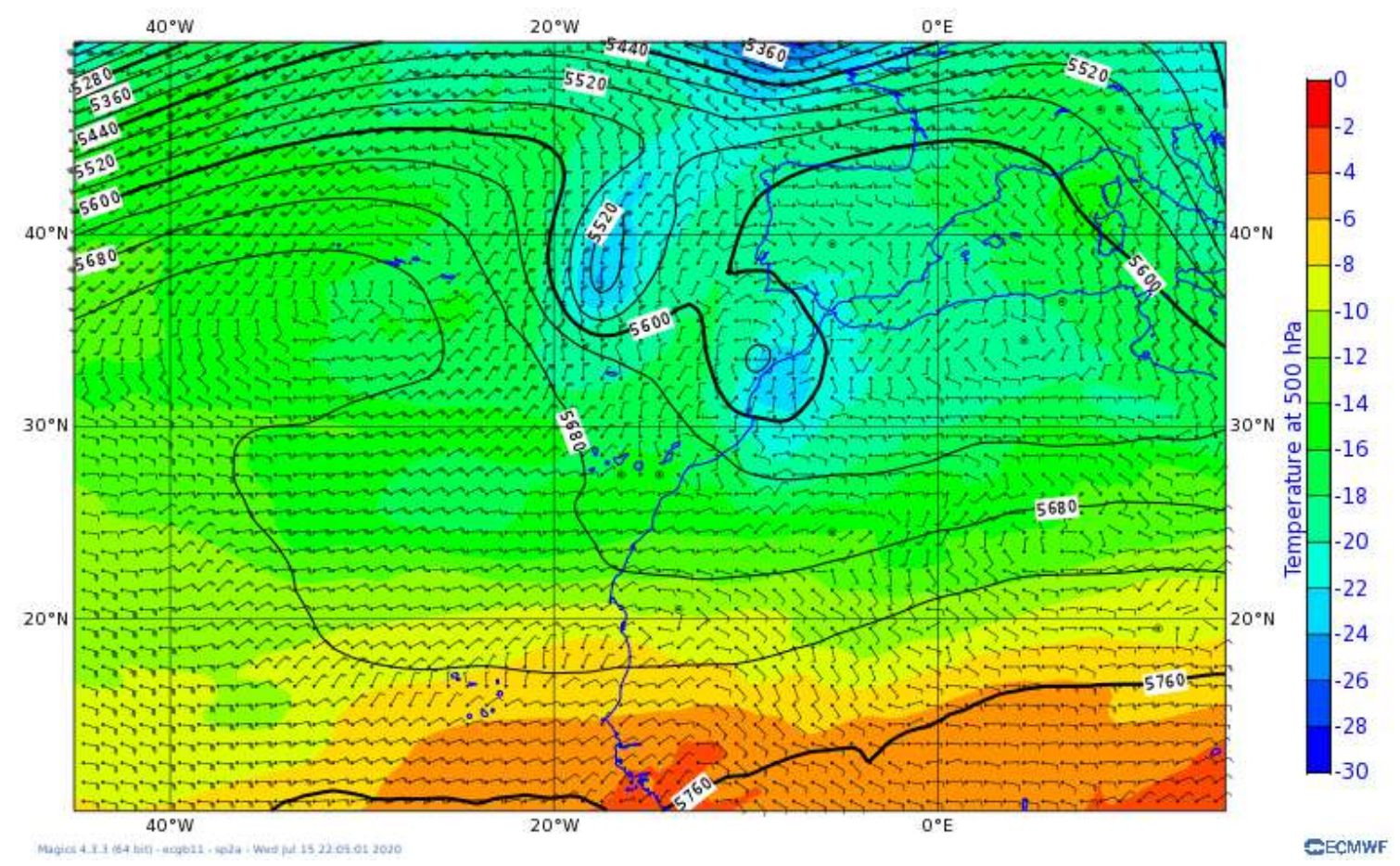

Figure 2.1. Analysis of the ECMWF HRES-I FS model of geopotential height (black lines), temperature ( colour contouring) at $500 \mathrm{hPa}$ and wind barbs at $850 \mathrm{hPa}$ on 20/2/2020 at 1200 UTC

In the previous process of isolation, the absorption of a pre-existing, quasi-stationary upperlevel low over the Gulf of Cadiz (Figure 2.2) altered the processes of circulation of the low, which kept the anterior and posterior jets separate from the low, with the formation of new axes of lower wavelength troughs that induced processes of decreased surface pressure on the SE flank of the low. 


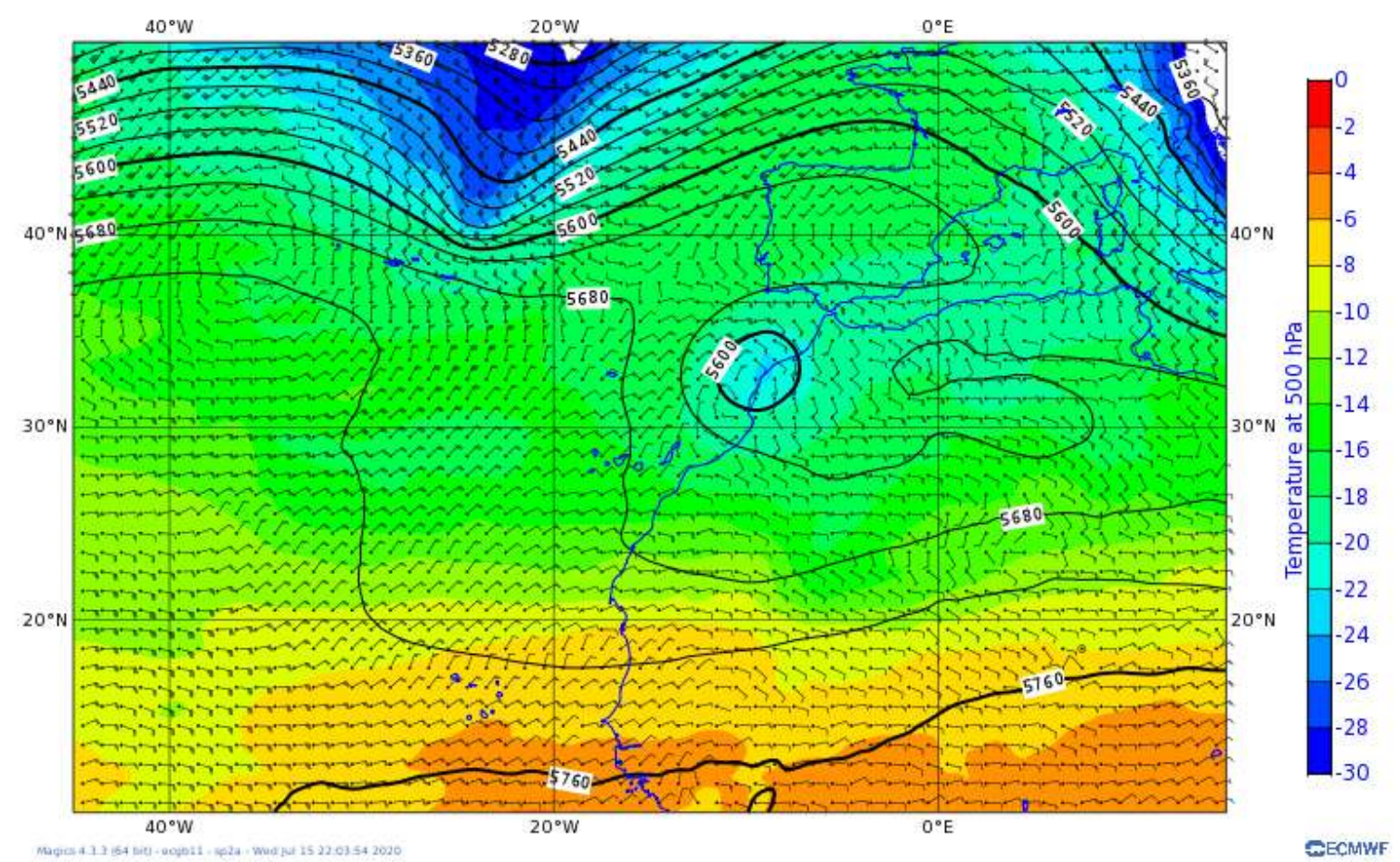

Figure 2.2. Analysis of the ECMWF HRES-IFS model of geopotential height (black lines), temperature (colour contouring) at $500 \mathrm{hPa}$ and wind barbs at $850 \mathrm{hPa}$ on 20/ 2/ 2020 at 00 UTC

On February 23 at 00 UTC, the synoptic configuration at low levels (Figure 2.3(b)) shows a marked latitudinal dipole, with an anticyclone of $1035 \mathrm{hPa}$ to the $\mathrm{W}$ of the Iberian Peninsula and low pressure to the $\mathrm{S}$ of the Canary Islands. In addition, the orographic dipole of the Atlas mountains increased the pressure gradient to the $S$ of this mountain range, and established a circulation in the form of a jet current channelled in the ESE direction at low levels of up to $50 \mathrm{kt}(\sim 90 \mathrm{~km} / \mathrm{h})$ in $850 \mathrm{hPa}$ which, in addition to a strong storm, produced the lifting and very rapid transport of large amounts of mineral dust from the desert to the islands. The arrival of the African air mass was modulated by the presence of a warm ridge at $850 \mathrm{hPa}$ (Figure 2.3(b)). 
(a)

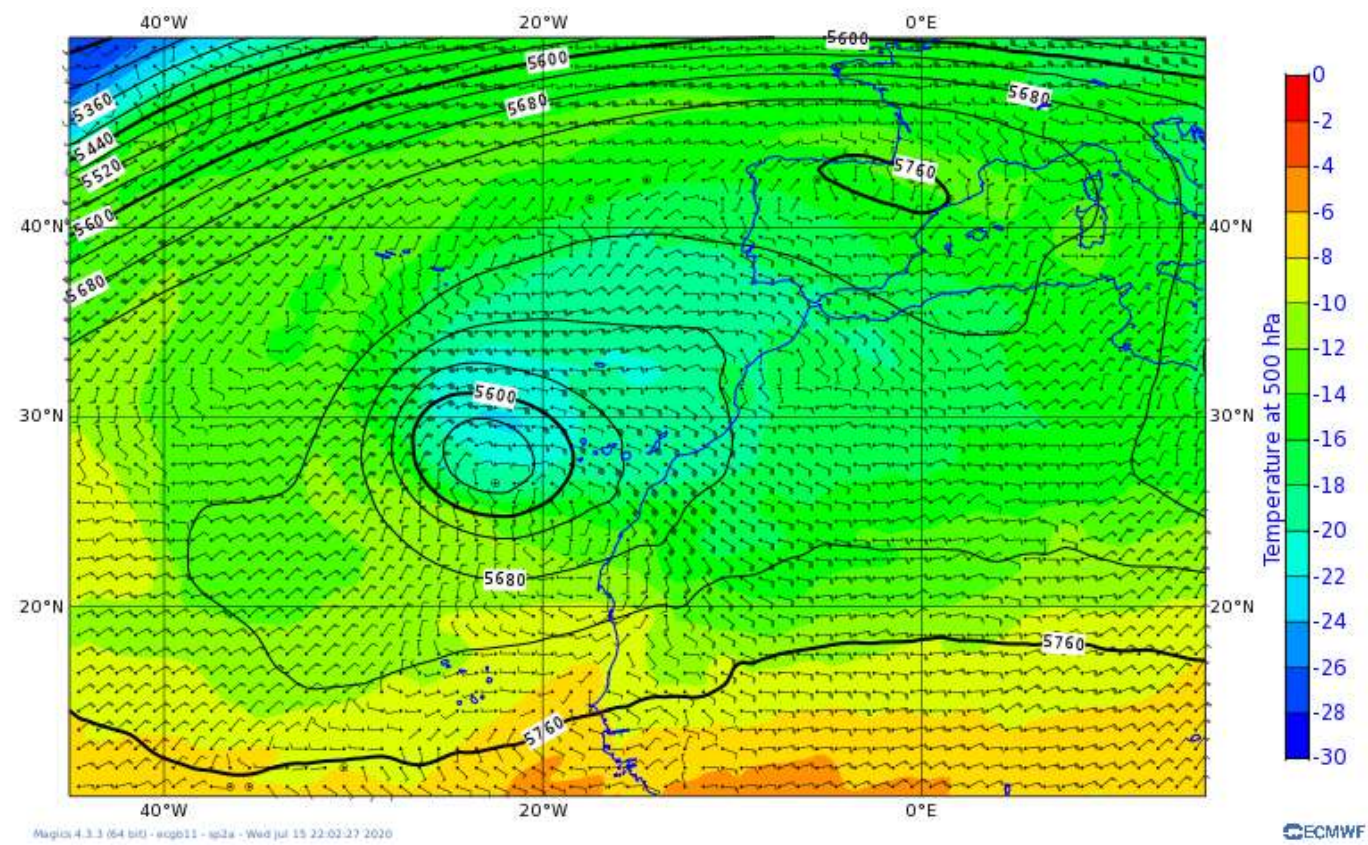

(b)

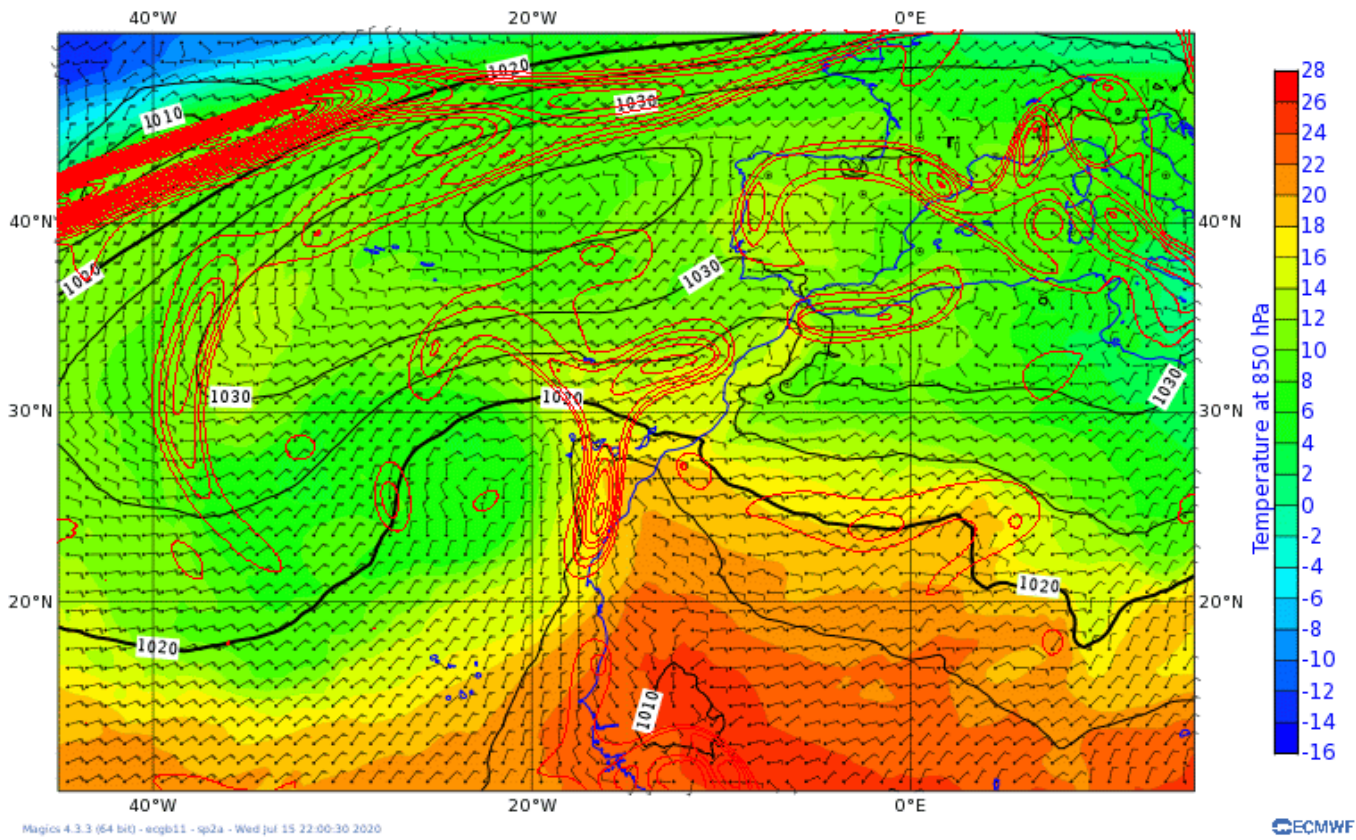

Figure 2.3. Analysis of the ECMWF HRES-I FS model on 23/ 2/ 2020 at 00 UTC of: (a) geopotential height (black lines), temperature (colour contouring) at $500 \mathrm{hPa}$ and wind barbs at $850 \mathrm{hPa}$, (b) Pressure at sea level in $\mathrm{hPa}$, temperature (colour contouring) at 850 $\mathrm{hPa}$, wind barbs at $850 \mathrm{hPa}$ and Thermal Front Parameter at $1000 \mathrm{hPa}$ (red contours)

The involvement of an Inverted $V$ wave (Frank, 1967) in the "dust injection" process, was considerable. A convergence zone was formed at the $E$ of the axis of that wave, and this could have constituted an amplifying mechanism in the mineral dust congregation. 
This is corroborated by the signal showing the Thermal Front Parameter (TFP) at $1000 \mathrm{hPa}$ (Figure 2.3(b), red contours). The TFP marks a narrow and elongated area indicating a border between two well-differentiated air masses. On the one hand is the maritime air mass, and on the other hand is the mass of warm and continental air. As it moves towards the ocean, the continental mass passes over the maritime air mass and ascends. This ascent of the air mass, caused by both the convergences of low levels associated with the Inverted $\mathrm{V}$ pattern and the frontal area, generated cloudiness (Figure 2.7) which was embedded by the cold core of the upper-level low (Figure 2.3(a) located to the $\mathrm{W}$ of the Canary Islands archipelago. The dust leaving the African continent interacted with the low that remained virtually stationary until the end of 25 February. The instability associated with the upper-level low caused the dust layer to extend from the surface to about $5 \mathrm{~km}$ altitude. In addition, the stationary state of the upperlevel low caused the recirculation of the dust and resulted in three intense dust peaks during this episode.

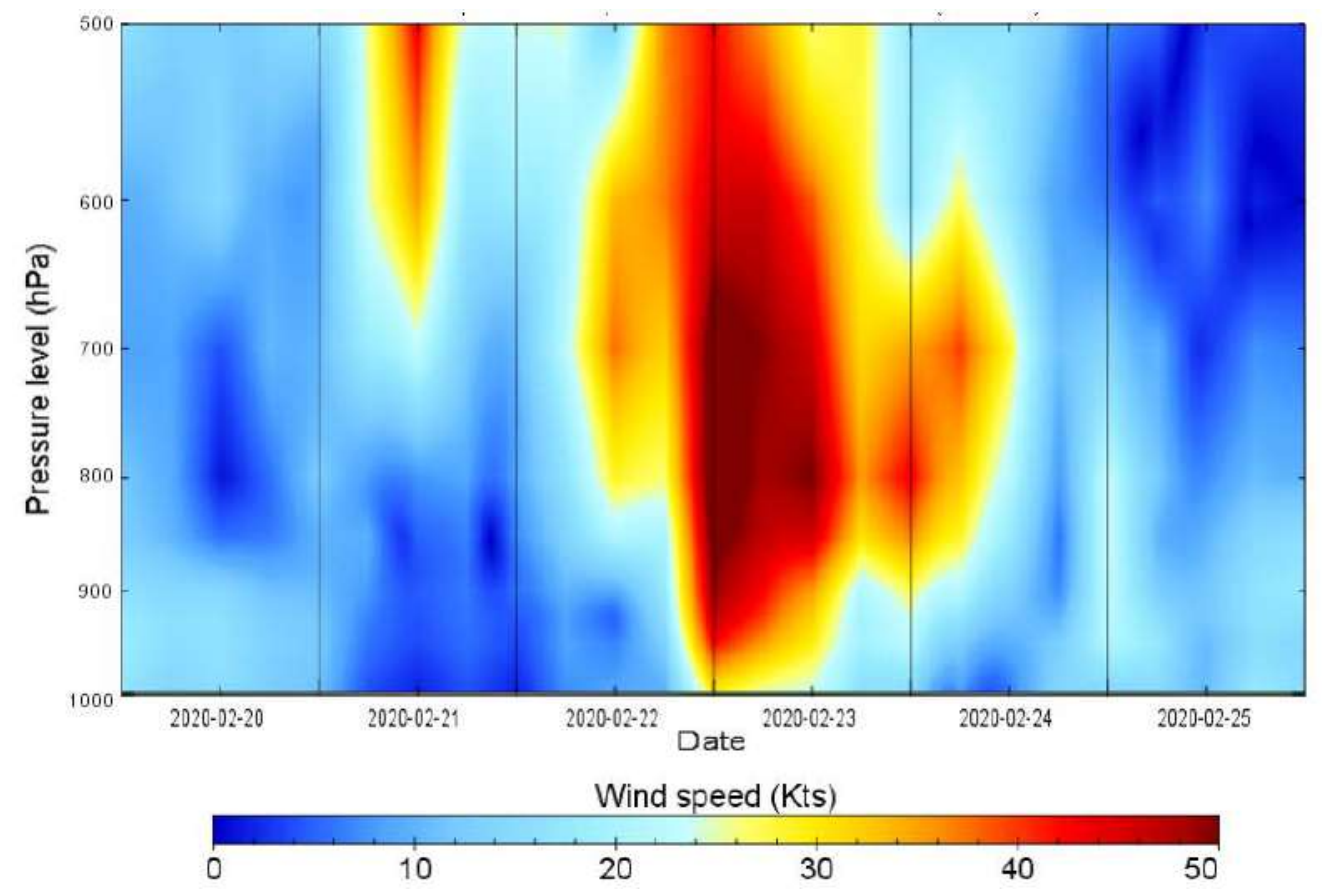

Figure 2.4. Temporal evolution of the vertical wind profile located above Tenerife $\left(28.5^{\circ} \mathrm{N}-16.5^{\circ} \mathrm{W}\right)$ from $20-25$ February 2020. ECMWF HRES-I FS model analysis. 


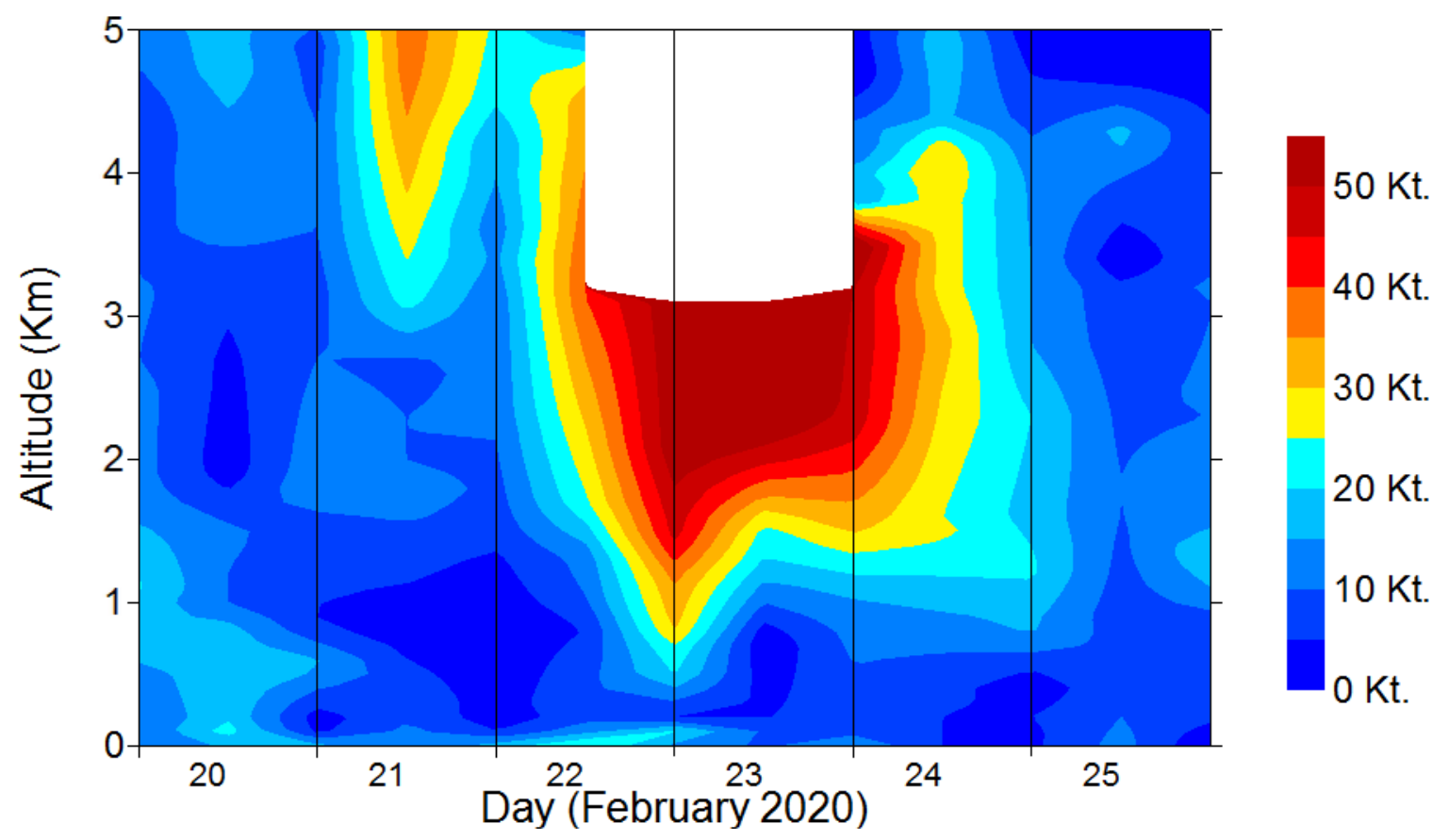

Figure 2.5: Temporal evolution of the vertical wind profile from Tenerife (Güímar) radiosonde observational data for 20- 25 February 2020

Figure 2.4 depicts the temporal evolution of the vertical wind profile from $1000 \mathrm{hPa}$ to $500 \mathrm{hPa}$ of the ECMWF HRES-IFS model analysis at $28.5^{\circ} \mathrm{N}, 16.5^{\circ} \mathrm{W}$ over the island of Tenerife. This demonstrates the intensity of the maximum wind speed affecting the entire low troposphere between 22 and 23 February 2020. In addition, the Tenerife (Güímar) radiosonde observational data (Figure 2.5) corroborate the diagnosis of the analysis of the ECMWF HRES- IFS model during the episode.

The 10-day back-trajectories (Figure 2.6) show the origin of the different air masses that arrived on the islands (in this case the back-trajectories calculated for Tenerife are shown). In the lower troposphere (Figure 2.6, altitudes of $150 \mathrm{~m}$ and $1500 \mathrm{~m}$ ) the air mass was of continental origin (Saharan air mass) and the air mass had a more southern origin as the altitude increases. At the $1500 \mathrm{~m}$ level, the air mass starts from latitudes near Cape Verde and as it moves northward, the air mass descends due to the cooling effect and as it enters an area of high pressure dominated by subsidence. In the middle troposphere ( $5000 \mathrm{~m}$ level) we observe that the mass of air arriving to Tenerife is of maritime origin, while at the $3000 \mathrm{~m}$ level the air mass travelled over the NW of the African continent before reaching the island. 

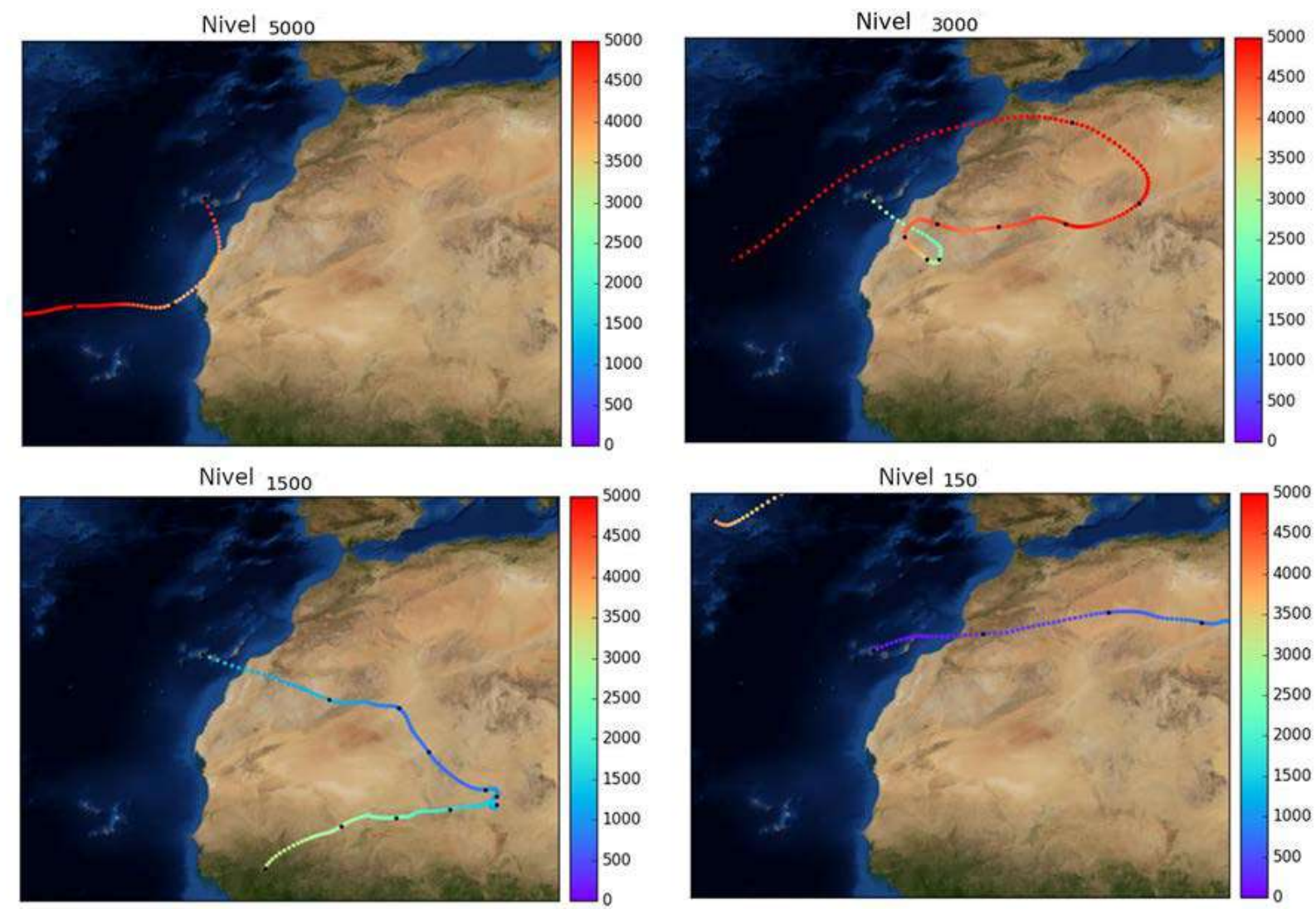

Figure 2.6. Back-trajectories (10-day) calculated with the HYSPLIT model for Tenerife at different altitudes (from $150 \mathrm{~m}$ to $5000 \mathrm{~m}$ ) for 23 February 2020 at 00 UTC. The black dots represented on the path mark each 24 hours.

The back-trajectories of the lower altitudes mark how the dust came from source areas very close to the islands, from the coast of western Sahara, with hardly any input from other source regions further inland. In addition, the back-trajectories show that this transport was very fast, this can be seen by the distance between two consecutive black dots, which are plotted over the trajectories. Every 24 hours a black dot is represented on the path. If the distance between the points increases, it means a faster displacement of the air mass. 
(a)

(b)

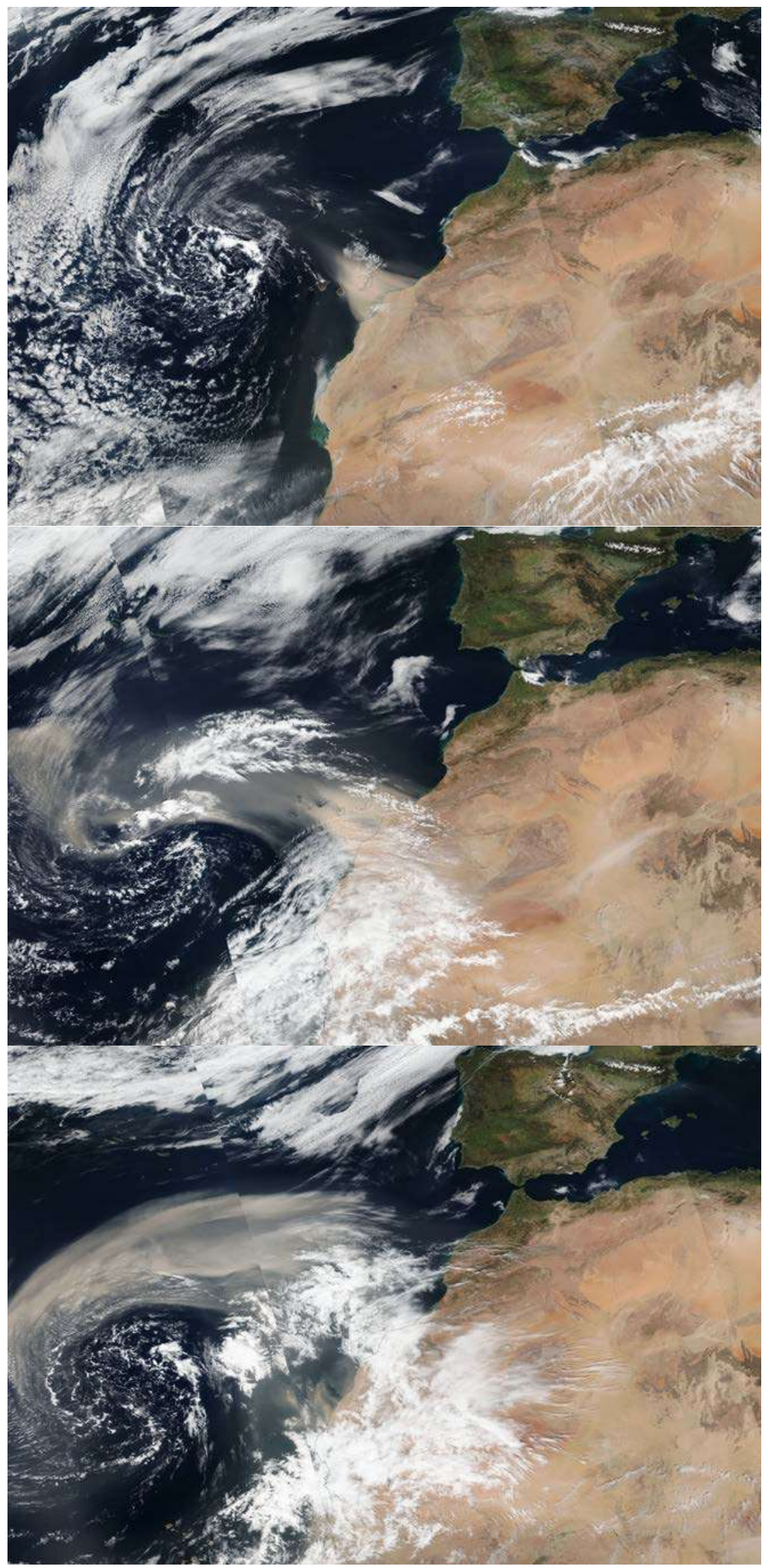

Figure 2.7. I mages obtained by the Visible I nfrared I maging Radiometer Suite abord the NASA Suomi polar satellite corresponding to the days of (a) 22 February 2020 ,

(b) 23 February 2020, and (c) 24 February 2020 
Suomi satellite images from 22-24 February 2020 (Figure 2.7) show the intense dust plume, directly injected into the archipelago and originating near the African coast. In addition, the image of 23 and 24 February shows the presence of clouds, which were increasing in the following days.

\subsection{Conclusions}

A detailed analysis has been carried out of the meteorological situation of the 22-24 February 2020 dust outbreak. This dust outbreak was caused by a very deep cut-off low that became detached from the mid-latitudes' circulation, becoming a deep low as it moved south, and once centred to the $\mathrm{W}$ of the Canary I slands, advected a large amount of mineral dust over the archipelago from the desert areas of western Sahara. Such situations are typical in winter in the Canary Islands and are one of the most effective mechanisms to generate Saharan dust outbreaks over the archipelago at this time of the year. This event was characterized by more intense winds located at a higher altitude than those usually produced by such baroclinic processes near the Canary Islands in winter.

\section{$2.4 \quad$ References}

Alonso-Pérez, S., E. Cuevas, X. Querol, M. Viana and J.C. Guerra, 2007: Impact of the Saharan dust outbreaks on the ambient levels of total suspended particles (TSP) in the Marine Boundary Layer (MBL) of the Subtropical Eastern North Atlantic Ocean, Atmos. Environ.,41/40, 9468-9480. https://www.sciencedirect.com/science/article/abs/pii/S1352231007007674

Alonso-Pérez, S., E. Cuevas, C. Pérez, X. Querol, J.M. Baldasano, R. Draxler, and J.J. de Bustos, 2011a: Trend changes of African Airmass intrusions in the marine boundary layer over the subtropical Eastern North Atlantic region in winter. Tellus B, 63, 255-265, https://onlinelibrary. wiley.com/doi/abs/10.1111/j.1600-0889.2010.00524.x

Alonso-Pérez, S., E. Cuevas and X. Querol, 2011b: Objective identification of synoptic meteorological patterns favouring African dust intrusions into the marine boundary layer of the subtropical eastern north Atlantic region, Meteorol. Atmos. Phys., 113, 109-124.

Frank, N.L., 1967: The "Inverted V" cloud pattern - an easterly wave? Monthly Weather Review, 97, 130-140. 
N. Prats, S. Rodríguez, C. Milford, J. Vilches, C. Bayo and R. Ramos

\subsection{Introduction}

This section presents in situ aerosol observations, including particulate matter concentration data ( $\mathrm{PM}_{10}$ and $\mathrm{PM}_{2.5}$ ), for the 22-24 February 2020 dust outbreak. Various measurement sites have been used for both in situ and column aerosol observations, details of their location are given in Table 3.1 and Figure 3.1. In addition, the location of the eight airports of the Canary Islands are also shown in Figure 3.1 along with their airport codes, these are used for horizontal visibility records (see Sections 6.5 and 8.3 ).

Table 3.1. Location of measurement sites

\begin{tabular}{|c|c|c|c|c|}
\hline Measurement site & Latitude & Longitude & $\begin{array}{l}\text { Altitude } \\
\text { (m a.s.l.) }\end{array}$ & Organization \\
\hline (1) Mercado Central & $28.134 \stackrel{\circ}{N}$ & $15.433^{\circ} \mathrm{W}$ & 11 & $\mathrm{AQMN}^{1}$ \\
\hline (2) Tomé Cano & $28.462 \% \mathrm{~N}$ & $16.262^{\circ} \mathrm{W}$ & 67 & AQMN \\
\hline (3) Santa Cruz Observatory (SCO) & $28.473 \circ \mathrm{N}$ & $16.247^{\circ} \mathrm{WW}$ & 52 & IARC-AEMET \\
\hline (4) Izaña Observatory (IZO) & $28.3099 \mathrm{~N}$ & $16.499 \circ \mathrm{W}$ & 2373 & IARC-AEMET \\
\hline (5) El Río & $28.145 \cong \mathrm{N}$ & 16.524 oW & 500 & AQMN \\
\hline
\end{tabular}

${ }^{1}$ Canary I slands Government Air Quality Monitoring Network (AQMN)

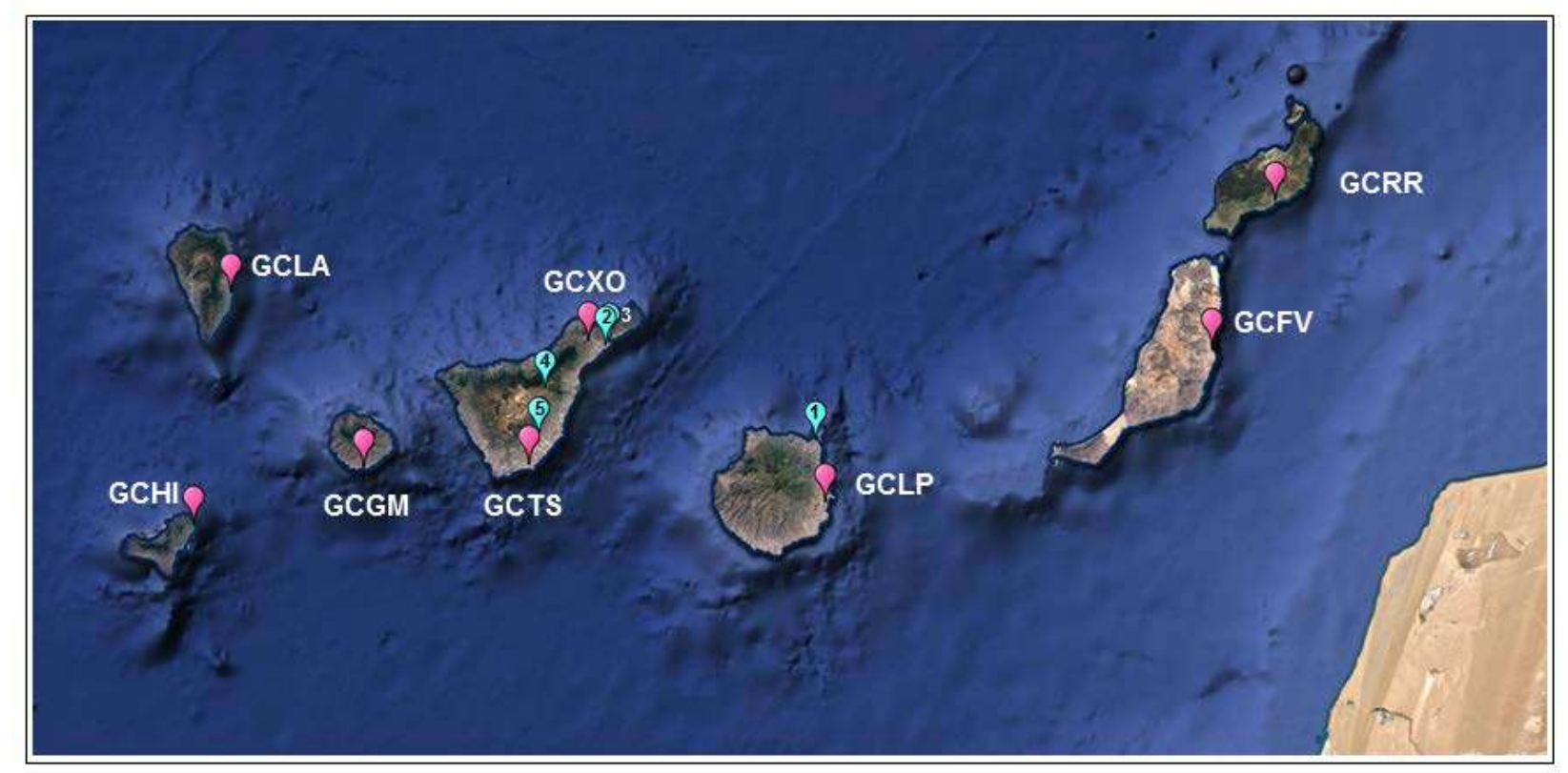

Figure 3.1. Location of measurement sites for in situ and column aerosol observations:

(1) Mercado Central, (2) Tomé Cano, (3) Santa Cruz Observatory, (4) I zaña Observatory, (5) El Río. In addition, the location of the eight airports of the Canary I slands are shown along with their airport codes 
Concentrations of respirable particles, of the size less than $10 \mu \mathrm{m}$ and $2.5 \mu \mathrm{m}\left(\mathrm{PM}_{10}\right.$ and $\left.\mathrm{PM}_{2.5}\right)$ in the Canary I slands are usually relatively low, due to favourable ventilation conditions caused by the trade winds (Guerra et al., 2004). In these trade wind conditions, $\mathrm{PM}_{10}$ and $\mathrm{PM}_{2.5}$ levels are typically within the ranges $15-25 \mu \mathrm{g} \mathrm{m}^{-3}$ and 3-8 $\mathrm{mg} \mathrm{m}^{-3}$, respectively. The main contributors to these particle levels are sea salt $\left(\sim 30 \%\right.$ of $\left.\mathrm{PM}_{\mathrm{x}}\right)$, traffic emissions $(\sim 12 \%)$, emissions linked to the combustion of heavy hydrocarbons in ships and power plants $(\sim 25 \%)$ and local dust ( $\sim 12 \%$ ) (Rodríguez et al., 2010). In the Canary Islands, the highest concentrations of $\mathrm{PM}_{10}$ and $\mathrm{PM}_{2.5}$ are usually recorded during the desert dust transport from the Sahara, known locally as "La Calima", when $\mathrm{PM}_{10}$ and $\mathrm{PM}_{2.5}$ concentrations usually range between 30 to $300 \mu \mathrm{g} \mathrm{m}^{-3}$ and 10 to $120 \mathrm{\mu g} \mathrm{m}^{-3}$, respectively (Rodríguez et al., 2015). Regarding the impact on air quality, the 22-24 February 2020 episode was absolutely extraordinary, as the hourly concentrations of $\mathrm{PM}_{10}$ and $\mathrm{PM}_{2.5}$ exceeded 3000 and $1000 \mathrm{\mu g} \mathrm{m}^{-3}$, respectively. Note that the thresholds established by WHO for health protection are $50 \mathrm{\mu g} \mathrm{m}^{-3}$ for $\mathrm{PM}_{10}$ and $25 \mu \mathrm{g} \mathrm{m}^{-3}$ for $\mathrm{PM}_{2.5}$ (24-h mean) (WHO, 2006).

Between 22 and 24 February 2020, a very severe episode of Saharan dust occurred, deteriorating air quality to unprecedented levels throughout the Canary Islands. As demonstrated by the satellite images presented in Section 2, the dust event affected the whole of the Canary Islands archipelago. We present particulate matter concentration data $\left(\mathrm{PM}_{10}\right.$ and $\mathrm{PM}_{2.5}$ ) from the two largest islands of the archipelago (Gran Canaria and Tenerife) to demonstrate the extensive geographical impact of this dust event. Data from representative measurement sites in each of the capital cities of Gran Canaria and Tenerife (Mercado Central in Las Palmas de Gran Canaria and Tomé Cano in Santa Cruz de Tenerife) are presented in Figure 3.2. These measurement sites are part of the Canary I slands Government Air Quality Monitoring Network. In addition, we present $\mathrm{PM}_{10}$ data from the SCO, Figure 3.2(c)) which is a measurement site managed by the Izaña Atmospheric Research Centre in Santa Cruz de Tenerife, as a GAW Regional station (see Cuevas et al., 2019 for more details).

The dust episode is seen in three intense peaks of particulate matter concentration, on 22, 23 and 24 February 2020. In Las Palmas de Gran Canaria, $\mathrm{PM}_{10}$ and $\mathrm{PM}_{2.5}$ concentrations reached values of $1870 \mu \mathrm{g} \mathrm{m}^{-3}$ and $590 \mathrm{\mu g} \mathrm{m}^{-3}$ during the first peak (22 February at 1700 UTC), $3200 \mu \mathrm{g} \mathrm{m}^{-3}$ and $1120 \mathrm{\mu g} \mathrm{m}^{-3}$ on 23 February (1600 UTC), during the second peak and $770 \mu \mathrm{g} \mathrm{m}^{-3}$ and $220 \mu \mathrm{g} \mathrm{m}^{-3}$ on 24 February (Figure 3.2(a)). These "extraordinarily high" concentrations of suspended particles represent a serious deterioration in air quality.

Similarly, in Santa Cruz de Tenerife in the Tomé Cano measurement station, $\mathrm{PM}_{10}$ and $\mathrm{PM}_{2.5}$ concentrations reached values of $1940 \mathrm{\mu g} \mathrm{m}^{-3}$ and $350 \mu \mathrm{g} \mathrm{m}^{-3}$ during the first peak (22 February at 1900 UTC) and $2930 \mathrm{\mu g} \mathrm{m}^{-3}$ and $1060 \mu \mathrm{g} \mathrm{m}^{-3}$ on 23 February, during the second peak (1800 UTC) (Figure 3.2(b)). On the third day of the episode (24 February 1000 UTC) in Tenerife, $\mathrm{PM}_{10}$ and $\mathrm{PM}_{2.5}$ concentrations peaked at concentrations similar to the first day of the episode, at $1970 \mu \mathrm{g} \mathrm{m}^{-3}$ and $460 \mu \mathrm{g} \mathrm{m}^{-3}$, respectively. This is in contrast to Gran Canaria, where on the third day the peak concentration was reduced compared to the previous two days. The $\mathrm{PM}_{10}$ concentrations registered at the SCO measurement station, also in Santa Cruz de Tenerife, reached values of $1420 \mathrm{\mu g} \mathrm{m}^{-3}$ during the first peak (22 February at 1900 UTC), $3490 \mu \mathrm{g} \mathrm{m}^{-3}$ on 23 February (1800 UTC), during the second peak and $1580 \mu \mathrm{g} \mathrm{m}^{-3}$ on 24 February (Figure 3.2(c)).

Recent studies in Tenerife have shown that exposure to desert dust episodes with $\mathrm{PM}_{10}$ concentrations between 50 and $150 \mu \mathrm{g} \mathrm{m}^{-3}$ (much lower than those recorded on 22, 23 and 24 February 2020) cause inflammation in the airways (Domínguez-Rodríguez et al., 2020 a) and are associated with intrahospital mortality from heart failure (Domínguez-Rodríguez et al., 2020b). 

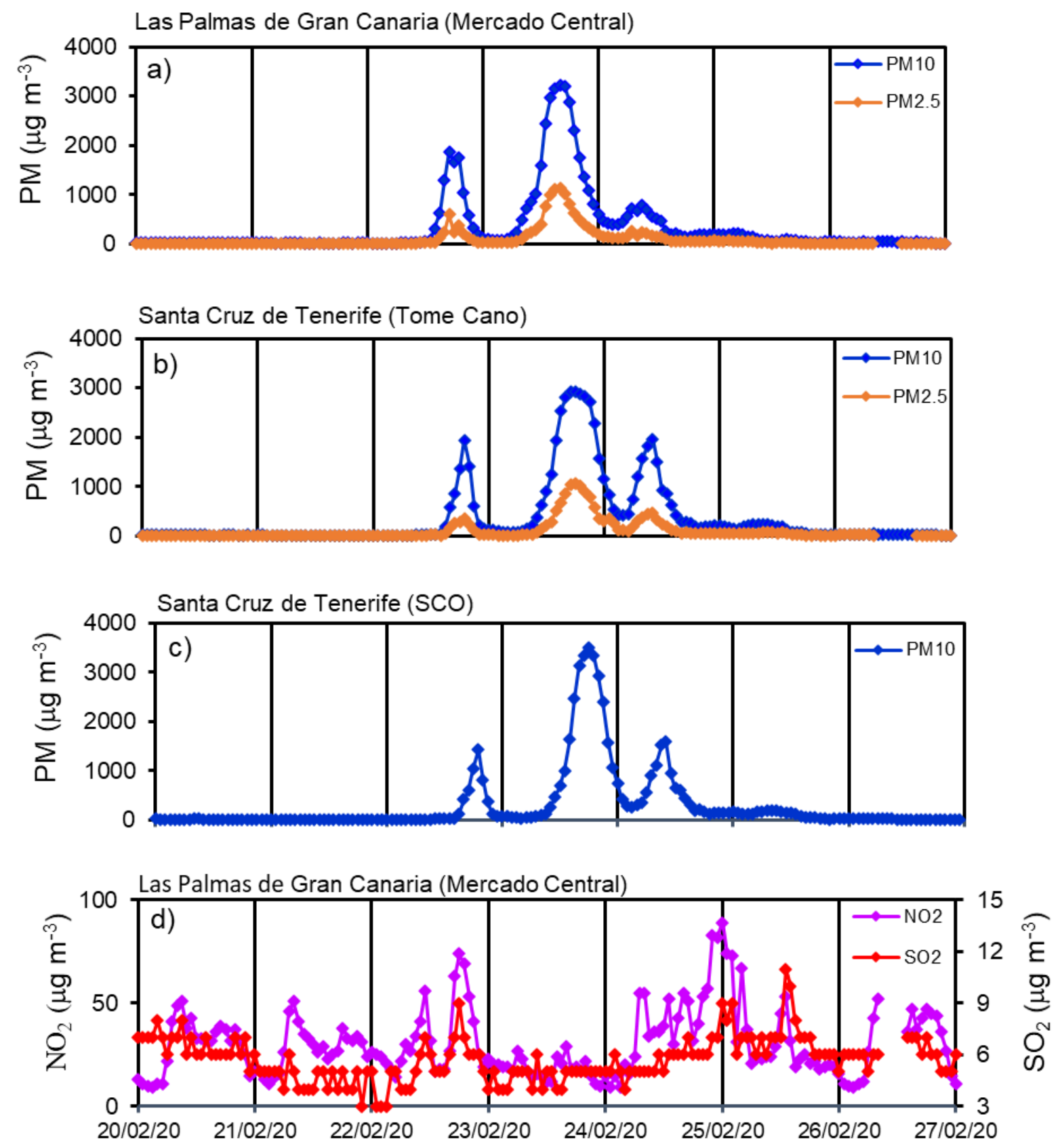

Figure 3.2. $P M_{10}$ and $P_{2.5}$ mean hourly concentrations for 20- 27 February 2020 in: (a) Las Palmas de Gran Canaria (Mercado Central) and (b) Santa Cruz de Tenerife (Tomé Cano), (c) $\mathrm{PM}_{10}$ mean hourly concentrations in Santa Cruz de Tenerife (SCO) and (d) $\mathrm{NO}_{2}$ and $\mathrm{SO}_{2}$ mean hourly concentrations in Las Palmas de Gran Canaria (Mercado Central). Data from the Canary I slands Government Air Quality Network (Mercado Central and Tomé Cano) and from I ARC-AEMET (SCO)

Previous studies have demonstrated that during desert dust outbreaks in the Canary Islands, there are usually increases in urban pollution levels linked to local combustion emissions, especially during the summer dust outbreaks. This is due to the meteorological conditions associated with these desert dust outbreaks, which result in a thinning of the marine boundary layer, caused by the advection of warm air over the cold marine boundary layer (Alastuey et al., 2005; Milford et al., 2020; Rodríguez et al., 2010).

However, in the 22-24 February 2020 dust outbreak, except in some locations, and at certain times, a significant increase in local urban pollution was not observed. This was likely due to a combination of factors. Firstly, the wind speed was high (up to $\sim 90 \mathrm{~km} \mathrm{~h}^{-1}$, see Section 2) and this high wind speed likely favoured the dispersion of local urban pollutants. Secondly, the day 
of the highest dust intensity, 23 February 2020, was a Sunday and therefore the local emissions, such as those from on-road traffic were reduced. In addition, this weekend was atypical (as discussed in Section 8.2) as it was in the middle of the Carnival celebrations and there were weather alerts for strong winds and for the dust outbreak from the Canary Islands Government to the citizens and this caused additional reduction of on-road traffic. Example data from a traffic measurement station located in the Centre of Santa Cruz de Tenerife (Figure 3.3) demonstrated the reduction in vehicle numbers during the days of the outbreak (22- 24 February 2020). Both Monday 24 February and Tuesday 25 February were holiday days due to the Carnival celebrations, so traffic numbers continued to be reduced right throughout this period. Data from the same traffic station for J anuary 2020 is shown in Figure 3.3 a for comparison.
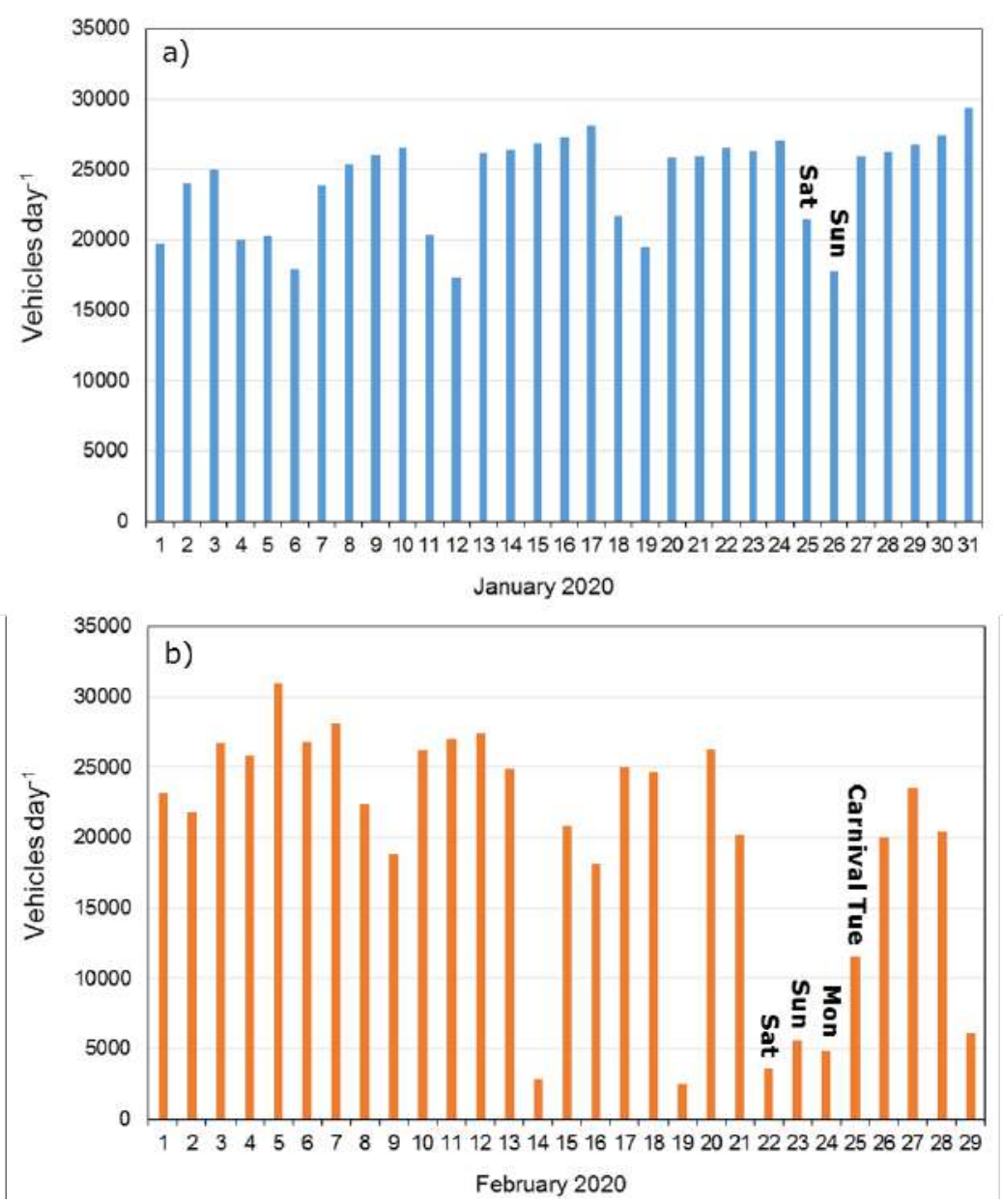

Figure 3.3. Daily number of vehicles for measurement station PER-901, located in the Centre of Santa Cruz de Tenerife, during (a) J anuary and (b) February 2020

\subsubsection{Uncertainty in $\mathrm{PM}_{10}$ and $\mathrm{PM}_{2.5}$ concentrations}

A technical aspect to consider is the uncertainty in $\mathrm{PM}_{10}$ and $\mathrm{PM}_{2.5}$ measurements, due to two reasons. Firstly, the reference methods, and their equivalents, for measuring $\mathrm{PM}_{10}$ and $\mathrm{PM}_{2.5}$ in the European Union, are designed for a range of concentrations between $1 \mathrm{\mu g} \mathrm{m}^{-3}$ and $150 \mu \mathrm{g}$ $\mathrm{m}^{-3}$ for $\mathrm{PM}_{10}$ and up to $120 \mu \mathrm{g} \mathrm{m}^{-3}$ for $\mathrm{PM}_{2.5}$ (EN 12341:2015), values well below the $3000 \mu \mathrm{g}$ $\mathrm{m}^{-3}$ concentrations observed during this episode.

Secondly, in high wind speed conditions such as those recorded between 22 to 24 February 2020 (up to $\sim 90 \mathrm{~km} \mathrm{~h}^{-1}$ ), the sampling efficiency of coarse particles (aerodynamic diameter $>2.5 \mu \mathrm{m}$ ) in $\mathrm{PM}_{10}$ impactors and selection cyclones decays significantly, which is why $\mathrm{PM}_{10}$ concentrations in the air quality network could be undervalued. That is, $\mathrm{PM}_{10}$ and $\mathrm{PM}_{2.5}$ measurements during this episode are subject to greater uncertainty than under "normal" conditions, i.e. concentrations below $100 \mu^{-3} \mathrm{~m}^{-3}$ (EN 12341:2015). 
Air quality deteriorated to unprecedented levels throughout the Canary Islands during the 22- 24 February 2020 dust outbreak. The air quality stations of the Canary Islands recorded three peaks of $\mathrm{PM}_{10}$ and $\mathrm{PM}_{2.5}$ concentrations on 22, 23 and 24 February 2020, with extremely high $\mathrm{PM}_{10}$ and $\mathrm{PM}_{2.5}$ hourly concentrations, which exceeded 3000 and $1000 \mu \mathrm{g} \mathrm{m}^{-3}$, respectively, during the largest peak recorded on 23 February 2020. There was no significant increase in local urban during these days, likely due to the high wind speed and the local emissions, such as those from on-road traffic, being reduced.

\subsection{References}

Alastuey, A., X. Querol, S. Castillo, M. Escudero, A. Avila, E. Cuevas, C. Torres, P. Romero, F. Expósito, and O. García, 2005: Characterization of TSP and PM2.5 at Izaña and Sta. Cruz de Tenerife (Canary Islands, Spain) during a Saharan dust Episode (July 2002), Atmos. Environ., 39(26), 4715-4728, https://www. sciencedirect.com/journal/atmospheric-environment/vol/39/issue/26.

Cuevas, E., C. Milford, J.J. Bustos, O.E. García, R.D. García, A.J. Gómez-Peláez, C. GuiradoFuentes, C. Marrero, N. Prats, R. Ramos, A. Redondas, E. Reyes, P.P. Rivas-Soriano, S. Rodríguez, P.M. Romero-Campos, C.J. Torres, M. Schneider, M. Yela, J. Belmonte, R. del Campo-Hernández, F. Almansa, A. Barreto, C. López-Solano, S. Basart, E. Terradellas, E. Werner, S. Afonso, C. Bayo, A. Berjón, V. Carreño, N.J. Castro, N. Chinea, A.M. Cruz, M. Damas, F. De Ory-Ajamil, M.I. García, V. Gómez-Trueba, C. Hernández, Y. Hernández, B. Hernández-Cruz, S.F. León-Luís, R. López-Fernández, J. López-Solano, F. Parra, E. Rodríguez, M. Rodríguez-Valido, C. Sálamo, E. Sanromá, D. Santana, F. Santo Tomás, E. Sepúlveda, and E. Sosa: 2019: I zaña Atmospheric Research Centre Activity Report 2017-2018. (Eds. Cuevas, E., Milford, C. and Tarasova, O.), State Meteorological Agency (AEMET), Madrid, Spain and World Meteorological Organization, Geneva, Switzerland, WMO/GAW Report No. 247.

Domínguez-Rodríguez, A., S. Rodríguez, N. Baez-Ferrer, P. Abreu-Gonzalez, J. AbreuGonzalez, P. Avanzas, M. Carnero, C. Moris, J. López-Darias, and D. Hernández-Vaquero, 2020a: Impact of Saharan dust exposure on airway inflammation in patients with ischemic heart disease, Transl. Res., 224, 16-25, https://pubmed.ncbi.nlm.nih.gov/32504824/ .

Domínguez-Rodríguez, A., N. Báez-Ferrer, S. Rodríguez, P. Avanzas, P. Abreu-Gonzalez, E. Terradellas, E. Cuevas, S. Basart, and E. Werner, 2020b: Saharan dust Events in the Dust Belt - Canary Islands- and the Observed Association within Hospital Mortality of Patients with Heart Failure, J. Clin. Med., 9(2), 376, https://www. mdpi.com/2077$0383 / 9 / 2 / 376$.

Guerra, J.-C., S. Rodríguez, M.-T. Arencibia, and M.-D. García, 2004: Study on the formation and transport of ozone in relation to the air quality management and vegetation protection in Tenerife (Canary Islands), Chemosphere, 56(11), 1157-1167, https://pubmed.ncbi.nlm.nih.gov/15276729/.

Milford, C., E. Cuevas, C.L. Marrero, J.J. Bustos, V. Gallo, S. Rodríguez, P.M. Romero-Campos, and C. Torres, 2020: Impacts of Desert Dust Outbreaks on Air Quality in Urban Areas, Atmosphere (Basel), 11(1), 23, https://www.mdpi.com/2073-4433/11/1/23.

Rodríguez, S., A. Alastuey, M. Viana, and X. Querol, 2010: Estudios de contaminación por material particulado en Canarias durante los años 2007 a 2010, Inf. Elabor. por el CSIC, AEMET y la Univ. Huelva para la Cons. del Medio Ambient. y Ord. Territ. del Gob. Canar. 
Rodríguez, S., E. Cuevas, J.M. Prospero, A. Alastuey, X. Querol, J. López-Solano, M.I. García, and S. Alonso-Pérez, 2015: Modulation of Saharan dust export by the North African dipole, Atmos. Chem. Phys., 15(13), 7471-7486,

https://acp. copernicus.org/articles/15/7471/2015/acp-15-7471-2015-discussion.html.

WHO Air Quality Guidelines: Global Update 2005-Particulate Matter, Ozone, Nitrogen Dioxide and Sulfur Dioxide; World Health Organization Regional Office for Europe: Copenhagen, Denmark, 2006. 


\section{S. Rodríguez, J. de la Rosa and J. Vilches}

\subsection{Introduction}

Composition of desert dust modulates dust impacts and processes involved in the dust cycle (Shao et al., 2011). Roughly, dust composition is not very different to that of the Earth crust (Scheuvens et al., 2013), however, apparently small variations in dust composition linked to variability in the mixing of minerals (Kandler et al., 2009; Reid, 2003) and/or alterations of dust properties due to interaction with the atmosphere (the so-called atmospheric processing; Gaston, 2020) have an influence on dust impacts (Shi et al., 2012). Feldspars act as ice nuclei (Atkinson et al., 2013), hematite absorbs UV radiation (Alfaro, 2004), calcium carbonate neutralizes acid pollutants (Ito and Feng, 2010), whereas iron bearing clays and oxides provide iron that fertilizes the ecosystems (Rizzolo et al., 2017). Studies performed in Tenerife, at Izaña Observatory, have shown that the interaction of dust minerals with acids, the exposure of dust to oxidants and sunlight, and the in cloud processing modifies the original ability of dust particles to acts as ice nuclei in cloud formation processes (Boose et al., 2016) and enhances iron solubility (Ravelo-Pérez et al., 2016).

Dust typically arriving to the Canary Islands is linked to sources in the mid north of the Sahara region (Alonso-Pérez et al., 2007). Dust originating in northeast Algeria and Tunisia tends to be rich in calcium, strontium and magnesium, whereas that originating in northwest Algeria is rich in sodium and chloride and that arriving from southern Sahara hot spots is rich in silicon and iron (Rodríguez et al., 2020). Moreover, dust is frequently mixed with key pollutants, such as sulphate, nitrate, ammonium and some trace metals (e.g. copper, chromium, nickel and zinc), linked to emission in the industrial areas of Morocco, Algeria and Tunisia (Rodríguez et al., 2011, 2020). The variability in dust composition is also influenced by the variability of the meteorology in North Africa. In summertime, the change of phase (negative to positive) of the North AFrican Dipole Intensity (NAFDI) (Cuevas et al., 2017; Rodríguez et al., 2015) is associated with east to west shifts of the North African anticyclone, Harmattan wind band and the Saharan Heat Low, resulting in east to west segregated activation of dust sources. Events of moderate NAFDI values $(0$ to +2.5$)$ tend to be associated with $\mathrm{Ca}, \mathrm{K}, \mathrm{Na}, \mathrm{Mg}$ and $\mathrm{S}$ rich dust linked to dust sources in NE Algeria, whereas events of higher NAFDI values $(+2.5$ to +4$)$ tend to be linked to Fe-rich dust ( $\mathrm{Ca}, \mathrm{Na}$ and $\mathrm{S}$ depleted) due to dust sources in SW Sahara Western Sahel (Rodríguez et al., 2020).

The 22-24 February 2020 dust event represents an anomaly in terms of its intensity, the huge dust concentrations recorded, and the associated meteorological situation. The chemical composition of the respirable aerosols, or particulate matter, was studied, by collecting samples of PM10 in Tenerife.

\subsection{PM chemical composition observations}

The samples of $\mathrm{PM}_{10}$ were collected on filters at the rural air quality monitoring station in El Río site (southern Tenerife). Concentration of $\mathrm{PM}_{10}$ was determined using the European reference method for air quality monitoring. Laboratory analysis allowed the determination of major elements ( $\mathrm{Si}, \mathrm{Al}, \mathrm{Fe}, \mathrm{Ca}, \mathrm{Na}$, among others, by Inductively Coupled Plasma Optical Emission Spectroscopy), of trace elements ( $\mathrm{V}, \mathrm{Ni}, \mathrm{Zn}, \mathrm{Cd}, \mathrm{Ti}$, among others by Inductively Coupled Plasma Mass Spectrometry), of anions and cations (sulphate, nitrate, ammonium, chloride, by ion chromatography), of elemental carbon (a metric representative of the content of black carbon, by thermo-optical transfer) and of organic carbon (by thermo-optical transfer), following methodologies described previously (Rodríguez et al., 2012). 
During $21,22,23,24$ and 25 February 2020, mean daily concentrations (24-h mean) of PM 10 particles experienced a significant increase, with values of $22,271,1644,419$ and $135 \mathrm{\mu g} \mathrm{m}^{-3}$, respectively. During the most intense period of the event (22-25 Feb), dust was enriched in $\mathrm{Ca}, \mathrm{Mg}$ and $\mathrm{K}$ (ratios to $\mathrm{Al}$ equal to $0.87,0.27$ and 0.27 , respectively), depleted in $\mathrm{Na}$ and $\mathrm{Cl}$ (ratios to $\mathrm{Al}$ equal to 0.17 and 0.06 , respectively) and exhibited an average amount of $\mathrm{Fe}$ (ratios to Al equal to 0.49 ).

Figure 4.1 shows the chemical composition of these $\mathrm{PM}_{10}$ particles, highlighting the contribution of (i) desert dust (brown) and (ii) sea salt (blue), nitrate (violet), sulphate (yellow), ammonium (red), elemental carbon (EC, black), organic matter (OM, grey), organic soil carbon (OCs, green) and trace metals (pink). The contributions of the non-desert dust components to the total mass is broken down in the right column in Figure 4.1.

- $\quad$ On 21 February, before the dust outbreak, the 24-h mean concentration of $\mathrm{PM}_{10}$ was $22 \mu \mathrm{g} \mathrm{m}^{-3}$ mainly because of the contribution of local dust (which contributed $15.2 \mu \mathrm{g} \mathrm{m}^{-3}, 69 \%$ of $\left.\mathrm{PM}_{10}\right)$ sea salt $\left(4.5 \mu \mathrm{g} \mathrm{m}^{-3}, 20 \% \mathrm{PM}_{10}\right)$ and (minor) inputs of contaminants such as nitrate $(2.6 \%)$, sulphate $(2 \%)$, elemental carbon $(1 \%)$ and organic matter (3\%);

- $\quad$ On 22 February (start of the dust episode) the 24-h mean concentration of $\mathrm{PM}_{10}$ was $271 \mathrm{\mu g} \mathrm{m}^{-3}$, mainly because of desert dust, which contributed $95 \%$ of $\mathrm{PM}_{10}$ $\left(257 \mathrm{~m} \mathrm{~m}^{-3}\right)$, there was a minor contribution of sea salt $(1.8 \%)$, sulphate $(0.5 \%)$, organic soil compounds $(0.6 \%)$ and trace elements $(0.6 \%)$;

- $\quad$ On 23 February 23 (maximum intensity of the episode) $1644 \mu \mathrm{g} \mathrm{m}^{-3}$ of $\mathrm{PM}_{10}$ were recorded, of which $98 \%\left(1608 \mu \mathrm{g} \mathrm{m}^{-3}\right)$ were desert dust minerals;

- On 24 February, 24-h mean $\mathrm{PM}_{10}$ concentrations decreased to $419 \mu \mathrm{g} \mathrm{m}^{-3}$, with $96 \%\left(404 \mathrm{\mu g} \mathrm{m}^{-3}\right)$ contribution of desert dust;

- On 25 February, 24-h mean $\mathrm{PM}_{10}$ concentrations decreased further to $135 \mu \mathrm{g} \mathrm{m}^{-3}$, with $96 \%\left(130.6 \mu \mathrm{g} \mathrm{m}^{-3}\right)$ contribution of desert dust.

Between 22 and 24 February, the period of maximum concentrations of dust, high organic matter/elemental carbon ratios were recorded, much higher than those associated with inputs from combustion sources and formation of secondary organic compounds. These "extra" contributions of organic compounds (OCs, Figure 4.1) are due to the contributions of biological material of the soil, identified in previous studies (García et al., 2017).

The presence of sulphate, nitrate and ammonium mixed with Saharan dust is common, due to background pollution in North Africa, affected by industrial emissions from Morocco, Algeria and Tunisia, among other regions (Rodríguez et al., 2011). There is also a very significant increase in trace metal concentrations, such as vanadium, nickel, arsenic, cadmium, zinc and chromium, which are naturally present in Saharan dust but have also been associated with industrial emissions in North Africa (Rodríguez et al., 2020). The increase in sea salt concentrations observed on 23 and 24 February (up to between 6.7 and $8.8 \mu \mathrm{g} \mathrm{m}^{-3}$ ) is associated with the high wind speed on the ocean surface, which favoured the mixture of desert dust and sea salt. 


\section{$\mathbf{P M}_{10}\left(\mu \mathrm{g} \mathrm{m}^{-3}\right)$}
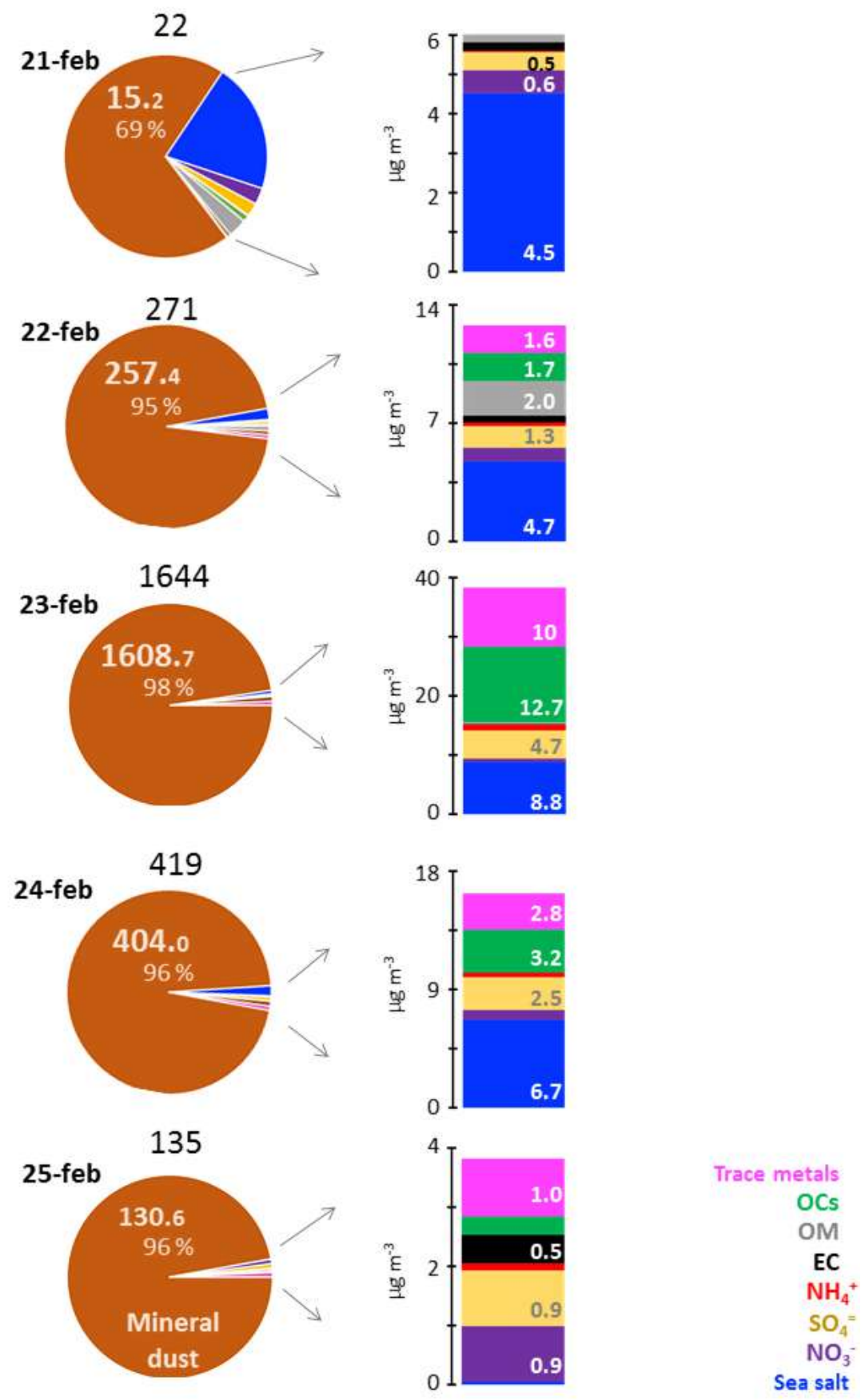

Figure 4.1. Chemical composition of $\mathrm{PM}_{10}$ particles in Tenerife (EI Río) between 21 and 25 February 2020. On top of each circle is shown (in black) the average daily (24-h mean) concentration of $\mathrm{PM}_{10}$ obtained by gravimetry. Each circle indicates the contribution to $\mathrm{PM}_{10}$ of (i) desert dust (brown) and (ii) sea salt (blue), nitrate (violet), sulphate (yellow), ammonium (red), elemental carbon (EC, black), organic matter (OM, grey), organic soil carbon (OCs, green) and trace metals (pink). The contributions of the non-desert dust components to the total mass is broken down in the right column. 
From 22 to 25 February 2020 the respirable $\mathrm{PM}_{10}$ particles in the ambient air reached extremely high values, up to $1644 \mu_{g^{-3}}$ (24-h average), measured using the European reference gravimetric method. Analysis of the aerosol chemical composition demonstrated that desert dust was, by far, the most important contributor to $\mathrm{PM}_{10}$ (95-98\%). These desert dust particles were enriched in calcium, magnesium and potassium, depleted in sodium and chloride and exhibited average amounts of iron, with respect to the composition of the Saharan dust that regularly arrives to the Canary Islands. Dust arrived mixed with air pollutants (which accounted for 2 to $5 \%$ of $\mathrm{PM}_{10}$ ), as sulphate, nitrate, ammonium and trace metals, linked to the background air pollution of North Africa.

\subsection{References}

Alfaro, S. C., 2004: Iron oxides and light absorption by pure desert dust: An experimental study, J. Geophys. Res., 109(D8), D08208, https://agupubs.onlinelibrary.wiley.com/doi/full/10.1029/2003J D004374.

Alonso-Pérez, S., E. Cuevas, X. Querol, M. Viana, and J.C. Guerra, 2007: Impact of the Saharan dust outbreaks on the ambient levels of total suspended particles (TSP) in the marine boundary layer (MBL) of the Subtropical Eastern North Atlantic Ocean, Atmos. Environ., 41(40), 9468-9480, https://www.sciencedirect.com/science/article/abs/pii/S1352231007007674.

Atkinson, J. D., B.J. Murray, M.T. Woodhouse, T.F. Whale, K.J. Baustian, K.S. Carslaw, S. Dobbie, D. O'Sullivan, and T.L. Malkin, 2013: The importance of feldspar for ice nucleation by mineral dust in mixed-phase clouds, Nature, 498(7454), 355-358, https: //www. nature.com/articles/nature12278.

Boose, Y., B. Sierau, M.I. García, S. Rodríguez, A. Alastuey, C. Linke, M. Schnaiter, P. Kupiszewski, Z.A. Kanji, and U. Lohmann, 2016: Ice nucleating particles in the Saharan Air Layer, Atmos. Chem. Phys., 16(14), 9067-9087, https://acp.copernicus.org/articles/16/9067/2016/.

Cuevas, E., A.J. Gómez-Peláez, S. Rodríguez, E. Terradellas, S. Basart, R.D. García, O.E. García, and S. Alonso-Pérez, 2017: The pulsating nature of large-scale Saharan dust transport as a result of interplays between mid-latitude Rossby waves and the North African Dipole Intensity, Atmos. Environ., 167, 586-602, https://www.sciencedirect.com/science/article/pii/S1352231017305757.

García, M. I., B.L. van Drooge, S. Rodríguez, and A. Alastuey, 2017: Speciation of organic aerosols in the Saharan Air Layer and in the free troposphere westerlies, Atmos. Chem. Phys., 17(14), 8939-8958, https://acp.copernicus.org/articles/17/8939/2017/.

Gaston, C. J., 2020: Re-examining Dust Chemical Aging and Its Impacts on Earth's Climate, Acc. Chem. Res., https://pubs.acs.org/doi/abs/10.1021/acs.accounts.0c00102.

Ito, A. and Y. Feng, 2010: Role of dust alkalinity in acid mobilization of iron, Atmos. Chem. Phys., 10(19), 9237-9250, https://acp.copernicus.org/articles/10/9237/2010/.

Kandler, K., L. SchüTZ, C. Deutscher, M. Ebert, H. Hofmann, S. JäCKEL, R. J aenicke, P. Knippertz, K. Lieke, A. Massling, A. Petzold, A. Schladitz, B. Weinzierl, A. Wiedensohler, S. Zorn, and S. Weinbruch1, 2009: Size distribution, mass concentration, chemical and mineralogical composition and derived optical parameters of the boundary layer aerosol at Tinfou, Morocco, during SAMUM 2006, Tellus B. Chem. Phys. Meteorol., 61(1), 32-50, https://www.tandfonline.com/doi/abs/10.1111/j.16000889.2008.00385.x. 
Ravelo-Pérez, L. M., S. Rodríguez, L. Galindo, M.I. García, A. Alastuey, and J. López-Solano, 2016: Soluble iron dust export in the high altitude Saharan Air Layer, Atmos. Environ., 133, 49-59, https://www.sciencedirect.com/science/article/ pii/S135223101630200X.

Reid, E. A., 2003: Characterization of African dust transported to Puerto Rico by individual particle and size segregated bulk analysis, J. Geophys. Res., 108(D19), 8591, https://agupubs.onlinelibrary. wiley.com/doi/full/10.1029/2002J D002935.

Rizzolo, J. A., C.G.G. Barbosa, G.C. Borillo, A.F.L. Godoi, R.A.F. Souza, R.V. Andreoli, A.O. Manzi, M.O. Sá, E.G. Alves, C. Pöhlker, I.H. Angelis, F. Ditas, J. Saturno, D. MoranZuloaga, L.V. Rizzo, N.E. Rosário, T. Pauliquevis, R.M.N. Santos, C.I. Yamamoto, M.O. Andreae, P. Artaxo, P.E. Taylor, and R.H.M. Godoi, 2017: Soluble iron nutrients in Saharan dust over the central Amazon rainforest, Atmos. Chem. Phys., 17(4), 26732687, https://acp.copernicus.org/articles/17/2673/2017/.

Rodríguez, S., A. Alastuey, S. Alonso-Pérez, X. Querol, E. Cuevas, J. Abreu-Afonso, M. Viana, N. Pérez, M. Pandolfi, and J. de la Rosa, 2011: Transport of desert dust mixed with North African industrial pollutants in the subtropical Saharan Air Layer, Atmos. Chem. Phys., 11(13), 6663-6685, https://acp.copernicus.org/articles/11/6663/2011/.

Rodríguez, S., A. Alastuey, and X. Querol, 2012: A review of methods for long-term in situ characterization of aerosol dust, Aeolian Res., 6, 55-74,

https:// www.sciencedirect.com/journal/aeolian-research/vol/6/suppl/C.

Rodríguez, S., E. Cuevas, J.M. Prospero, A. Alastuey, X. Querol, J. López-Solano, M.I. García, and S. Alonso-Pérez, 2015: Modulation of Saharan dust export by the North African dipole, Atmos. Chem. Phys., 15(13), 7471-7486,

https://acp. copernicus.org/articles/15/7471/2015/acp-15-7471-2015-supplement. pdf.

Rodríguez, S., G. Calzolai, M. Chiari, S. Nava, M.I. García, J. López-Solano, C. Marrero, J. López-Darias, E. Cuevas, S. Alonso-Pérez, N. Prats, F. Amato, F. Lucarelli, and $X$. Querol, 2020: Rapid changes of dust geochemistry in the Saharan Air Layer linked to sources and meteorology, Atmos. Environ., 223, 117186, https://www.sciencedirect.com/science/article/abs/pii/S1352231019308258.

Scheuvens, D., L. Schütz, K. Kandler, M. Ebert, and S. Weinbruch, 2013: Bulk composition of northern African dust and its source sediments - A compilation, Earth-Science Rev., 116, 170- 194, https://www.sciencedirect.com/science/article/pii/S0012825220303421.

Shao, Y., K.-H. Wyrwoll, A. Chappell, J. Huang, Z. Lin, G.H. McTainsh, M. Mikami, T.Y. Tanaka, $X$. Wang, and S. Yoon, 2011: Dust cycle: An emerging core theme in Earth system science, Aeolian Res., 2(4), 181-204, https://www.sciencedirect.com/science/article/abs/pii/S1875963711000085.

Shi, Z., M.D. Krom, T.D. Jickells, S. Bonneville, K.S. Carslaw, N. Mihalopoulos, A.R. Baker, and L.G. Benning, 2012: Impacts on iron solubility in the mineral dust by processes in the source region and the atmosphere: A review, Aeolian Res., 5, 21-42, https:// www.sciencedirect.com/science/article/abs/pii/S1875963712000146. 
A. Barreto, R.D. García and R. Ramos

\section{$5.1 \quad$ Introduction}

This section presents column aerosol observations, using both passive and active remote sensing techniques, and radiative forcing calculations. These different observations and techniques have been used to characterize the 22 and 24 February 2020 dust episode in terms of columnar aerosol load, particle size distribution, vertical structure and radiative impact.

\subsection{Column aerosol observations}

\subsubsection{Photometric column aerosol observations}

Column aerosol observations were made by solar photometry, using a Cimel CE318-T photometer installed at the Santa Cruz de Tenerife (SCO) AERONET station (AErosol RObotic NETwork; https://aeronet.gsfc.nasa.gov/) (Holben et al., 1998; Barreto et al., 2016; Giles et al., 2019). AERONET is a global, federated network that uses CE318-T photometers as a reference instrument and is established in terms of standardized calibration, processing and quality control protocols. This instrument is capable of measuring direct radiation from the Sun using narrow interference filters (between 2 and $40 \mathrm{~nm}$ bandwidth), centred at the following nominal wavelengths: 1640, 1020,940, 870,675, 500, 440, 380 and $340 \mathrm{~nm}$. This type of device allows measurement of the AOD and its spectral dependence, the Angstrom exponent $(A E)$. CE318-T photometers also perform two different sequences for the measurement of sky radiance (almucantar and principal plane). This set of spectral and multiangular measurements allows certain microphysical and radiative properties of column aerosols to be estimated, such as size distribution, simple dispersion albedo or phase function, among others, through complex inversion algorithms.

In this study, AOD, AE and size distribution data provided by the AERONET network have been extracted for two stations: Santa Cruz (SCO, $52 \mathrm{~m}$ a.s.I.) and Izaña (IZO, $2373 \mathrm{~m}$ a.s.I.). Data processed to version 3 and corresponding to levels 1.0 and 1.5 have been used. Level 1.0 data lacks quality control and corresponds to processed data without applying any quality control filters, including the cloud filter. Level 1.5 data have had the cloud filter and quality algorithm applied. It is normally recommended to use level 1.5 or higher-level data. However, in this study it was not possible to use level 1.5 data on 22 and 23 February 2020, due to the intensity and speed of the dust intrusion affecting the observatory, which was incorrectly attributed to the presence of clouds and eliminated by AERONET control algorithms to access level 1.5. The photometric information acquired on the rest of the days corresponds to level 1.5. Version 3 and level 1.5 data was used for Izaña with the only exception of data on February 23, when level 1.0 data was used.

Figure 5.1 shows the temporal evolution of AOD at $500 \mathrm{~nm}$ and the Ångstrom exponent calculated with AOD data between $440 \mathrm{~nm}$ and $870 \mathrm{~nm}\left(\mathrm{AE}_{440-870}\right)$ during the period 21- 27 February 2020 for Santa Cruz and Izaña. A rapid increase in AOD can be observed during the second half of February 22 (from approximately 1500 UTC), reaching a value of 2.59 at the end of the day. This increase leads to the consequent decrease in $\mathrm{AE}_{440-870}$ associated with the increase in particle size, with a minimum value of 0.16 at the end of the day. The next day the dust intrusion is still present, with $A O D$ values around $1\left(A E_{440-870}\right.$ around 0.58 ) in the early hours of the day, progressively increasing to 3.11 during the latter hours of the day $\left(A E_{440-870}\right.$ of 0.35$)$. It is not surprising, in view of the rapid increase in $A O D$ in such a short time interval, that the data during 22 and 23 February was filtered by AERONET's quality control algorithm. No AOD data are available on 24 February due to the presence of altocumulus clouds associated with the top of the Saharan Air Layer. Data for 25 and 26 February confirms the withdrawal of the intrusion, with a return to clean atmospheric conditions at the end of 26 February ( $A O D$ around 0.04 and $A_{440-870}$ of 0.85 ). 
Figure 5.1(b) presents the $A O D$ and $A E_{440-870}$ evolution at Izaña, confirming the increased vertical extent of this event from the second half of 22 February, but in a less intense way than in Santa Cruz. During this day AOD is still low (0.05) and $\mathrm{AE}_{440-870}$ shows intermediate values of 0.38. Similarly, to the evolution observed in Santa Cruz, AOD reached its maximum (0.84) on 23 February 2020 , with nearly zero and even negative $A E_{440-870}$ values. $A O D$ gradually decreased the following days, with pristine conditions found in the second half of 26 February. This dust outbreak at I zaña, although less intense than the event observed in Santa Cruz, is unusual taking into account that dust transport in wintertime is mainly restricted to lower levels (below 2-3 km), and rarely reach the altitude of Izaña.
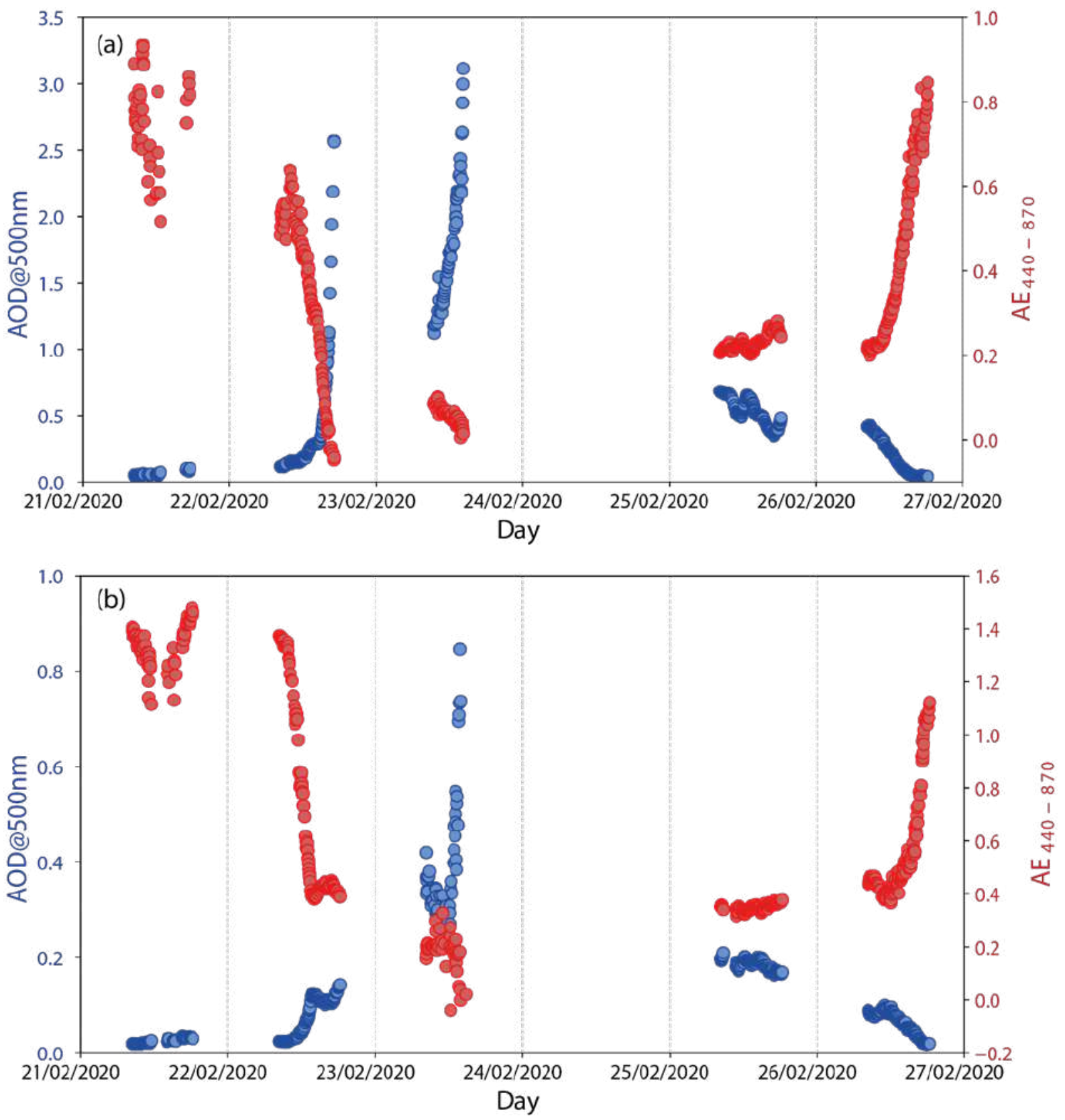

Figure 5.1. Evolution of AOD at $500 \mathrm{~nm}$ and $A E_{440-870}$ for 21- 27 February 2020 from the CE318T photometer in (a) Santa Cruz de Tenerife (SCO) and (b) I zaña (I ZO), extracted from the AERONET network 
Figure 5.2(a) presents the size distribution measured with the CE318-T photometer in Santa Cruz de Tenerife (SCO), obtained from AERONET during this episode. In addition, in Figure 5.2(b), the size distribution obtained from a different inversion algorithm is presented. This was developed by the University of Granada (UGR) (Olmo et al. 2006; 2008 and Valenzuela et al. 2012) using CE318 measurements of direct and diffuse radiation and using spheroid approximation.
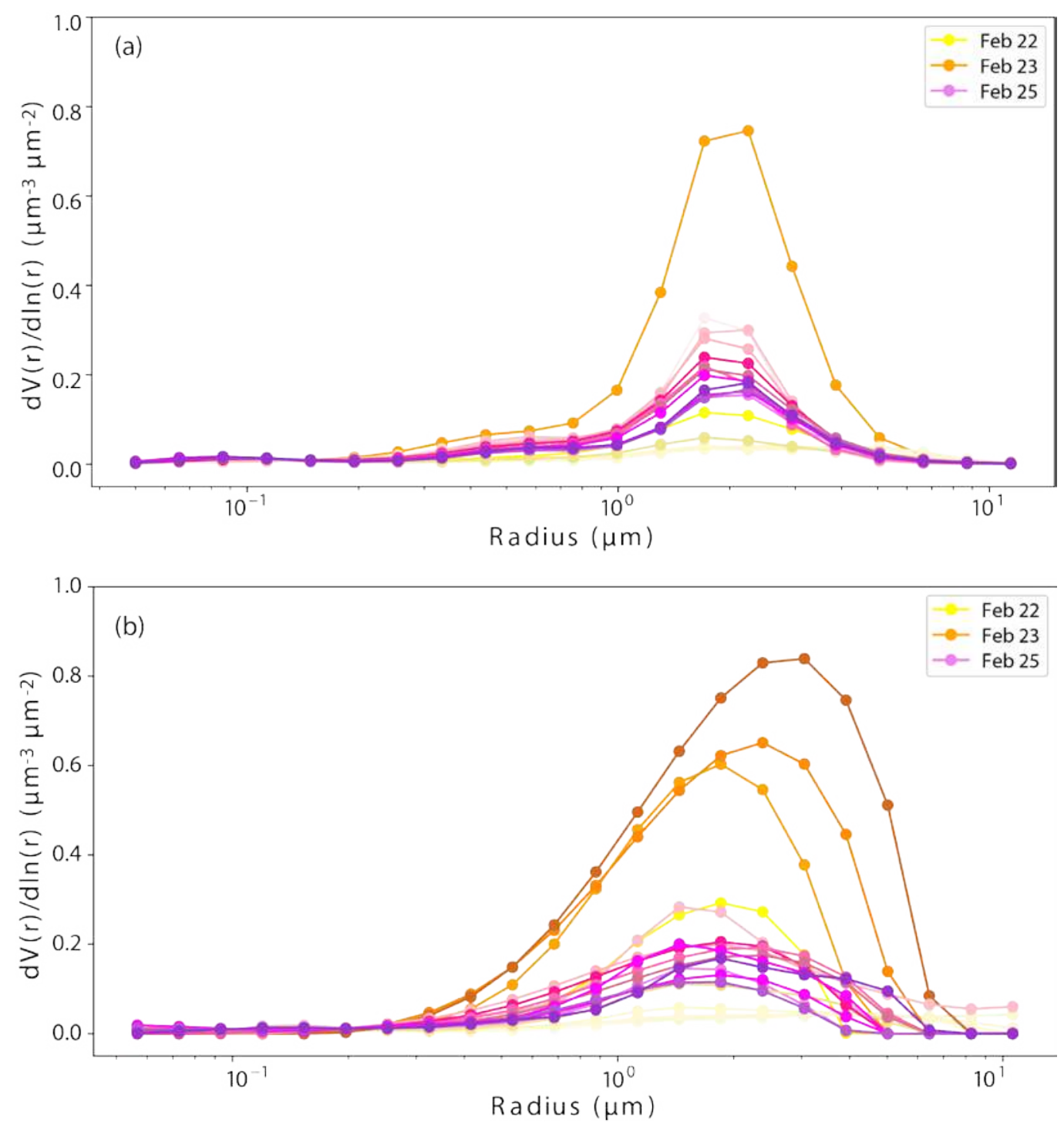

Figure 5.2. Evolution of volumetric size distribution measured with the CE318-T photometer in Santa Cruz de Tenerife (SCO) between 22-25 February 2020 extracted from (a) AERONET and (b) through the UGR inversion software. Data for day 22, 23 and 25 February are represented with a range of yellows, orange and violet respectively. Light colours refer to the early hours of the day and acquire darker tones as the day goes on.

These two figures highlight the noticeable increase in the coarse mode in the particle size distributions from the last hours of 22 February onwards, indicating an important contribution of particles of radii $>1 \mu \mathrm{m}$ during this episode. The size distributions extracted from AERONET are essentially bimodal, with a primary maximum in the coarse mode, around $2 \mu \mathrm{m}$, and a secondary maximum in the fine mode, around $0.9 \mu \mathrm{m}$. 
However, the UGR inversion algorithm shows a more prominent coarse mode, with an important contribution of particulate matter up to $6 \mu \mathrm{m}$, and a negligible fine mode. As a main difference between the two distributions it is worth highlighting the displacement of the peak of the coarse mode as the intrusion is intensified on 23 February, with a maximum of about $2 \mu \mathrm{m}$ around 10.30 UTC (similar to the only size distribution data available from AERONET for 23 February) which then increases to about $3 \mu \mathrm{m}$ at 12:30 UTC.

The rapid decline of the coarse mode in the size distribution during subsequent days (25 February) is evident in this figure. Due to the proximity of the dust emission source and the high wind speed in this particular dust episode, it is expected that the efficiency of dry deposition atmospheric processes is reduced, with the consequent arrival of coarse and giant particles that are not included within the inversion algorithms. The greater uncertainty in size distribution near the extremes of the distribution and the possible overestimation of fine and coarse modes as a result of the size limitation imposed in the AERONET inversion method are the results which were already published in previous work (Schepanski et al. 2009, Ryder et al. 2015, Dubovik et al. 2006).

\subsubsection{Lidar vertical profiles}

This analysis of column aerosol observations was complemented by observations made using active remote sensing techniques. The study of the vertical and temporal evolution of the atmosphere during this period was conducted by means of a Micro Pulse Lidar (MPL-4) operating at $532 \mathrm{~nm}$, as shown in Figure 5.3. This type of instrument is part of the NASA MPLNET network (https://mplnet.gsfc.nasa.gov), which is a global and standardized network, with the MPL as a reference instrument. In Figure 5.3 the Normalized Relative Backscatter (NRB) signal is presented. The NRB signal is a measure of the relative intensity of energy backscattered by atmospheric components (this includes aerosols, as well as particles which are components of clouds and atmospheric molecules). The NRB signal includes a correction based on the altitude of the signal, normalization by the energy of the laser pulse and a number of specific calibrations. See Campbell et al. (2002) and Welton and Campbell (2002) for more details on the MPL system.

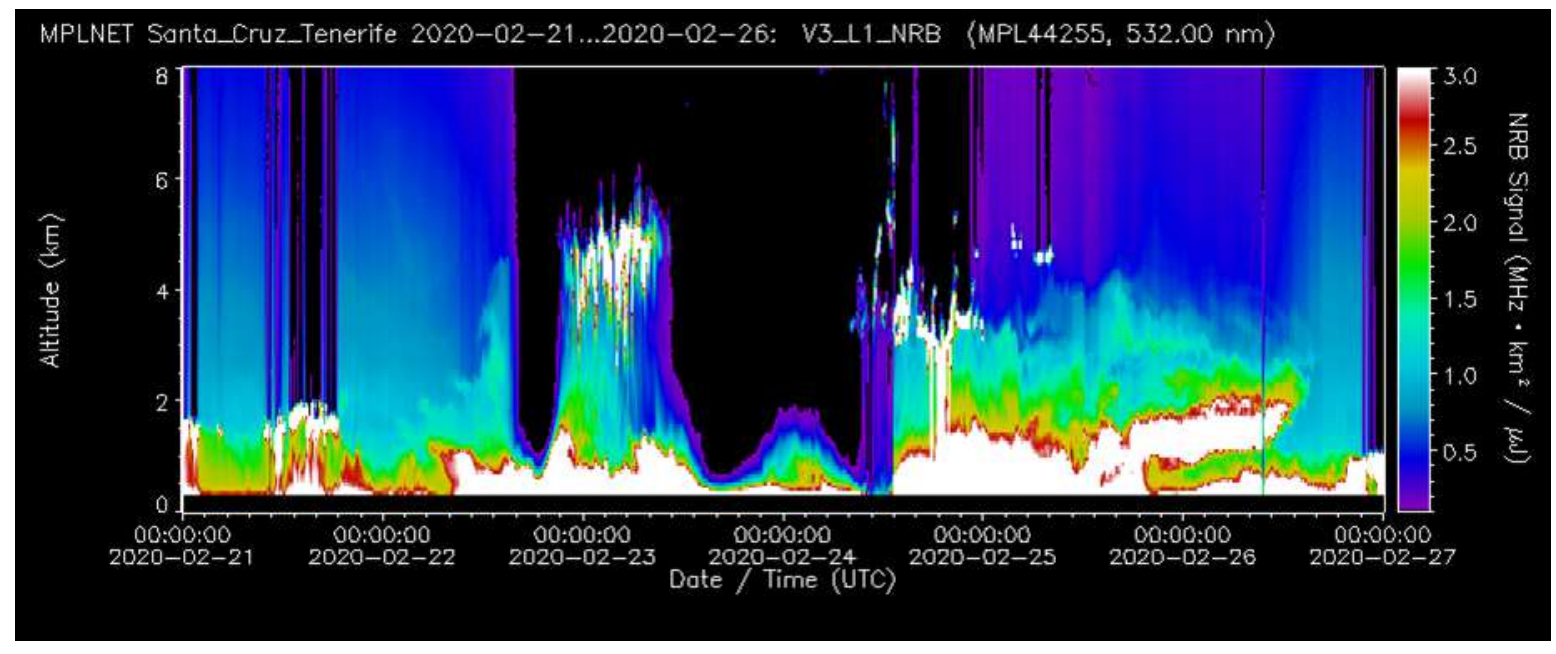

Figure 5.3. Vertical and temporal evolution of the NRB signal extracted with the Micro Pulse Lidar (MPL-4) between 21- 27 February 2020 in Santa Cruz de Tenerife (extracted from https:/ / mplnet.gsfc.nasa.gov) 
In Figure 5.3 we observe the evolution of the NRB signal and the beginning of the dust intrusion in the early hours of 22 February, which intensifies in altitude from noon, reaching $5 \mathrm{~km}$ in height. At 1500 UTC, the dust intrusion becomes so intense that it saturates the lidar signal from $1 \mathrm{~km}$ high, this is corroborated by the solar photometry data. This situation persists until 2100 UTC, at which time the presence of altocumulus associated with the top of the Saharan layer, located around $5 \mathrm{~km}$, are distinguished. The dust intrusion saturates the lidar signal again from 1000 UTC 23February to 1000 UTC 24 February. After this period the presence of high altocumulus and a Saharan layer with vertical extension up to $4 \mathrm{~km}$ high is observed again, with the end of the dust episode occurring about noon on 26 February.

It is worth noting the exceptionality of this episode, with the presence of a layer of mineral dust from the Sahara with an unusual vertical extension, given the time of year in which the event took place. As Cuevas et al. (2015) and other studies show, Saharan dust intrusions into the Canary Islands in winter/spring are normally confined to heights below $2-3 \mathrm{~km}$. In contrast, in the summer period, these intrusions usually have a considerable vertical extension, typically reaching $6 \mathrm{~km}$ in height. The reason for these differences is the different height reached by the Saharan convective layer (Guirado et al., 2014), and the different mechanisms of mineral dust emission from source areas depending on the season. With regard to the latter, mechanical mechanisms (driven by strong winds usually associated with the passage of fronts or storms with strong frontogenetic activity) predominate in winter/spring, and thermal mechanisms (strong surface heating with associated convective processes) predominate in summer.

\subsection{Radiative forcing}

\subsubsection{Basic concepts}

The Earth's radiative balance is defined by the relationship between the energy input, which can be reflected and absorbed, and the energy emitted by the Earth's system. At the upper limit of the atmosphere (Top Of the Atmosphere, TOA) this balance is zero if the Earthatmosphere system is in radiative equilibrium with its environment. However, any factor that alters radiation received from the Sun, or alters the redistribution of energy within the Earthatmosphere system, can affect this balance and, consequently, our climate. To quantify changes in the net energy available in the Earth-atmosphere system, the concept of radiative forcing $(\Delta \mathrm{F})$ is introduced (IPCC, 2014).

In this report we focus on the effect of aerosols, and specifically mineral dust, on the $\Delta \mathrm{F}$ of the atmosphere. It depends on the size, shape and chemical composition of the particles and also on various aspects of the hydrological cycle (e.g. cloud formation). Therefore, $\Delta \mathrm{F}$ is defined as the difference between the energy measured on the Earth's surface under the presence of aerosols, $\mathrm{F}^{\mathrm{A}}$, against which it would be measured under the same conditions, but in the absence of aerosols, $\mathrm{F}^{\mathrm{L}}$, that is, radiation under clean sky conditions:

$\Delta F=F^{A}-F^{L}$

We limit all analysis to cases in the absence of clouds, so the variations in energy or forcing found are due only to the presence of suspended dust. The value of the forcing obtained from the above equation is an instantaneous value, from which we can obtain the daily average value of it from the following equation:

$D F=\frac{1}{24} \int_{t 1}^{t 2} \Delta F(t) d t$

where $t_{1}$ and $t_{2}$ are the calculation times for the instantaneous forcing. From the definition of $\Delta \mathrm{F}$ the instantaneous $\Delta \mathrm{F}$ efficiency $\left(\Delta F^{e f f}\right)$ is defined as the variation of $\Delta \mathrm{F}$ per unit of AOD:

$\Delta F^{e f f}=\frac{\Delta F}{A O D}$ 
The main advantage of introducing this parameter is that it eliminates the marked influence of the aerosol loading on forcing, which facilitates the comparison of the direct radiative effect of different aerosols. In addition, knowledge of this value allows us to evaluate, in a first approximation, the radiative forcing from only the optical thickness of aerosols present.

The efficiency value obtained from Eq. 3 is an instantaneous value. However, in the literature this magnitude is also evaluated as the variation of $\Delta F$ per unit of AOD variation through the so-called slope method (e.g., Bush and Valero, 2003; García et al., 2008; García et al., 2014). In this method, the efficiency is extracted from the slope of the linear representation between $\Delta F$ and AOD.

The $\Delta \mathrm{F}$ due to atmospheric aerosols is determined from Eq. 1 . To do this we study the difference between the radiation measurements taken experimentally in Santa Cruz de Tenerife $\left(F^{A}\right)$, and the same measurements simulated in the absence of aerosols $\left(F^{L}\right)$, for this we use the LibRadtran model (Mayer and Kylling, 2005; Emde et al., 2016).

Figure 5.4 shows the evolution of $\mathrm{AOD}$ at $500 \mathrm{~nm}$ and the $\Delta \mathrm{F}$ of global and direct radiation during the study period in Santa Cruz de Tenerife. We observe a considerable increase in $\Delta F$ as the concentration of aerosols in the atmosphere increases. The daily $D F$ obtained from Eq. 2 between the first two days of the event increased by $41 \%\left(-17.48 \mathrm{~W} \mathrm{~m}^{-2}\right.$ on 22 February 2020 to $-42.72 \mathrm{~W} \mathrm{~m}^{-2}$ on 23 February 2020) in the case of global radiation, and by $67 \%$ for direct radiation (-116.94 $\mathrm{W} \mathrm{m}^{-2}$ on 22 February to $-175.01 \mathrm{~W} \mathrm{~m}^{-2}$ on 23 February) (see Table 5.1).

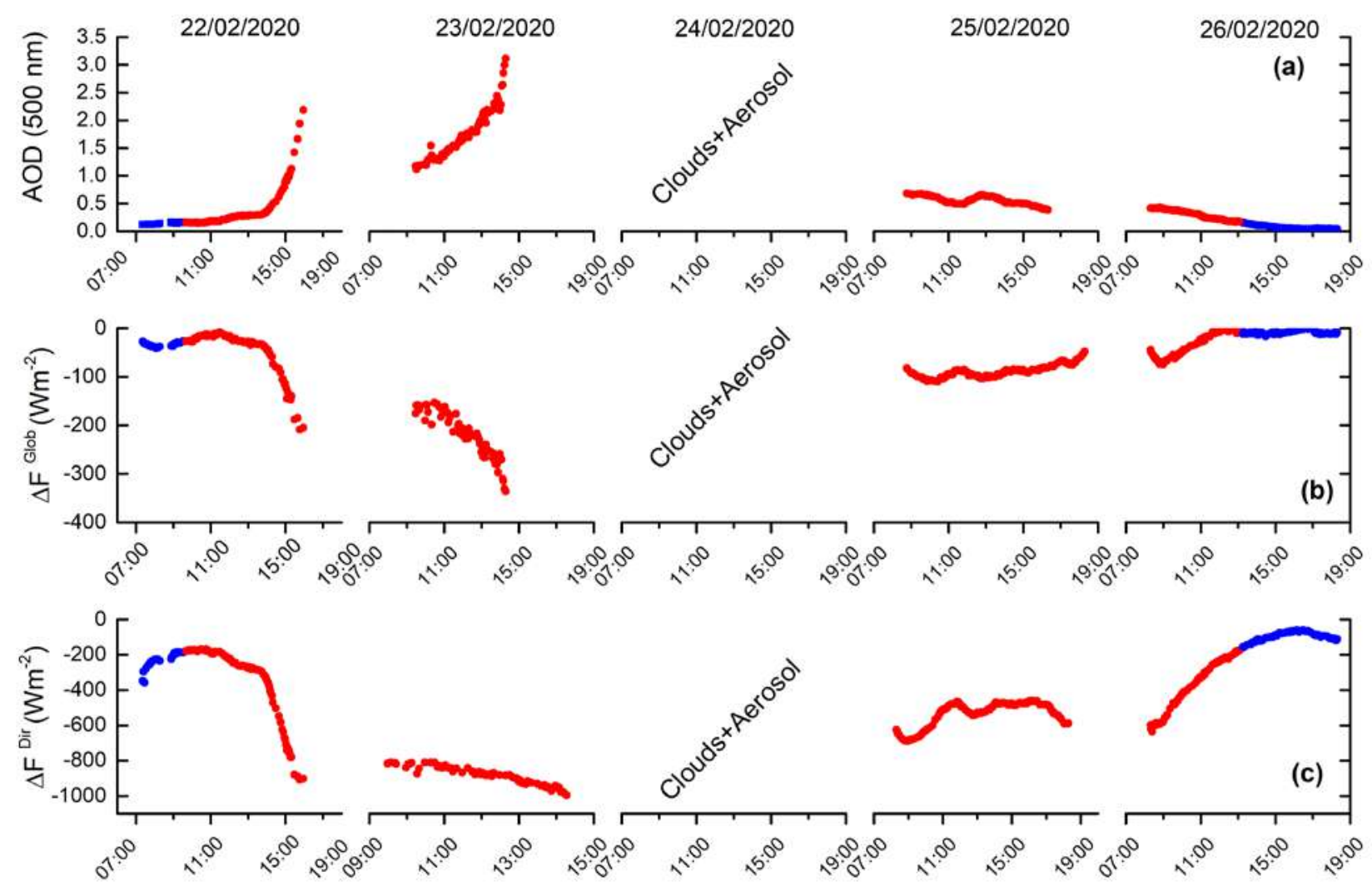

Figure 5.4.- Evolution of (a) AOD at $500 \mathrm{~nm}$ and instantaneous radiation forcing of (b) global radiation and (c) direct radiation due to the presence of aerosols at the Santa Cruz de Tenerife station between 22-26 February 2020. Blue dots indicate AOD $<0.15$ and red dots indicate AOD > 0.15 (dust conditions at Santa Cruz station). 
Table 5.1. Daily radiative forcing of global and direct radiation in $W^{-2}$, AOD, and $A E$ at the Santa Cruz de Tenerife station during the study period. The standard deviation associated with the AOD and AE mean values is included. On 24 February there are no measurements because of the presence of clouds.

\begin{tabular}{lllcll}
\hline Parameter & $22 / 02 / 2020$ & $23 / 02 / 2020$ & $24 / 02 / 2020$ & $25 / 02 / 2020$ & $26 / 02 / 2020$ \\
\hline $\operatorname{DF}^{\mathrm{Glob}}\left(\mathrm{W} \mathrm{m}^{-2}\right)$ & -17.48 & -42.72 & - & -36.49 & -8.46 \\
$\mathrm{DF}^{\mathrm{Dir}}\left(\mathrm{W} \mathrm{m}^{-2}\right)$ & -116.94 & -175.01 & - & -222.59 & -95.06 \\
$\mathrm{AOD}(500 \mathrm{~nm})$ & $0.295 \pm 0.239$ & $1.780 \pm 0.471$ & - & $0.533 \pm 0.103$ & $0.185 \pm 0.136$ \\
$\mathrm{AE}$ & $0.371 \pm 0.174$ & $0.056 \pm 0.020$ & - & $0.229 \pm 0.019$ & $0.440 \pm 0.206$ \\
\hline
\end{tabular}

The variation of $\triangle \mathrm{F}$ per unit of $\mathrm{AOD}$ variation in the study period (Figure 5.5 ) reveals that the efficiency is $-120.60 \pm 1.44 \mathrm{Wm}^{-2} \mathrm{AOD}$ for the case of global radiation, and $-1161.96 \pm 16.03$ $\mathrm{Wm}^{-2} \mathrm{AOD}$ for direct radiation during the study of this event in Santa Cruz de Tenerife.

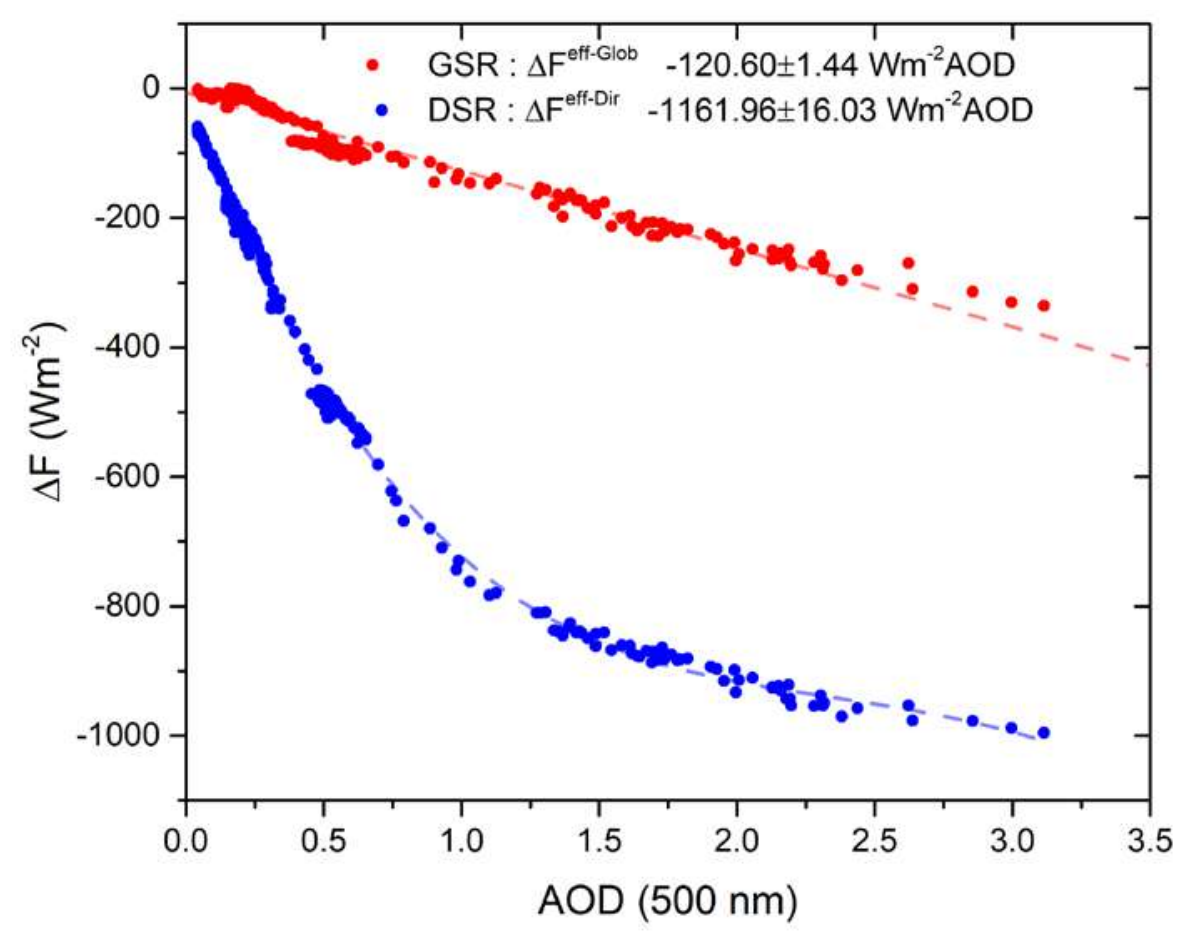

Figure 5.5. Radiative forcing of global solar radiation (GSR) and direct solar radiation (DSR) in W $\mathbf{~ m}^{-2}$ versus AOD at $500 \mathrm{~nm}$ at the Santa Cruz de Tenerife (SCO) station during the study period. The slope values of the respective curves tell us the value of the radiative forcing efficiency.

\subsection{Conclusions}

In this section, the temporal evolution of two important parameters for aerosol characterization (AOD and AE) are shown for 21-27 February 2020 to characterize the dust episode. Our results confirmed the rapid increase in terms of AOD and particle size, reaching the maximum on 23 February 2020, when AOD reached the value of 3.11 and AE of near zero. This observed increase of AOD in the atmosphere led to an increase in negative radiative forcing. The daily DF increased by $41 \%\left(-17.48 \mathrm{~W} \mathrm{~m}^{-2}\right.$ on 22 February to $-42.72 \mathrm{~W} \mathrm{~m}^{-2}$ on 23 February) in the case of global radiation, and by $67 \%$ for direct radiation $\left(-116.94 \mathrm{~W} \mathrm{~m}^{-2}\right.$ on 22 February to $-175.01 \mathrm{~W} \mathrm{~m}^{-2}$ on 23 February). 
Inversion results confirmed the noticeable increased in the coarse mode of the particle size distribution, with an important contribution of particles up to $6 \mu \mathrm{m}$ and a negligible fine mode. This dust intrusion appeared as a thick layer reaching $5 \mathrm{~km}$ in height in the light of the results provided by the MPL lidar system, with an unusual vertical extension taking into account the time of year in which this event took place. This unusual vertical extension caused the Izaña Observatory to be affected by this dust outbreak, although in a less intense way than the event observed in Santa Cruz (maximum AOD of 0.84 on 23 February 2020, with nearly zero and even negative $A E$ values). Altocumulus associated with the top of the Saharan layer were also observed at around $5 \mathrm{~km}$ with this lidar system.

\section{$5.5 \quad$ References}

Barreto, Á., E. Cuevas, M.-J. Granados-Muñoz, L. Alados-Arboledas, P.M. Romero, J. Gröbner, N. Kouremeti, A. F. Almansa, T. Stone, C. Toledano, R. Román, M. Sorokin, B. Holben, M. Canini, and M. Yela, 2016: The new sun-sky-lunar Cimel CE318-T multiband photometer - a comprehensive performance evaluation, Atmos. Meas. Tech., 9, 631654, https://amt. copernicus.org/articles/9/631/2016/.

Bush, B., and F.P.J . Valero, 2003: Surface aerosol radiative forcing at Gosan during the ACEAsia campaign, J. Geophys. Res., 108, 8660, https: //agupubs.onlinelibrary. wiley.com/doi/pdfdirect/10.1029/2002J D003233.

Campbell, J.R., D.L. Hlavka, E.J . Welton, C.J. Flynn, D.D. Turner, J.D. Spinhirne, V.S. Scott, and I.H. Hwang, 2002: Full-time, Eye-Safe Cloud and Aerosol Lidar Observation at Atmospheric Radiation Measurement Program Sites: Instrument and Data Processing, J. Atmos. Oceanic Technol., 19, 431-442.

Dubovik, O., A. Sinyuk, T. Lapyonok, B.N. Holben, M. Mishchenko, P. Yang, T.F. Eck, H. Volten, O. Munoz, B. Veihelmann, W.J. van der Zande, J.F. Leon, M. Sorokin, and I. Slutsker, 2006: Application of spheroid models to account for aerosol particle non-sphericity in remote sensing of desert dust, J. Geophys. Res. Atmos., 111, D11208, https: //agupubs.onlinelibrary. wiley.com/doi/10.1029/2005JD006619.

Emde, C., R. Buras-Schnell, A. Kylling, B. Mayer, J. Gasteiger, U. Hamann, J. Kylling, B. Richter, C. Pause, T. Dowling, et al. 2016: The LibRadtran software package for radiative transfer calculations (version 2.0. 1), Geoscientific Model Development, pp. 1647-1672, https://gmd.copernicus.org/articles/9/1647/2016/.

García, O. E., A. M. Díaz, F. J. Expósito, J. P. Díaz, A. Redondas, and T. Sasaki, 2008: Aerosol radiative forcing and forcing efficiency in the UVB for regions affected by Saharan and Asian mineral dust, J. Atmos. Sci., 66, 1033-1040, https://journals. ametsoc.org/view/journals/atsc/66/4/2008jas2816.1.xml.

García, R. D., O.E. García, E. Cuevas, V.E. Cachorro, P.M. Romero-Campos, R. Ramos, and A.M. de Frutos, 2014: Solar radiation measurements compared to simulations at the BSRN I zaña station. Mineral dust radiative forcing and efficiency study, J. Geophys. Res., 119, 179-194, https://agupubs.onlinelibrary.wiley.com/doi/full/10.1002/2013] D020301.

Giles, D. M., A. Sinyuk, M.G. Sorokin, J.S. Schafer, A. Smirnov, I. Slutsker, T.F. Eck, B.N. Holben, J.R. Lewis, J.R. Campbell, E.J. Welton, S.V. Korkin, and A.I. Lyapustin, 2019: Advancements in the Aerosol Robotic Network (AERONET) Version 3 database automated near-real-time quality control algorithm with improved cloud screening for Sun photometer aerosol optical depth (AOD) measurements, Atmos. Meas. Tech., 12, 169-209, https://amt. copernicus.org/articles/12/169/2019/. 
Guirado, C., E. Cuevas, V.E. Cachorro, C. Toledano, S. Alonso-Pérez, J J. Bustos, S. Basart, P.M. Romero, C. Camino, M. Mimouni, L. Zeudmi, P. Goloub, J.M. Baldasano, and A.M. de Frutos, 2014: Aerosol characterization at the Saharan AERONET site Tamanrasset, Atmos. Chem. Phys., 14, 11753-11773, https://acp.copernicus.org/articles/14/11753/2014/acp-14-11753-2014.html.

Holben, B. N., T.F. Eck, I. Slutsker, D. Tanre, J.P. Buis, A. Setzer, E. Vermote, J.A. Reagan, Y. Kaufman, T. Nakajima, F. Lavenue, I. Jankowiak, and A. Smirnov, 1998: AERONET - A federated instrument network and data archive for aerosol characterization, Remote Sens. Environ., 66, 1-16,

https://www.sciencedirect.com/science/article/abs/pii/S0034425798000315.

Holben, B., D. Tanre, A. Smirnov, T. Eck, I. Slutsker, N. Abuhassan, W. Newcomb, J. Schafer, B. Chatenet, F. Lavenu, et al, 2001: An emerging ground-based aerosol climatology: Aerosol optical depth from AERONET, Journal of Geophysical Research: Atmospheres,106, 12 067-12 097, https://agupubs.onlinelibrary.wiley.com/doi/abs/10.1029/2001JD900014.

Mayer, B. and A. Kylling, 2005: Technical note, The LibRadtran software package for radiative transfer calculations - description and examples of use, Atmos. Chem. Phys., 5, 18551877, https://acp.copernicus.org/articles/5/1855/2005/.

Olmo, F.J., A. Quirantes, A. Alcántara, H. Lyamani, and L. Alados-Arboledas, 2006: Preliminary results of a non-spherical aerosol method for the retrieval of the atmospheric aerosol optical properties, J. Quant. Spectrosc. Radiat. Transf., 100, 305-314, https://www.sciencedirect.com/science/article/abs/pii/S002240730500395X?via\% 3Dihub.

Olmo, F. J., A. Quirantes, V. Lara, H. Lyamani and L. Alados-Arboledas, 2008: Aerosol optical properties assessed by an inversion method using the solar principal plane for nonspherical particles. Journal of Quantitative Spectroscopy and Radiative Transfer, 109, 1504-1516, 2008.

https:// www. sciencedirect.com/science/article/abs/pii/S0022407307003688?via\% 3Dihub

Ryder, C. L., J.B. McQuaid, C. Flamant, P.D. Rosenberg, R. Washington, H.E. Brindley, E.J. Highwood, J.H. Marsham, D.J. Parker, M.C. Todd, J.R. Banks, J.K. Brooke, S. Engelstaedter, V. Estelles, P. Formenti, L. García-Carreras, C. Kocha, F. Marenco, H. Sodemann, C.J.T. Allen, A. Bourdon, M. Bart, C. Cavazos-Guerra, S. Chevaillier, J. Crosier, E. Darbyshire, A.R. Dean, J.R. Dorsey, J. Kent, D. O'Sullivan, K. Schepanski, K. Szpek, J. Trembath, and A. Woolley, A, 2015: Advances in understanding mineral dust and boundary layer processes over the Sahara from Fennec aircraft observations, Atmos. Chem. Phys., 15, 8479-8520, https://acp.copernicus.org/articles/15/8479/2015/.

Schepanski, K., I. Tegen, and A. Macke, 2009: Saharan dust transport and deposition towards the tropical northern Atlantic, Atmos. Chem. Phys., 9, 1173-1189, https://acp. copernicus.org/articles/9/1173/2009/.

Valenzuela, A., F.J. Olmo, H. Lyamani, M. Antón, A. Quirantes, L. Alados-Arboledas, 2012: Aerosol radiative forcing during African desert dust events (2005-2010) over Southeastern Spain. Atmospheric Chemistry and Physics, 12, 10331-10351, 2012. https://acp.copernicus.org/articles/12/10331/2012/

Welton, E.J., and J.R. Campbell, 2002: Micro-pulse Lidar Signals: Uncertainty Analysis, J. Atmos. Oceanic Technol., 19, 2089-2094. 
C. Milford, E. Cuevas, R.D. García, N. Prats, A. Barreto, J. Vilches, D. Suárez and C.L. Marrero

\subsection{Introduction}

One of the most frequently questions asked by many citizens on social media about the dust event of 22-24 February 2020 is: "Was it the most severe dust episode the Canary archipelago has ever suffered"?

The question has no easy answer for several reasons:

(4) it depends on the parameter and technique used to determine the intensity of the dust event, (e.g. $\mathrm{PM}_{10}$, AOD, extinction, etc.),

(5) as discussed in Section 3.2, the uncertainty in $\mathrm{PM}_{10}$ and $\mathrm{PM}_{2.5}$ measurements is much greater at the high concentration levels observed during this intense dust episode and

it depends on whether we refer to daily mean, instantaneous, or maximum values of the parameter used to quantify the dust episode. In this section we seek to answer this question utilizing different long-term observation records.

\subsection{In situ $\mathrm{PM}_{10}$ and $\mathrm{PM}_{2.5}$ observations}

As discussed in previous sections (Section 1 and 3 ), the most commonly used parameters to continuously estimate the particulate matter concentration near the surface and to best represent the impact that the dust event had on the population are $\mathrm{PM}_{10}$ and $\mathrm{PM}_{2.5}$. These parameters are also legally established in the air quality regulations of both the European Commission and Spain. Reliable $\mathrm{PM}_{10}$ and $\mathrm{PM}_{2.5}$ records, subject to quality controls and regular calibrations, are available in the Canary I slands since 2001. We present long-term $\mathrm{PM}_{10}$ and $\mathrm{PM}_{2.5}$ data from the same two Air Quality Monitoring Network measurement sites that were introduced in Section 3.2 (Mercado Central in Las Palmas de Gran Canaria and Tomé Cano in Santa Cruz de Tenerife).

The $\mathrm{PM}_{10}$ hourly concentrations at Mercado Central, Las Palmas de Gran Canaria during 20012019 (Figure 6.1) reached a maximum of $1303 \square \mathrm{g} \mathrm{m}^{-3}$ on $17 / 1 / 2005$ with similar values in the episodes of January 2002 and March 2004. As shown in Section 3.2, during the February 2020 dust episode, $\mathrm{PM}_{10}$ hourly concentrations at Mercado Central reached a maximum of $3231 \square \mathrm{g} \mathrm{m}^{-3}$ on $23 / 2 / 2020$ at 1600 UTC, a large increase with respect to the hourly maximum during 2001-2019. 


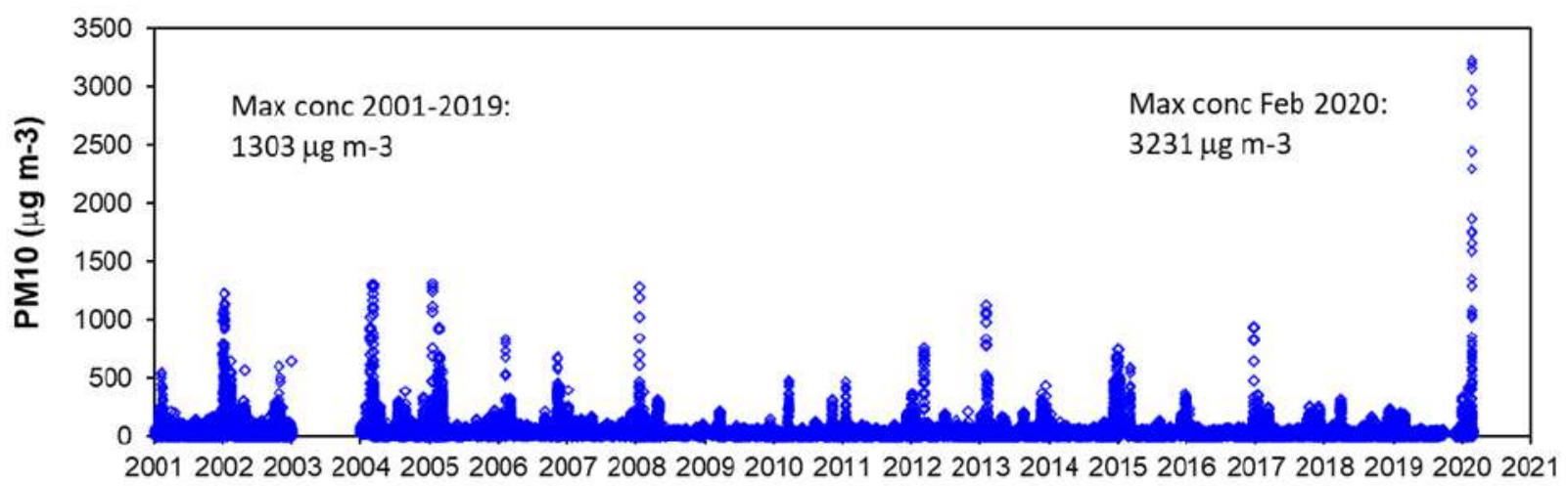

Figure 6.1. PM10 mean hourly concentrations in Las Palmas de Gran Canaria (Mercado Central) for the period 2001- 2020. Data from the Canary I slands Government Air Quality Network.

The $\mathrm{PM}_{10}$ hourly concentrations at Tomé Cano, Santa Cruz de Tenerife during 2001-2019 (Figure 6.2) reached a maximum of $1312 \square \mathrm{g} \mathrm{m}^{-3}$ on 3-4/3/2004 with similar values in episodes in January 2002 and February 2005. During the February 2020 dust episode, $\mathrm{PM}_{10}$ hourly concentrations at Tomé Cano reached a maximum of $2932 \square \mathrm{g} \mathrm{m}^{-3}$ on 23 February 2020 at 1800 UTC, a similarly large increase with respect to the hourly maximum during 20012019.

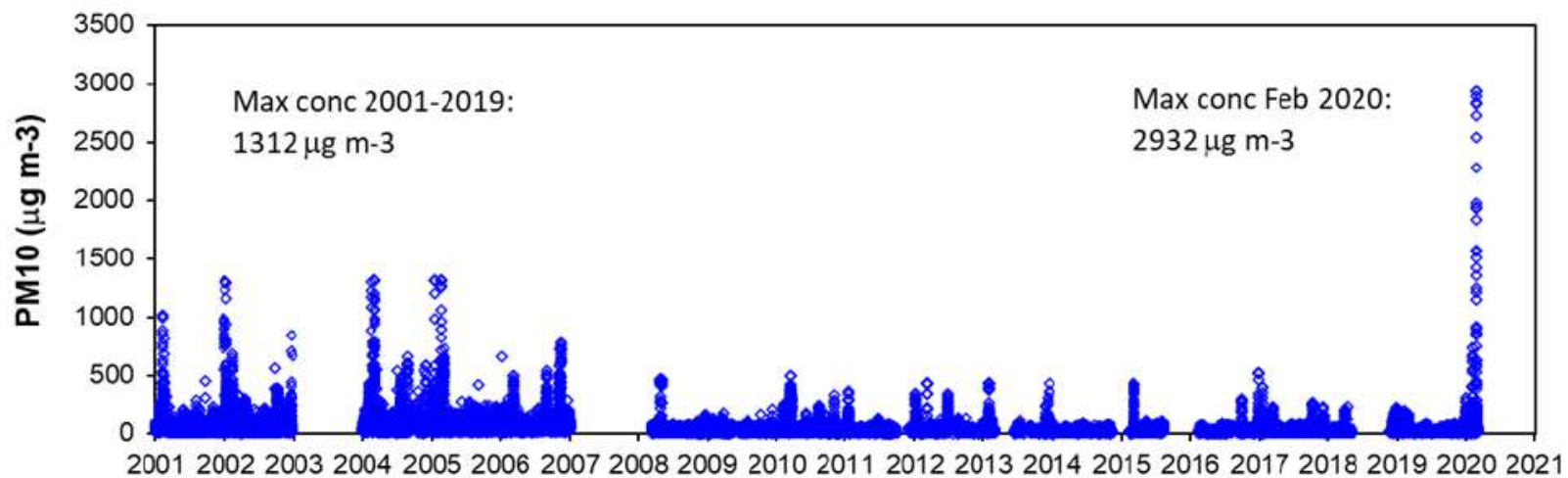

Figure 6.2. $\mathrm{PM}_{10}$ mean hourly concentrations in Santa Cruz de Tenerife (Tomé Cano) for the period 2001- 2020. Data from the Canary I slands Government Air Quality Network.

The $\mathrm{PM}_{10}$ daily (24-h mean) concentrations at Mercado Central, Las Palmas de Gran Canaria, during 2001-2019 (Figure 6.3) reached a maximum of $795 \mu \mathrm{g} \mathrm{m}^{-3}$ whereas during the February 2020 dust episode, $\mathrm{PM}_{10}$ daily concentrations at Mercado Central reached a maximum of $1283 \mu \mathrm{g} \mathrm{m}^{-3}$ on 23 February 2020.

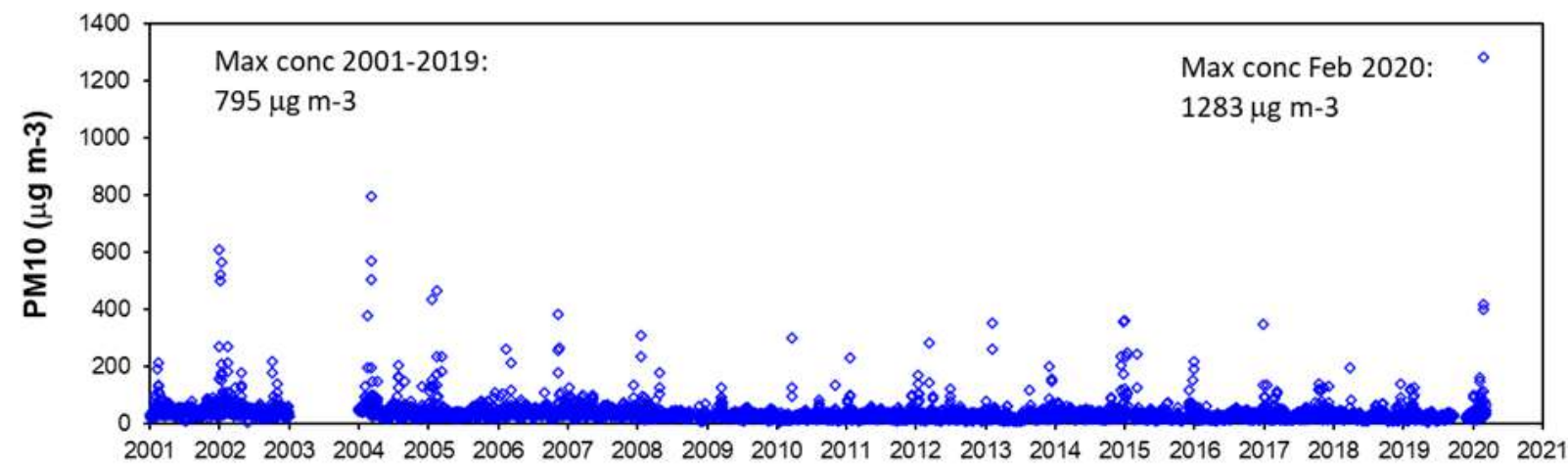

Figure 6.3. $\mathrm{PM}_{10}$ daily (24-h mean) concentrations in Las Palmas de Gran Canaria ( Mercado Central) for the period 2001- 2020 
The $\mathrm{PM}_{10}$ daily (24-h mean) concentrations at Tomé Cano, Santa Cruz de Tenerife during 2001-2019 (Figure 6.4) reached a maximum of $919 \mu \mathrm{g} \mathrm{m}^{-3}$ whereas during the February 2020 dust episode, $\mathrm{PM}_{10}$ daily concentrations at Tomé Cano reached a maximum of $1238 \mathrm{\mu g} \mathrm{m}^{-3}$ on 23 February 2020.

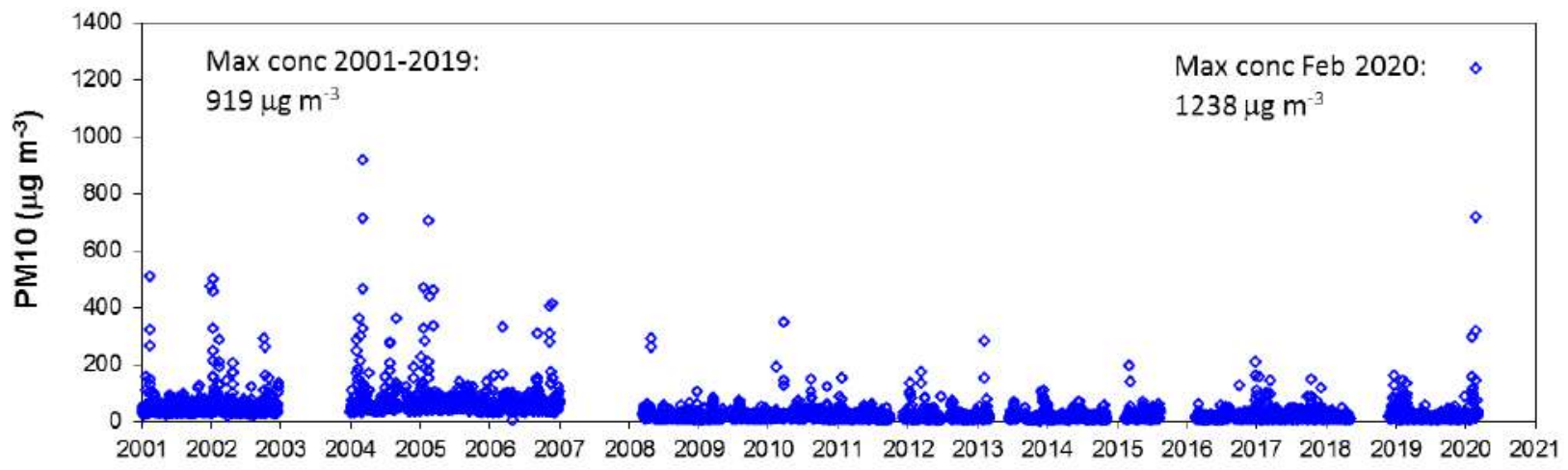

Figure 6.4. $\mathrm{PM}_{10}$ daily (24-h mean) concentrations in Santa Cruz de Tenerife (Tomé Cano) for the period 2001-2020

$\mathrm{PM}_{2.5}$ measurements in the Canary I slands Air Quality Monitoring Network started later than $\mathrm{PM}_{10}$ measurements, in Mercado Central they started in 2009 and in Tomé Cano they started in 2015. The $\mathrm{PM}_{2.5}$ daily (24-h mean) concentrations at Mercado Central, Las Palmas de Gran Canaria, during 2009-2019 (Figure 6.5) reached a maximum of $144 \mu^{-3} \mathrm{~m}^{-3}$ whereas during the February 2020 dust episode, $\mathrm{PM}_{2.5}$ daily concentrations at Mercado Central reached a maximum of $390 \mathrm{\mu g} \mathrm{m}^{-3}$ on 23 February 2020, this is really an astonishingly high concentration for $\mathrm{PM}_{2.5}$. Note that the WHO health protection threshold for $\mathrm{PM}_{2.5}$ (24-h mean) is $25 \mu \mathrm{g} \mathrm{m}^{-3}$ (as discussed in Section 3.2) (WHO, 2006), therefore the maximum observed $\mathrm{PM}_{2.5}$ daily concentration was more than 15 times that of the health protection threshold. The maximum $\mathrm{PM}_{2.5}$ daily (24-h mean) concentration in Santa Cruz de Tenerife (Tomé Cano) was $363 \mu \mathrm{g} \mathrm{m}^{-3}$ on 23 February 2020 (Figure 6.6), similar to the maximum value observed in Gran Canaria.

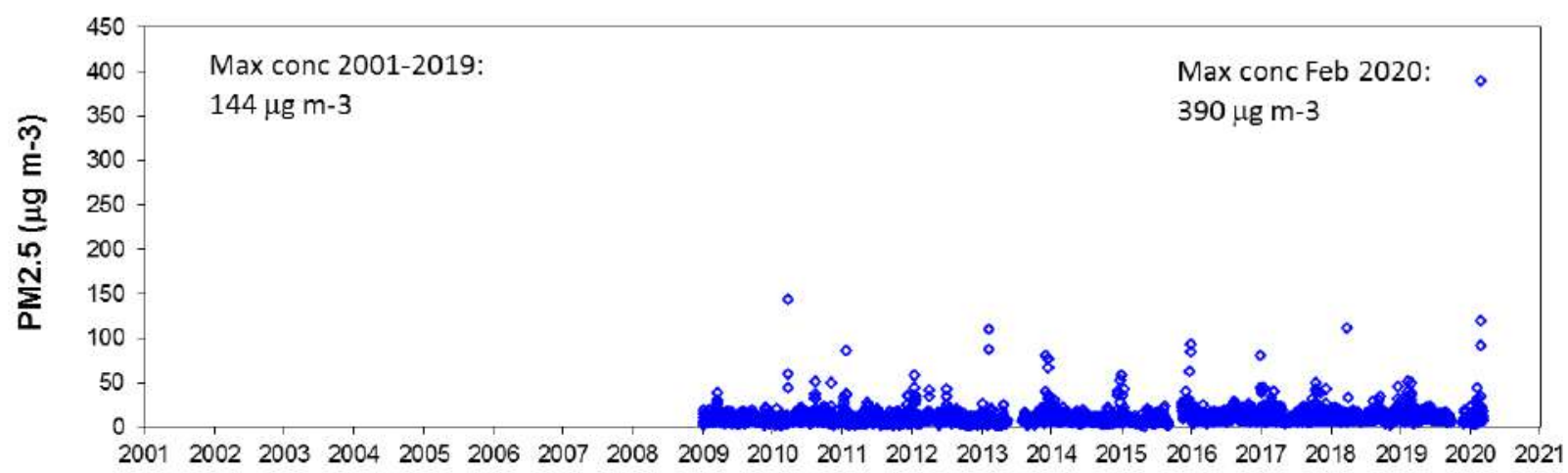

Figure 6.5. $\mathrm{PM}_{2.5}$ daily (24-h mean) concentrations in Las Palmas de Gran Canaria (Mercado Central) for the period 2009- 2020 


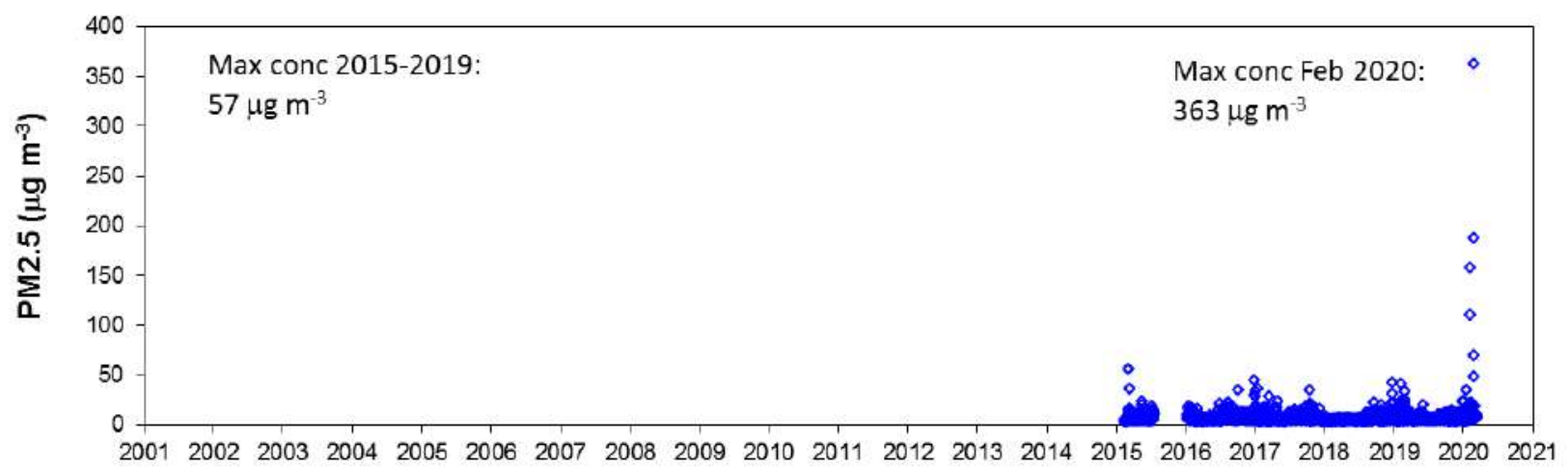

Figure 6.6. $\mathrm{PM}_{2.5}$ daily (24-h mean) concentrations in Santa Cruz de Tenerife (Tomé Cano) for the period 2015-2020

\subsection{Ground-based remote sensing}

The second category of long-term observational record that we present are column aerosol observations made by ground-based solar photometry as described in Sections 1.4.2 and 5.2.1. The daily maximum values of AOD at $500 \mathrm{~nm}$ from the CE318-T photometer in Santa Cruz de Tenerife (SCO) for the period 2005-2020 clearly shows that the two highest values of AOD in this 15-year series, were recorded on 23 and 22 February 2020 with values of 3.1 and 2.6, respectively (Figure 6.7 and Table 6.1).

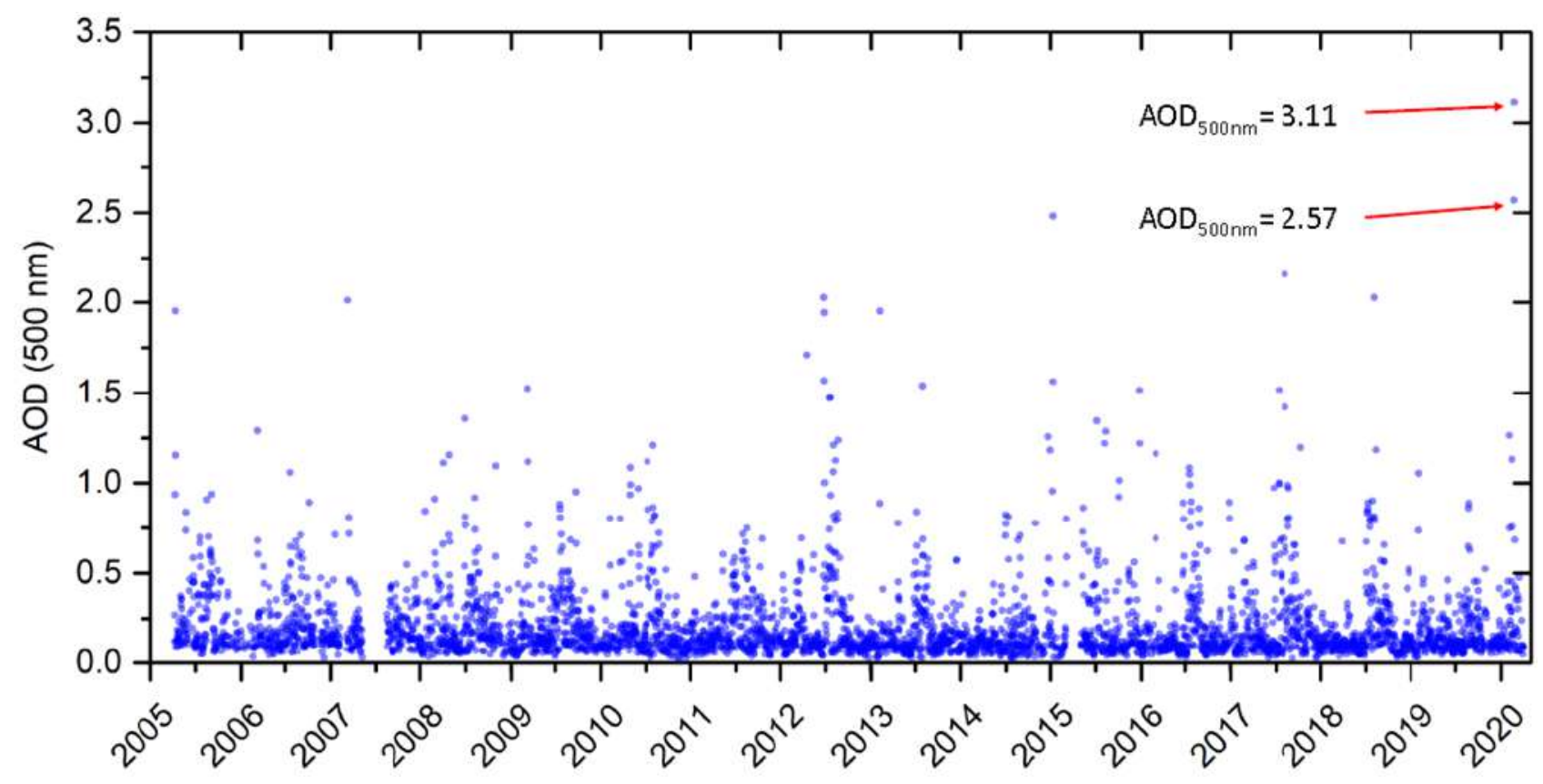

Figure 6.7. Daily maximum values of AOD at $500 \mathrm{~nm}$ from the CE318-T photometer in Santa Cruz de Tenerife (SCO) for the period 2005- 2020 


\begin{tabular}{lc}
\hline Date & AOD $500 \mathrm{~nm}$ \\
\hline $23 / 02 / 2020$ & 3.11 \\
$22 / 02 / 2020$ & 2.57 \\
$13 / 01 / 2015$ & 2.48 \\
$07 / 08 / 2017$ & 2.16 \\
$25 / 06 / 2012$ & 2.03 \\
$04 / 08 / 2018$ & 2.03 \\
$10 / 03 / 2007$ & 2.01 \\
\hline
\end{tabular}

\subsection{Satellite remote sensing}

The third category of long-term observation record that we present are column aerosol observations made by satellite remote sensing as described in Section 1.4.3. We have obtained the combined series of daily AOD values at $550 \mathrm{~nm}$ using SeaWifs data (from 3 September 1997 to 3 July 2002) with $0.5^{\circ} \times 0.5^{\circ}$ resolution, and Modis-Aqua (from 4 July 2002 to 8 April 2020) (Figure 6.8(a)). The AOD values are those averaged in a geographical area $\left(16.0^{\circ} \mathrm{W}, 28.4^{\circ} \mathrm{N}, 15.0^{\circ} \mathrm{W}, 29.2^{\circ} \mathrm{N}\right)$ located over the Atlantic Ocean in the central part of the Canary Islands archipelago in the vicinity of the two main islands (Tenerife and Gran Canaria) so that the measurements were not affected by the islands (Figure 6.8(b)). The values have been extracted from the NASA Giovanni application (https://giovanni.gsfc. nasa.gov/giovanni/).

The daily averaged values of AOD at $500 \mathrm{~nm}$ from the satellite remote sensing for the period 1997-2020 show that the highest value of AOD in this 23-year series was recorded on 22 February 2020 with a value of 3.44 (Figure 6.8(a)). Satellite AOD data are not available for 23 February 2020, the day of maximum dust intensity in the February 2020 dust outbreak. 


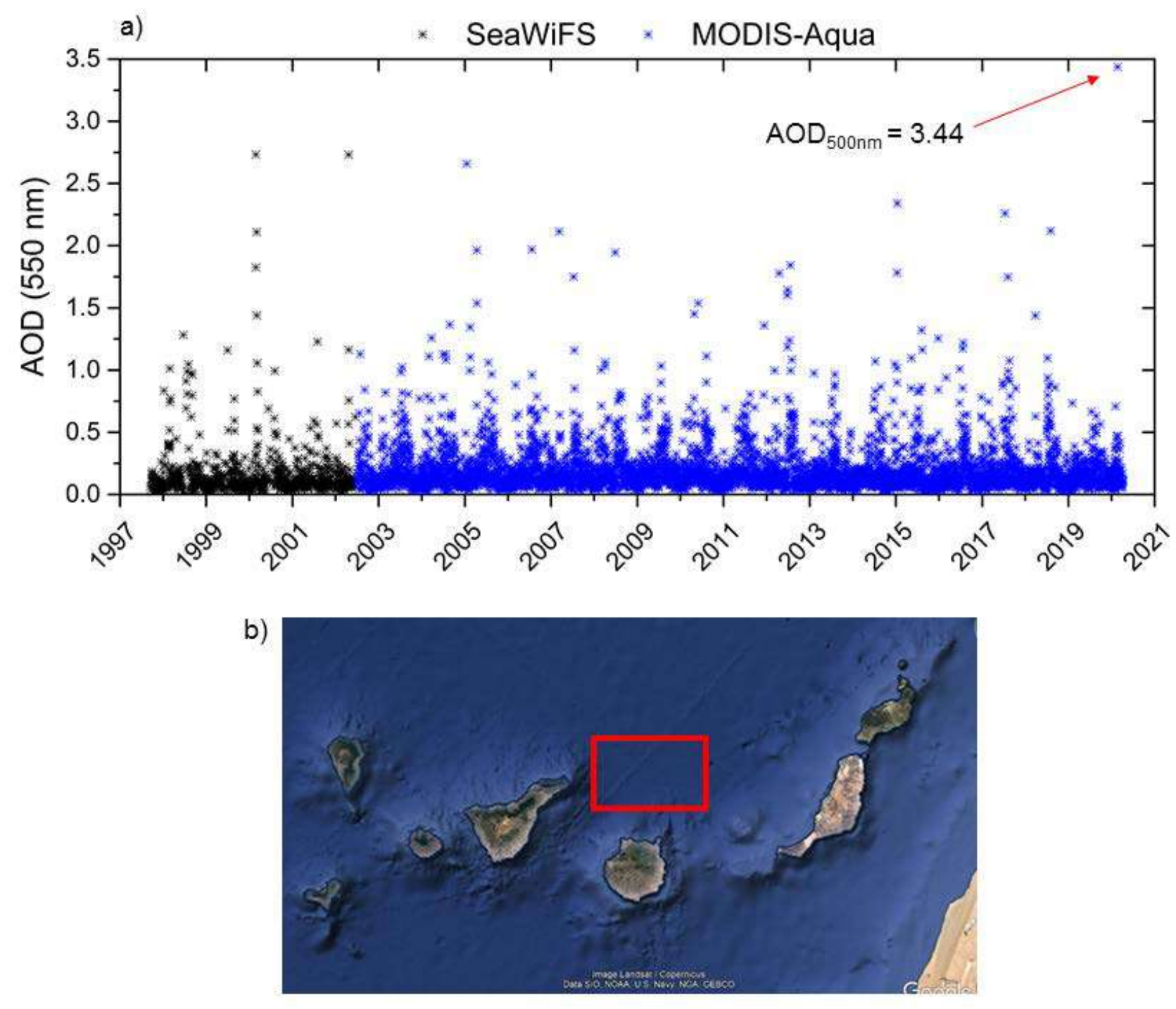

Figure 6.8. (a) Daily values of averaged AOD at $500 \mathrm{~nm}$ from satellite remote sensing for the period 1997-2020. SeaWifs data are utilized from 3/ 09/ 1997 to 3/ 07/ 2002 and Modis-Aqua data from 4/ 7/ 2002-8/ 4/ 2020.

(b) geographical area $\left(16.0^{\circ} \mathrm{W}, 28.4^{\circ} \mathrm{N}, 15.0^{\circ} \mathrm{W}, 29.2^{\circ} \mathrm{N}\right)$ over which the AOD values are averaged, in the vicinity of the two main islands (Tenerife and Gran Canaria).

(Source: https://giovanni.gsfc.nasa.gov/giovanni/).

\subsection{Long-term horizontal visibility records}

Meteorological visibility (by day) and meteorological visibility at night are defined as the greatest distance at which a black object of suitable dimensions (located on the ground) can be seen and recognized when observed against the horizon sky during daylight or could be seen and recognized during the night if the general illumination were raised to the normal daylight level (WMO, 1992). Airlight is light from the sun and the sky which is scattered into the eyes of an observer by atmospheric suspensoids, such as fog, biomass burning aerosols, sea salt aerosols, mineral dust, and, to a slight extent, by air molecules, lying in the observer's cone of vision. Airlight is the fundamental factor limiting the daytime horizontal visibility for black objects, because its contributions, integrated along the cone of vision from eye to object, raise the apparent luminance of a sufficiently remote black object to a level which is indistinguishable from that of the background sky (WMO, 2018). Contrary to subjective estimates, most of the airlight entering observers' eyes originates in portions of their cone of vision lying rather close to them. 
The errors of visibility measurements increase in proportion to the visibility, and measurement scales take this into account. This fact is reflected in the code used for synoptic and METAR reports. The Canary I slands airports normally use two linear segments with decreasing resolution, namely, 100 to $5000 \mathrm{~m}$ in steps of $100 \mathrm{~m}$, and 6 to $30 \mathrm{~km}$ in steps of $1 \mathrm{~km}$, although in practice, visibility is reported if it is less than $10 \mathrm{~km}$.

The reduction in horizontal visibility may be due to the presence of fog and/or different aerosols in the atmosphere. For this study, we have selected the horizontal visibility range values when the synoptic reports indicate the presence of haze. In the Canary Islands, haze is always associated with the presence of suspended dust, and it is not confused at all with mist.

There is a clear relationship between reduction in horizontal visibility and $\mathrm{PM}_{10}$ concentration, such as the one established by Camino et al. (2015) $\left(\mathrm{PM}_{10}=1772.24 \mathrm{~V}-1.1\right.$, where $\mathrm{V}$ is the visibility in $\mathrm{km}$ ), and others referenced herein. Estimated absolute maximum $\mathrm{PM}_{10}$ values from visibility during the 22-24 February 2020 dust episode at Tenerife North (GCXO), Tenerife South (GCTS), and Gran Canaria (GCLP) airports, following Camino et al. (2015), are shown in Table 6.2. These values are of the same order of magnitude as hourly $\mathrm{PM}_{10}$ values recorded by the air quality stations of Santa Cruz de Tenerife and Las Palmas de Gran Canaria (see Section 3.2). The reduction in horizontal visibility is therefore a good proxy for the presence of suspended dust.

\section{Table 6.2. Estimated maximum $\mathrm{PM}_{10}$ values from horizontal visibility during the 22- 24 February dust episode at the Tenerife North (GCXO), Tenerife South (GCTS), and Gran Canaria (GCLP) airports, following Camino et al. (2015)}

\begin{tabular}{lcl}
\hline Airport & $\begin{array}{c}\text { Estimated maximum } \\
\text { PM }_{10} \text { concentration } \\
\text { from visibility }\end{array}$ & $\begin{array}{l}\text { Day / time } \\
\text { February 2020 }\end{array}$ \\
\hline Tenerife North (GCXO) & $3798 \mu \mathrm{g} \mathrm{m}^{-3}$ & $23 / 1600$ UTC \\
Tenerife South (GCTS) & $4265 \mu \mathrm{g} \mathrm{m}^{-3}$ & $23 / 1900$ UTC \\
Gran Canaria (GCLP) & $4855 \mathrm{\mu g} \mathrm{m}^{-3}$ & $22 / 1800$ UTC \\
\hline
\end{tabular}

Since 1980, long-term data series of horizontal visibility at the three most important airports of the Canary Islands, namely GCXO, GCTS, and GCLP, are available from the AEMET climatological database from SYNOP reports. The time series of annual minimum visibility caused exclusively by haze for each of the three airports in the period 1980-2020 are shown in Figure 6.9. It can be clearly seen that the episode of 22-24 February 2020 has been the most intense in terms of horizontal visibility reduction (below $600 \mathrm{~m}$ ) of the entire 40 -year series, occurring simultaneously at the three airports, something that had not happened previous to the 2020 episode. 


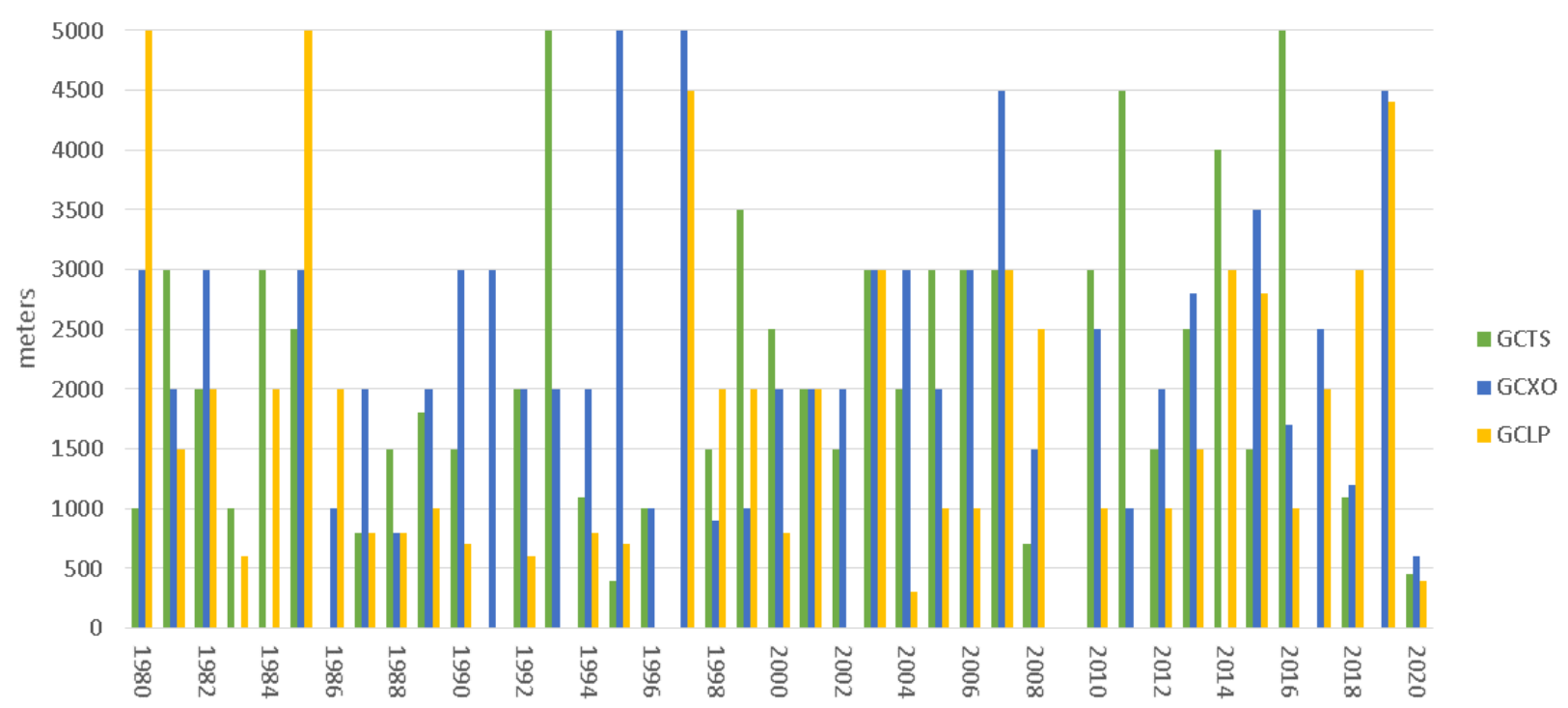

Figure 6.9. Time data series of annual minimum visibility caused exclusively by haze for each of the three airports (GCTS, GCXO and GCLP) in the period 1980- 2020

\section{6}

\section{Conclusions}

As a result of the analysis of the four different long-term observational records, we can confirm that the dust outbreak that occurred between 22-24 February 2020 was the most intense dust episode so far recorded in the Canary Islands. Here we presented long-term aerosol observations records of 19 years $\left(\mathrm{PM}_{10}\right), 15$ years (ground-based $\mathrm{AOD}$ ), 23 years (satellite borne AOD) and 40 years of horizontal visibility as a proxy of suspended dust.

The maximum PM concentration and AOD was recorded on 23 February 2020. As a result of the intensity of the dust episode, on 23 February 2020 the airspace in the Canary Islands was closed for a few hours and all flights (both incoming and outgoing) at the eight Canarian airports were cancelled, for the first time in history (see Section 8.3).

\subsection{References}

Camino, C., E. Cuevas, S. Basart, S. Alonso-Pérez, J.M. Baldasano, E. Terradellas, B. Marticorena, S. Rodríguez and A. Berjón, 2015: An empirical equation to estimate mineral dust concentrations from visibility observations in Northern Africa, Aeolian Research, 16, 55-68

WHO, 2006: WHO Air Quality Guidelines: Global Update 2005-Particulate Matter, Ozone, Nitrogen Dioxide and Sulfur Dioxide; World Health Organization, Regional Office for Europe, Copenhagen, Denmark.

WMO, 1992: International Meteorological Vocabulary, WMO-No.182, Geneva, Switzerland.

WMO, 2018: Guide to Instruments and Methods of Observation, 2018 edition, Volume I: Measurement of Meteorological Variables, Geneva, Switzerland. 


\section{NUMERI CAL MODELLI NG OF THE FEBRUARY 2020 DUST EVENT}

E. Werner and S. Basart

\subsection{Introduction}

Currently, there are many operational systems (Benedetti et al., 2014) that provide dust forecasts at global scale but also at regional scales for those regions where desert dust is a contributor to the aerosol budget. Ensemble prediction (i.e. using an ensemble of models) aims to describe the future state of the dust content in the atmosphere from a probabilistic point of view. Multi-model forecasting intends to alleviate the shortcomings of individual models while offering an insight on the uncertainties associated with a single model forecast. Use of ensemble forecast is especially encouraged in the case of unstable weather patterns, or in extreme conditions as is the case of the 22-24 February 2020 extreme dust outbreak.

\subsection{Probabilistic and multi-model dust products}

The Regional Centre for the Sand and Dust Storm Warning Advisory and Assessment System for Northern Africa, the Middle East and Europe (SDS-WAS NAMEE RC, Terradellas et al., 2015; Basart et al., 2019) is a WMO project, officially launched in 2007 and jointly managed by AEMET and BSC (see Section 1.6 for more details). In this regional Centre, probabilistic and multi-model dust products are generated from the models received from more than 10 international research and operational institutions (https://sds-was.aemet. es/forecastproducts/dust-forecasts/forecast-comparison).

Probability maps are generated from the SDS-WAS multi-model ensemble and show us the probability of exceeding a particular daily threshold of surface dust concentration and dust AOD (https://sds-was. aemet.es/forecast-products/dust-forecasts/probability-maps-dustsurface-concentration). Figure 7.1 shows the probability maps for surface concentration of various threshold values $\left(100,600\right.$, and $\left.1000 \mathrm{\mu g} \mathrm{m}^{-3}\right)$ generated on 22 February 2020 for 23 and 24 February 2020 . These maps show high probabilities $(40 \%-60 \%)$ to exceed the threshold of $1000 \mathrm{\mu g} \mathrm{m}^{-3}$ for much of the archipelago on 23 and 24 February 2020. 


\section{$\mathrm{D}+1$}

Daily Maximum of Dust SFC Concentration Probability of exceeding $100 \mu \mathrm{g} / \mathrm{m} 3$

ENS members: 11 Run: 22/02/2020 Valid for: 23/02/2020

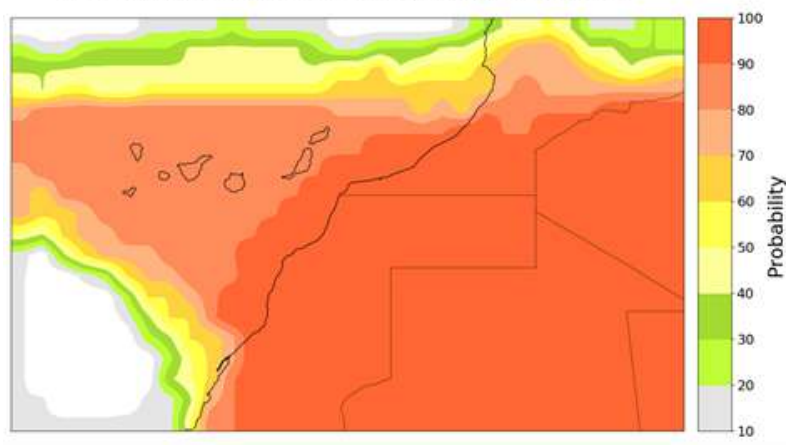

Daily Maximum of Dust SFC Concentration Probability of exceeding $600 \mu \mathrm{g} / \mathrm{m} 3$

ENS members: 11 Run: 22/02/2020 Valid for: $\mathbf{2 3 / 0 2 / 2 0 2 0}$

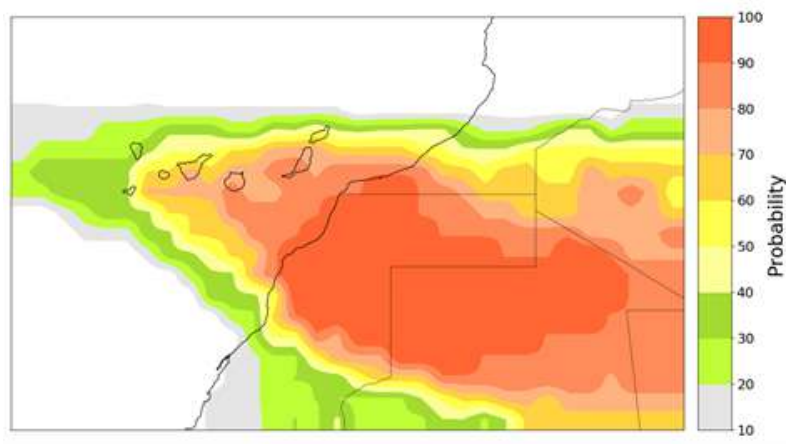

Daily Maximum of Dust SFC Concentration Probability of exceeding $1000 \mu \mathrm{g} / \mathrm{m} 3$ ENS members: 11 Run: 22/02/2020 Valid for: 23/02/2020

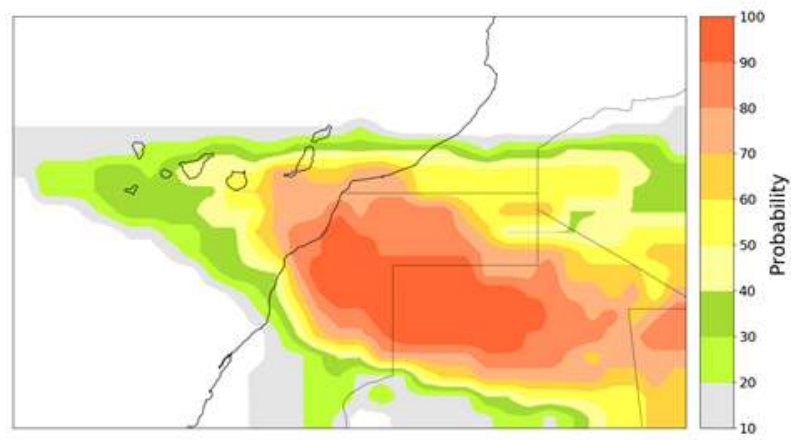

$\mathrm{D}+2$
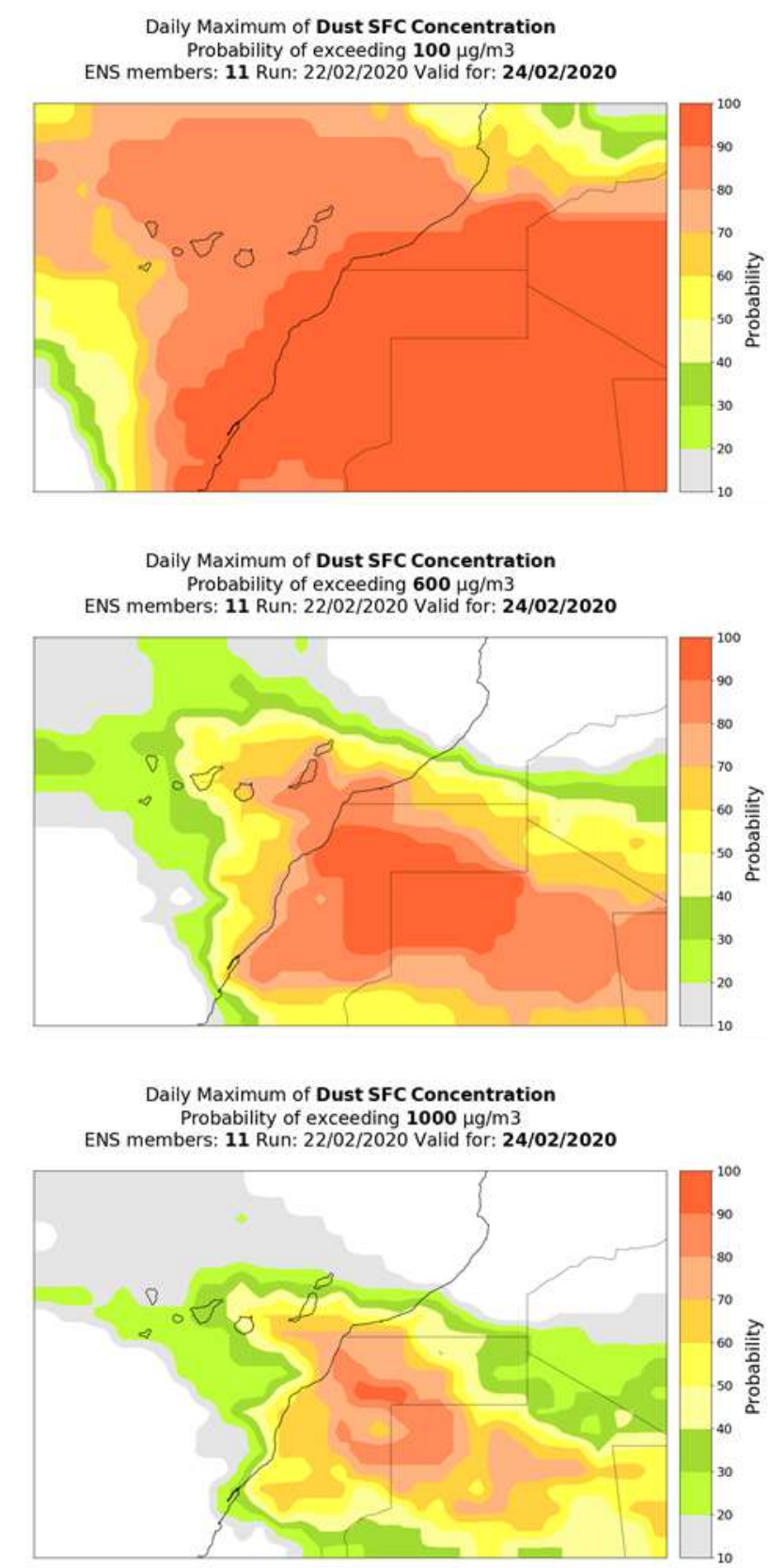

Figure 7.1. Probability of exceeding various threshold values $\left(100,600\right.$ and $\left.1000 \mathrm{\mu g} \mathrm{m}^{-3}\right) \mathrm{of}^{-1}$ surface dust concentration in the forecast runs on 22 February 2020 for $D+1$ ( 23 February 2020) and D+2 ( 24 February 2020)

An ENSgram is an ensemble meteogram that describes the temporal evolution of the distribution of model predictions. These diagrams show the potential of using multiple models at the same time. Figure 7.2 shows ENSgrams for Santa Cruz de Tenerife based on the SDSWAS multi-model ensemble for daily runs before the dust outbreak on 21 and 22 February 2020. The median (the red line in Figure 7.2) gives us a consistent evolution of the surface dust concentration and the maximum distribution lies close to that observed. The temporal evolution is also well represented although the prediction advances by 3 hours the maximum peak on 23 February 2020 and lengthens the outbreak during the afternoon of 24 February. These results highlight the ability of the current dust operational models to predict this extreme event 3-days in advance. 

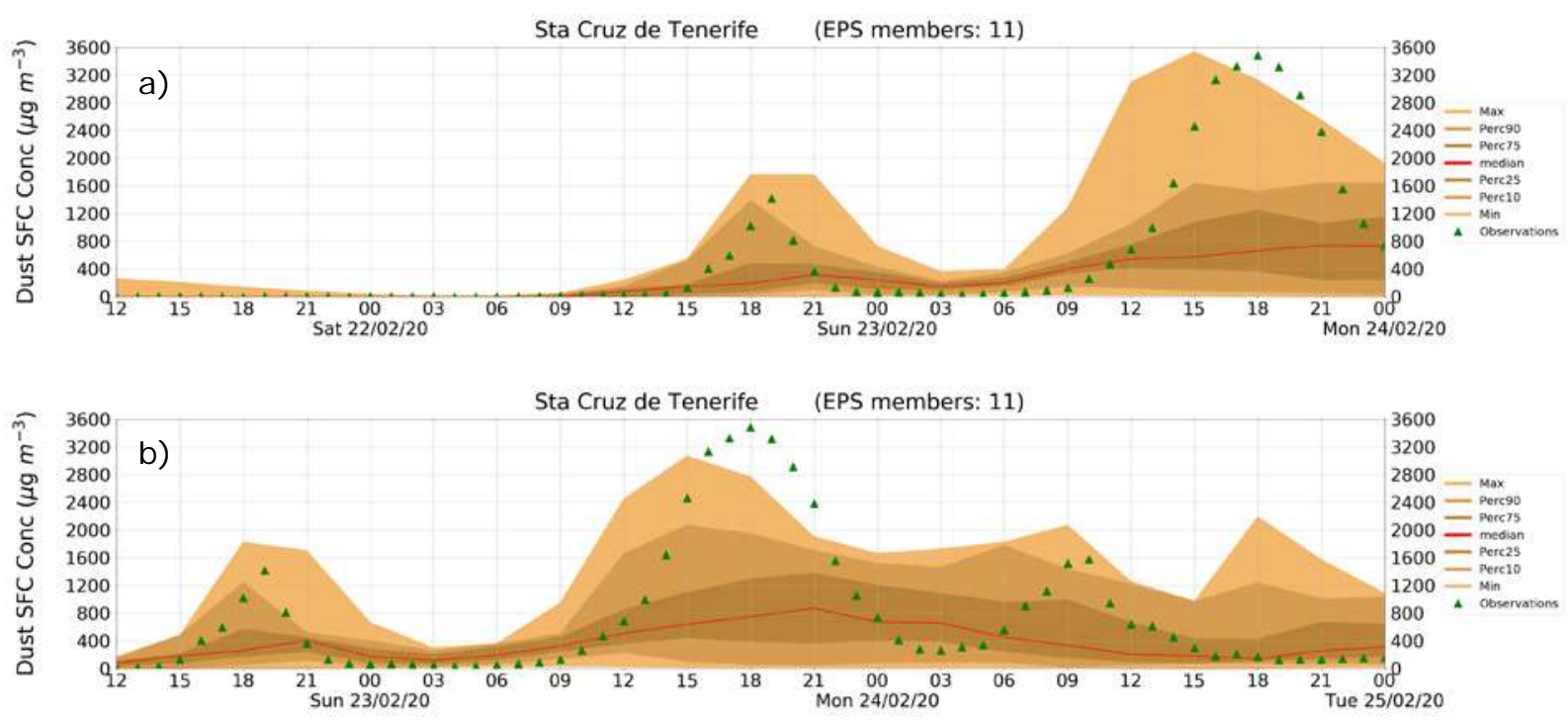

Figure 7.2. ENSgrams for time series of surface total dust concentration in Santa Cruz de Tenerife. Shaded lines correspond to the 3-days forecasts of the SDS-WAS multi-model ensemble percentiles (i.e. Maximum, P90, P75, P50, P25 P10 and minimum). Green triangles correspond to $\mathrm{PM}_{10}$ observations from SCO measurement station (the levels of PM10 are dominated by dust in this episode). Model data corresponds to 3-day dust forecast starting on (a) 21 February 2020, 1200 UTC and (b) 22 February 2020, 1200 UTC.

\subsection{Operational model performance during the 22- 24 February 2020 dust event}

For an extended analysis of the 22-24 February 2020 dust outbreak, we will consider the predictions of the transport-chemistry MONARCH (Multiscale Online Non-hydrostatic AtmospheRe Chemistry) model. The MONARCH model is part of the SDS-WAS multi-model ensemble but also is the operational dust reference model of the Barcelona Dust Forecast Centre (BDFC) (Terradellas et al., 2016). The BDFC is the WMO Regional Specialized Meteorological Centre with activity specialization in Atmospheric Sand and Dust Forecasting (RSMC-ASDF) for the northern African, Middle East and European (NAMEE) region. The Centre, operational since February 2014, is jointly managed by AEMET and BSC. The operational dust reference model MONARCH (formerly NMMB/BSC-Dust) (Perez et al., 2011) provides daily predictions of the following atmospheric dust parameters: surface concentration, optical thickness, surface extinction, total load, and dry and wet deposition. The forecast range of the prediction is 72 hours, with a prediction time-step of 3 hours and a horizontal resolution of $0.10^{\circ} \times 0.10^{\circ}(\sim 10 \mathrm{~km}$ in the Equator). These predictions and model evaluations are publicly available in the BDFC website (https://dust.aemet.es).

\subsubsection{Dust column-load: dust AOD}

The performance of the model on a synoptic scale is optimal, reproducing in general the spatial and temporal characteristics of the dust mass intrusion from the African coast over the Canary Islands. A first check is obtained by comparing the images of the NASA Suomi polar satellite equipped with the VIIRS sensor with the corresponding MONARCH dust optical depth (dust AOD) (Figure 7.3(a) and 7.3(b). This dimensionless parameter gives us information about the total amount of mineral dust in the atmospheric column, and it is based on the variation of the optical properties of the atmosphere due to the suspended mineral dust.

In the three daily model runs prior to the dust outbreak, the model is consistent and unchanged at a synoptic scale, reproducing the event from the first day of prediction in which the first maximum dust concentration is reached, i.e. three days earlier. 


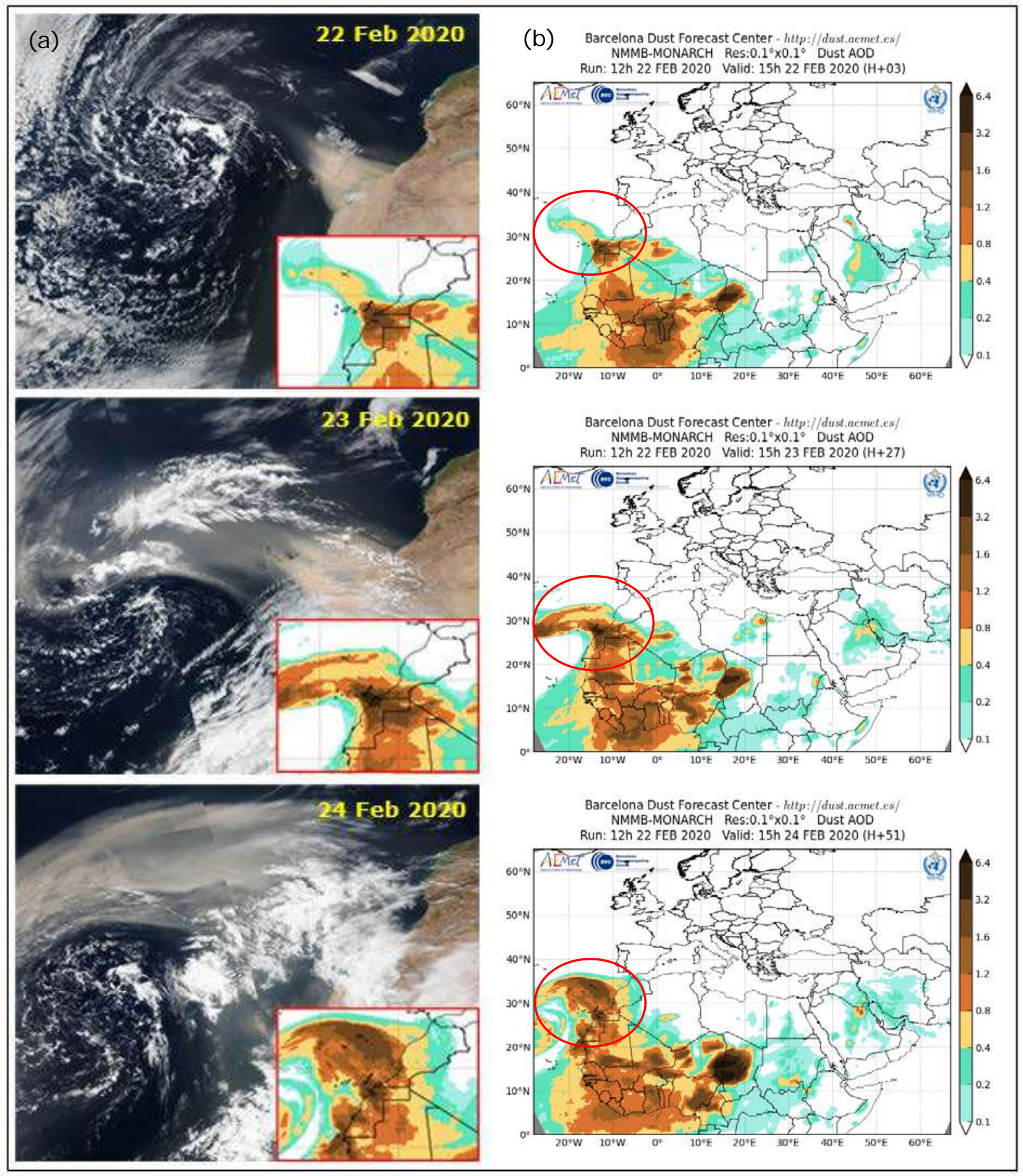

Figure 7.3 (a) I mages for 22-24 February 2020 obtained by the VIIRS sensor abord the NASA Suomi polar satellite. The images are daily and were taken between 13 and 14 UTC,

(b) Dust AOD forecast for twenty-second, twenty-third and twenty-fourth February 2020 at 15 UTC. Note that dust AOD forecasts correspond to the daily run of 22 February 2020 at 12UTC. We acknowledge the use of imagery provided by services from NASA's GI BS, part of NASA's EOSDIS.

The comparison of the MONARCH model with the data provided by the AERONET solar photometer network (see Section 5) in Santa Cruz de Tenerife for February 2020 (SCO; see Figure 7.4) shows how the model can reproduce the day of the maximum incidence over Santa Cruz the Tenerife ( 3 hours in advance) during the 22-24 February dust event. The maximum AOD observed values were 2.57 recorded on 22 February and 3.11 recorded on 23 February 2020. Meanwhile, maximum AOD values predicted by the model are 3.34 at the end of 22 February and 3.74 on 23 February 2020. 


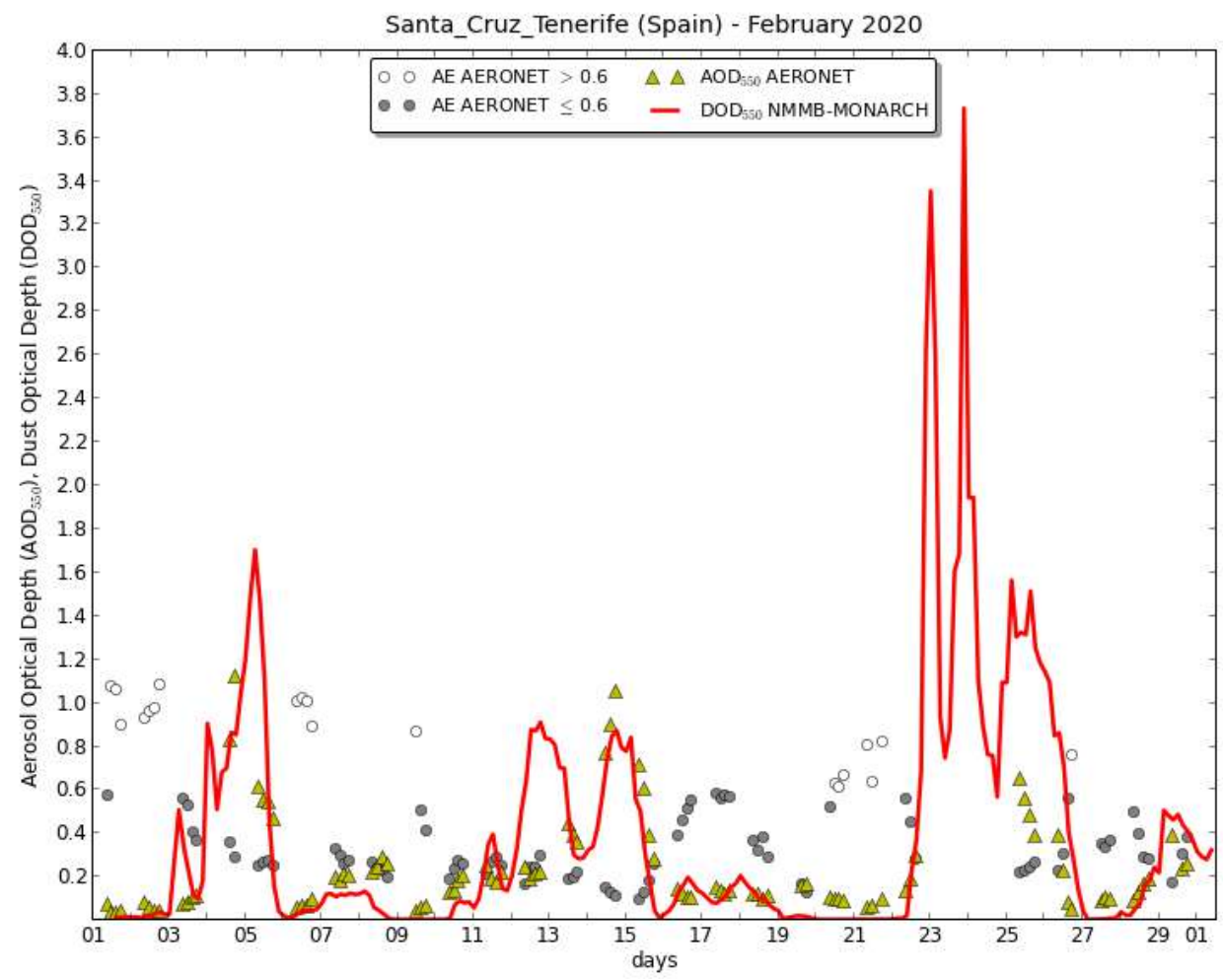

Figure 7.4. Dust AOD comparison of MONARCH predictions (for 24h forecast, at 3-hourly basis) and AERONET observations over the Santa Cruz de Tenerife (SCO) station for February 2020

\subsubsection{Vertical structure}

Simulations of the vertical cross sections of dust concentrations $\left(\mu \mathrm{g} \mathrm{m}^{-3}\right)$ (Figure 7.5) show the vertical structure of the dust mass and demonstrates the height at which it is moving. This information allows estimation of the altitude of the intrusion and therefore whether it will affect inhabited areas at sea level or if it will move to high levels with a lower impact on the population. Such graphics can also be a valuable tool for aviation as they "radiograph" the vertical structure of the dust mass and its temporal evolution. 
(a)

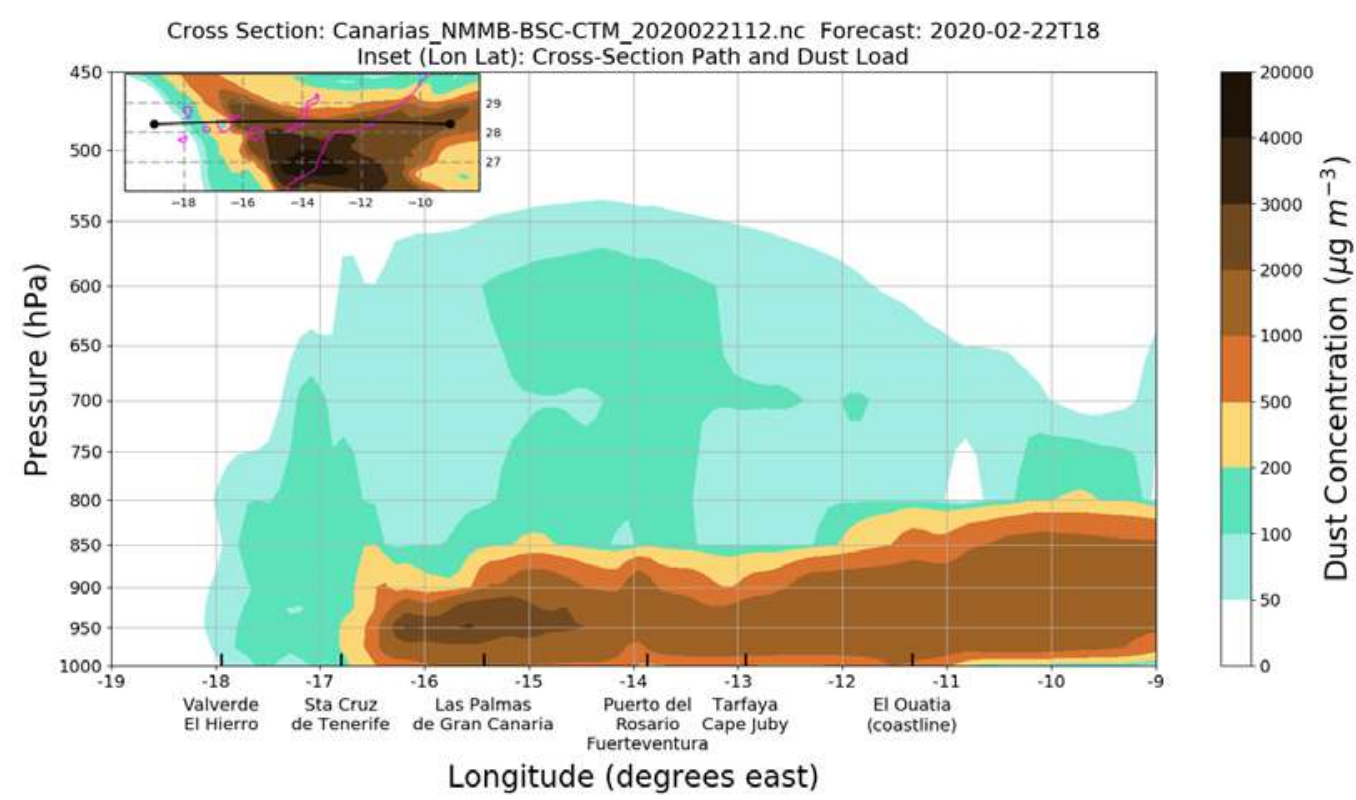

(b)

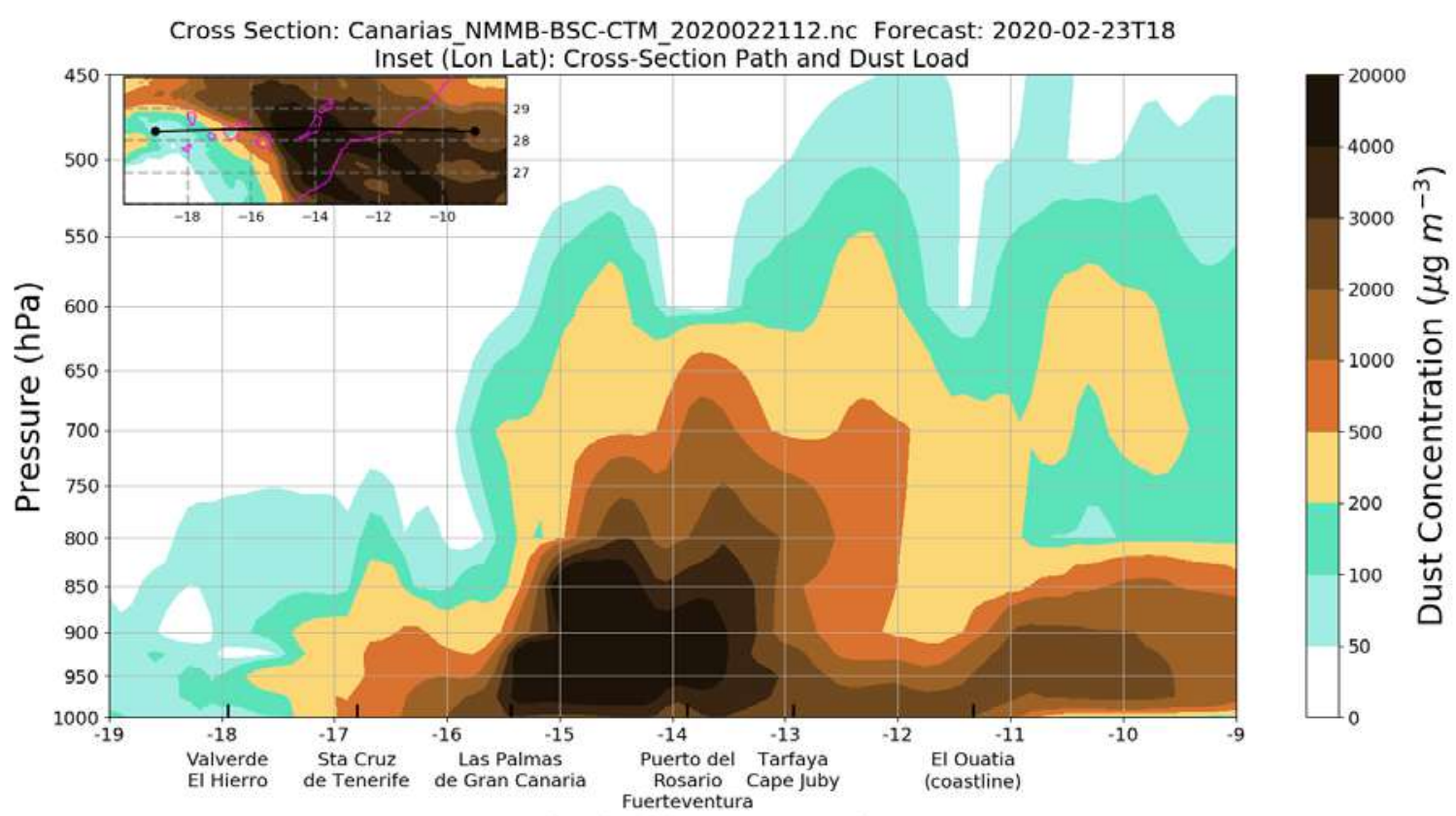

Longitude (degrees east)

Figure 7.5. Vertical dust forecast concentration $\left(\mu \mathrm{m}^{-3}\right)$ along a horizontal transect across the Canary I slands ( transect shown on the embedded chart). The dust forecast corresponds to the 72-hour daily run of 22 February 2020 at 12UTC.

(a) 22 February 2020 at 1800 UTC, and (b) 23 February 2020 at 1800 UTC.

On 23 February 2020, the day of maximum intensity of the dust outbreak, we observe how the model predicted dust plume extends to a height of approximately $5500 \mathrm{~m}$ ( $500 \mathrm{hPa}$ )

(Figure 7.5(b)), an unusual situation in winter Saharan dust outbreaks over the Canary Islands whose top is usually around $2000 \mathrm{~m}$.

Figure 7.6 compares the vertical cross section of Normalized Relative Backscatter as measured by the Micro Pulse lidar (MPL-4) located in Santa Cruz de Tenerife (SCO), and the output of the model (dust concentration in $\mu \mathrm{g} \mathrm{m}^{-3}$ ) for 22, 23 and 24 February 2020. These images show us the vertical structure in the parameter in question at one point and its temporal evolution. We 
observe that the model has managed to reproduce the information of the vertical dust profile obtained by the lidar, differentiating the maximums and their vertical extension. In addition, it complements the information that, due to the attenuation produced by the high concentration of dust in low layers, the lidar cannot offer (see Section 5). The maximum dust concentration of the MONARCH model (shown in Figure 7.6(b)) could not be detected by the lidar because the dust concentration was so high at low altitudes that it saturated the signal at higher altitudes (Figure 7.6(a)).

(a)

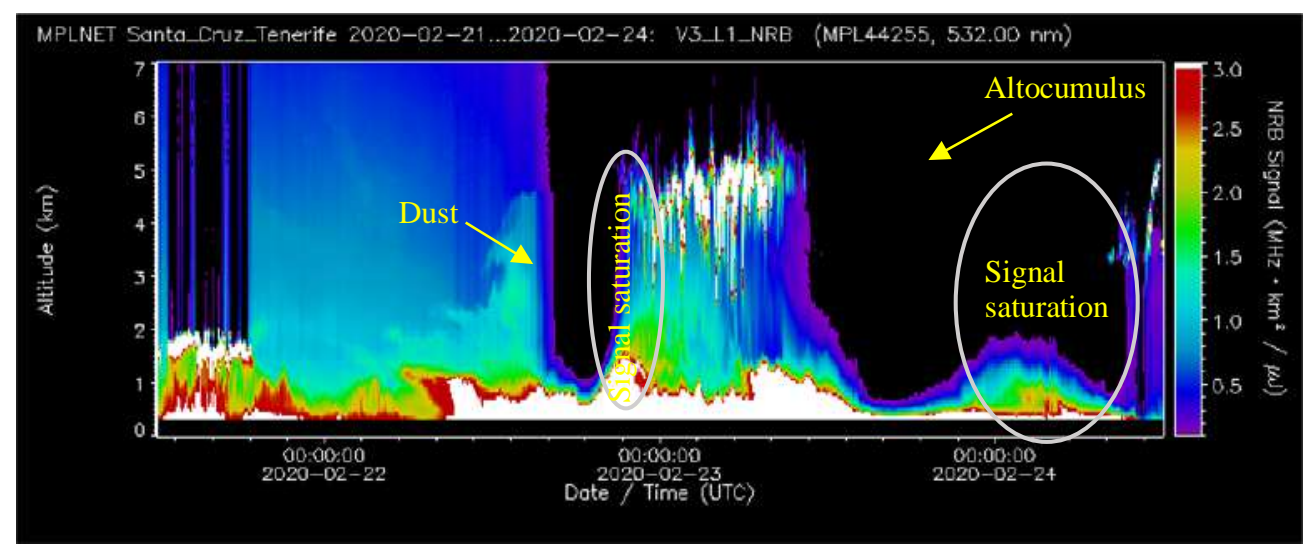

(b)

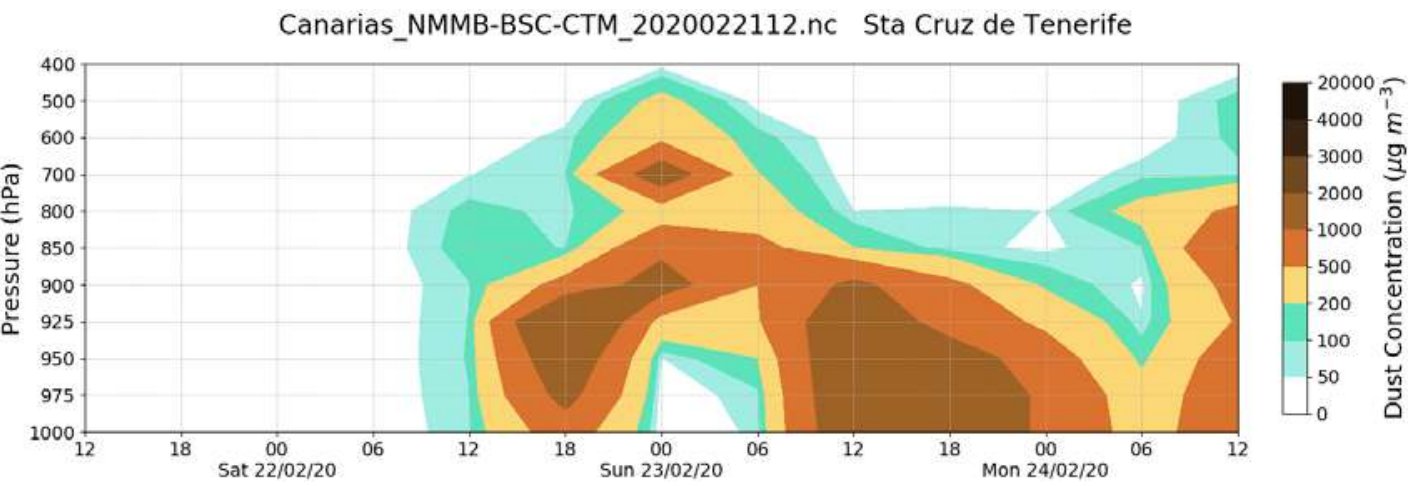

Figure 7.6. Comparison of the vertical section of (a) NRB as measured by the Micropulse lidar located in Santa Cruz de Tenerife (SCO) and (b) the 72-hour vertical dust forecast concentration corresponding to the 72 -hour daily run of 22 February 2020 at 12 UTC

\subsubsection{Surface concentration}

MONARCH forecasts are also compared with $\mathrm{PM}_{10}$ in situ concentrations in SCO and in Mercado Central in Las Palmas de Gran Canaria (see Figure 7.7). Although there is a difference between the intensity of the $\mathrm{PM}_{10}$ observed maximum $\left(3000 \mu \mathrm{g} \mathrm{m}^{-3}\right)$ and the forecasted maximum $\left(2000 \mathrm{mg} \mathrm{m}^{-3}\right)$, we consider the prediction to be fairly good, since the correlation between the observed and forecasted concentrations is high and the order of magnitude of the forecasted maximum is correct. 
(a)

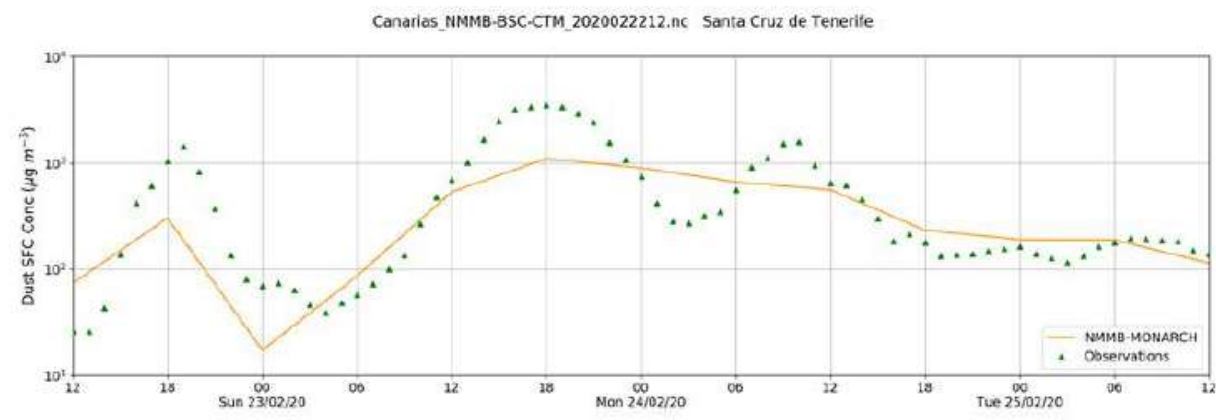

(b)

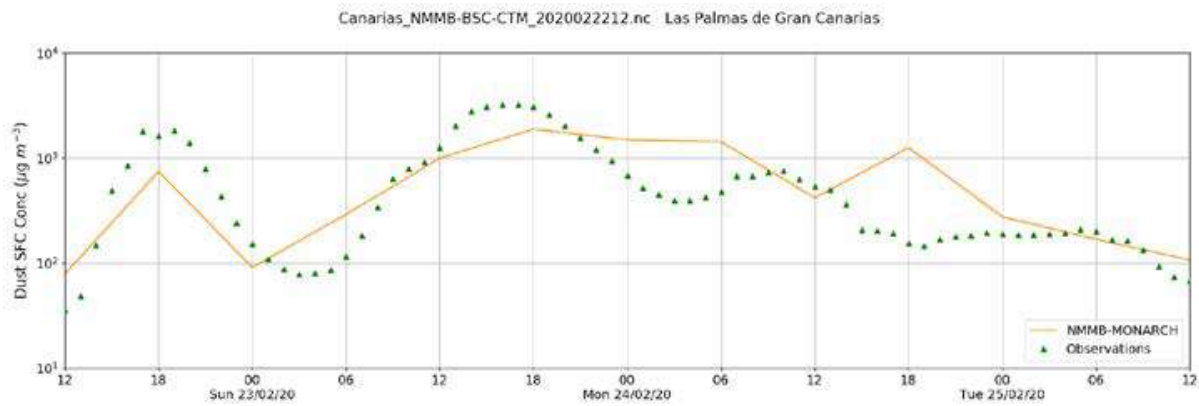

Figure 7.7. Surface dust concentration time series for 22- 25 February 2020. Observed PM10 is measured with PM10 analysers and forecasted dust is based on the 72-hour daily run of 23 February 2020 at 12UTC in a) Santa Cruz de Tenerife (SCO) and b) Las Palmas de Gran Canaria (Mercado Central) for the period 22 (12UTC)-25 (12 UTC) February 2020.

\subsubsection{Visibility forecast}

Regarding ground transportation, circulation can be affected by road closures due to either poor visibility caused by dust or dust deposition on the road surface. Indeed, various studies in different geographical areas, such as Iran, Kuwait and Germany, showed a clear correlation between Sand and Dust Storms (SDS) and traffic accidents (Al-Hemoud et al., 2017; Miri et al., 2009; Deetz et al., 2016). Regarding aviation, airports located in areas commonly affected by SDS are obliged to close during intense dust events, causing flight delays or cancellations, while they need to apply special take-off and landing protocols and re-assess their flight management strategies.

There are different methodologies for estimating visibility from model predictions. There are theoretical approximations obtained from the physical development of radiation attenuation through an atmosphere with mineral dust in suspension, such as Koschmieder's classic formula or modifications thereof, e.g. Bennett (2012), and also empirical relationships between visibility and surface dust concentration (Camino et al., 2015).

Different methodologies employing either theoretical or empirical equations (see Table 7.1 and Figure 7.8) are applied and tested for the conversion of either dust surface concentration $\left(\mathrm{PM}_{10}\right)$ or surface extinction coefficient $(\mathrm{ec})$ to visibility. 


\begin{tabular}{|c|c|c|c|}
\hline Equation* & Name & Comments & Reference \\
\hline$e c=\frac{3.92}{V}$ & Koschmieder & $\begin{array}{l}\text { Proposes that visibility is inversely } \\
\text { proportional to the extinction coefficient. } \\
\text { Considers the contrast between a dark } \\
\text { object set against the horizon and a } \\
\text { constant contrast threshold identifiable } \\
\text { by an observer equal to } 0.02 \text {. }\end{array}$ & \\
\hline$e c=\frac{3.00}{V}$ & Biral & $\begin{array}{l}\text { Variation of Koschmieder's equation that } \\
\text { considers a contrast threshold of } 0.05 \text {, } \\
\text { resulting in a conversion factor of } 3.00 \\
\text { which is also used in practice for the } \\
\text { calculation of Meteorological Optical } \\
\text { Range (MOR). }\end{array}$ & $\begin{array}{l}\text { Bennett, } 2012 \\
\text { (Biral report) }\end{array}$ \\
\hline $\begin{array}{l}P M_{10} \\
=1772.24 \cdot V^{-1.1}\end{array}$ & IZO & $\begin{array}{l}\text { Derived from observations performed } \\
\text { during the period } 2003-2010 \text { at the } \\
\text { Izaña Observatory in Tenerife, Spain. }\end{array}$ & $\begin{array}{l}\text { Camino et al. } \\
\text { (2015) }\end{array}$ \\
\hline $\begin{array}{l}P M_{10} \\
=914.0 \cdot V^{-0.73} \\
+19.03\end{array}$ & Almeida & $\begin{array}{l}\text { Calibrated with observations of } \mathrm{PM}_{10} \\
\text { obtained during a field campaign in Niger } \\
\text { from January } 1981 \text { to December } 1982 \text {, } \\
\text { with visibility ranges from } 0.2 \text { to } 40 \mathrm{~km} \text {. }\end{array}$ & $\begin{array}{l}\text { D'Almeida } \\
\text { (1986) }\end{array}$ \\
\hline
\end{tabular}

* Note: "V" is visibility, "ec" is surface extinction coefficient at $550 \mathrm{~nm}$ and "PM10" is surface PM concentration with aerodynamic diameters $<10 \mu \mathrm{m}$.

Comparison of the observed and model calculated visibility for the airports of Tenerife North and Gran Canaria (Figure 7.8 (a) and (b) shows that the best approximation for visibility is obtained using the empirical formulas IZO and Almeida with the surface dust concentration forecasts of the model. In Tenerife North, minimum visibility values were observed on 23 February in the afternoon. IZO equation gives visibility estimates at $1400 \mathrm{~m}$ and Almeida equations gives visibility estimate of $800 \mathrm{~m}$ at 1800 UTC meanwhile the observations show minimum values of $550 \mathrm{~m}$ at 1700 UTC. In Gran Canaria, the observed minimum visibility value was $700 \mathrm{~m}$ on 24 February in the morning and a second minimum (with visibility around $1000 \mathrm{~m}$ ) was on 23 February in the afternoon. In Gran Canaria Airport, IZO equation can reproduce the magnitude and timing to the observations meanwhile Almeida tends to underpredict the visibility. Although the predicted visibility minimums are shifted somewhat in time (1-3 hours). 
(a)

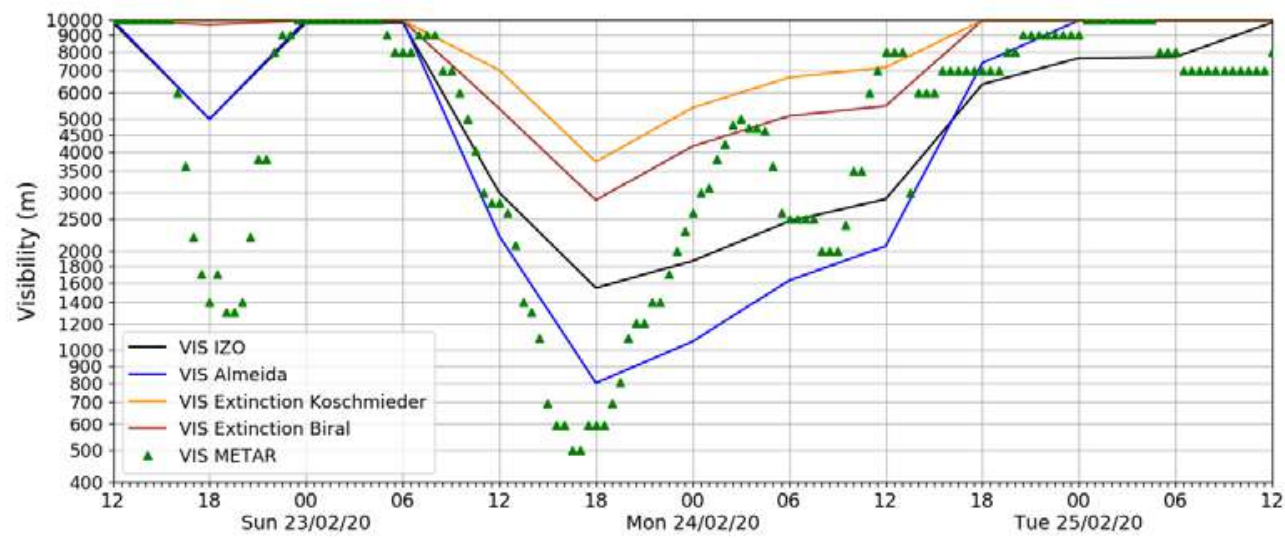

(b)

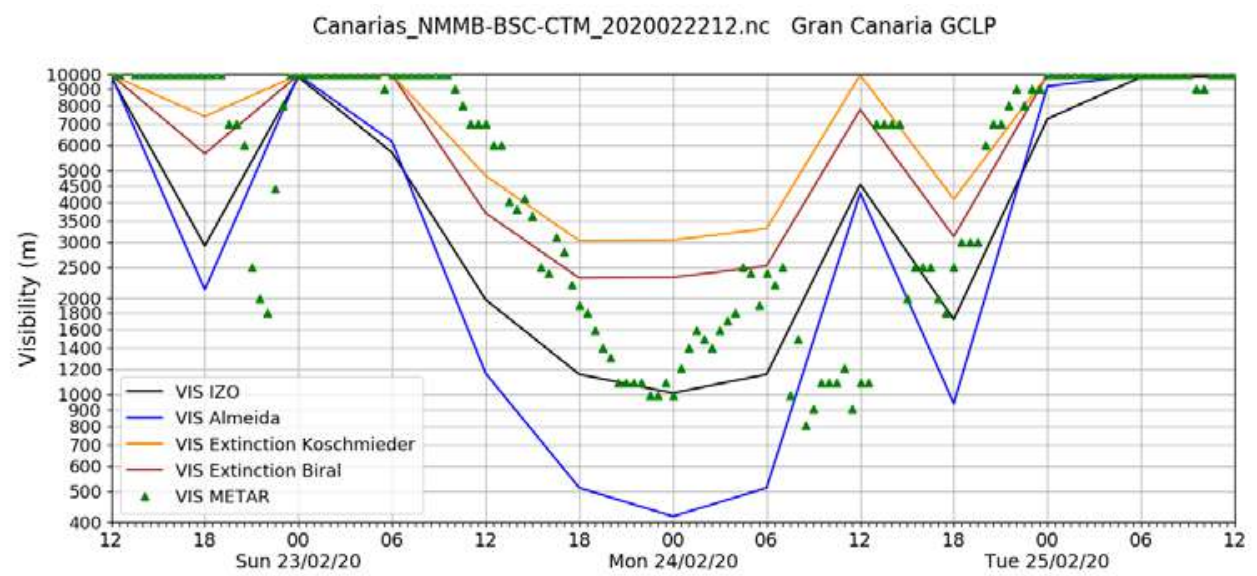

Figure 7.8 Visibility time series for airports (a) Tenerife North and (b) Gran Canaria.

Visibility is diagnosed from PM10 observations using several experimental equations and forecasted from MONARCH surface extinction based on 72-hour daily run of 23 February 2020 at 12 UTC. The corresponding description of each visibility parametrization is considered in Table 7.1.

\subsubsection{Dry and wet deposition}

Other parameters also predicted in the MONARCH operational system are the dry and wet deposition of mineral dust. Dust deposition is an important parameter in several fields, in particular solar energy production as it significantly decreases the performance of solar panels (as shown in Section 8.4) and also agriculture by preventing plants from performing photosynthetic function correctly and even impairing flowering.

The MONARCH model predicted appreciable wet deposition on the Gran Canaria island on 24 February (Figure 7.9(b), 3-hourly accumulated dry deposition above $70 \mathrm{mg} \mathrm{m}^{-2}$ and accumulated wet deposition above $230 \mathrm{mg} \mathrm{m}^{-2}$ at 18 UTC), and to a lesser extent, in Tenerife island (Figure 7.9(a), 3-hourly accumulated dry deposition above $20 \mathrm{mg} \mathrm{m}^{-2}$ and accumulated wet deposition above $25 \mathrm{mg} \mathrm{m}^{-2}$ at 18 UTC). For 25 February, model forecast gave the wet deposition event for both Santa Cruz de Tenerife and Las Palmas de Gran Canaria. The presence of rain over these sites was confirmed with the weather observation. Rainfall was recorded between 2 and $6 \mathrm{~mm} \mathrm{~d}^{-1}$ in Tenerife in comparison to Gran Canaria where the precipitation intensity was $1 \mathrm{~mm} \mathrm{~d}^{-1}$ in San Bartolome de Tirajana, and $1.4 \mathrm{~mm} \mathrm{~d}^{-1}$ at Gran Canaria Airport. 
(a)

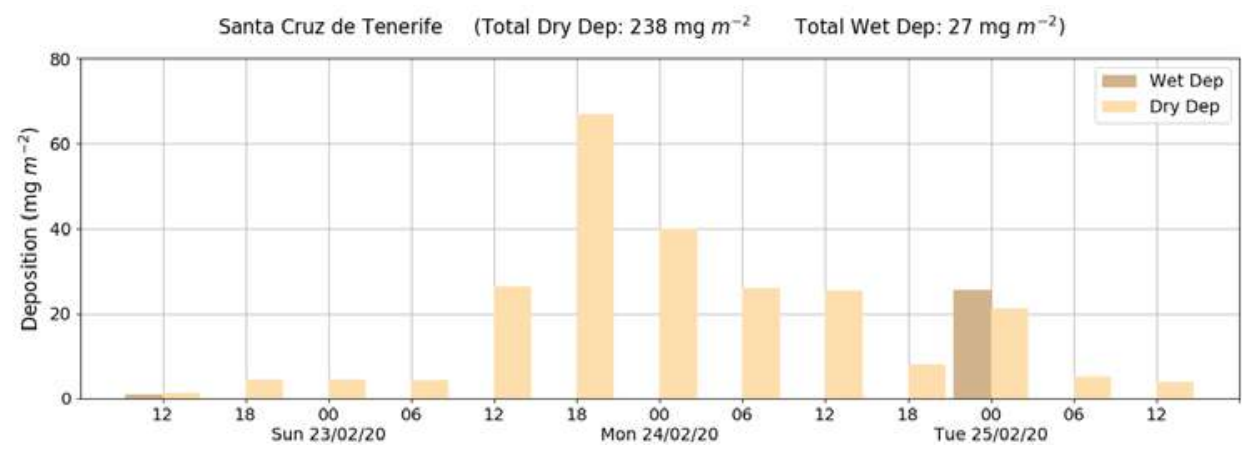

(b)

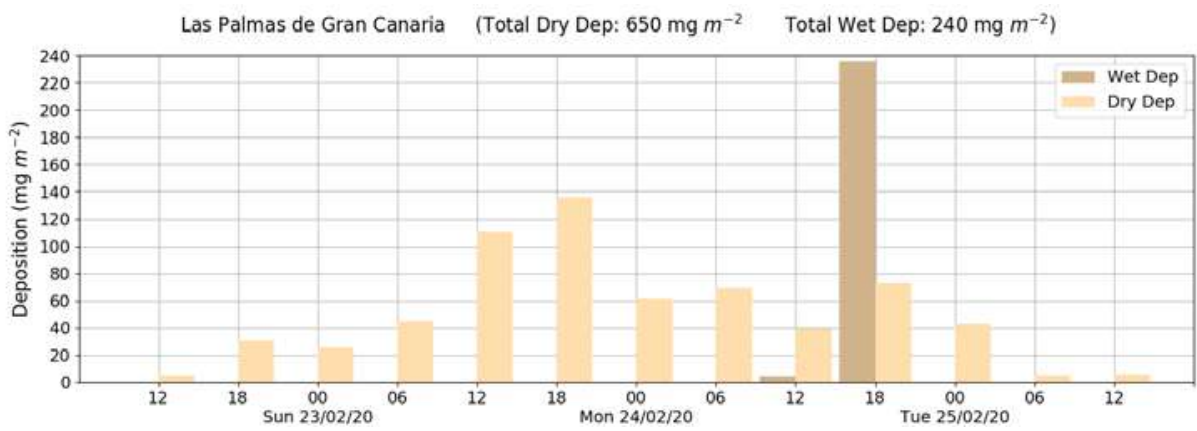

Figure 7.9. Dry and wet deposition of mineral dust estimated with MONARCH operational model in (a) Santa Cruz de Tenerife ( $\mathrm{SCO}$ ) and (b) in Las Palmas de Gran Canaria (Mercado Central) for 22- 25 February 2020

\subsection{Conclusions}

The 22-24 February 2020 dust outbreak over Canary I slands was predicted by the dust operational models participating in the SDS-WAS multi-model ensemble. The ensemble of model forecasts predicted maximum surface concentrations over $1000 \mu \mathrm{g} \mathrm{m}^{-3}$ and dust AOD above three in agreement with the ground-based and satellite observations. The spatial and temporal evolution of the event was well reproduced by the SDS-WAS multi-model ensemble.

Taking a close look at the results of the MONARCH model (the model is part of the SDS-WAS multi-model ensemble and the reference model of the BDFC), it was observed that the model can predict this exceptional event, especially for the easternmost islands, delaying the entry (1-3 hours) of the dust intrusion into Tenerife and forecasting a lower intensity on this island than observed. Dust plume reached dust AOD above 4, surface concentrations above $1000 \mu \mathrm{m}$ $\mathrm{m}^{-3}$, visibility reductions below $1000 \mathrm{~m}$, dust plume altitudes of $5000 \mathrm{~m}$ (typically observed altitudes in wintertime are around $2000 \mathrm{~m}$ ) and accumulated dust deposition above $650 \mathrm{mg} \mathrm{m}$ 2 in the easternmost islands.

As shown, daily dust forecast products can provide useful information 3 days in advance. This type of information is fundamental for preparing mitigation strategies and to alert the most vulnerable sectors of the population (see Section 8 ). 
Al-Hemoud, A., M. Al-Sudairawi, S. Neelamanai, A. Naseeb, and W. Behbehani, 2017: Socioeconomic effect of dust storms in Kuwait. Arab. J. Geosci., 10, 18, https: // www.springerprofessional.de/en/economic-impact-of-sand-and-dust-storms-onthe-oil-sector-in-kuw/16403386.

Benedetti, A., J. M. Baldasano, S. Basart, F. Benincasa, O. Boucher, M. E. Brooks. and L. Jones, 2014: Operational dust prediction. In Mineral Dust (pp. 223-265). Springer, Dordrecht.

Biral, B., 2012: Introduction to atmospheric visibility estimation. https://www. biral.com/wpcontent/uploads/2015/02/Introduction_to_visibility-v2-2.pdf

Camino, C., E. Cuevas, S. Basart, S. Alonso-Pérez, J.M. Baldasano, E. Terradellas, B. Marticorena, S. Rodríguez and A. Berjón, 2015: An empirical equation to estimate mineral dust concentrations from visibility observations in Northern Africa, Aeolian Research, 16, 55-68.

D'Almeida, G. A., 1986: A model for Saharan dust transport. Journal of climate and applied meteorology, 25(7), 903-916.

Deetz, K., M. Klose, I. Kirchner and U. Cubasch, 2016: Numerical simulation of a dust event in northeastern Germany with a new dust emission scheme in COSMO-ART. Atmospheric Environment, 126, 87-97.

Miri, A., H. Ahmadi, M. R. Ekhtesasi, N. Panjehkeh and A. Ghanbari, 2009: Environmental and socio-economic impacts of dust storms in Sistan Region, Iran. International journal of environmental studies, 66(3), 343-355.

Pérez Garcia-Pando C., K. Haustein, Z. Janjic, O. Jorba, N. Huneeus, J.M. Baldasano, T. Black, S. Basart, S. Nickovic, R.L. Miller J.P. Perlwitz, M. Schulz and M. Thomson, 2011: Atmospheric dust modelling from meso to global scales with the online NMMB/BSC-Dust model-Part 1: Model description, annual simulations and evaluation. Atmospheric Chemistry and Physics, 11, 13001-13027.

Terradellas, E., S. Basart and E. Cuevas, 2016: Airborne Dust: From R\&D to Operational Forecast, 2013-2015 Activity Report of the SDS-WAS Regional Centre for Northern Africa, Middle East and Europe.

WMO SDS-WAS NAMEE Regional Centre, 2020): Technical report: Model intercomparison and evaluation of dust forecasts, https: //sds-was.aemet.es/forecast-products/forecastevaluation/model-inter-comparison-and-forecast-evaluation/at_download/file 


\subsection{Introduction}

The wide variety of impacts that dust storms can have on different socio-economic sectors, human health, and ecosystems are well summarized in Section 1 (Introduction). To evaluate all impacts caused by a given dust storm, observational tools and valuation methodologies are needed that allow identification and quantification of the specific impacts in a reasonable period of time. Of all the possible impacts that dust outbreaks can have on the Canary Islands, this report addresses only those in which a public or private body has been able to identify and quantify the corresponding damage for this particular episode, at least qualitatively. We are aware that there are other significant impacts of dust outbreaks, such as impacts on agriculture, livestock farming, road transport, fertilization of the ocean, as well as consequences for fishing, tourism (beyond the cancellation of flights), fire management, etc. However, for many of the mentioned impacts it is possible to obtain information, either because the effects have not yet been well studied, or because the procedures and protocols for estimation or quantification of the impacts have not yet been established.

\subsection{Health I mpact Assessment}

E. López-Villarrubia, S. Rodríguez-Mireles and M.L. Pita Toledo

\subsubsection{Introduction}

In recent decades the importance of the effect of fine particles $\left(\mathrm{PM}_{2.5}\right)$ and ultrafine particles $\left(P M_{1}\right)$ on health has been underlined, however, there is increasing evidence that coarse particles ( $\left.\mathrm{PM}_{10-2.5}\right)$ mainly of natural origin (desert dust, crustal material, sea salt, pollen, spores, fly ash, and plant and insect parts) have a comparable impact. The results of our previous studies in the cities of Las Palmas de Gran Canaria (L/P de Gran Canaria) and Santa Cruz de Tenerife ( $\mathrm{S} / \mathrm{C}$ de Tenerife), have shown that there was an association between $\mathrm{PM}_{10}$ during Saharan dust days (SDDs) with mortality and emergency hospital admissions for respiratory disease. The results suggested that $\mathrm{PM}_{2.5}$ were associated with an increased risk of mortality from circulatory diseases, whereas $\mathrm{PM}_{10-2.5}$ were associated with increased mortality from respiratory diseases (Lopez-Villarrubia et al., 2010; 2012). Regarding the association with emergency hospital admissions, a higher risk of emergency hospital admission for asthma was observed in L/P de Gran Canaria, while in S/C de Tenerife the highest impact was observed on admissions due to all respiratory system diseases (ARSD) and chronic obstructive pulmonary disease (COPD) (Lopez-Villarrubia et al., 2016); regarding the association between SDDs and health, our results showed that exposure to SDDs carry an increased risk of emergency hospital admission for COPD and for respiratory disease in S/C de Tenerife and for asthma in L/P de Gran Canaria, in addition, the estimated risks accumulated and spread over several consecutive days (from 0 to fifth day) (Lopez-Villarrubia et al., 2020).

\subsubsection{Saharan dust episode from 22- 26 February 2020 in Las Palmas de Gran Canaria and Santa Cruz de Tenerife: Social and public health context}

Of the total of 91 days constituting the first quarter of 2020, $60.4 \%$ correspond to SDDs. The month of February was under the influence of Saharan dust advections on 25 of its 29 days. The extreme episode between 22-26 February 2020 followed the other long episode of 25 days in duration, ending on 19 February, and was followed by another episode that started on 28 February and lasted 4 days. Therefore, there was no period of 10 consecutive days without the influence of Saharan dust advections, neither before nor after the episode, with which to establish an immediate comparison in terms of its effects on health (Figure 8.2.1). 
Likewise, the magnitude and severity of this Saharan dust episode, which was accompanied by strong winds and extreme reduction of visibility, forced the closure of airspace and the suspension of outdoor Carnival events (Tomaino et al., 2020), to such an extent that, in our opinion, a substantial number of residents clearly perceived the risk that spending time outdoors might entail. Simultaneously, weather alerts and early warning system for SDDs from the health and environmental authorities to the citizens and their recommendations to reduce exposure were published immediately by means of the media and social networks, which were welcomed by increasingly well-informed citizens, who are familiar with this natural phenomenon. Thus, this scenario could lead to a lower resident's exposure to Saharan dust, and, as a result, decreased the use of emergency hospital services.

Furthermore, during that same period, the COVID-19 epidemic reached the Canary Islands, with the first imported case declared on 3 February 2020. On 14 March 2020, the state of alarm was declared to manage the health crisis caused by what had become a global pandemic, and so a lockdown was established to limit the movement of people throughout Spain. The situation again led to a drop in the influx of patients to health services for, amongst other things, the provision of emergency health care, which registered a decrease of $23-54 \%$ in March-May 2020 compared to the same period of the previous year. Thus, from the declaration of the state of alarm to 1 April 2020 in S/C de Tenerife and 5 April 2020 in L/P de Gran Canaria, there were no emergency hospital admissions for respiratory or cardiac causes.

In fact, as shown in Figure 8.2.1., which represents the number of daily admissions for respiratory diseases during the first quarter of 2020 in both cities and whose scope is limited to the episode under study, the number of admissions did not increase notably during the episode or on subsequent days, when compared with admissions associated with the SDDs in the prior weeks. Likewise, the abrupt drop is observed in the number of admissions when the state of alarm was declared.

It should be noted that, in time series of previous years, it has been observed that, in both cities, the number of emergency hospital admissions for chronic obstructive disease (COPD), and for ARSD registered during SDDs is slightly higher than those on non-SDDs, being this difference, statistically significant (Table 8.2.1).

Table 8.2.1. Descriptive Statistics on daily emergency hospital admissions for circulatory and respiratory disease and particulate matter fractions (2008- 2019).

\begin{tabular}{|c|c|c|c|c|c|c|c|c|c|c|}
\hline & \multicolumn{5}{|c|}{ L/P de Gran Canaria } & \multicolumn{5}{|c|}{ S/C de Tenerife } \\
\hline & \multicolumn{2}{|c|}{ Non-SDD } & \multicolumn{3}{|c|}{ SDDs } & \multicolumn{2}{|c|}{ Non-SDD } & \multicolumn{3}{|c|}{ SDDs } \\
\hline & Mean & $\operatorname{Min} / \max$ & Mean & $\operatorname{Min} / \max$ & $\mathrm{P}^{1}$ & Mean & $\operatorname{Min} / \max$ & Mean & $\mathrm{Min} / \max$ & $\mathrm{P}^{1}$ \\
\hline Circulat & 8.94 & $0 / 29$ & 8.91 & $0 / 25$ & 0.793 & 4.45 & $0 / 17$ & 4.37 & $0 / 14$ & 0.241 \\
\hline ARSD & 5.59 & $0 / 18$ & 5.85 & $0 / 21$ & 0.001 & 3.23 & $0 / 19$ & 3.46 & $0 / 12$ & 0.001 \\
\hline COPD & 0.72 & $0 / 5$ & 0.8 & $0 / 6$ & 0.001 & 0.4 & $0 / 5$ & 0.48 & $0 / 4$ & 0.000 \\
\hline asthma & 0.36 & $0 / 4$ & 0.39 & $0 / 6$ & 0.057 & 0.17 & $0 / 3$ & 0.19 & $0 / 3$ & 0.194 \\
\hline $\mathrm{PM}_{10^{2}}$ & 20.8 & $6.2 / 66.9$ & 39.75 & $9.2 / 357.2$ & 0.000 & 14.26 & $1 / 47.9$ & 33.73 & $1 / 348.3$ & 0.000 \\
\hline $\mathrm{PM}_{2.5^{2}}$ & 8.79 & $2.1 / 32.6$ & 16.63 & $3.5 / 143.5$ & 0.000 & 5.44 & $1 / 56.3$ & 10.36 & $1 / 56.3$ & 0.000 \\
\hline
\end{tabular}

${ }^{1} \mathrm{p}$-value for comparison during SDDs and non-SDDs t-Test

${ }^{2} \mu \mathrm{g} / \mathrm{m}^{3}$ 


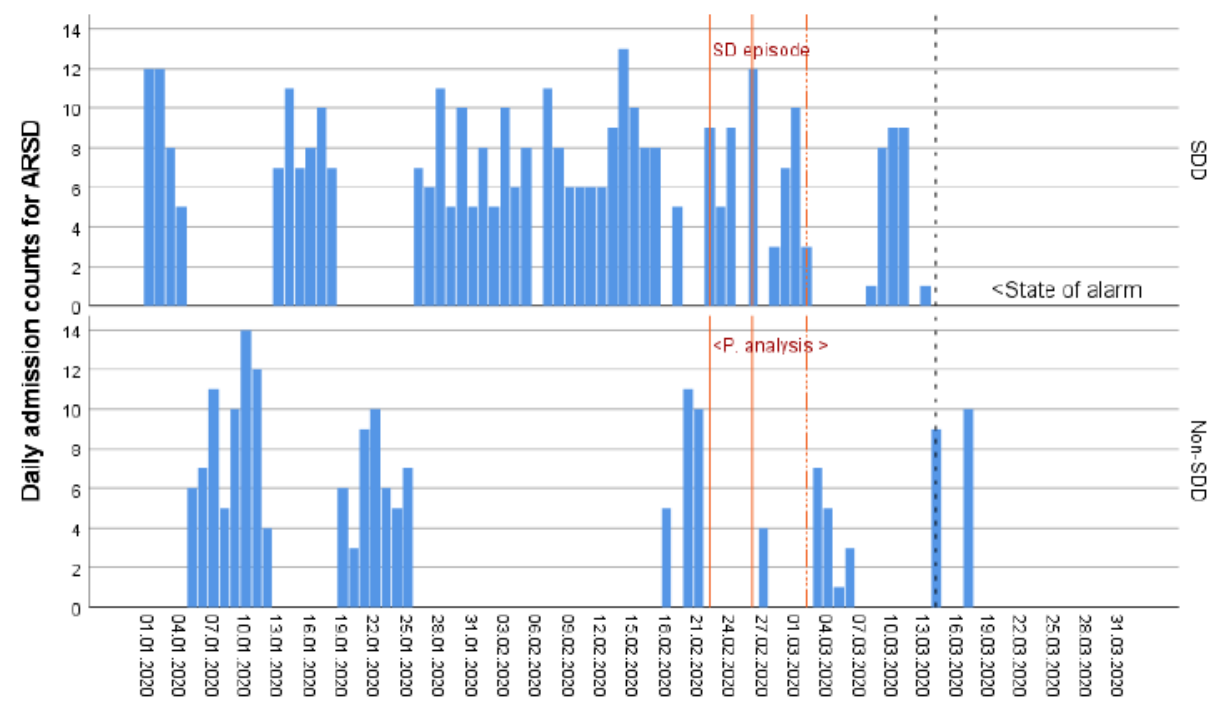

S/ C de Tenerife. February 2020

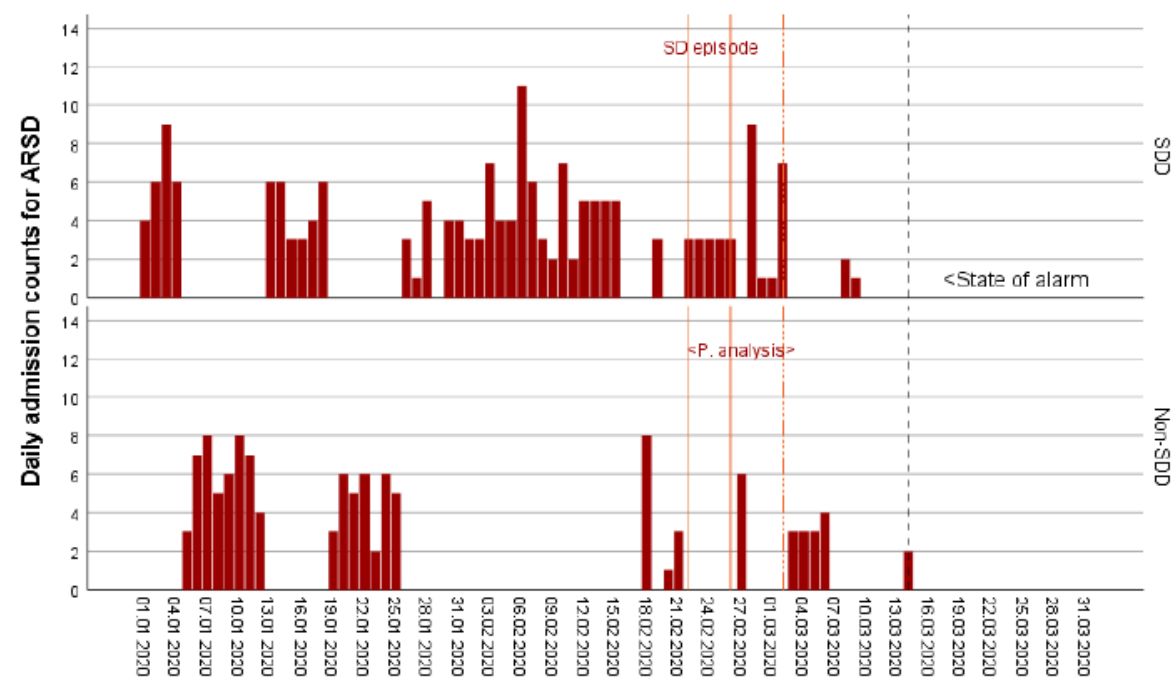

Figure 8.2.1. Emergency hospital admissions for all respiratory system diseases on SDDs and non-SDDs in L/ P de Gran Canaria and S/ C de Tenerife (J anuary-March 2020)

\subsubsection{Saharan dust episode: 22-26 February and period of influence, until 2 March. Emergency hospital admissions}

As described in scientific literature and in our previous studies (Lopez-Villarrubia et al., 2020), the effects on health associated with exposure to SDDs are not only observed on the same day (lag 0 ) but over several consecutive days (at least until 5 days after the exposure). For that reason, the period of interest would be defined by the specific Saharan dust episode under study (22-26 February) and its period of influence (22 February-2 March). In neither of the two cities did the number of hospital admissions increase in proportion to the levels of $\mathrm{PM}_{10}$ that were reached, at least as would be expected, if compared with the number of admissions that occurred on SDDs on the previous dates (Figure 8.2.2). 


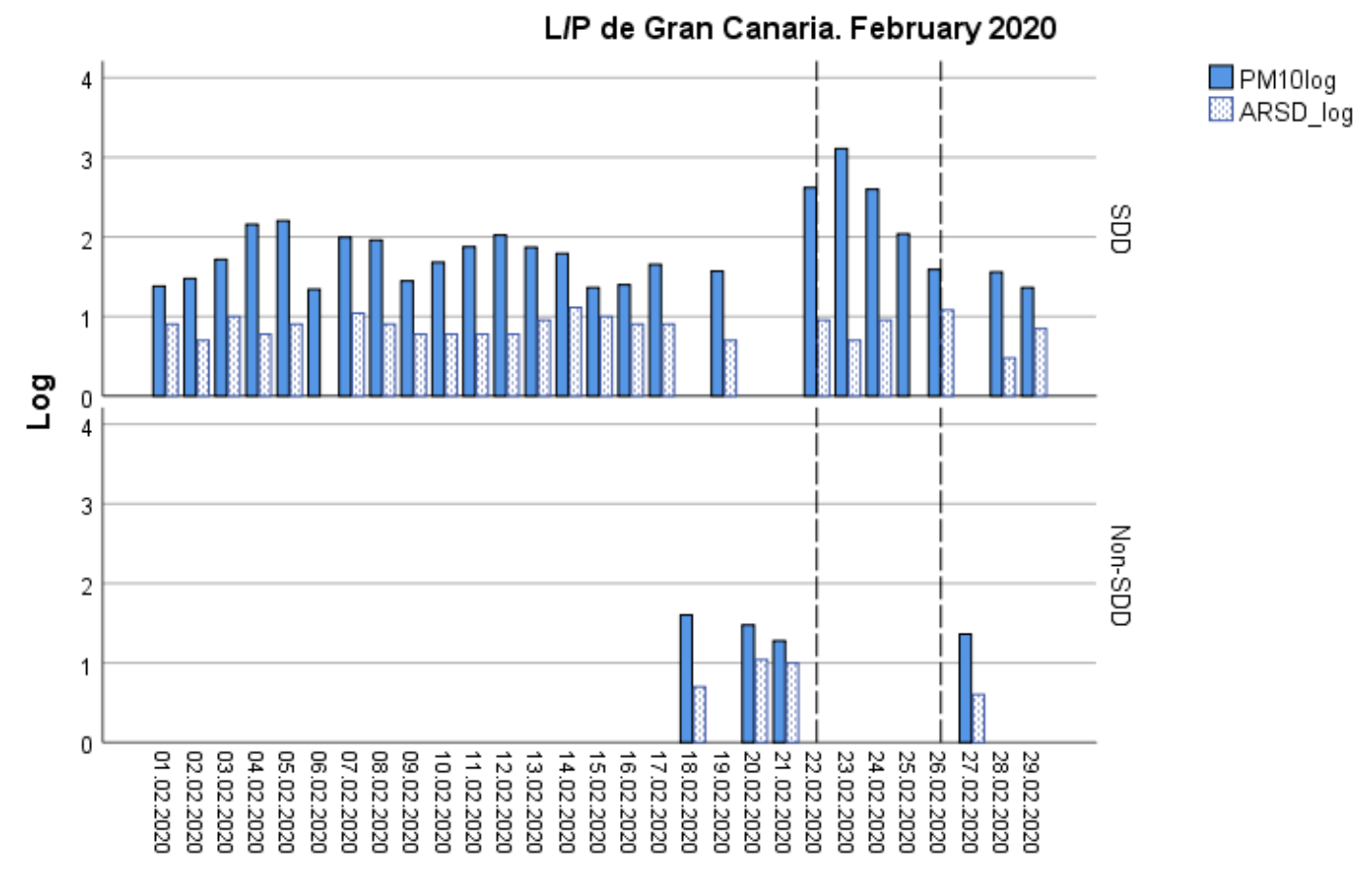

SIC de Tenerife. February 2020

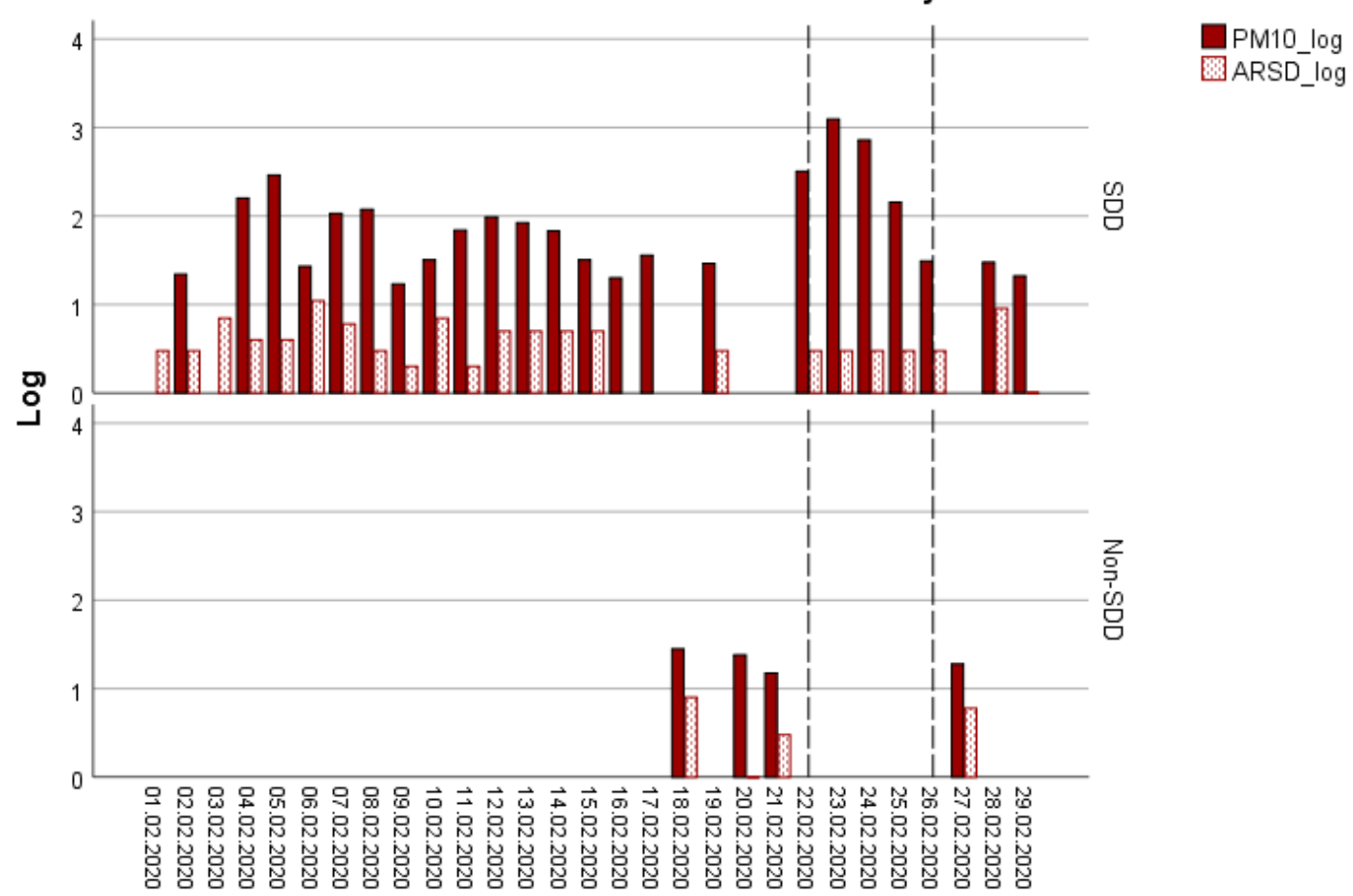

Figure 8.2.2. Emergency hospital admissions for all respiratory system diseases and $P_{10}$ on SDDs and non-SDDs, log transformation (February 2020). Solid bars: PM10, log and dotted bars: ARSD log (daily).

Table 8.2.2 shows the number of hospital admissions during SDDs and the successive 5 days ( 22 February to 2 March). In L/P de Gran Canaria, there were 35 hospital admissions for ARSD between 22 and 26 February (SDDs), with a daily average of 7 ; in S/C de Tenerife the number of admissions was 15 , with a daily average of three. Likewise, the number of hospital admissions for circulatory diseases decreased in comparison with what would be usual (Table 8.2.1), and even fell below the number of admissions for respiratory disease on some days. 
Table 8.2.2. Daily emergency hospital admissions and daily average of PM fractions during February 22- 26 episode and period of influence

\begin{tabular}{|c|c|c|c|c|c|c|c|c|c|c|c|c|}
\hline \multirow[b]{2}{*}{2020} & \multicolumn{6}{|c|}{ L/ P de Gran Canaria } & \multicolumn{6}{|c|}{ S/ C de Tenerife } \\
\hline & ARSD & COPD & asthma & circulatory & $\mathrm{PM}_{10}$ & $\mathrm{PM}_{2.5}$ & ARSD & COPD & asthma & circulatory & $\mathrm{PM}_{10}$ & $\mathrm{PM}_{2.5}$ \\
\hline $02 / 22$ & 9.0 & 1.0 & 1.0 & 7.0 & 416 & 93 & 3.0 & 0.0 & 0.0 & 5.0 & 319 & 70 \\
\hline $02 / 23$ & 5.0 & 2.0 & 0.0 & 5.0 & 1283 & 390 & 3.0 & 0.0 & 0.0 & 6.0 & 1238 & 363 \\
\hline $02 / 24$ & 9.0 & 3.0 & 1.0 & 7.0 & 397 & 121 & 3.0 & 0.0 & 0.0 & 0.0 & 720 & 188 \\
\hline $02 / 25$ & 0.0 & 0.0 & 0.0 & 7.0 & 109 & 35 & 3.0 & 0.0 & 0.0 & 3.0 & 143 & 49 \\
\hline $02 / 26$ & 12.0 & 2.0 & 0.0 & 4.0 & 39 & 9 & 3.0 & 1.0 & 1.0 & 1.0 & 31 & \\
\hline $02 / 27$ & 4.0 & 0.0 & 0.0 & 5.0 & 23 & 7 & 6.0 & 0.0 & 0.0 & 6.0 & 19 & 7 \\
\hline $02 / 28$ & 3.0 & 0.0 & 0.0 & 8.0 & 36 & 10 & 9.0 & 0.0 & 1.0 & 1.0 & 30 & 11 \\
\hline $02 / 29$ & 7.0 & 1.0 & 0.0 & 3.0 & 23 & 6 & 1.0 & 1.0 & 0.0 & 1.0 & 21 & 8 \\
\hline 03/01 & 10.0 & 0.0 & 1.0 & 3.0 & 38 & 11 & 1.0 & 1.0 & 0.0 & 4.0 & 41 & 13 \\
\hline $03 / 02$ & 3.0 & 0.0 & 1.0 & 4.0 & 79 & 23 & 7.0 & 1.0 & 1.0 & 2.0 & 74 & 19 \\
\hline
\end{tabular}

\begin{tabular}{|l|rrrrrrr|}
\hline N & 35.0 & 8.0 & 2.0 & 30.0 & & \\
Mean & 7.0 & 1.6 & 0.4 & 6.0 & 448.8 & 129.6 \\
Min & 0.0 & 0.0 & 0.0 & 4.0 & 39.0 & 9.0 \\
Max & 12.0 & 3.0 & 1.0 & 7.0 & 1283.0 & 390.0 \\
\hline
\end{tabular}

\begin{tabular}{|rrrrrr|}
\hline 15.0 & 1.0 & 1.0 & 15.0 & & \\
3.0 & 0.2 & 0.2 & 3.0 & 490.2 & 167.5 \\
3.0 & 0.0 & 0.0 & 0.0 & 31.0 & 49.0 \\
3.0 & 1.0 & 1.0 & 6.0 & 1238.0 & 363.0 \\
\hline
\end{tabular}

22- 26 February 2020

\begin{tabular}{|l|rrrrrr|}
\hline N & 62.0 & 9.0 & 4.0 & 53.0 & & \\
Mean & 6.2 & 0.9 & 0.4 & 5.3 & 244.3 & 70.5 \\
Min & 0.0 & 0.0 & 0.0 & 3.0 & 23 & 6 \\
Max & 12.0 & 3.0 & 1.0 & 8.0 & 1283 & 390 \\
\hline
\end{tabular}

22 February - 2 March 2020

\begin{tabular}{|rrrrrr|}
\hline 39.0 & 4.0 & 3.0 & 29.0 & & \\
3.9 & 0.4 & 0.3 & 2.9 & 263.6 & 80.9 \\
1.0 & 0.0 & 0.0 & 0.0 & 19 & 7 \\
9.0 & 1.0 & 1.0 & 6.0 & 1238 & 363 \\
\hline
\end{tabular}

Given the limitations previously described and as a methodological approach, we decided to explore the possibility of estimating how many emergency hospital admissions for ARSD, out of the total number of hospital admissions for this cause, would be attributable to short-term exposure to $\mathrm{PM}_{10}$ levels that exceeded the average $\mathrm{PM}_{10}$ of non-SDD for each city, levels that we could equate to the urban background of each city, with their specificities in terms of urban background pollution.

Regards other causes of hospital admission for specific respiratory diseases, such as COPD or asthma, these were not included in the analysis since the average number of daily admissions is well below the unit, so that, in such a short annual period and in the context of decreased admissions mentioned, there were several days with no admissions for these causes.

\subsubsection{Methodology}

The study areas are the city of L/P de Gran Canaria with a population of 379.925 in January 2019 and that of S/C de Tenerife with a population of 207.312. As sources of information, we used PM data from a representative station in each of the cities (Mercado Central in L/P de Gran Canaria and Tomé Cano in S/C de Tenerife) and data on emergency hospital admissions came from the Register of Specialized Health Activity-Minimum Basic Data Set (RAE-CMBD in Spanish). 


\subsubsection{Design}

We had to consider several factors to be able to assess the possible impact of the episode on hospital admissions. On the one hand, the episode taking place between 22 and 26 February 2020 is a winter episode. Winter episodes have different characteristics compared with summer Saharan dust episodes. On the other hand, as explained above, the magnitude of the episode caused citizens to avoid exposure to Saharan dust, resulting in a lower impact on the emergency services. A decrease in hospital admissions from March 14 due to the establishment of the state of alarm adds to that. We carried out a comparison between the first quarter of 2020 and the same period of previous years, which allowed us to maintain homogeneity with respect to potential confounding variables, such as meteorological variables, flu epidemics, hospital admissions policy, the environmental context, air quality and, characteristics of the Saharan dust transport. Therefore, the period of analysis, in a first approximation, is assumed to be between 1 J anuary and 31 March of each of the years (20162019).

\subsubsection{Estimation of the burden on emergency hospital admissions attributable to short-term exposure to Saharan Dust Days}

To estimate the burden on emergency hospital admissions attributable to short-term exposure to SDDs, and based on the comparative risk analysis method of the "Environmental Burden of Disease" series (Prüss-Üstün, 2003; Ostro, 2013), we use AirQ software, developed by the $\mathrm{WHO}$, in which the following information must be entered:

- $\quad$ Exposure to PM in the population of each city: based on data from the representative stations of each of the cities, i.e., Mercado Central in L/P de Gran Canaria and Tome Cano in $\mathrm{S} / \mathrm{C}$ de Tenerife, from which data on $\mathrm{PM}_{10}$ and $\mathrm{PM}_{2.5}$ between 1 J anuary and 31 March of each of the years were obtained.

- $\quad$ Number of people exposed: the total population was obtained from the municipal registers of each city.

- $\quad$ Baseline incidence: rates of emergency hospital admission for ARSD (ICD-10: J00 to $\mathrm{J}^{1}$ ) for each city from 2006 to 2019 were applied.

- $\quad$ Concentration-response functions (CRFs) that relate the increase in $\mathrm{PM}_{10}$ levels with changes in the number of hospital admissions. Generally, relative risks (RR) obtained from the results of epidemiological studies (meta-analysis and multicentre studies) carried out in Europe (Atkinson, 2005; WHO, 2013), are used, in this case $\mathrm{RR}=1.0114$ (95\% confidence interval $(\mathrm{Cl}): 1.0062$ to 1.0167$)$. From these, we derive the $\beta$ coefficient that we used for our estimates. In addition, a sensitivity analysis was performed using the RRs from the Commission for Atmospheric Sciences (CAS) Project.

- $\quad$ Counterfactual exposure: $\mathrm{PM}_{10}$ level with which the current levels of each city are contrasted. The scenario that arises is one in which there was no contribution of particulate matter of African origin, so we consider the average of the $\mathrm{PM}_{10}$ levels on non-SDDs in the first quarter of the years analysed (Table 8.2.3).

\footnotetext{
${ }^{1}$ https://www.icd10data.com/ICD10CM/Codes/J00-J 99
} 


\subsubsection{Statistical analysis}

AirQ allows the estimation of the impact on health of a certain pollutant in a specific location and period. These estimates are based on the calculation of: 1 . the "attributable proportion" (fraction of hospital admissions for the analysed cause that can be attributed to exposure, in this case to days with a $\mathrm{PM}_{10}$ average higher than the average on non-SDDs), 2. the number of emergency admissions per $10^{5}$ inhabitants attributable to exposure or "excess incidence" and 3. the "number of emergency admissions attributable to exposure". Furthermore, the program allows estimation of the number of emergency admissions in each exposure category $\left(\mathrm{PM}_{10}\right.$ level).

\subsubsection{Results}

\subsubsection{Data description}

Table 8.2.3 shows the descriptive statistics of the variables, in the quarters analysed from the period 2016 to 2019 and 2020, for SDDs and non-SDDs. A remarkable difference in the levels of $\mathrm{PM}_{10}$ on SDDs in 2020 with respect to the four previous years can be observed.

Table 8.2.3. Descriptive statistics on non-SDDs and SDDs. first trimester 2016-2019

\begin{tabular}{|c|c|c|c|c|c|c|c|c|c|c|c|c|}
\hline & & & \multicolumn{5}{|c|}{ L/P de Gran Canaria } & \multicolumn{5}{|c|}{$\mathrm{S} / \mathrm{C}$ de Tenerife } \\
\hline & \multirow{3}{*}{$\begin{array}{c}\text { Non- } \\
\text { SDD } \\
n\end{array}$} & \multirow{3}{*}{$\begin{array}{c}\text { SDD } \\
n\end{array}$} & \multirow{3}{*}{$\begin{array}{c}\mu_{\mathrm{g} \mathrm{m}}^{-3} \\
{ }_{n}\end{array}$} & \multirow{2}{*}{\multicolumn{2}{|c|}{$\begin{array}{l}\mathrm{PM}_{10}{ }^{1} \\
\text { Mean }\end{array}$}} & \multicolumn{2}{|c|}{ ARSD } & & \multicolumn{2}{|c|}{$\mathrm{PM}_{10}$} & \multicolumn{2}{|c|}{ ARSD } \\
\hline & & & & & & & & $\begin{array}{c}>50 \\
\mu \mathrm{g} \mathrm{m}^{-3}\end{array}$ & & & $\mathrm{Me}$ & \\
\hline & & & & $\begin{array}{l}\text { Non- } \\
\text { SDD }\end{array}$ & SDD & $\begin{array}{l}\text { Non- } \\
\text { SDD }\end{array}$ & SDD & $\mathrm{n}$ & $\begin{array}{l}\text { Non- } \\
\text { SDD }\end{array}$ & SDD & $\begin{array}{l}\text { Non- } \\
\text { SDD }\end{array}$ & SDD \\
\hline 2020 & 36.0 & 54.0 & 23.0 & 22.4 & 87.2 & 5.0 & 6.4 & 17.0 & 16.4 & 93.8 & 3.2 & 3.3 \\
\hline $\begin{array}{c}2016 \text { a } \\
2019\end{array}$ & 172.0 & 189.0 & 79.0 & 19.4 & 37.7 & 6.7 & 7.0 & 107.0 & 12.0 & 35.7 & 5.2 & 4.7 \\
\hline
\end{tabular}

\subsubsection{Hospital admissions for all respiratory system diseases attributable to SDDs, first trimester 2020}

In order to compare the impact of SDDs during the first quarter of 2020 with immediately preceding years, attributable admissions are estimated when exposure to $\mathrm{PM}_{10}$ exceeds the average on non-SDDs in the 2016-2019 period (19.4 $\mathrm{\mu g} \mathrm{m}^{-3}$ in L/P de Gran Canaria and $12.0 \mu \mathrm{g} \mathrm{m}^{-3}$ in $\mathrm{S} / \mathrm{C}$ de Tenerife).

Table 8.2.4 shows the percentage of admissions attributable to SDDs above the counterfactual $\mathrm{PM}_{10}$ levels for each city during the first quarter of 2016-2019 and for the year 2020. In L/P de Gran Canaria $6.7 \%$ (95\% Cl: 3.1 to 11.9 ) of emergency hospital admissions for respiratory diseases that occurred during the first quarter of 2020 are attributed to short-term exposure to $\mathrm{PM}_{10}$ levels above $19.4 \mu \mathrm{g} \mathrm{m}^{-3}$. This percentage was $0.71 \%$ if we consider the first quarter of the previous 4 years as a whole, with the number of attributable cases being similar in both cases, 27 admissions (95\% Cl: 15 to 39 ) and 35 admissions (95\% Cl: 16 to 61 ) just in the first quarter of 2020. 
Table 8.2.4. Emergency hospital admissions for respiratory system diseases attributable to Saharan dust days in first trimester 2020, compared with the same months for period 20162019

\begin{tabular}{|c|c|c|c|c|c|c|}
\hline \multicolumn{7}{|c|}{ L/ P de Gran Canaria } \\
\hline $\begin{array}{l}\text { Counterfactual } \\
{ }^{1} 19.40 \mu \mathrm{g} \mathrm{m}^{-3}\end{array}$ & \multicolumn{2}{|c|}{ Relative Risk } & $\begin{array}{c}\text { Baseline } \\
\text { Incidence } \\
\text { per } 10^{5}\end{array}$ & $\begin{array}{l}\text { Attributable\% } \\
\text { (I C95\%) }\end{array}$ & $\begin{array}{c}\text { Excess } \\
\text { admissions } \\
\text { no (IC95\%) }\end{array}$ & $\begin{array}{l}\text { Excess } \\
\text { incidence } \\
\text { per } 10^{5} \\
(I C 95 \%)\end{array}$ \\
\hline \multirow{2}{*}{$2016-2019$} & $\begin{array}{l}\text { Atkinson, } \\
2005\end{array}$ & $\begin{array}{c}1.0114 \\
(1.0062 \text { to } \\
1.0167)\end{array}$ & 543.34 & $\begin{array}{c}1.3 \\
(0.71 \text { to } 1.91)\end{array}$ & $\begin{array}{c}27 \\
\text { (15 to } 39)\end{array}$ & $\begin{array}{c}7 \\
(4 \text { to } 10)\end{array}$ \\
\hline & $\begin{array}{l}\text { Lopez- } \\
\text { Villarrubia et } \\
\text { al., } 2016\end{array}$ & $\begin{array}{c}1.0054 \\
(0.9992 \text { to } \\
1.0116)\end{array}$ & 543.34 & $\begin{array}{c}0.6 \\
(-0.0 \text { to } 1.3)\end{array}$ & $\begin{array}{c}13 \\
(-2 \text { to } 27)\end{array}$ & $\begin{array}{c}3 \\
(0 \text { to } 7)\end{array}$ \\
\hline \multirow{2}{*}{2020} & $\begin{array}{l}\text { Atkinson, } \\
2005\end{array}$ & $\begin{array}{c}1.0114 \\
(1.0062 \text { to } \\
1.0167)\end{array}$ & 543.34 & $\begin{array}{c}6.7 \\
\text { (3.1 to } 11.9)\end{array}$ & $\begin{array}{c}35 \\
\text { (16 to } 61)\end{array}$ & $\begin{array}{c}36 \\
\text { (17 to } 64)\end{array}$ \\
\hline & $\begin{array}{l}\text { Lopez- } \\
\text { Villarrubia et } \\
\text { al., } 2016\end{array}$ & $\begin{array}{c}1.0054 \\
(0.9992 \text { to } \\
1.0116)\end{array}$ & 543.34 & $\begin{array}{c}2.6 \\
(-0.3 \text { to } 6.8)\end{array}$ & $\begin{array}{c}14 \\
(-2 \text { to } 35)\end{array}$ & $\begin{array}{c}14 \\
(-2 \text { to } 37)\end{array}$ \\
\hline
\end{tabular}

S/ C de Tenerife

\begin{tabular}{|c|c|c|c|c|c|c|}
\hline $\begin{array}{l}\text { Counterfactua } \\
\qquad \begin{array}{c}I^{1} 11.96 \\
\mu \mathrm{g} / \mathrm{m}^{3}\end{array}\end{array}$ & \multicolumn{2}{|c|}{ Relative Risk } & $\begin{array}{c}\text { Baseline } \\
\text { Incidence } 2 \\
\text { per } 10^{5}\end{array}$ & $\begin{array}{l}\text { Attributable\% } \\
\text { (IC95\%) }\end{array}$ & $\begin{array}{l}\text { Excess } \\
\text { admissions } \\
\text { no (IC95\%) }\end{array}$ & $\begin{array}{l}\text { Excess } \\
\text { incidence } \\
\text { per } 10^{5} \\
(I C 95 \%)\end{array}$ \\
\hline \multirow{2}{*}{ 2016-2019 } & $\begin{array}{l}\text { Atkinson, } \\
2005\end{array}$ & $\begin{array}{c}1.0114 \\
(1.0062 \text { to } \\
1.0167)\end{array}$ & 570.95 & $\begin{array}{c}1.6 \\
(0.8 \text { to } 2.3)\end{array}$ & $\begin{array}{c}18 \\
(10 \text { to } 27)\end{array}$ & $\begin{array}{c}9 \\
\text { (5 to 13) }\end{array}$ \\
\hline & $\begin{array}{l}\text { Lopez- } \\
\text { Villarrubia et } \\
\text { al., } 2016\end{array}$ & $\begin{array}{c}1.0107 \\
(1.0036 \text { to } \\
1.0178)\end{array}$ & 570.95 & $\begin{array}{c}1.5 \% \\
(0.5 \text { to } 2.4)\end{array}$ & $\begin{array}{c}17 \\
\text { (6 to } 29)\end{array}$ & $\begin{array}{c}8 \\
\text { (3 to } 14 \text { ) }\end{array}$ \\
\hline \multirow{2}{*}{2020} & $\begin{array}{l}\text { Atkinson, } \\
2005\end{array}$ & $\begin{array}{c}1.0114 \\
(1.0062 \text { to } \\
1.0167)\end{array}$ & 570.95 & $\begin{array}{c}8.1 \\
\text { (3.8 to 14) }\end{array}$ & $\begin{array}{c}24 \\
(11 \text { to } 42)\end{array}$ & $\begin{array}{c}46 \\
\text { (22 to } 80)\end{array}$ \\
\hline & $\begin{array}{l}\text { Lopez- } \\
\text { Villarrubia et } \\
\text { al., } 2016\end{array}$ & $\begin{array}{c}1.0107 \\
(1.0036 \text { to } \\
1.0178)\end{array}$ & 570.95 & $\begin{array}{c}7.4 \\
(2.1 \text { to } 15.5)\end{array}$ & $\begin{array}{c}22 \\
(6 \text { to } 46)\end{array}$ & $\begin{array}{c}42 \\
\text { (12 to } 89)\end{array}$ \\
\hline
\end{tabular}

${ }^{1}$ Average $\mathrm{PM}_{10}$ of Days w/o PM between January and March, 2016-2019

${ }^{2}$ Baseline incidence rate of emergency hospital admissions for respiratory disease, 2008-2019

In S/C de Tenerife, the percentage of emergency admissions that would not have occurred in the absence of Saharan dust in the first quarter of 2020 was estimated at $8 \%(95 \% \mathrm{Cl}: 3.8$ to 14.0) of the total emergency admissions for respiratory diseases, compared to $1.6 \%$ (95\% $\mathrm{Cl}: 0.85$ to 2.3 ) estimated for the entire period from 2016 to 2019 . This represents an excess of 24 admissions (95\% Cl: 11 to 42 ) and $18(95 \% \mathrm{Cl}: 10$ to 27$)$ respectively.

If the estimates made with the recommended RRs of Atkinson (2005) and those of the CAS Project are compared, the impact estimates for the city of S/C de Tenerife are quite similar, while, as the RR estimate using CAS approach in the city of L/P de Gran Canaria was not statistically significant, the estimates are lower and not significant. 


\subsubsection{Hospital admissions attributable to 22- 26 February 2020 Saharan dust episode}

Figures 8.2.3(a)-3(b) show the estimated distribution of excess emergency hospital admissions by $\mathrm{PM}_{10}$ exposure level, including the $95 \%$ confidence intervals. This enables us to approximate the impact that the episode could have on emergency hospital admissions on those days.

(a)

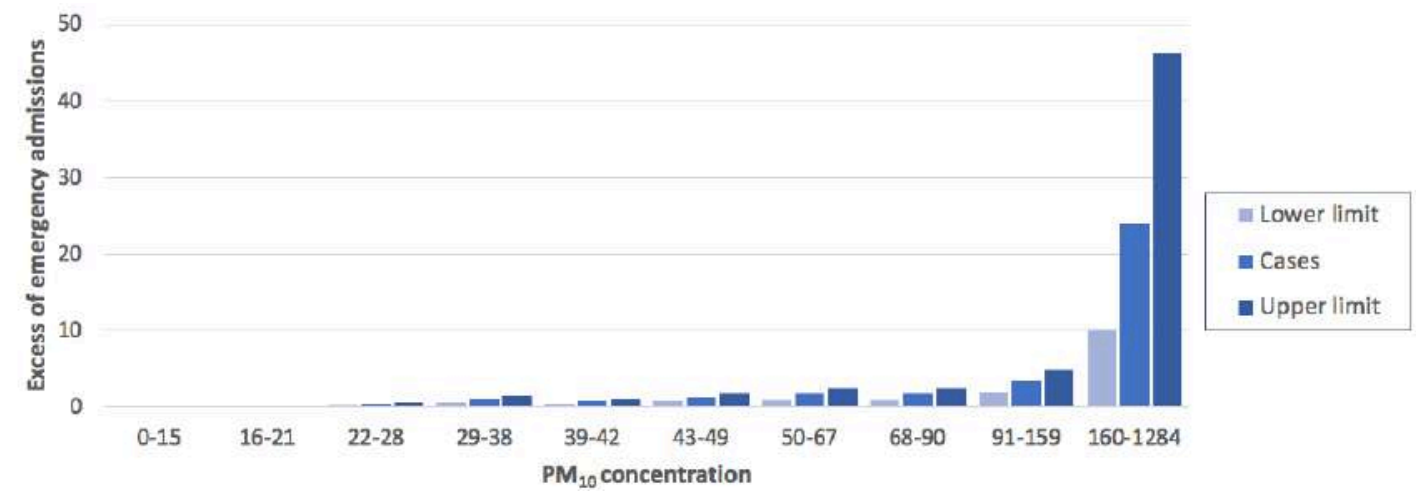

(b)

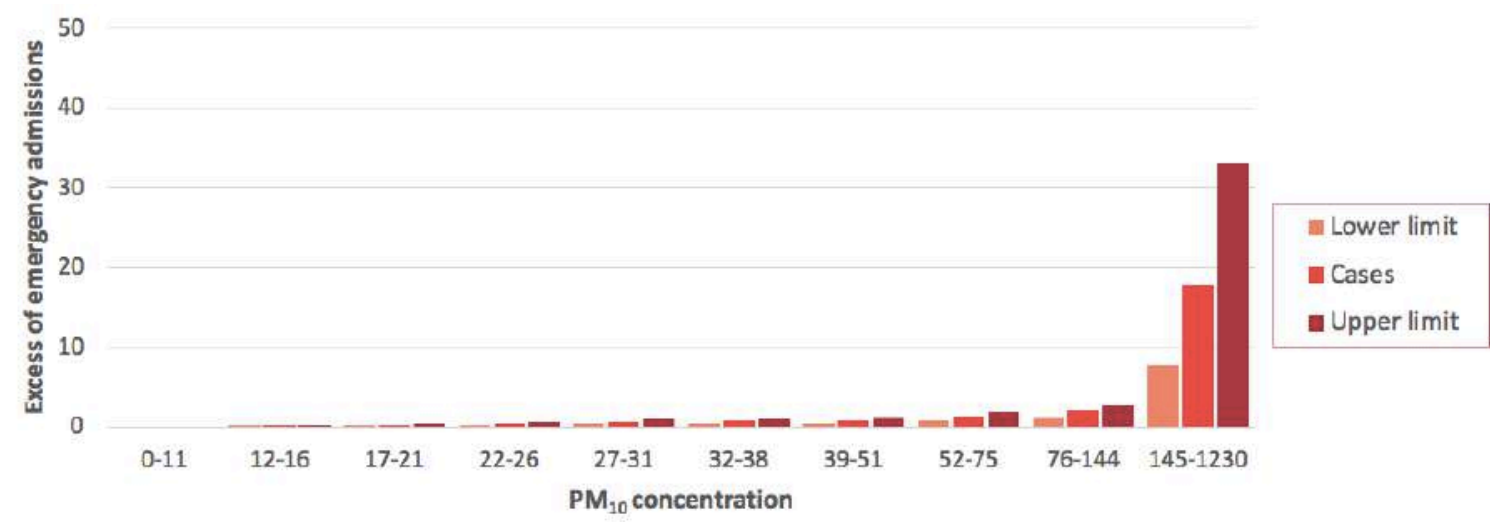

Figure 8.2.3 Excess emergency admissions for various categories of $\mathrm{PM}_{10}$ concentration in (a) L/ P de Gran Canaria and (b) S/ C de Tenerife (first trimester 2020)

Thus, the number of emergency admissions for respiratory diseases attributable to the episode, taking into account its possible delayed impact (between 22 February and 2 March) was $24.3(95 \% \mathrm{Cl}: 10.3$ to 46.9$)$ in L/P de Gran Canaria out of a total of 62 , while the estimates for 23 February with $1283 \mu \mathrm{g} \mathrm{m}^{-3}$ of $\mathrm{PM}_{10}$ was $17(95 \% \mathrm{Cl}: 6.6$ to 36.0 ); in $\mathrm{S} / \mathrm{C}$ de Tenerife, of the 39 registered admissions, $17.3(95 \% \mathrm{Cl}: 7.4$ to 31.8$)$ can be attributed to the episode and five following days (Table 8.2.5) and 10.2 admissions (95\% $\mathrm{Cl}: 4.0$ to 21.0 ) on day 23 February. 
Table 8.2.5. Excess emergency hospital admissions for all respiratory system disease

\begin{tabular}{|c|c|c|}
\hline & $\begin{array}{c}\text { L/ P de } \\
\text { Gran Canaria }\end{array}$ & S/ C de Tenerife \\
\hline Hospital admissions for the first quarter of 2020 & 530 & 295 \\
\hline Admissions excess (IC95\%) & $35.0(16.0$ to 61.0$)$ & 24 (11.0 to 42.0$)$ \\
\hline Hospital admissions 22 February - 2 March 2020 & 62 & 39 \\
\hline Admissions excess (IC95\%) & 24.3 ( 10.3 to 46.9$)$ & $17.3(7.4$ to 31.8$)$ \\
\hline Hospital admissions 22- 26 February 2020 & 35 & 15 \\
\hline Admissions excess (IC95\%) & 23.7 (9.9 to 46.0 ) & $16.5(7.1$ to 31.1$)$ \\
\hline Hospital admissions on 23 February 2020 & 15 & 3 \\
\hline Admissions excess (IC95\%) & $17.0(6.6$ to 36.0$)$ & $10.2(4.0$ to 21.0$)$ \\
\hline
\end{tabular}

\subsubsection{Discussion}

The Saharan dust episode that occurred between 22 and 26 February 2020 was of such outstanding magnitude that, probably, the collective memory did not remember having experienced something similar. This translated into a lower exposure of people to Saharan dust, with fewer people venturing outdoors and, therefore, into less impact on the health of the general and the vulnerable population (those with asthma, the elderly and those with cardiorespiratory disease). For example, if we contrast what happened in this episode with another one of similar duration, such as that of 31 December 2014 to 5 January 2015, with daily averages of $350 \mathrm{\mu g} \mathrm{m}^{-3}$, an episode that can be classified as significant, the number of admissions for respiratory disease were 50 (average 8.3) in L/P de Gran Canaria and 26 in S/C de Tenerife with an average of 4.3, compared to 7 and 3 respectively in February 2020 episode. In the analysis of the potential impact of this episode, we had to take this context into account, together with the establishment of the state of alarm, which conditioned the low number of admissions with which to establish an association.

Of the 530 emergency admissions for ARSD registered in the city of L/P de Gran Canaria in the first quarter of 2020,35 ( $95 \% \mathrm{Cl}: 16$ to 41$)$ would be attributable to short-term exposure to daily averages of $\mathrm{PM}_{10}$ above $19.4 \mathrm{\mu g} \mathrm{m}^{-3}$, and of these, $24.3(95 \% \mathrm{Cl}: 10.3$ to 46.9$)$ would have occurred in this episode and the days immediately afterwards. In S/C de Tenerife, 24 of the 295 admissions ( $95 \% \mathrm{Cl}: 11$ to 42 ) could be attributed to short-term exposure to $\mathrm{PM}_{10}$ levels above $11.96 \mathrm{\mu g} \mathrm{m}^{-3}$ in the first quarter of 2020 and, of these, $17.3(95 \% \mathrm{Cl}: 7.4$ to 31.8) would be attributed to the period from 22 February to 2 March, i.e., almost $70 \%$ of the excess of cases estimated due to SDDs for the whole of the first quarter in the two cities.

Marzouni et al. (2016) estimated that in the Iranian city of Kermanshah, with 857.000 inhabitants, $13.5 \%$ and $10.8 \%$ of hospital admissions for respiratory diseases in 2011 and 2012, respectively, were attributable to exposure to Middle East Dust (MED). Another study in the same region, estimated that $6.62 \%$ (4.08 to 9.03) admissions for respiratory diseases were attributable to exposure to $\mathrm{PM}_{10}>10 \mu \mathrm{g} \mathrm{m}{ }^{-3}$ between 2014-2015 (Goudarzi et al., 2017). Likewise, $6.1 \%$ (3.7 to 8.3) of emergency admissions for respiratory diseases were estimated to be a consequence of exposure to $\mathrm{PM}_{10}$ levels above $10 \mu \mathrm{g} \mathrm{m}^{-3}$ in the city of Tehran (Naddafi et al., 2012). We are not aware of studies carried out in Europe with which to compare our results, however, our results seem to be in line with those mentioned: between $6.7 \%(95 \%$ $\mathrm{Cl}: 3.1$ to 11.9$)$ and $8 \%(95 \% \mathrm{Cl}: 3.8$ to 14$)$ in 2020. 
The methodology we have used is based on the WHO series on the burden of disease associated with environmental factors (Prüss-Üstün, 2003; Ostro, 2013) and has certain inherent limitations. One of these is the choice of exposure-response curves for the estimation of risk. In our estimates, we have used the relative risk obtained from meta-analysis (Atkinson, 2005), recommended by Medina et al. (2009), which would contribute a lower degree of uncertainty to the estimates made on a given territory. However, the Canary Islands are under the influence of specific factors, such as high levels of Saharan dust, with a wide range of $\mathrm{PM}_{10}$ concentrations. Therefore, it should be borne in mind that curves derived from epidemiological studies carried out in western cities do not necessarily represent those for our cities. Consequently, we have carried out a sensitivity analysis using the RRs for emergency hospital admissions for ARSD for lag 0 (current day) of the CAS Project (Lopez-Villarrubia et al., 2016) .

In S/C de Tenerife, the estimates were very similar in magnitude with respect to those obtained with the standard curves, in any case and in comparative terms, both attribute a slightly higher burden of admissions due to ARSD in the Tenerife city. Another uncertainty originates in the shape of the exposure-response curve, in which a linear relationship is assumed within the usual exposure limits, with no threshold below which there are no health effects. However, in locations with very high $\mathrm{PM}_{10}$ levels, the association is likely to be loglinear, as we found in the association between particulate matter and mortality (LopezVillarrubia et al., 2012). Another limitation is related to the possibility of confounding effects by other pollutants. It is unlikely that with such extremely high $\mathrm{PM}_{10}$ concentrations, there will be confounding effect of other urban pollutants or interaction with them, also taking into account the decrease in volume of traffic that weekend and considering that we have already shown the independent effect of PM fractions and gaseous pollutants on health (Lopez-Villarrubia et al., 2010; 2012; 2016). A separate issue would be the chemical and biological composition of these transported $\mathrm{PM}_{10}$. Likewise, we estimate that the $\mathrm{PM}_{10}$ measurements recorded at the stations are representative of the exposure of the population, as it is a natural exposure that is homogeneously distributed in the ambient air in all areas of the cities under study.

Other issues to take into account and that require us to interpret the results with certain caution, is that we have had to assume that the levels of particles on a given day have an effect only during that day, when it is known that there is a lagged and cumulative effect on health indicators, a fact that is also in line with the results of the CAS Project (Lopez-Villarrubia et al., 2010; 2012; 2016; 2020). In this sense, we increased the number of days for analysis after the episode. The precision of the estimates is low because a period of 15 months between 2016 and 2020 was analysed, with low number of emergency hospital admissions. This analysis addresses environmental exposure of natural origin where action to reduce the specific weight on health indicators is not possible, but in the context of the aforementioned limitations, we think that it shows an approximate pattern of the potential burden on health of this episode and its potential effect, providing an indicator to environmental and public health authorities to evaluate the existing strategies for reducing PM exposure and implement new measures and thus reduce the burden of morbidity that is attributable to it.

\subsubsection{Conclusions}

Our results suggest that exposure to $\mathrm{PM}_{10}$ levels above the usual averages during non-SDD for each city, especially during Saharan dust episodes, poses a burden on emergency hospital admissions for all respiratory system diseases in both cities; these results are consistent with those of the CAS Project, in which a risk of emergency admission due to exposure to SDDs was evaluated. Despite the effectiveness of weather alerts and early warning systems, which prevented part of the population from being exposed to exceptional $\mathrm{PM}_{10}$ levels during the Saharan dust episode of 22- 26 February 2020, our results suggest that there were hospital admissions attributable to this episode. In the first trimester of 2020 , in which more than $60 \%$ of the days were under the influence of Saharan dust episodes, of the excess hospital admissions attributable to that, around $70 \%$ were related to this particular episode. 
Atkinson, R. W., H.R. Anderson, S. Medina, C. Iñiguez, B. Forsberg, B. Segerstedt, A. Lefranc, 2005: Analysis of all-age respiratory hospital admissions and particulate air pollution within the APHEIS programme. APHEIS Air Pollution and information System (Vol. 3).

Goudarzi, G., S.M. Daryanoosh, H. Godini, P.K. Hopke, P. Sicard, A. De Marco, H.D. Rad, A. Harbizadeh, F. Jahedi, M.J. Mohammadi, J. Savari, S. Sadeghi, Z. Kaabi, Y. Omidi Khaniabadi, 2017: Health risk assessment of exposure to the Middle-Eastern Dust storms in the Iranian megacity of Kermanshah. Public Health, 148, 109-116. https://www.sciencedirect.com/science/article/abs/pii/S0033350617301269?via\% 3Dihub.

López-Villarrubia, E., F. Ballester, C. Iñiguez, \& N. Peral, 2010: Air pollution and mortality in the Canary Islands: a time series analysis. Environmental Health, 9(1), 8. https://ehjournal. biomedcentral.com/articles/10.1186/1476-069X-9-8.

López-Villarrubia, E., O. Costa Estirado, C. Íñiguez Hernández, \& F. Ballester Díez, 2020: Do Saharan Dust Days Carry a Risk of Hospitalization From Respiratory Diseases for Citizens of the Canary Islands (Spain)? Archivos de Bronconeumología, (In press). https://www.sciencedirect.com/science/article/abs/pii/S0300289620300879?via\% 3Dihub.

López-Villarrubia, E., C. Iñiguez, O. Costa, \& F. Ballester, 2016: Acute effects of urban air pollution on respiratory emergency hospital admissions in the Canary Islands. Air Quality, Atmosphere \& Health, 9(7), 713- 722. https://link.springer.com/article/10.1007/s11869-015-0382-z.

López-Villarrubia, E., C. Iñiguez, N. Peral, M.D García, \& F. Ballester, 2012: Characterizing mortality effects of particulate matter size fractions in the two capital cities of the Canary Islands. Environmental Research, 112, 129-138.

https://www.sciencedirect.com/science/article/abs/pii/S0013935111002490?via\% 3Dihub

Marzouni, M. B., T. Alizadeh, M.R. Banafsheh, A.M. Khorshiddoust, M.G. Ghozikali, S. Akbaripoor, G. Goudarzi, 2016: A comparison of health impacts assessment for PM 10 during two successive years in the ambient air of Kermanshah, I ran. Atmospheric Pollution Research, 7(5), 768-774.

https://www.sciencedirect.com/science/article/pii/S1309104215301252?via\%3Dihub

Medina, S., A. Le Tertre, \& M. Saklad, 2009: The APHEIS project: Air Pollution and Health-A European Information System. Air Quality, Atmosphere \& Health, 2(4), 185-198. https://link.springer.com/article/10.1007/s11869-009-0050-2

Naddafi, K., M.S. Hassanvand, M. Yunesian, F. Momeniha, R. Nabizadeh, S. Faridi, \& A. Gholampour, 2012: Health impact assessment of air pollution in megacity of Tehran, Iran. Iranian J ournal of Environmental Health Science \& Engineering, 9(1), 28. https://pubmed.ncbi.nlm.nih.gov/23369114/

Ostro, B., 2004: Outdoor air pollution: Assessing the environmental burden of disease at national and local levels. (WHO Enviro). Geneva: World Health Organization.

Prüss-Üstün, A., 2003: Introduction and methods: assessing the environmental burden of disease at national and local levels. (A. Prüss-Üstun, Ed.) (Environment). Geneva: World Health Organization.

Tomaino, L., J. Pinilla, S. Rodríguez-Mireles, B.G. López-Valcárcel, P. Barber-Pérez, A. Sierra, C. La Vecchia, 2020: Impact of sandstorm and Carnival celebrations on SARS-CoV-2 spreading in Tenerife and Gran Canaria (Canary Islands, Spain). Gaceta Sanitaria, (In press). https://www.sciencedirect.com/science/article/pii/S0213911120302119?via\% 3Dihub

World Health Organization, 2013: Health risks of air pollution in Europe - HRAPIE project. World Health Organization. https://pubs.acs.org/doi/10.1021/acs. est.5b05833. 


\subsection{I mpact on visibility and aeronautics/ airport activity}

D. Suárez, E. Cuevas, N. Prats and S. Basart

\subsubsection{I ntroduction}

Reduced visibility is one of the main impacts of severe dust intrusions, which in turn affects road and air transport (see Section 1.3). Route changes and disruptions in airport operations (delays and flight cancellations) are some of the consequences of reduced visibility due to high concentrations of suspended mineral dust (e.g. Al-Hemoud et al., 2017; ICAO, 2016; Weinzierl et al., 2012). The dust outbreak from 22 to 24 February 2020 caused unprecedented air traffic disruption in the Canary Islands, leading to airspace closure for a few hours. This section describes the reduction of visibility at Canary airports during this intense dust episode and estimates the economic cost of the cancelled flights.

\subsubsection{Reduction of visibility at airports in the Canary I slands during the 22- 24 February 2020 dust outbreak}

The locations of the Canary Islands airports are given in Table 8.3.1 and shown in Figure 8.3.1. The minimum visibility reported in the METAR (Aerodrome routine meteorological report) for each of the eight Canary I slands airports during the 22-24 February 2020 dust event is shown in Figure 8.3.1. The minimum visibility recorded ranged from $400 \mathrm{~m}$ at Gran Canaria Airport (GCLP) to $1000 \mathrm{~m}$ registered at El Hierro Airport (GCHI).

Table 8.3.1. Location of Canary I slands airports and airport code

\begin{tabular}{|c|c|c|c|c|}
\hline Airport & Airport code & Latitude & Longitude & $\begin{array}{c}\text { Altitude } \\
\text { (m a.s.I.) }\end{array}$ \\
\hline (1) Lanzarote & GCRR & $28.952^{\circ} \mathrm{N}$ & $13.600 \mathrm{oW}$ & 14 \\
\hline (2) Fuerteventura & GCFV & $28.445^{\circ} \mathrm{N}$ & $13.8630 \mathrm{~W}$ & 25 \\
\hline (3) Gran Canaria & GCLP & $27.918 \cong \mathrm{N}$ & $15.395 \circ \mathrm{W}$ & 32 \\
\hline (4) Tenerife North & GCXO & $28.4780 \mathrm{~N}$ & $16.3290 \mathrm{~W}$ & 632 \\
\hline (5) Tenerife South & GCTS & $28.0470 \mathrm{~N}$ & $16.561^{\circ} \mathrm{W}$ & 64 \\
\hline (6) La Gomera & GCGM & $28.030^{\circ} \mathrm{N}$ & $17.215^{\circ} \mathrm{W}$ & 219 \\
\hline (7) La Palma & GCLA & $28.633 \mathrm{~N}$ & 17.755 oW & 33 \\
\hline (8) El Hierro & $\mathrm{GCHI}$ & $28.819 \circ \mathrm{N}$ & $17.889 \circ \mathrm{W}$ & 32 \\
\hline
\end{tabular}




\section{0}

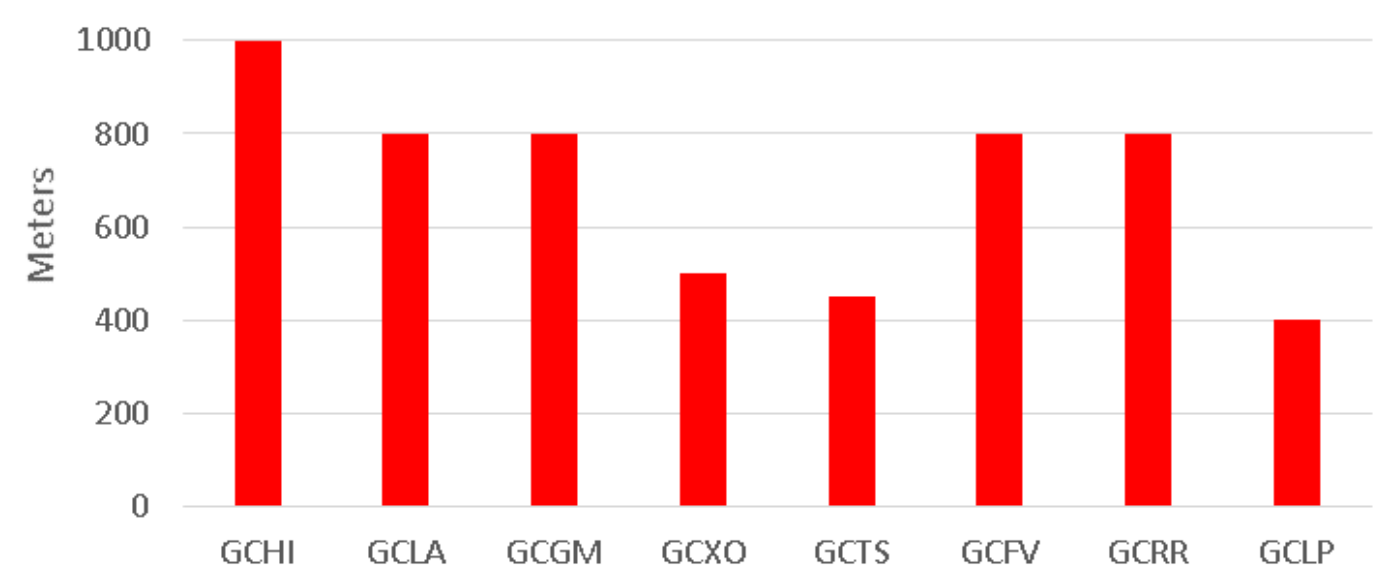

Figure 8.3.1. Minimum horizontal visibility reported at the Canary Islands airports during the 22- 24 February 2020 dust outbreak

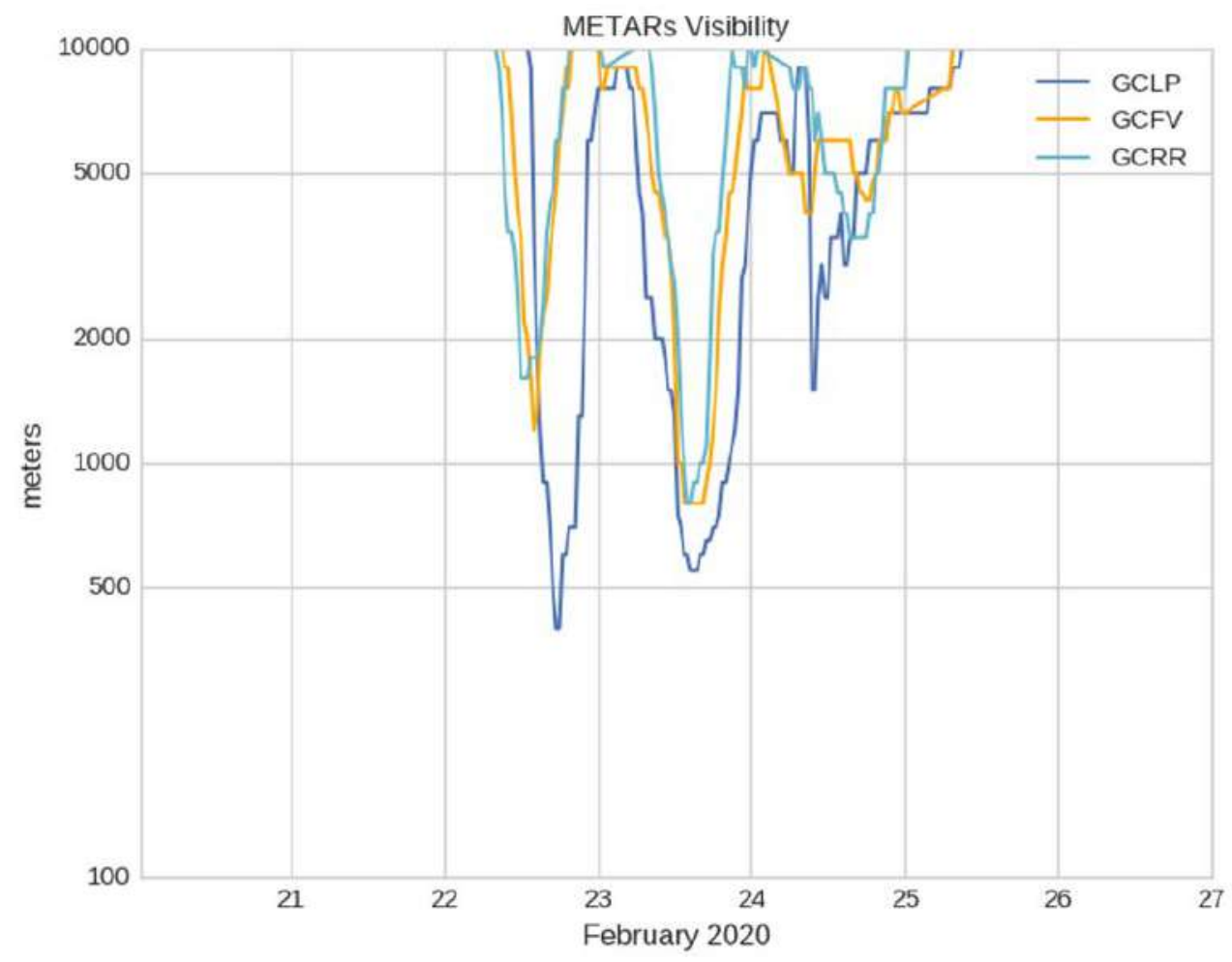

Figure 8.3.2. Horizontal visibility recorded by the airports of the eastern Canary I slands: Gran Canaria (GCLP), Fuerteventura (GCFV) and Lanzarote (GCRR), during the 22- 24 February 2020 dust outbreak 


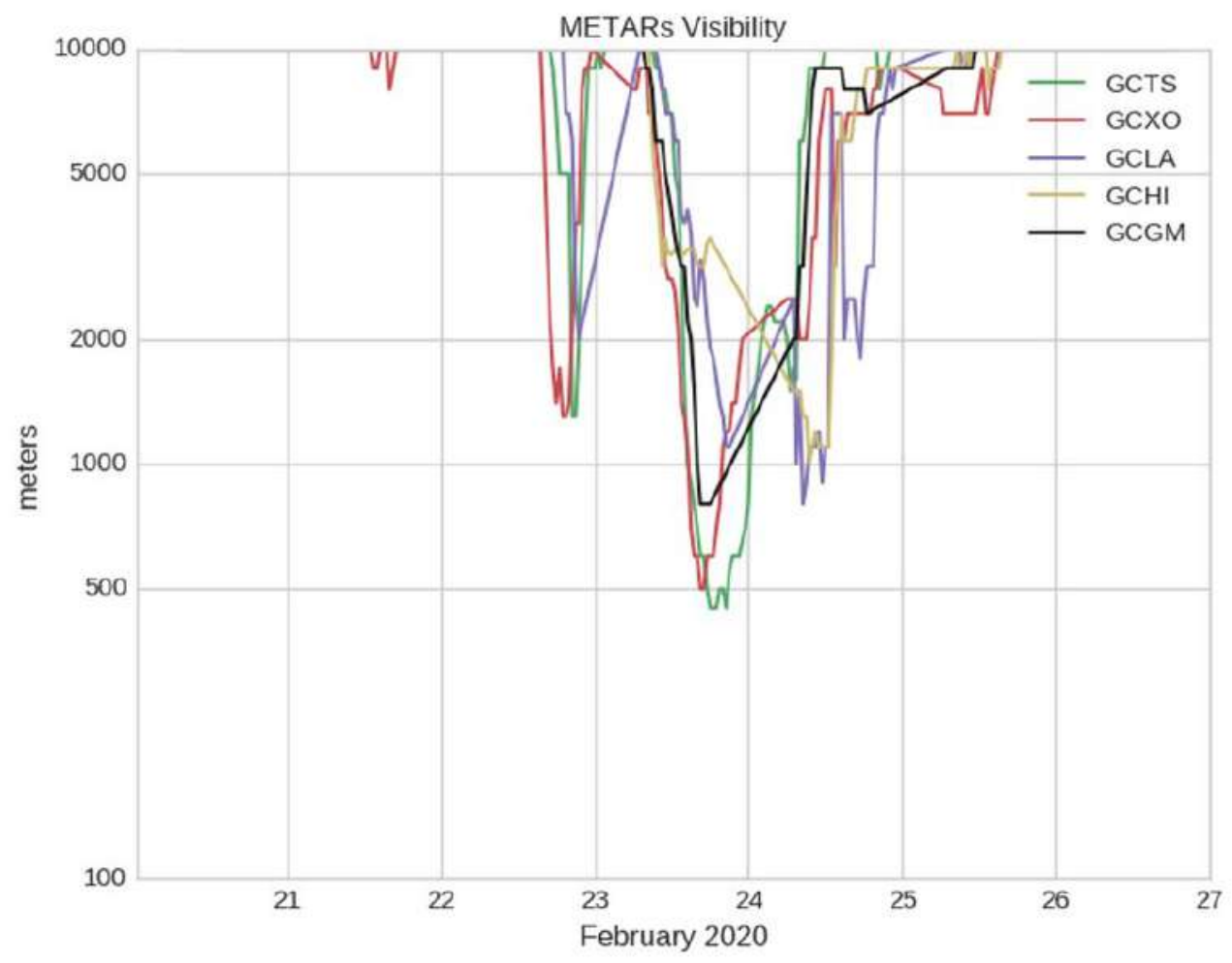

Figure 8.3.3. Horizontal visibility recorded by the airports of the western Canary Islands: Tenerife South (GCTS), Tenerife North (GCXO), La Palma (GCLA), El Hierro (GCHI) and La Gomera (GCGM), during the 22- 24 February 2020 dust outbreak

The temporary evolution of visibility for the eight Canary airports is shown in Figure 8.3.2 (eastern islands) and Figure 8.3.3 (western islands). Note that the $Y$ axis of these figures is on a logarithmic scale.

The visibility data demonstrate how the dust outbreak first affected (during 22 February 2020) the visibility of the easternmost airports (Lanzarote and Fuerteventura) followed by Gran Canaria (GCLP), Tenerife North (GCXO) and Tenerife South (GCTS). During 23 February 2020 the visibility of all airports was greatly affected. This sequence of events is also well captured by the satellite images (Figure 8.3.4) which show the dust outbreak affecting the easternmost islands first, before affecting all the islands on 23 February 2020. 
(a)

(b)

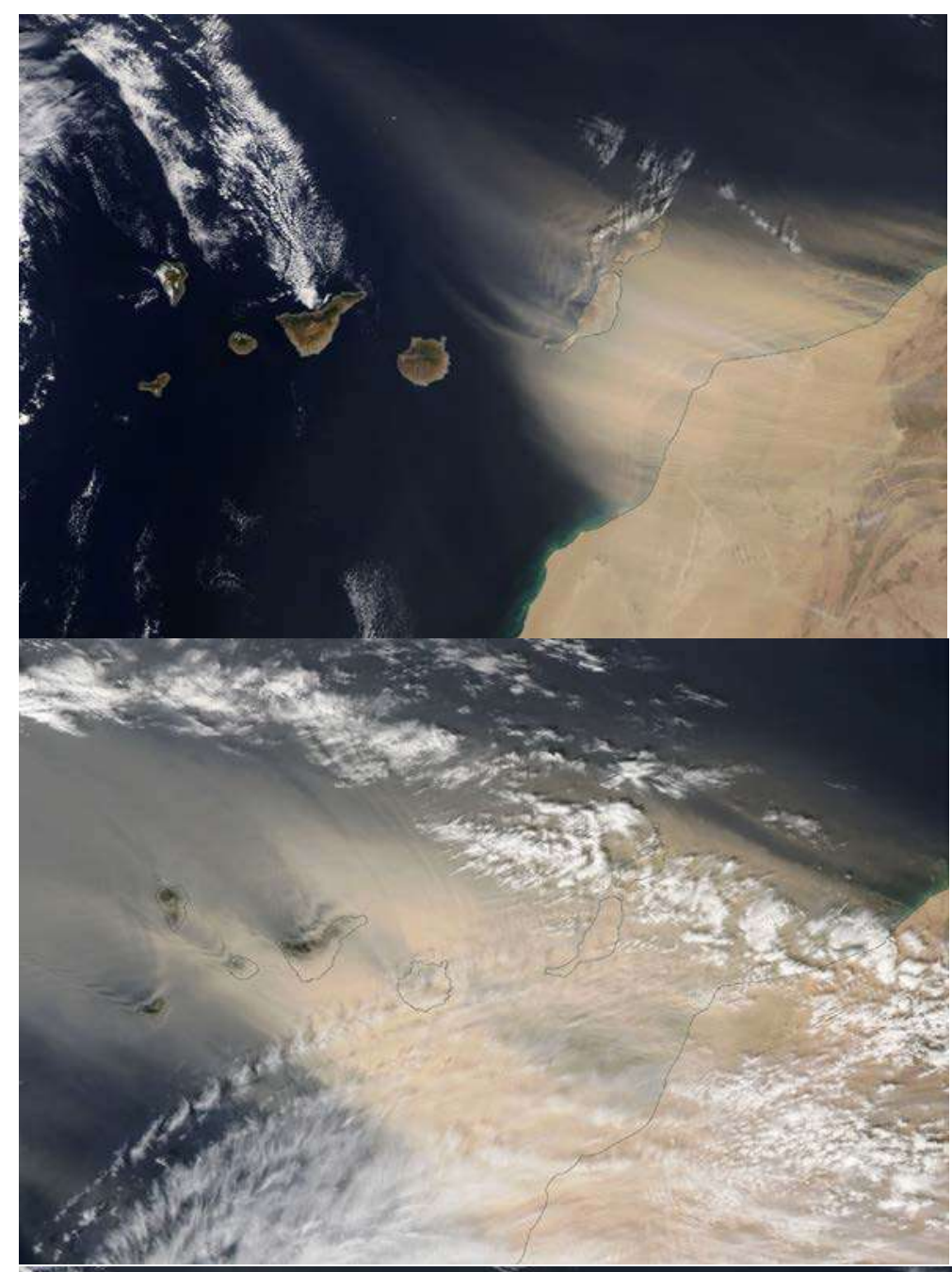

(c)

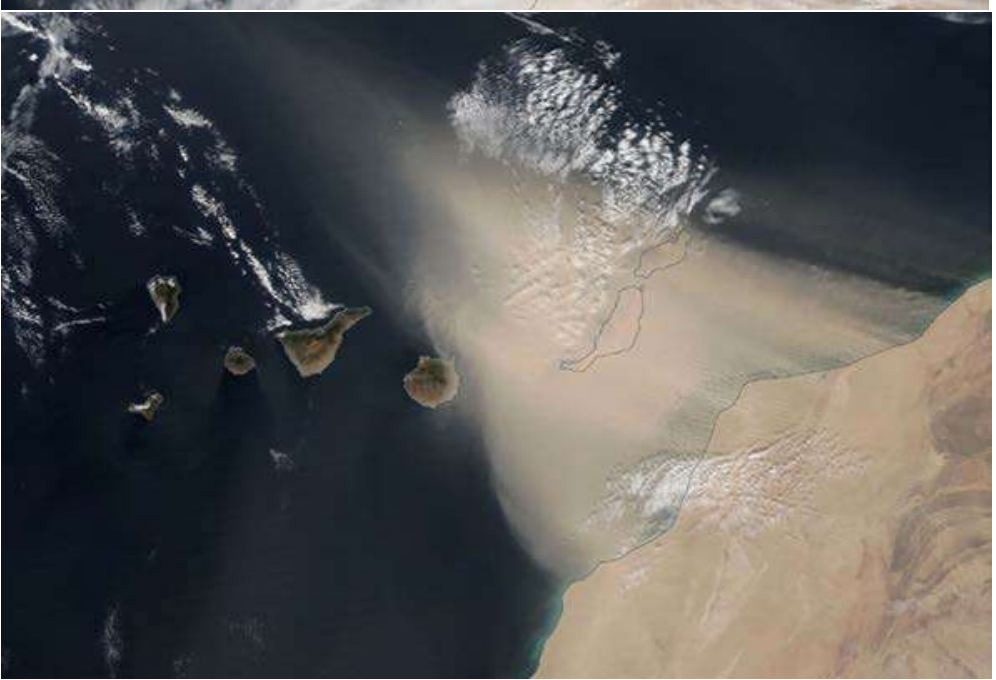

Figure 8.3.4 I mages obtained by (a) MODI S sensor aboard the Terra satellite on 22 February ( 11:50 UTC), (b) VIIRS sensor aboard the Suomi polar satellite on 22 February ( 14:10 UTC) and (c) MODIS sensor aboard the Aqua satellite on 23 February 2020 ( 14:05 UTC). We acknowledge the use of imagery provided by services from NASA's GI BS, part of NASA's EOSDIS. 
Minimum visibility during the 22-24 February 2020 dust outbreak was observed at different times for each airport. It is striking that at Gran Canaria Airport (GCLP) the minimum visibility during the dust outbreak occurred on 22 February 2020 at 1730 UTC. For all other airports, the minimum visibility was observed on 23 February between 1300 and 2030 UTC, except for the westernmost islands (La Palma and El Hierro), where the minimum visibility was recorded during the morning of 24 February. The data also highlight the persistence of the minimum visibility for Tenerife South airport (GCTS), which recorded two and a half hours with visibility below $500 \mathrm{~m}$ on 23 February (Figure 8.3.3). On 24 February and 25 February 2020, the westernmost islands (mainly La Palma on 24 February and Tenerife North airport on the 25 February) were the most affected, albeit in lower intensity than the previous days, following the recirculation of the dust plume.
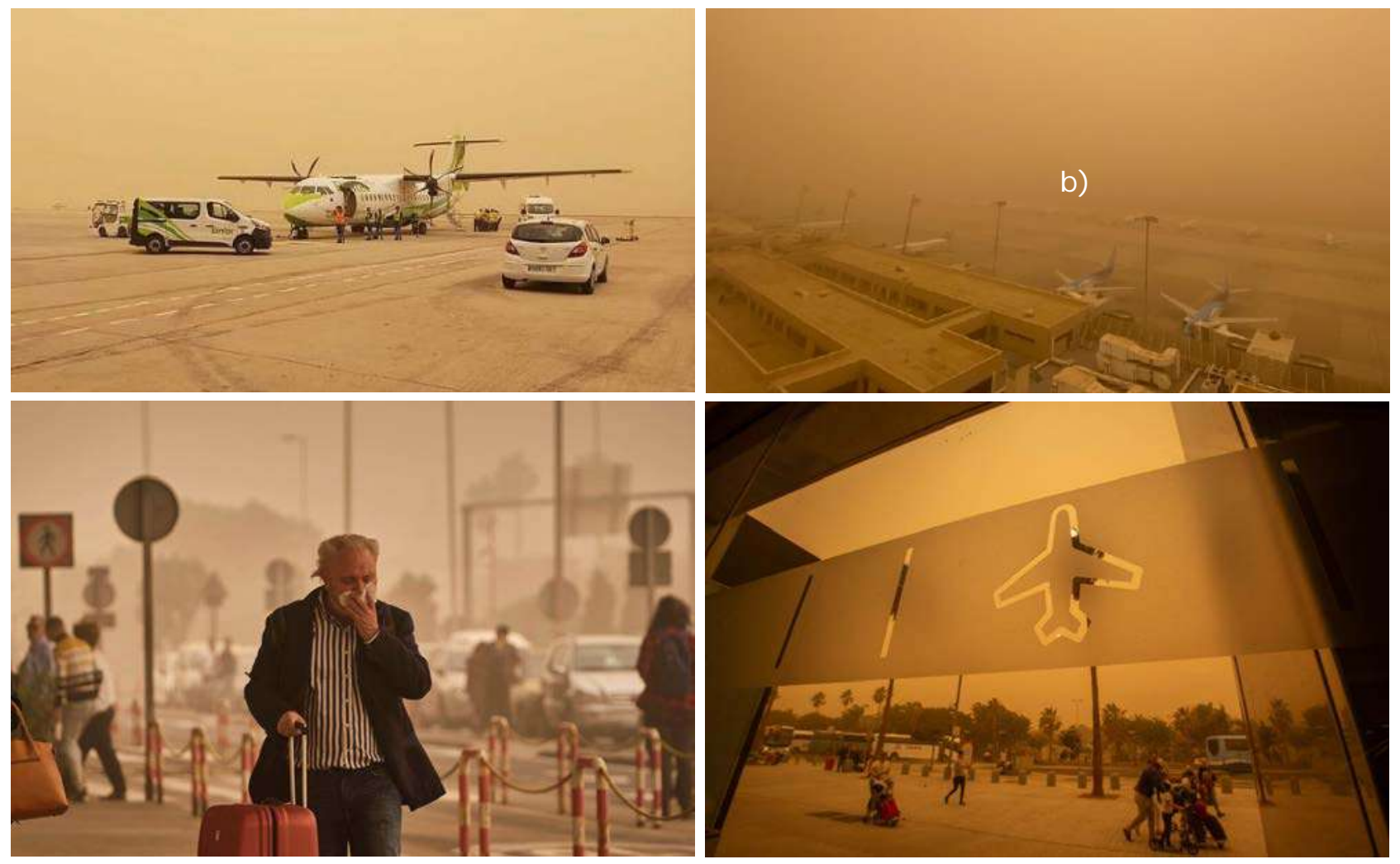

Figure 8.3.5. I mages related to flight cancellations in the Canary I slands during the 22- 24 February 2020 dust outbreak

\subsubsection{I mpact on the operations at airports in the Canary I slands during the 22- 24 February 2020 dust outbreak}

During 22- 24 February 2020, the Canary Islands airports experienced air traffic restrictions and the temporary closure of the airspace. According to data from the Spanish airport and air navigation authority (AENA), between 22 and 23 February 2020, 1000 flights and about 120.000 passengers in the archipelago were affected. Sunday 23 February 2020 experienced the greatest impact with 745 cancellations and 84 diverted flights. There was also, to a lesser extent, an impact on subsequent days, until the relocation of the affected passengers was completed.

It has not been possible for major airlines operating in the Canary archipelago, both regionally, nationally and internationally, to provide us with figures on the economic impact caused by cancellation, delay or flight diversion. However, we can make an approximate estimate taking into account the report of the European Organization for the Safety of Air Navigation (EUROCONTROL, 2018) which states that the average cost of cancellation per flight is 17.650 EUR. Therefore, the total cost for cancelled flights alone during the 22-24 February 2020 dust outbreak would have been approximately 17,650,000 EUR. We should add to this the costs 
of delayed flights (average delay cost is suggested as 100 EUR per minute delay), and rerouting costs, which is the cost of the diversion of a flight to an airport other than the one initially planned. The average of rerouting costs is 830 - 5900 EUR for regional flights and $1180-8900$ EUR for continental flights (EUROCONTROL, 2018).

\subsubsection{Conclusions}

The reduction in visibility at the Canary I slands airports, caused by the severe outbreak of dust from the Sahara from 22-24 February 2020, has been a milestone in air transport in the Canary Islands. The minimum visibility recorded at airports ranged between $400 \mathrm{~m}$ at Gran Canaria Airport and $1000 \mathrm{~m}$ at El Hierro Airport. For the first time in its history, the eight Canary I slands airports and the airspace of the archipelago were closed on 23 February 2020 for a few hours. This resulted in the cancellation of 1000 flights throughout the Canary archipelago, which is estimated to have cost $\sim 17,650,000$ EUR, as a minimum estimate, in addition to the enormous disruption for the hundreds of thousands of passengers who were trapped on the islands for at least one or two days.

\subsubsection{References}

Al-Hemoud, A., M. Al-Sudairawi, S. Neelamanai, A. Naseeb, and W. Behbehani, 2017: Socioeconomic effect of dust storms in Kuwait. Arab. J. Geosci., 10, 18, https://link.springer.com/article/10.1007/s12517-016-2816-9.

EUROCONTROL, Standard Inputs for EUROCONTROL Cost-Benefit Analyses, Edition number 8 , EUROCONTROL Headquarters, 96 Rue de la Fusée, B-1130 BRUSSELS, publications@eurocontrol.int February 2018; available at https://www.eurocontrol.int/sites/default/files/publication/files/standard-input-foreurocontrol-cost-benefit-analyses-2018-edition-8-version-2.6.pdf.

ICAO: Doc 013 European Guidance Material On All Weather Aerodrome Operations, 5th Edition, 2016

Weinzierl, B., D. Sauer, A. Minikin, O. Reitebuch, F. Dahlkötter, B. Mayer, C. Emde, I. Tegen, J. Gasteiger, A. Petzold, A. Veira, U. Kueppers, U. Schumann, 2012: On the visibility of airborne volcanic ash and mineral dust from the pilot's perspective in flight. J. Phys. Chem. Earth, 45-46, 87-102, https://www.sciencedirect.com/science/article/pii/S1474706512000496?via\% 3Dihub. 


\subsection{I mpact on photovoltaic energy production}

O. González, R.D. García and E. Cuevas

\subsubsection{I ntroduction}

The growing popularity of renewable energy in recent decades has gained momentum due to the decline in availability of fossil fuels and the need to reduce greenhouse gas emissions to mitigate global warming. In this context, the photovoltaic (PV) industry has grown continuously at a rapid pace. However, certain environmental factors can reduce the energy production efficiency of PV systems. One of these, which is of great importance in large arid and semi-arid regions of the Earth, is mineral dust. This is related to the attenuation of radiation from the sun by suspended mineral dust particles (Kosmopoulos et al., 2017 and references therein), and to the deposition of dust on the photovoltaic modules reducing their performance (e.g. Gholami et al., 2018; Hao et al., 2018; Kaldellis and Kapsali, 2011; Sulaiman et al., 2011). In arid areas where water is a scarce commodity, the effect on the yield of PV plants due to dust deposition can last for months until the next rainfall cleans the surfaces of the PV modules (e.g. Javed et al., 2017; Fountoukis et al., 2018). This section describes and quantifies the effects of the 22-24 February 2020 dust outbreak on the generation of electricity in PV plants on the island of Tenerife, managed by Instituto Tecnológico y de Energías Renovables (ITER).

\subsubsection{Observations}

As we saw in Section 5.3, global solar radiation decreased significantly due to the high concentration of atmospheric dust at the Santa Cruz de Tenerife station, causing an increase in negative radiative forcing as the concentration of dust in the atmosphere increased. In particular, daily radiative forcing increased in absolute value by $41 \%$ between 22 and 23 February (-17.48 $\mathrm{W} \mathrm{m}^{-2}$ on 22 February to $-42.72 \mathrm{~W} \mathrm{~m}^{-2}$ on 23 February) (see Table 5.1).

This decrease in radiation was also observed by ITER with the daily measured values of global solar radiation and the energy production of its photovoltaic plants during the study period. These plants are located in the south of the island of Tenerife, in the industrial estate of Granadilla at sea level (Figure 8.4.1) about $50 \mathrm{~km}$ in the SW direction from the Santa Cruz de Tenerife station.

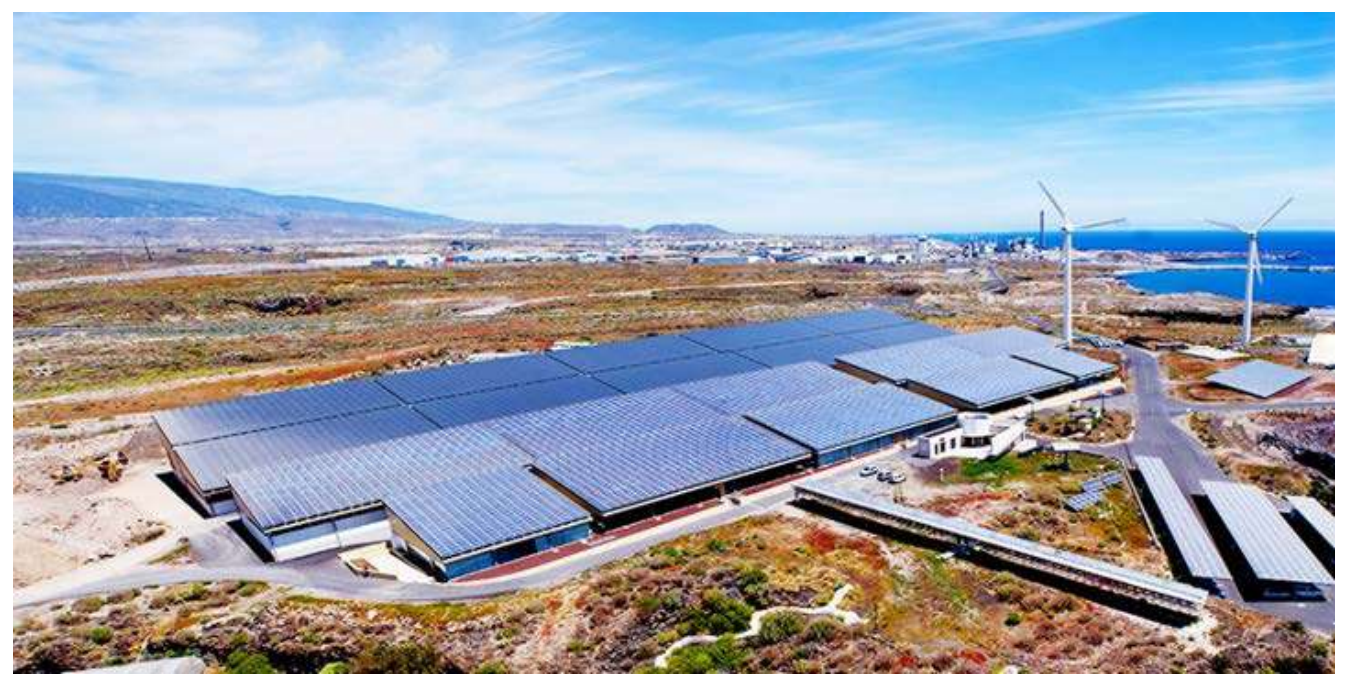

Figure 8.4.1. Photovoltaic plant located in the Institute of Technology and Renewable Energies (ITER) in the south of Tenerife 
Figure 8.4 .2 shows the daily solar energy (in $\mathrm{MJ} \mathrm{m}^{-2}=0.28 \mathrm{~kW} \mathrm{~m}^{-2}$ ) measured with a broadband pyranometer, the energy generation of three lines of the photovoltaic plant (lines 1 , 2 and 3) and the AOD for the period 20-26 February 2020. We can see the significant decrease in both solar energy and energy production by the different lines of the photovoltaic plant.

In the days before the episode (20-21 February 2020) the solar energy measured was around $20 \mathrm{MJ} \mathrm{m}^{-2}$, although here we must take into account that on 21 February, when solar energy decreased to about $16 \mathrm{MJ} \mathrm{m}^{-2}$, it was affected by the presence of clouds. As the dust-laden Saharan air mass reached the Canary Islands in the afternoon of 22 February, solar energy

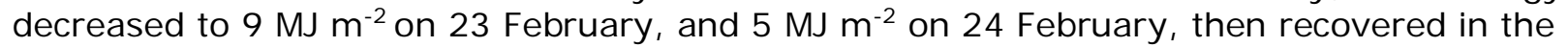
following days as the dust episode weakened. In fact, there is a strong anticorrelation $\left(R^{2}=\right.$ -0.78) between solar energy and the energy production of the photovoltaic plant with AOD.

The solar energy measured with a pyranometer is higher than the energy produced by photovoltaic plants, this can be seen in Figure 8.4.2 on 21, 22 and 25 February. This is because there are several factors that affect the operation of photovoltaic plants, such as the temperature, dirt on the photovoltaic modules and the decrease in performance of photovoltaic plants over their lifetime. The ITER photovoltaic plants in 2020 have had more than 12 years of operation and the decrease in their performance is currently estimated at approximately $5 \%$. The energy performance of the installation is called "Performance Ratio" (PR), defined as the efficiency of the installation under real working conditions. The analysis of this parameter tells us that, throughout the first quarter of 2020 , the installation performance ratio was in a range of $85 \%$ to $90 \%$. On 23 and 24 February, coinciding with the days of higher dust concentration in the atmosphere $(A O D>1)$ the observed and produced solar energy decreased greatly, and on these days, they were practically equal.

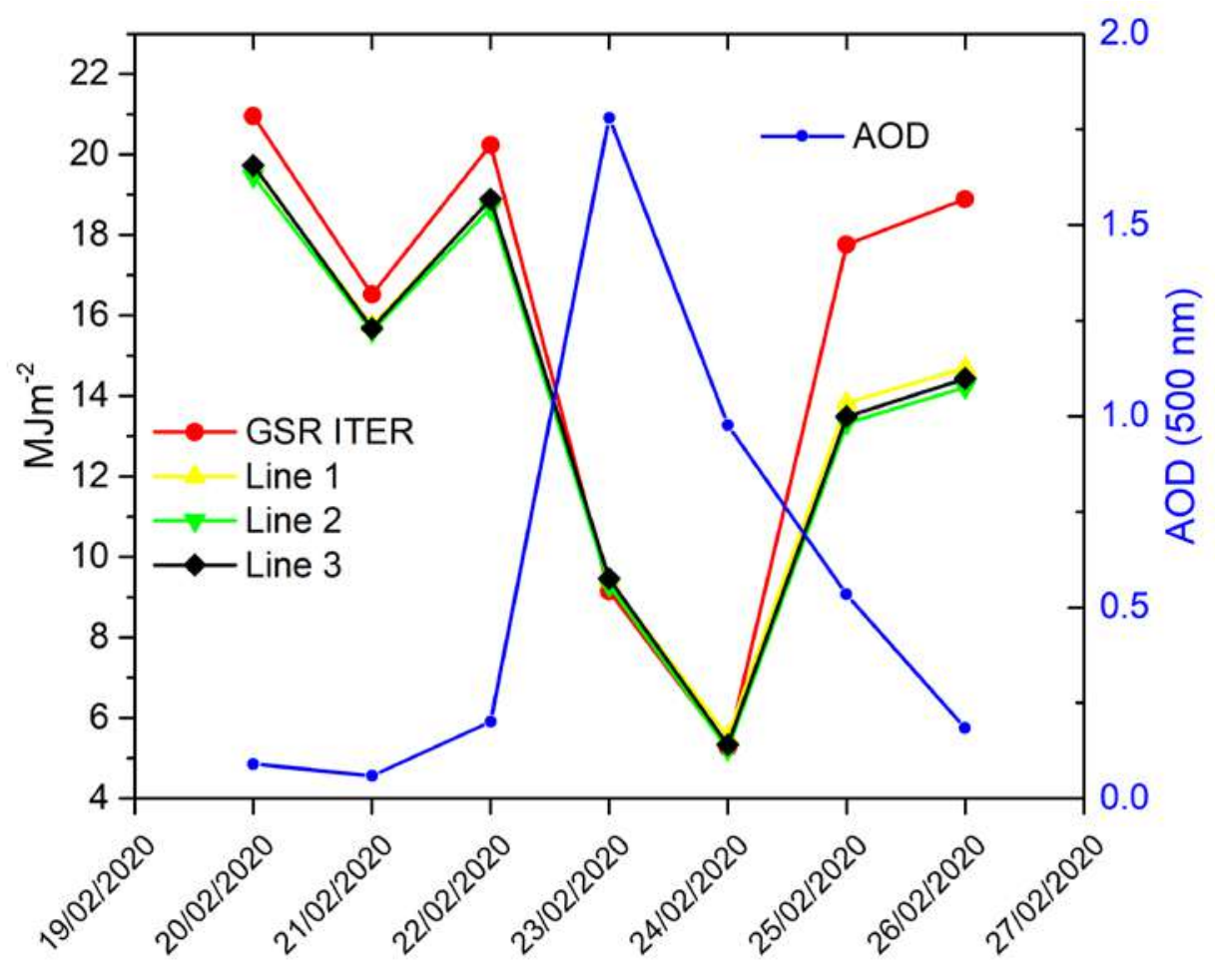

Figure 8.4.2. Values of daily solar energy measured with a pyranometer (red line) and daily energy production of the different lines of the photovoltaic plant installed at ITER in Tenerife in the period 20-26 February 2020. The right-hand axis represents the daily average value of AOD measured at the Santa Cruz de Tenerife station (blue line). 
Taking as a reference the 20 February, which was not affected by clouds or the presence of dust, and in which solar energy of $\approx 21 \mathrm{MJ} \mathrm{m}^{-2}$ was recorded, we observe that energy production on 23 February decreased by $52 \%$, while on 24 February decreased it by $72 \%$ (Figure 8.4.3). In the following days, when the dust concentration gradually decreased, energy production began to recover, but without reaching levels prior to 20 February due to the significant presence of dust deposited on the photovoltaic modules. It is noteworthy that before the start of the dust event, both the measured solar energy and the energy produced have very close values, with differences of $<1 \mathrm{MJ} \mathrm{m}^{-2}(\sim 4 \%)$. This difference increases to $>4 \mathrm{MJ} \mathrm{m}^{-2}(\sim 25 \%)$ after the episode. This is due to the presence of dust deposited on the photovoltaic modules. Although no dust deposition observations were available during this period, the MONARCH model of the BDFC has estimated the total accumulated dry deposition of the dust episode as $240 \mathrm{mg} \mathrm{m}^{-2}$ in Tenerife and $650 \mathrm{mg} \mathrm{m}^{-2}$ in Gran Canaria (see Section 7.3.5 for more details).

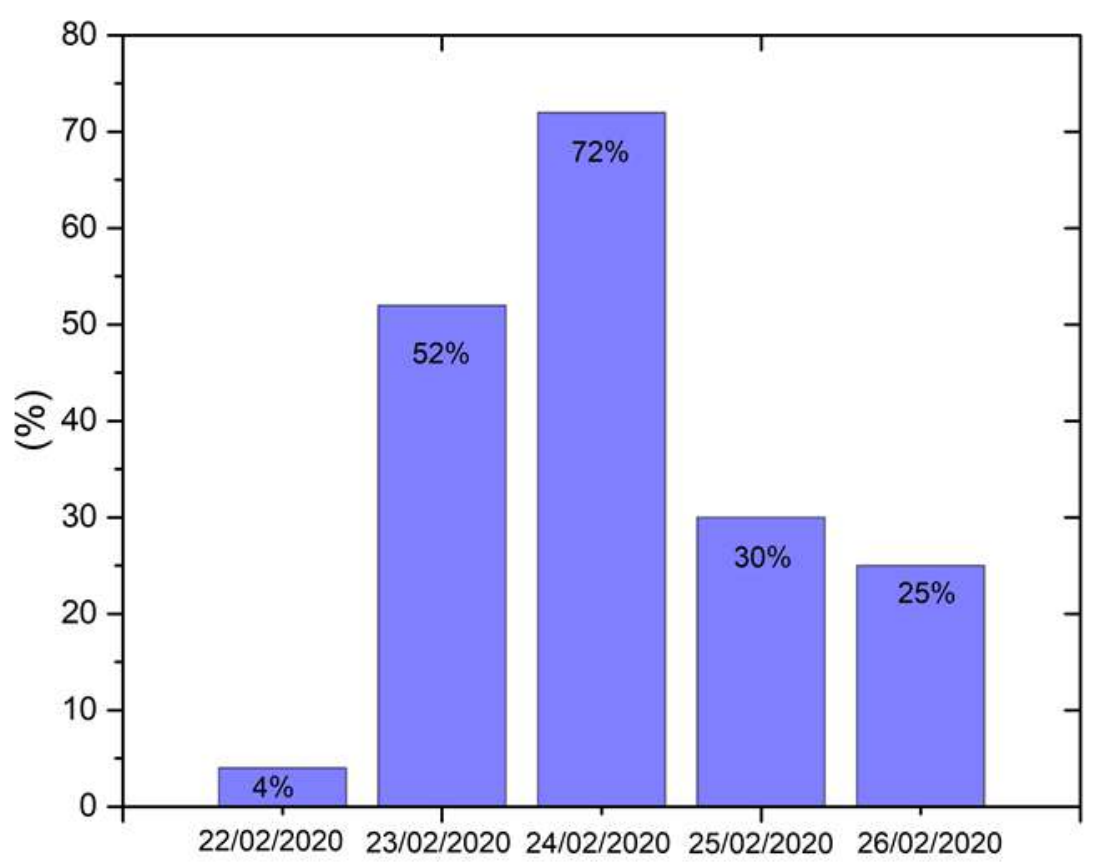

Figure 8.4.3. Decrease in energy production (in \% ) in Line one of the photovoltaic plant installed in I TER compared to the energy production generated on 20 February 2020

The accumulation of dust on the surface of the photovoltaic modules results in a lower performance and daily energy losses due to the decrease in the transmittance of the glass cover and an increase in the temperature of this cover, significantly reducing the PR. In long periods without precipitation, daily energy losses may exceed $20 \%$ (Hussain et al., 2017). Our results indicate that the deposition of a large amount of dust was the determining factor for the decrease in the yield of $\sim 25 \%$ of the ITER solar plant after the event. This decrease in yield continued for almost one month (data not shown here), until the photovoltaic modules were cleaned with the precipitation of 22 and 23 March (Figure 8.4.4).

The three lines of the ITER photovoltaic installation (Lines 1,2 and 3) add up to a total of $20 \mathrm{MW}$ of power and the total loss of energy production during the period 23 February23 March 2020 was $400 \mathrm{MWh}$. Considering that the photovoltaic power currently installed in the Canary I slands amounts to $\sim 200 \mathrm{MW}$, we estimate that the losses in power generation caused by this dust episode are in the order of $4000 \mathrm{MWh}$. To analyse the economic impact of these losses, we multiply by the cost of generating this electricity through fossil fuels in the Canary I slands electricity system, which is currently in a price range of 200 to 250 EUR $M W \mathrm{~h}^{-1}$. Consequently, the economic impact for this reduction in photovoltaic production is estimated as one million euros. 


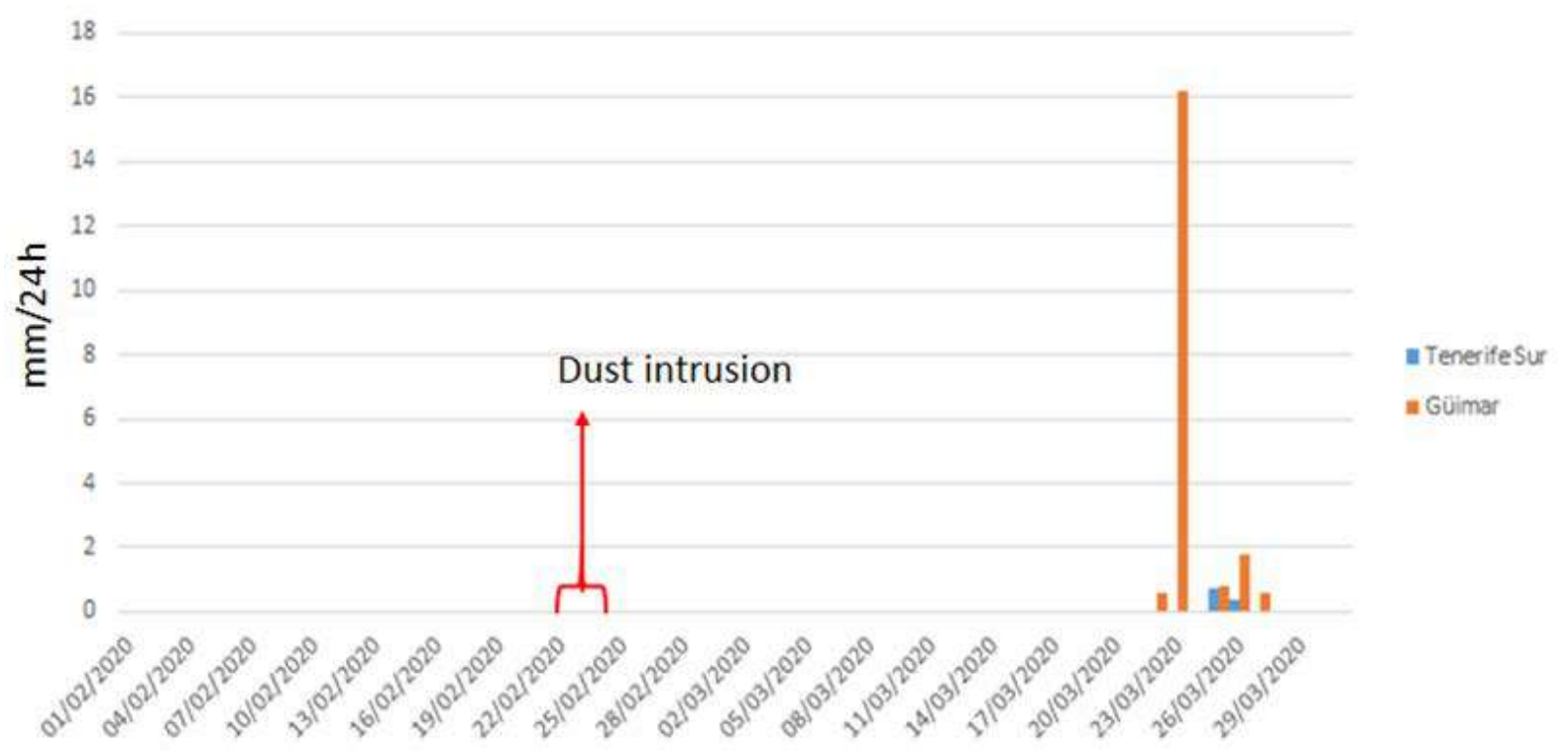

Figure 8.4.4. Daily ( $24 \mathrm{~h}$ ) accumulated precipitation ( $\mathrm{mm}$ ) in the period February-March 2020

\subsubsection{Conclusion}

As a result of the intense dust event of 22-24 February 2020, photovoltaic energy production fell by $52 \%$ on 23 February and $72 \%$ on 24 February compared to normal production. However, this was not the only impact of dust intrusion. Due to the intense dust deposition in the photovoltaic modules, the performance of the installation decreased from $96 \%$ under predust intrusion conditions, to $75 \%$ after the dust intrusion. This situation continued for almost a month until precipitation cleaned the modules. The losses that this dust event, and its subsequent consequences, caused in the Canary I slands energy system are estimated at one million euros.

\subsubsection{References}

Fountoukis, C., B. Figgis, L. Ackermann, M.A. Ayoub, 2018: Effects of atmospheric dust deposition on solar PV energy production in a desert environment. Sol. Energy, 164, 94-100.

Gholami, A., I. Khazaee, S. Eslami, M. Zandi, E. Akrami, 2018: Experimental investigation of dust deposition effects on photovoltaic output performance. Sol. Energy, 159, 346-352.

Hao, L.; Z. Wenjun, 2018: Effects of particle sizes and tilt angles on dust deposition characteristics of a ground-mounted solar photovoltaic system. Appl. Energy, 220, 514-526.

Hussain, A., A. Batra and R. Pachauri, 2017: An experimental study on effect of dust on power loss in solar photovoltaic module, Renewables 4, 9, https://doi.org/10.1186/s40807-017-0043-y

Javed, W., Y. Wubulikasimu, B. Figgis, B. Guo, 2017: Characterization of dust accumulated on photovoltaic panels in Doha, Qatar. Sol. Energy, 142, 123-135.

Kaldellis, J., M. Kapsali, 2011: Simulating the dust effect on the energy performance of photovoltaic generators based on experimental measurements. Energy, 36, 5154-5161.

Kosmopoulos, P. G., S. Kazadzis, M. Taylor, E. Athanasopoulou, O. Speyer, P.I. Raptis, E. Marinou, E. Proestakis, S. Solomos, E. Gerasopoulos, V. Amiridis, A. Bais, and C. Kontoes, 2017: Dust impact on surface solar irradiance assessed with model simulations, satellite observations and ground-based measurements, Atmos. Meas. Tech., 10, 2435-2453, https://amt. copernicus.org/articles/10/2435/2017/.

Sulaiman, S.A., H.H. Hussain, N. Leh, M.S. Razali, 2011: Effects of dust on the performance of PV panels. World Acad. Sci. Eng. Technol., 58, 588-593. 


\subsection{Ecological impact: I mpact on aerobiology}

J. Bel monte and R. Puigdemunt

\subsubsection{Introduction}

The Aerobiology programme at the IARC, carried out jointly by IARC-AEMET and the Laboratori d'Anàlisis Palinològiques (LAP) of the Universitat Autònoma de Barcelona (UAB) through the Eolo-PAT project, has been in operation since 2004. The aim of the programme is to analyse the daily pollen and fungal spores' diversity and concentration in the air of Santa Cruz de Tenerife and its relation with the meteorological conditions and the prevalence of respiratory allergy. The aim of the present section is to analyse the aerobiology of the 22-24 February 2020 dust intrusion.

\subsubsection{Material and methods}

The sampling instrument is a 7-day recorder VPPS 2000 spore trap (Lanzoni S.r.I.) installed at SCO in Santa Cruz de Tenerife (Figure 8.5.1).

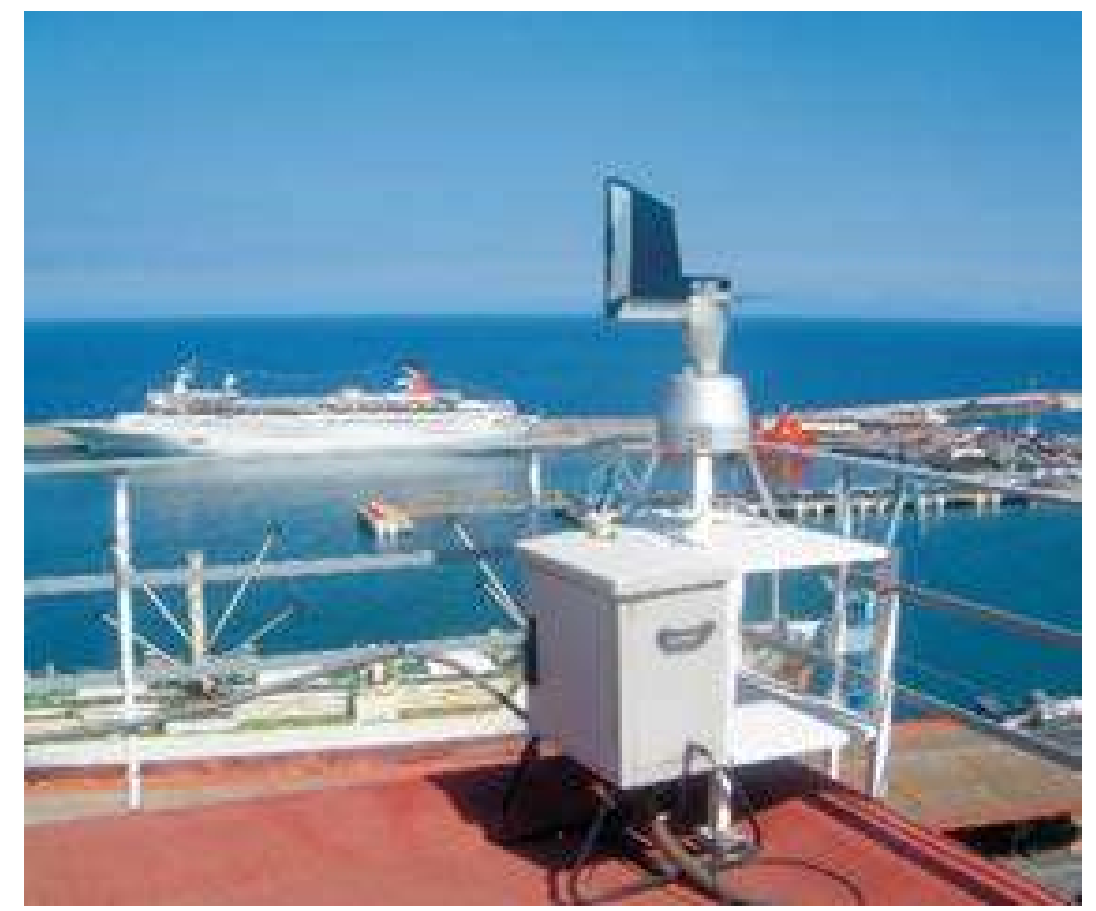

Figure 8.5.1. Hirst, 7-day recorder VPPS 2000 spore trap at SCO, Santa Cruz de Tenerife

This trap is based on Hirst (1952). It makes a sequential and non-interrupted sampling, aspiring air by means of a vacuum pump at a rate of $101 \mathrm{~min}^{-1}\left(14.4 \mathrm{~m}^{3}\right.$ day $\left.^{-1}\right)$. The air enters into the collector through an aperture of $14 \times 2 \mathrm{~mm}^{2}$ and impacts on a $19 \mathrm{~mm}$ wide plastic surface coated with silicon oil and cyclohexane to retain the particles. The capturing surface is tightly deposited around a cylindrical piece called the drum which is placed on a clockwork mechanism that makes it rotate at a speed of $2 \mathrm{~mm} \mathrm{~h}^{-1}$. This causes the particles propelled against the receiving surface to be retained sequentially. The drum and the plastic tape have dimensions that allow sampling during a week. Once a week, the tape is recovered from the drum and cut into the pieces that correspond to one day (0-23 h, UTC). Each daily sample deposited on a slide is identified with the corresponding date, stained with basic fuchsine and fixed with a coverslip. Figure 8.5.2 shows the slides of the study period prepared for analysis at the light microscope. 


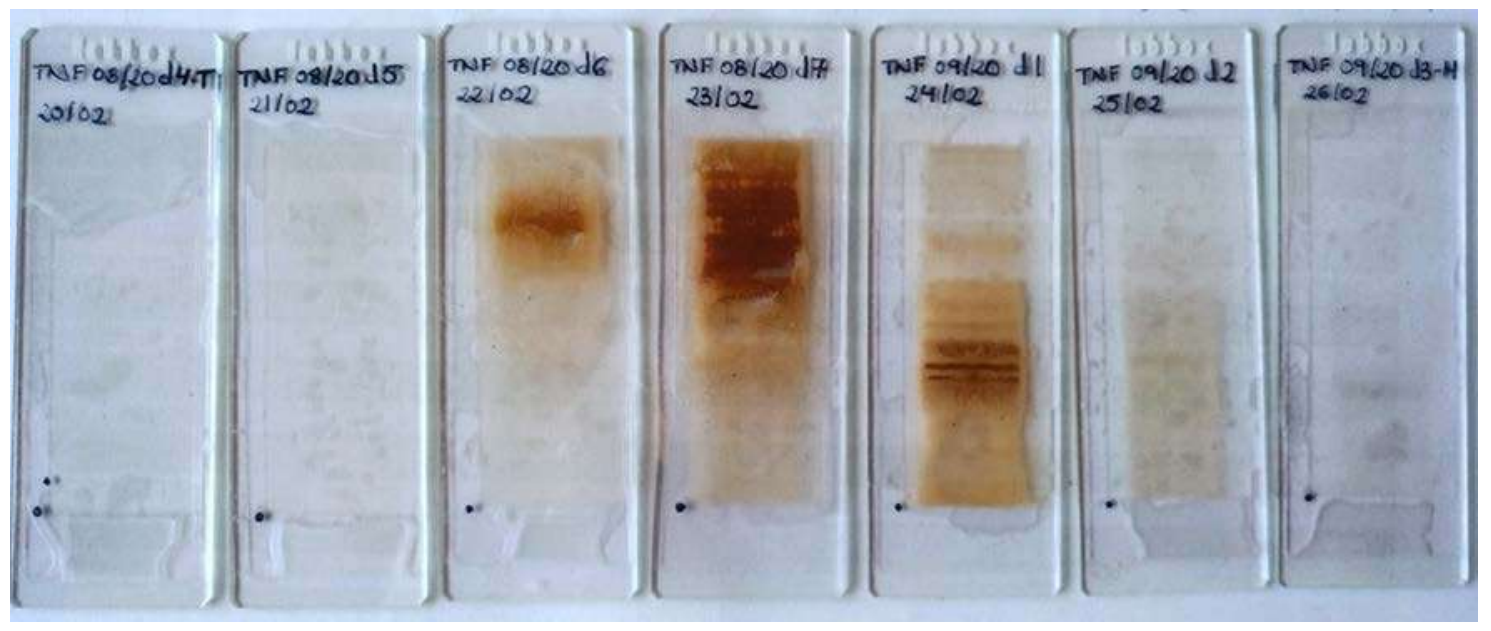

Figure 8.5.2. Aerobiological samples for the period 22-27 February 2020 ready for the analysis at the light microscope

The analysis of the slides is done by a palynologist, using a light microscope, $600 \times$ (Olympus $\mathrm{BH}-2$ ). The analysis is conducted using palynological methods to establish the biodiversity and quantity of pollen and fungal spores and following the recommendations of the Spanish Aerobiology Network management and quality manual (Galán et al., 2007) and the European Aerobiology Society (Galán et al., 2014), as well as the recommended terminology (Galán et al., 2017).

In the present work, samples have been analysed twice, firstly to obtain the mean daily pollen and fungal spores' spectra per day (expressed in $\mathrm{p} / \mathrm{m}^{3}$ day and $\mathrm{s} / \mathrm{m}^{3}$ day) and secondly to obtain the mean hourly pollen and spore spectra (expressed in $\mathrm{p} / \mathrm{m}^{3}$ hour and $\mathrm{s} / \mathrm{m}^{3}$ hour). Figure 8.5.3 shows images of the samples as seen through the light microscope.

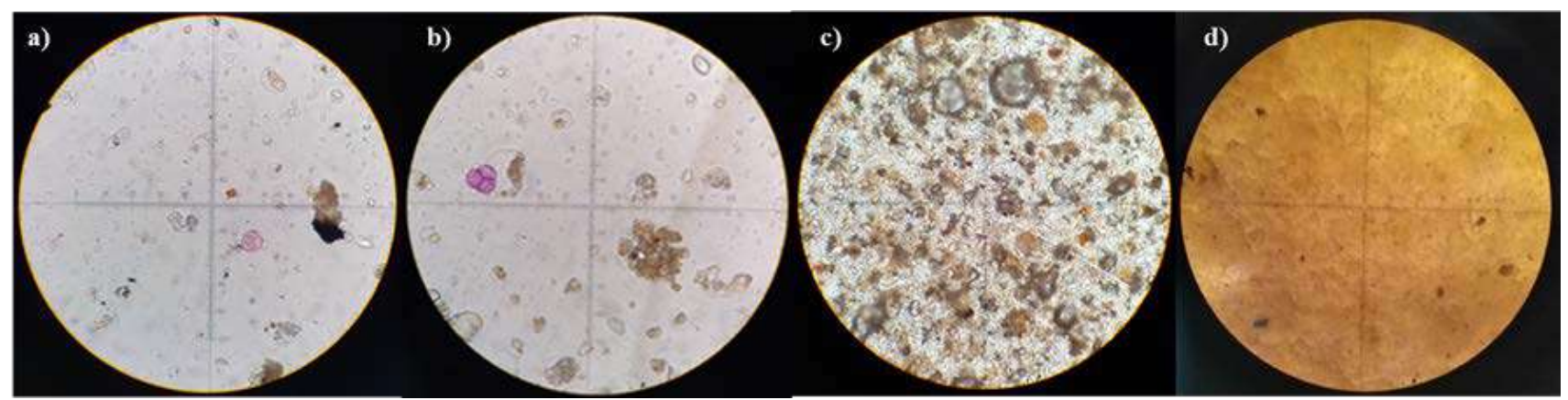

Figure 8.5.3. Microscopic view of the aerobiological slides. Samples shown correspond to: (a) and (b) TNF 8/20 d 4 (20/02/2020); c) TNF 8/20 d 6 (22/02/2020); d) TNF 8/ 20 d 7 (23/02/ 2020).

In some cases, when analysing the aerobiological samples, other organisms and materials aside from pollen and spores can be observed, for example, micro-arthropods, butterfly scales, algae, plant debris among others.

\subsubsection{Results}

Table 8.5.1 shows the mean daily pollen and spores' spectra for the period 20-26 February 2020 , expressed in concentrations. As seen in the table, the intrusions have provoked a drastic decrease of the airborne particles, mainly the pollen grains and notably in the case of Myrica, Ficus and Erica (characteristic of the Canarian vegetation). In addition, the fungal taxa Cladosporium, Ustilago and Agrocybe show decreased concentrations during the episode whereas Coprinaceae does not seem to be affected. 
Table 8.5.1. Mean daily pollen $\left(\mathrm{P} / \mathrm{m}^{3}\right)$ and fungal spores $\left(\mathrm{S} / \mathrm{m}^{3}\right)$ concentrations in the aerobiological station in Santa Cruz de Tenerife

Mean daily pollen $\left(\mathrm{P} / \mathrm{m}^{3}\right)$ and spores $\left(\mathrm{S} / \mathrm{m}^{3}\right)$ concentrations

\begin{tabular}{|c|c|c|c|c|c|c|c|}
\hline & $20 / 02 / 2020$ & $21 / 02 / 2020$ & $22 / 02 / 2020$ & $23 / 02 / 2020$ & $24 / 02 / 2020$ & $25 / 02 / 2020$ & $26 / 02 / 2020$ \\
\hline POLLEN from TREES & 16,8 & 4,2 & 0,0 & 0,0 & 0,0 & 0,0 & 0,7 \\
\hline Myrica & 2,8 & 2,1 & 0,0 & 0,0 & 0,0 & 0,0 & 0,7 \\
\hline CUPRESSACEAE & 0,0 & 1,4 & 0,0 & 0,0 & 0,0 & 0,0 & 0,0 \\
\hline Ficus & 13,3 & 0,0 & 0,0 & 0,0 & 0,0 & 0,0 & 0,0 \\
\hline Populus & 0,0 & 0,7 & 0,0 & 0,0 & 0,0 & 0,0 & 0,0 \\
\hline Schimus & 0,7 & 0,0 & 0,0 & 0,0 & 0,0 & 0,0 & 0,0 \\
\hline POLLEN from SHRUBS & 3,5 & 6,3 & 0,7 & 0,0 & 0,0 & 0,0 & 0,0 \\
\hline ERICACEAE & 3,5 & 6,3 & 0,7 & 0,0 & 0,0 & 0,0 & 0,0 \\
\hline POLLEN from HERBS & 0,7 & 0,0 & 0,7 & 0,7 & 0,7 & 2,8 & 2,8 \\
\hline Artemisia & 0,0 & 0,0 & 0,7 & 0,0 & 0,0 & 1,4 & 0,7 \\
\hline CYPERACEAE & 0,7 & 0,0 & 0,0 & 0,0 & 0,0 & 0,0 & 0,0 \\
\hline ASTERACEAE ECHINATED & 0,0 & 0,0 & 0,0 & 0,0 & 0,0 & 0,7 & 0,7 \\
\hline CHENOPODIACEAE/AMARANTHACEAE & 0,0 & 0,0 & 0,0 & 0,7 & 0,7 & 0,7 & 0,7 \\
\hline Rumex & 0,0 & 0,0 & 0,0 & 0,0 & 0,0 & 0,0 & 0,7 \\
\hline INDETERMINABLES & 1,4 & 0,7 & 0,0 & 0,0 & 0,0 & 0,0 & 0,7 \\
\hline TOTAL POLLEN & 22,4 & 11,2 & 1,4 & 0,7 & 0,7 & 2,8 & 4,2 \\
\hline FUNGAL SPORES & $20 / 02 / 2020$ & $21 / 02 / 2020$ & $22 / 02 / 2020$ & $23 / 02 / 2020$ & $24 / 02 / 2020$ & $25 / 02 / 2020$ & $26 / 02 / 2020$ \\
\hline Chaetominum & 0,0 & 0,0 & 2,8 & 0,0 & 0,0 & 0,0 & 2,8 \\
\hline Pleospora & 0,0 & 2,8 & 0,0 & 0,0 & 0,0 & 0,0 & 0,0 \\
\hline XYLARIACEAE & 0,0 & 0,0 & 0,0 & 0,0 & 2,8 & 0,0 & 0,0 \\
\hline Other ASCOSPORES 1-cel. & 2,8 & 0,0 & 0,0 & 0,0 & 0,0 & 0,0 & 8,4 \\
\hline Other ASCOSPORES 2-cel. & 11,2 & 5,6 & 11,2 & 8,4 & 5,6 & 2,8 & 8,4 \\
\hline Other ASCOSPORES n-cel. & 14,0 & 11,2 & 8,4 & 0,0 & 8,4 & 0,0 & 8,4 \\
\hline Agrocybe & 0,0 & 2,8 & 2,8 & 2,8 & 0,0 & 8,4 & 2,8 \\
\hline COPRINACEAE & 2,8 & 0,0 & 5,6 & 11,2 & 14,0 & 5,6 & 2,8 \\
\hline Ustilago & 5,6 & 0,0 & 0,0 & 5,6 & 0,0 & 11,2 & 5,6 \\
\hline Alternaria & 5,6 & 0,0 & 0,0 & 2,8 & 2,8 & 2,8 & 2,8 \\
\hline Arthrinium & 0,0 & 0,0 & 0,0 & 0,0 & 2,8 & 5,6 & 0,0 \\
\hline Cladosporium & 44,8 & 11,2 & 2,8 & 0,0 & 5,6 & 2,8 & 28,0 \\
\hline Curvularia & 0,0 & 0,0 & 0,0 & 0,0 & 0,0 & 2,8 & 2,8 \\
\hline Drechslera/Helminthosporium & 0,0 & 0,0 & 2,8 & 0,0 & 2,8 & 0,0 & 0,0 \\
\hline Torula & 0,0 & 2,8 & 0,0 & 0,0 & 0,0 & 0,0 & 0,0 \\
\hline TOTAL SPORES & 86,8 & 36,4 & 36,4 & 30,8 & 44,8 & 42,0 & $\mathbf{7 2 , 8}$ \\
\hline
\end{tabular}

Figure 8.5.4 shows the evolution of the mean hourly concentrations of the previously cited pollen and spores' taxa during the episode. Total Pollen and Total Spores taxa have been added to the graphs. The graphs confirm the observations concluded from Table 8.5.1. 

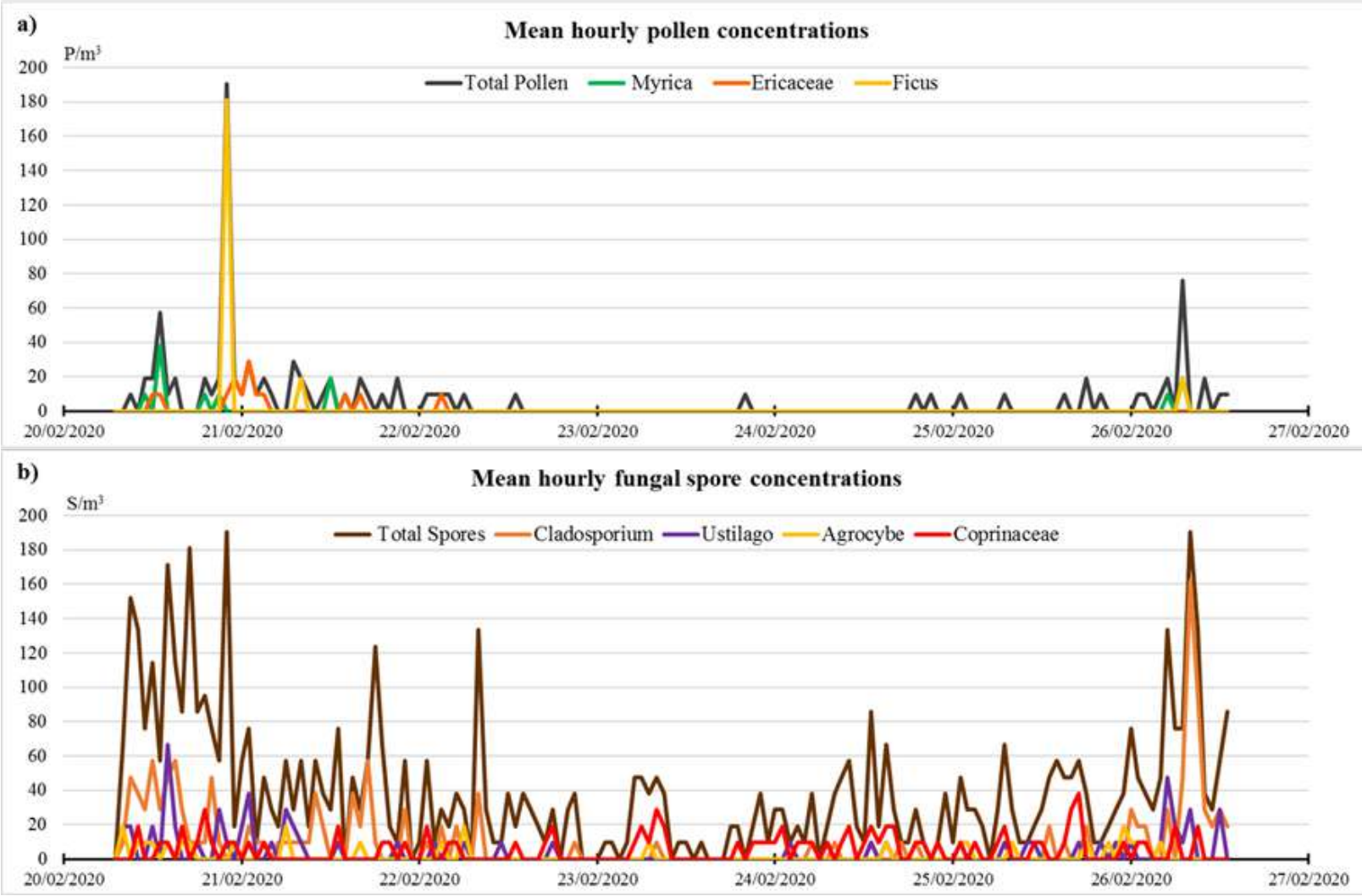

Figure 8.5.4. Mean hourly concentrations of main (a) pollen types and (b) fungal spore types, period 20- 27 February 2020

No animal or plant organisms other than pollen and spores have been observed in the present study.

\subsubsection{Discussion}

Plant and fungal species have their own phenology, shedding the corresponding pollen and spores to the environment due to and under certain meteorological conditions and in different moments of the year. In the Canary Islands, under a subtropical climate, the pollen concentrations of the taxon Total Pollen (all the taxa differentiated considered together) in the air increase slowly from January to February, quickly in March and keeping the high concentrations up to end of May to then decrease gradually to the end of the year (Belmonte et al., 2011). The concentration of fungal spores is stable throughout the year, with the exception of an increase in October-December (Belmonte et al, 2011). This agrees with the low mean daily pollen and spores' concentrations observed the days 20, 21, 26 and 27 February 2020 (Table 8.5.1).

Izquierdo et al. (2011) have detected, in a multi-year study, several extra-regional pollen transport episodes over Tenerife. Those having the origin in the Saharan sector were characterized by the presence of the pollen taxa Chenopodiaceae-Amaranthaceae, Cyperaceae and Poaceae wild-taxa. An intrusion episode can transport any type of element (i.e. pollen) present in the origin area. The episode from February 2020 under study occurred when none or few anemophilous plant species were in flower in the Saharian region where the intrusions originated, and this is the reason for no indicator pollen grains present in the aerobiological samples. Another explanation for the scarcity of pollen and spore particles found during the intrusion can be inferred from Figure 8.5.3, where the transparency/opacity to the light of the microscope of the samples is shown. 


\subsubsection{Conclusion}

The intrusion episode of 22-25 February 2020 caused a reduction in the pollen and spores' concentrations in the air. It did not suppose a risk of allergy for patients with respiratory allergy due to airborne pollen and/or fungal spores. Moreover, no micro-arthropods were observed in the aerobiological samples.

\subsubsection{References}

Belmonte, J., E. Cuevas, P. Poza, R. González, J.M. Roure, R. Puigdemunt, S. Alonso-Pérez, F. Grau, 2010: Aerobiología y alergias respiratorias de Tenerife. Editor: Agencia Estatal de Meteorología/Ministerio de Medio Ambiente y Medio Rural y Marino, NIPO (electronic version): 784-10-006-2.

Galán, C., A. Ariatti, M. Bonini, B. Clot, B. Crouzy, A. Dahl, D. Fernández-González, G. Frenguelli, R. Gehrig, S. Isard, E. Levetin, D.W. Li, P. Mandrioli, C.A. Rogers, M. Thibaudon, I. Sauliene, C. Skjoth, M. Smith, M. Sofiev, 2017: Recommended terminology for aerobiological studies. Aerobiologia, 33: 293-295.

Galán, C., M. Smith, M. Thibaudon, G. Frenguelli, J. Oteros, R. Gehrig, U. Berger, B. Clot, R. Brandao, and EAS QC Working Group, 2014: Pollen monitoring: minimum requirements and reproducibility of analysis. Aerobiologia 30:385-395.

Galán C, P. Cariñanos, P. Alcázar, E. Domínguez, 2007: Spanish Aerobiology Network (Rea): Management and Quality Manual. Servicio de Publicaciones de la Universidad de Córdoba, Córdoba, 61. Available in the web: https://www.uco.es/rea/infor_rea/manual_eng.pdf

Hirst J.M., 1952: An automatic volumetric spore trap. Ann. Appl. Biol., 39: 257-265.

Izquierdo, R., J. Belmonte, A. Avila, M. Alarcón, E. Cuevas, S. Alonso-Pérez, 2011: Source areas and long-range transport of pollen from continental land to Tenerife (Canary Islands). Int J Biometeorol 55:67-85. 


\section{J. A. Lorenzo}

\subsubsection{Introduction}

Apart from the high degree of endemicity of its avifauna, with the presence of six species exclusive to these islands, the Canary archipelago is also of outstanding importance to the migration of birds, with more than 300 migratory species identified to date.

The reason for this massive influx of migrating birds is due to the proximity of the archipelago to the neighbouring coast of Africa, an important flight path followed by many species from the western Palearctic as a corridor during their migrations south of the Sahara (East Atlantic Flyway). The autumn (post nuptial) passage leads migrating birds to their wintering grounds in tropical Africa, while the spring (prenuptial) passage is the route back to their breeding grounds in Europe.

These periods of passage are subject to variations due to various meteorological factors, which cause the sudden emergence of a good number of migrants, in numbers that exceed what is usual every year, as happened, for example, with the recent desert dust outbreak of 22- 24 February 2020 as described here, when many birds following the prenuptial passage were surprised and arrived exhausted on the islands from the neighbouring African coast.

Other species native to northern Europe travel south, fleeing from bad winter conditions. The bulk of these wintering birds spend the coldest months in the Iberian Peninsula and North Africa, but they also reach the islands, as usually occurs with the White Wagtail Motacilla alba, the Black Redstart Phoenicurus ochruros or the Song Trush Turdus philomelos.

Although most of the birds reaching the islands are from the Palearctic, a much smaller percentage of rarer birds of American, African or even Asian origin also reach the archipelago. These birds are popularly known as vagrant or rarities. Those of American origin are the most common on the islands, and usually appear in the summer and autumn months, sometimes associated with a Tropical Cyclone that pulls them towards this side of the Atlantic. In the case of African vagrant species, we distinguish between those that are from the desert environments of northwest Africa, which are those concerning us here in relation to the desert dust outbreak in February 2020, from the water species associated with the movements caused by the wet seasons south of the Sahel.

\subsubsection{I rruption of migratory birds during 22- 24 February 2020 desert dust outbreak}

As discussed in previous sections, the meteorological circumstances from 22-

24 February 2020 can be considered exceptional, and brought an unprecedented irruption of birds to the islands from the neighbouring African continent, among which were trans-Saharan migrant species that were setting off on the prenuptial passage towards their Euro-Siberian breeding grounds, and vagrant species typical of northwest Africa.

Most of the trans-Saharan migrant species were passerines. Among them, the Subalpine Warbler Sylvia cantillans stands out (Figure 8.6.1), with the highest numbers recorded to date in the Canary Islands, along with swallows and martins: the Sand Martin Riparia riparia, the Common Swallow Hirundo rustica, the House Martin Delichon urbicum and the Red-rumped Swallow Cecropis daurica. Curiously, there are precedents for outbreaks of this type dating back to February and March 1989 involving the Subalpine Warbler and the Red-rumped Swallow in Tenerife, although in lower numbers than those obtained in the recent episode of February 2020. 


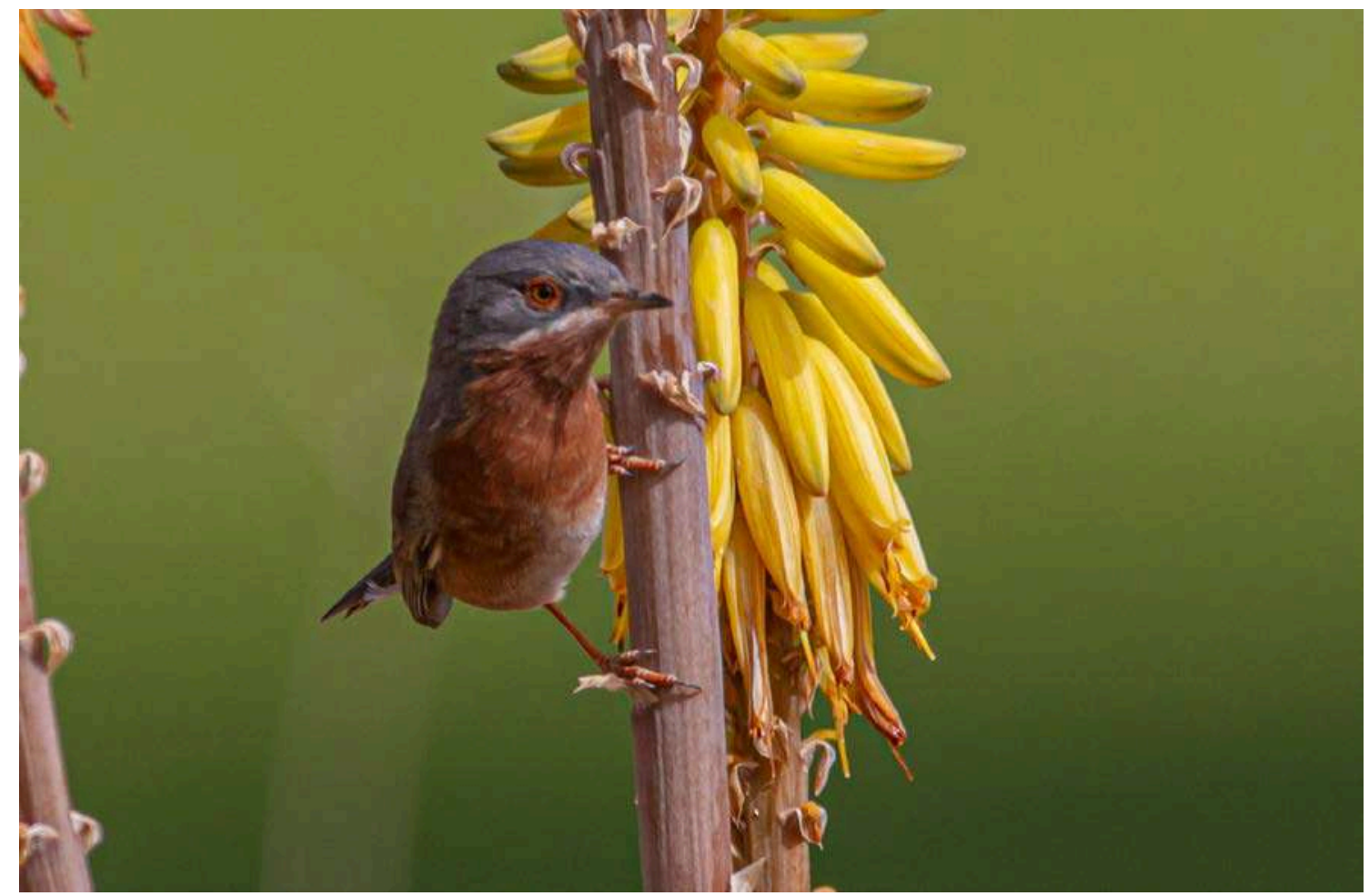

Figure 8.6.1. Subalpine Warbler, Sylvia cantillans. Photographer: Domingo Trujillo

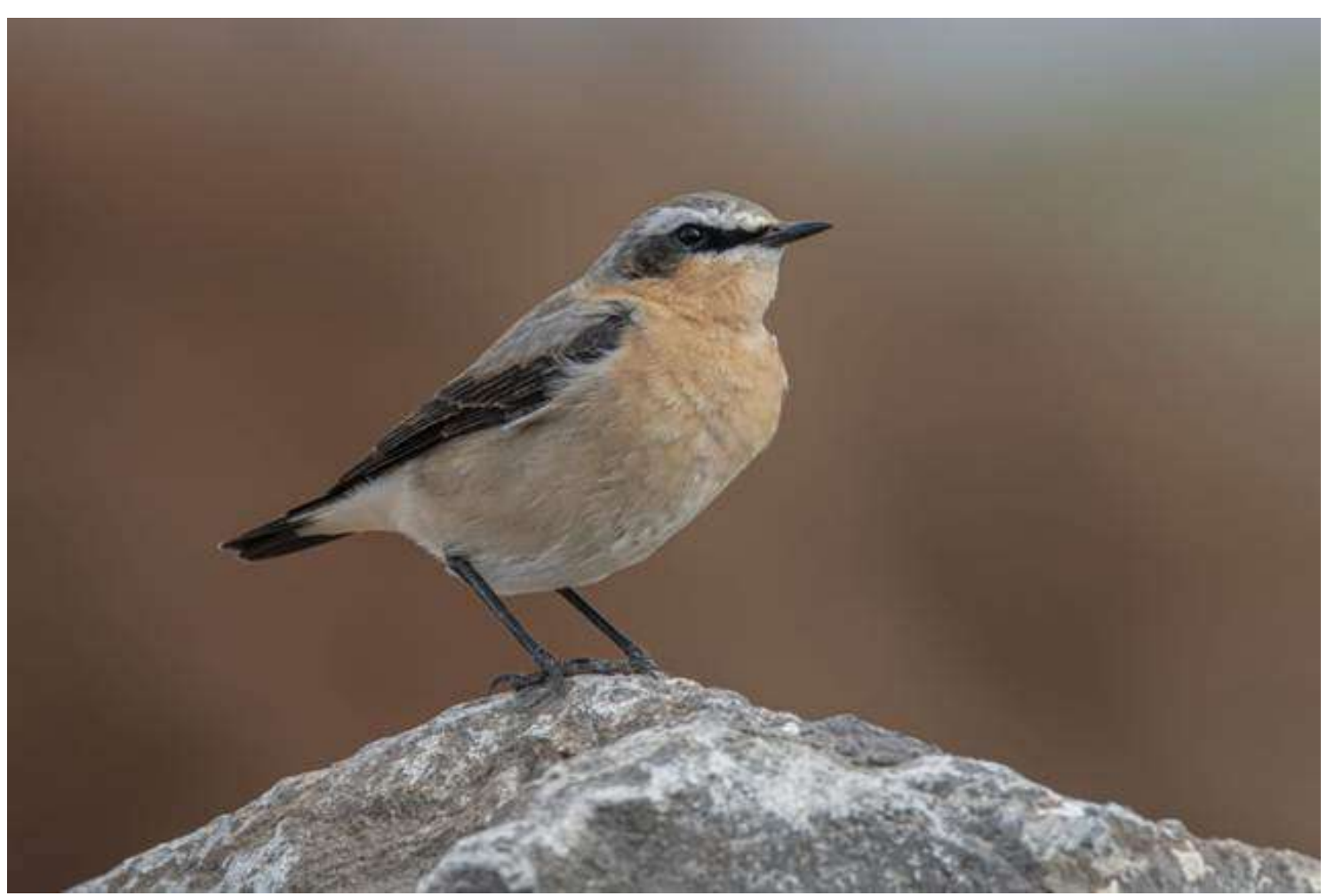

Figure 8.6.2. Northern Wheatear, Oenanthe oenanthe. Photographer: Ramón Fernández

Other migratory species within this group were the Woodchat Shrike Lanius senator, the Common Lark Calandrella brachydactyla, the Willow Warbler Phylloscopus trochilus and the Common Chiffchaff Phylloscopus collybita, the Sedge Warbler Acrocephalus schoenobaenus, the northern Wheatear Oenanthe oenanthe (Figure 8.6.2), western Yellow Wagtail Motacilla flava, and the Tree Pipit Anthus trivialis and the Tawny Pipit Anthus campestris, all described as regular migrants passing through the islands, but on this occasion, in much higher numbers than usual. 
Other species that are normally more unusual in migration through the archipelago were also discovered by observers on the islands during that period, for example a Bluethroat Nightingale Luscinia svecica and a Common Grasshopper Warbler Locustella naevia in La Restinga were the first records of both species on the island of El Hierro. Also in this group of accidental birds on the islands, but quite common on the neighbouring African coast, were several references on different islands to the western Orphean Warbler Sylvia hortensis and the Black-eared Wheatear Oenanthe hispanica (Figure 8.6.3), and a single record of a Little Swift Apus affinis, a western Olivaceous Warbler Iduna opaca and a Blue Rock Thrush Monticola solitarius.

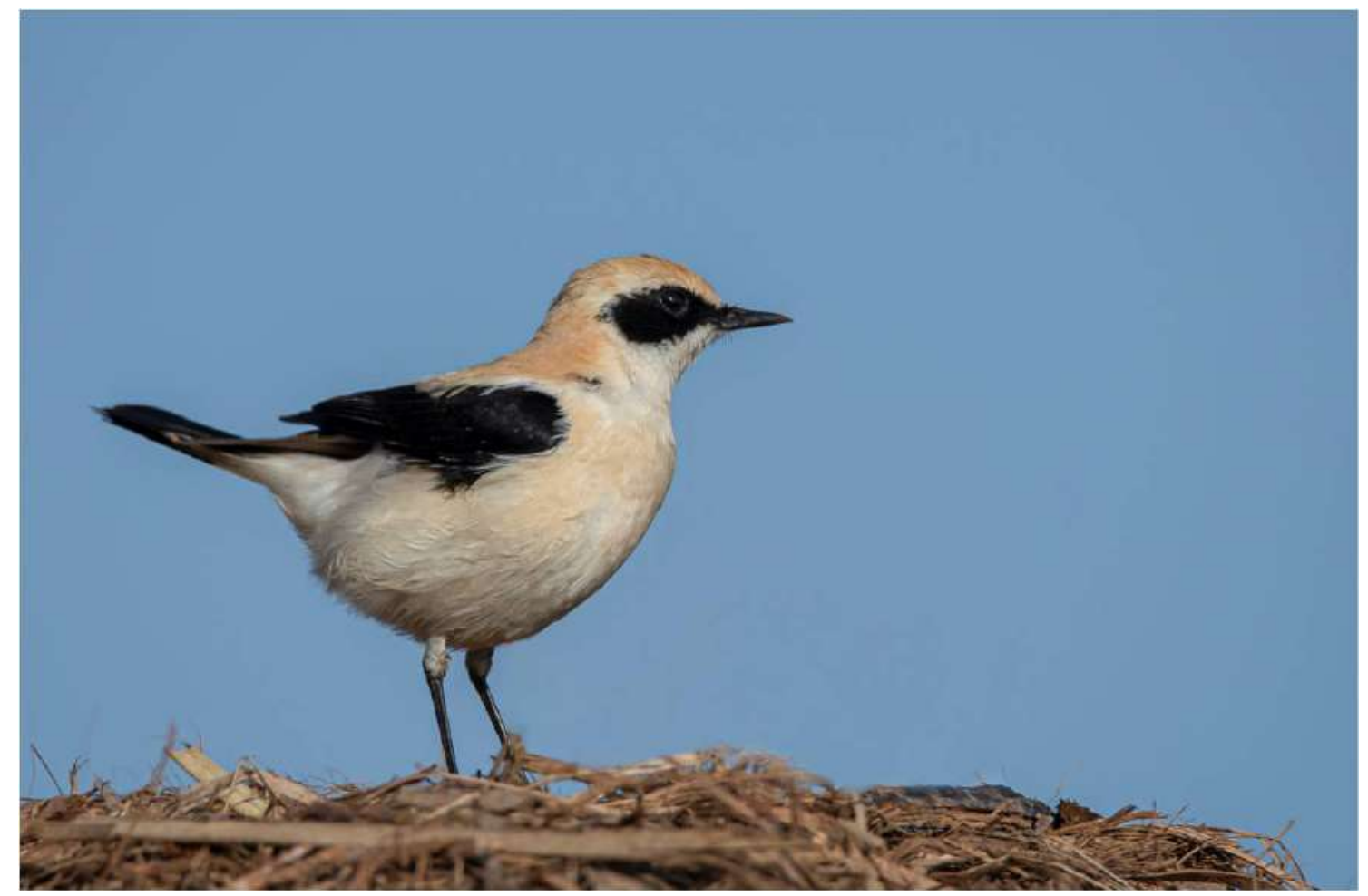

Figure 8.6.3. Black-eared Wheatear, Oenanthe hispanica. Photographer: Ramón Fernández

The compilation of all these reports on sightings of migratory birds made by the observers, are part of the different ornithological reports published regularly in the SEO/BirdLife magazine Ardeola. These reports compile the ornithological news referring to the most relevant nesting and migratory species of each year.

During the desert dust outbreak of 22-24 February 2020, vagrant species or rarities also reached the islands, for the most part typical of northwest Africa, either because they are typical of that region or because they were wintering. Again, some species arrived in unprecedented numbers, spread over different islands, such as more than 80 specimens of Desert Wheatear Oenanthe deserti, about 20 Isabelline Wheatears Oenanthe isabellina, as well as two Bar-tailed Larks Ammomanes cinctura, two African Desert Warblers Sylvia deserti, and solitary specimens of the Desert Grey Shrike Lanius excubitor elegans, Greater Hoopoe Lark ibis Alaemon alaudipes, Lesser Whitethroat Sylvia curruca, Tristram's Warbler Sylvia deserticola and White-crowned Wheatear Oenanthe leucopyga.

There are no precedents, neither in the Canary Islands nor in the rest of the Spanish territory, of the simultaneous arrival of so many accidental species typical of North Africa. The SEO/BirdLife Rarities Committee is responsible for the study of these records and their homologation. In fact, most, if not all of the records mentioned, have been referred to the said committee for study, most of which accompanied with photographs allowing corroboration of the correct identification of the different specimens and allowing the arrival of these species, associated with the desert dust outbreak, to be documented in detail. 
In February 1989, a similar episode was noted, but in lower numbers, and up to five specimens of Desert Wheatear were counted in Punta del Hidalgo in Tenerife, along with other, more regular migrant species, but again more abundant than usual. On that occasion, a Grey Shrike close to the wheatears could correspond to the Desert Grey Shrike mentioned in February 2020 for the first time in the Canary Islands and in Spain. Another similar irruption took place in the year 2000, with observations in Tenerife, Fuerteventura and La Graciosa. In any case, it should be noted that the desert dust outbreak involved in these two prior episodes was not as intense as that in February 2020.

\subsubsection{Bird monitoring as an effective tool to measure the health of our natural environment}

Birds are effective bioindicators of the state of the natural environment. Therefore, medium and long-term monitoring programmes of their populations are necessary to ensure enough data to establish patterns that will undoubtedly reflect the trends of other groups that are less represented, not so easy to observe, less abundant, etc. Many of these monitoring programmes form part of what is now known as citizen science; some of these programmes, initiated by SEO/BirdLife decades ago, are the Common Bird Monitoring Programme (SACRE, by its initials in Spanish), SACIN, the winter censuses of aquatic birds, etc. Many of them now have mobile device applications, or apps, making it easier for collaborators to collect and send data. Among all these tools, the eBird app stands out, it is international in scope with more than 579.000 observers or "birders" worldwide, approximately 10.480 of them are in Spain.

What happened in February 2020 in the Canary I slands is a good example of this network. The presence of observers on practically all the islands has made it possible to document the arrival of a good number of species in the days the dust episode lasted, and in the weeks following the event, and involved both rare species and the habitual migrants. This circumstance was unthinkable decades ago, when there were much fewer local observers, and also a low number of foreign observers visiting the islands for a few days. The current situation is quite different, and proof of that is the number of reports made on those days of February and the first weeks of March 2020 on different islands by different observers, many of which have already been collected or are being compilated in the corresponding reports: Ornithological news and observations of rare birds in Spain, respectively.

From all these data, for example, a greater arrival of birds to Gran Canaria and Tenerife can be inferred, and to a lesser extent to Fuerteventura, to the detriment of Lanzarote, contrary to the usual pattern, as migration through the eastern islands is usually more intense, especially on Lanzarote and its islets given their proximity to the neighbouring African coast. In fact, it is on these islets that a large colony of Eleonora's Falcon is found, a raptor specialized in capturing migratory birds. On these islets of Chinijo, it has been estimated that each breeding season the Eleonora's Falcon may capture up to 22.000 migratory birds during the post nuptial migration. The volume of information generated on this occasion permits quantitative and qualitative analysis, in addition to spatial and temporal analysis, of undoubted interest when it comes to understanding the phenomenon of storms originating in the Sahara, and the response of the organisms caught up in it. On this occasion with birds as protagonists, although it is known that representatives of other groups arrived along with them, such as invertebrates: dragonflies, butterflies, etc (see Section 8.7 for more details).

\subsubsection{Conclusion}

There are no precedents, neither in the Canary Islands nor in the rest of Spain, for the simultaneous arrival of so many accidental bird species from North Africa as those recorded during the intense episode of dust and very strong winds from western Sahara Africa from 22 to 24 February 2020. 


\section{P. Oromí}

\subsubsection{Introduction}

During the processes of strong Saharan winds with airborne dust, abundant individuals of certain species tend to reach the Canary Islands, carried by those winds. Many are regular migrants who follow a north/south route or vice versa and are diverted eastward, appearing in the Canary Islands. This is the particular case of two species of dragonfly (Anax ephippiger and Sympetrum fonscolombii), and of the migrating locust (Schistocerca gregaria).

\subsubsection{Arrival of invertebrates to the Canary I slands during the February 2020 dust outbreak: comparison with other dust outbreaks}

The vagrant emperor dragonfly (Anax ephippiger) (Figure 8.7.1) is permanently present throughout most of Africa but makes migrations to the north that are not very well explained (Boudot \& Kalkman, 2013), reaching Mediterranean Europe and is sometimes found much further north. These migrations are not very regular, and some years they preferably follow an eastern route and others, the westwern. In 1995 there was a great migration by the eastern route, and in 2011 it followed the western route. In the Canary Islands, the presence of this species has been cited on all the islands except El Hierro (Canary I slands Biodiversity Data Bank), but it is, in general, a rarely or very rarely observed dragonfly. In Fuerteventura the first citing was a few years ago (Weihrauch, 2016), and on some islands the citations are scarce or imprecise. Thus, of the great invasions, very few or no individuals are established in the archipelago. However, in the intense February 2020 dust outbreak, an unprecedented invasion of Anax ephippiger took place and reached all islands including El Hierro.

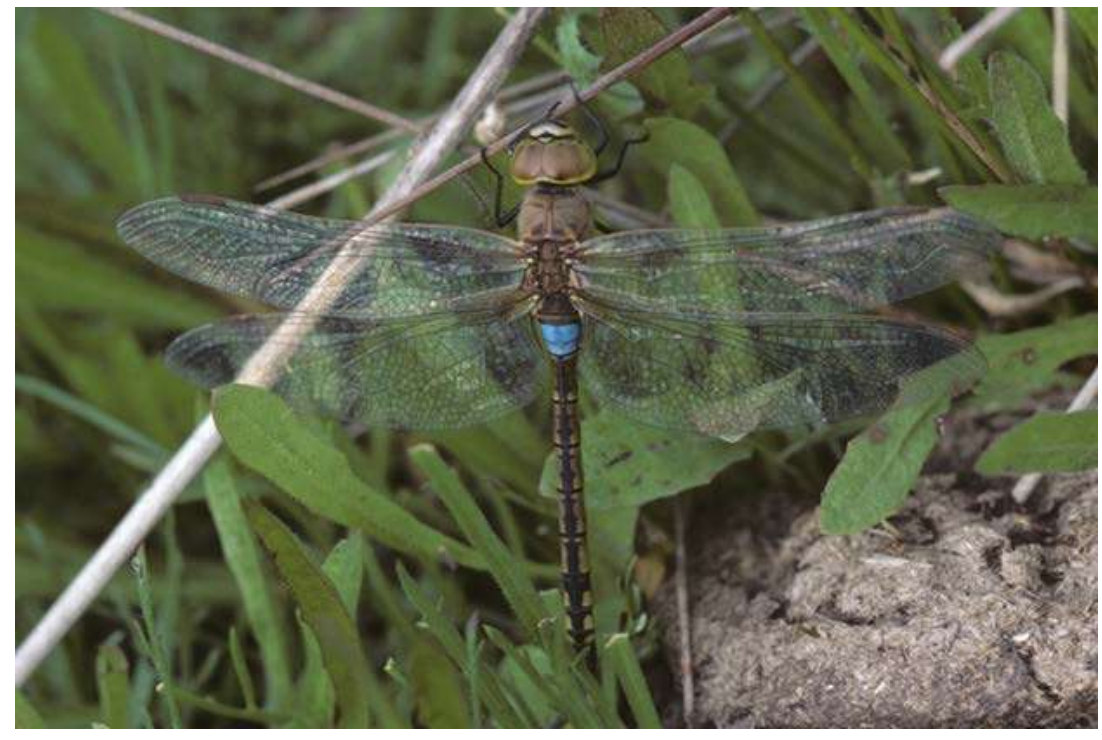

Figure 8.7.1. Anax ephippiger (Vagrant emperor dragonfly)

The red-veined darter (Sympetrum fonscolombii) (Figure 8.7.2), smaller than the latter, with red males and yellowish females, is also migratory insect but normally there are established populations in the Canary Islands. During the February 2020 dust outbreak, quite a large number of individuals were observed coinciding with the airborne dust episode, but in much smaller numbers than Anax ephippiger. 

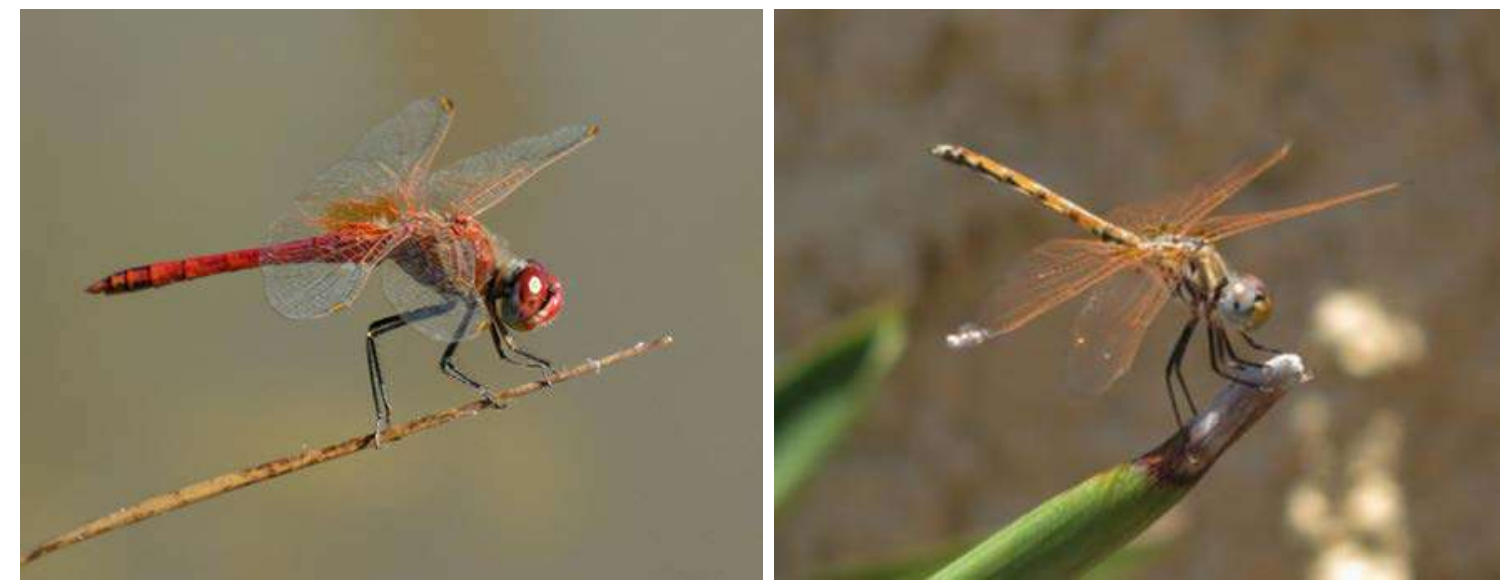

Figure 8.7.2. Male Sympetrum fonscolombii (red-veined darter) (left; photo by Alfonso Rodríguez) and female (right; photo by Pedro Oromí)

The Desert locust (Schistocerca gregaria) (Figure 8.7.3) is one of the locust species that swarms after rainy periods in arid areas of Africa. In the Canary Islands there have been no massive invasions since the 1950s, probably due to the intensive treatment and surveillance carried out by the Food and Agriculture Organization of the United Nations (FAO) and other organizations in their areas of origin. When they come in significant quantities, they take on a redder colour because they are in a gregarious phase, which prompts them to swarm and take flight to travel long distances. Specimens arrive in the Canary Islands every year, coinciding with desert dust outbreaks, but more rarely in the gregarious phase and not in the massive numbers that seriously affect crops or natural vegetation. After these episodes, they usually disappear and there are hardly any individuals left behind, so there are no stable populations on the islands. In the February 2020 dust outbreak, very few specimens arrived, and furthermore, some citations found actually referred to Locusta migratoria, a doubtful identification although individuals would have to be seen to certify this.

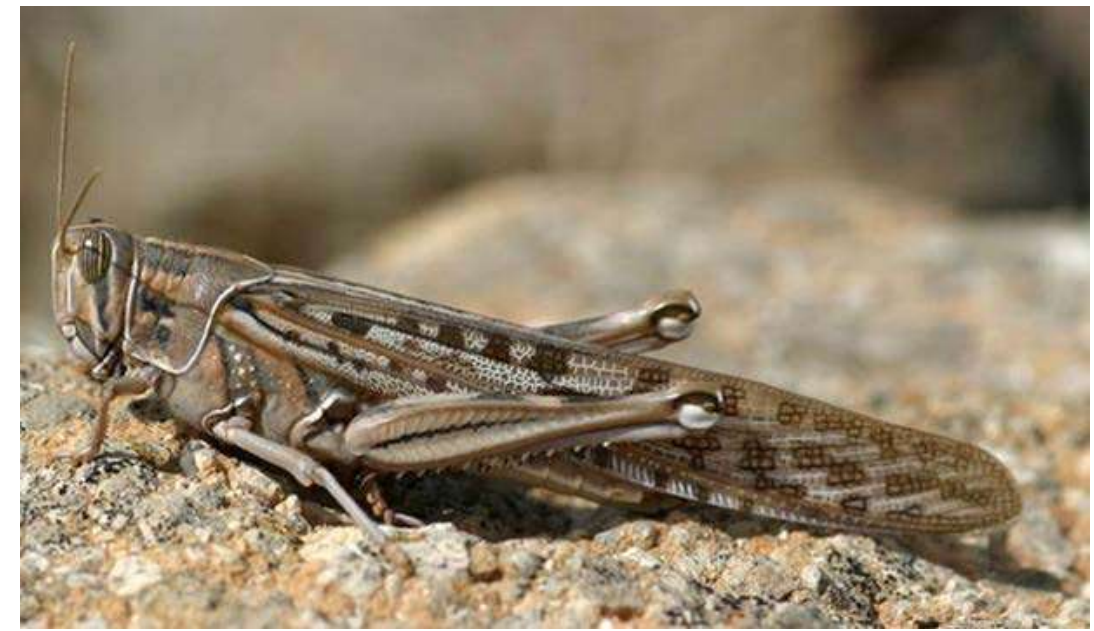

Figure 8.7.3. Desert locust (Schistocerca gregaria)

A special case is that of the Vanessa cardui butterfly (Painted Lady) (Figure 8.7.4), which makes extensive, multigenerational circular migrations from tropical Africa to Europe and vice versa (Talavera et al, 2018). At the end of summer, the species leaves Europe moving south, passing through the Canary Islands in early autumn, which is when they appear almost every year, at least on the eastern islands, even without marked Saharan weather. In autumn 2019 there was a massive irruption in the archipelago, which reached La Palma (R. García, personal communication). Most of the individuals either continue their journey south or die, but some remain on the islands and reproduce, so throughout the year adult individuals can be observed. In February 2020, there was no observed arrival of individuals, as it did not coincide with their time of passage through the African zone off the Canary Islands. 


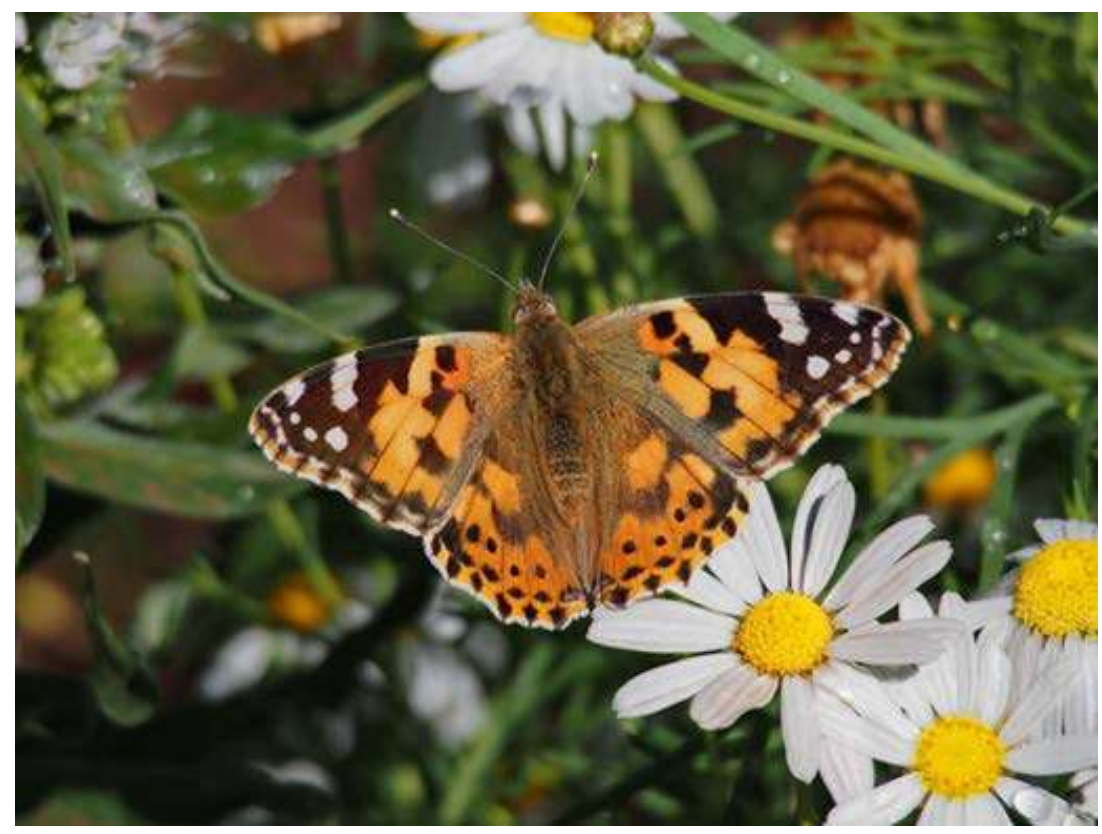

Figure 8.7.4. Painted Lady butterfly (Vanessa cardui)

With episodes of African air masses come, without a doubt, many other arthropods, both flying (insects) and flightless, since many spiders in their juvenile phases are transported on the wind using the ballooning method of flight, which consists of making a silk thread that serves as a kind of paraglider. In fact, air transport, active or passive, is considered as one of the main means of colonization of oceanic islands throughout their existence, both by animals and by many plant propagules. What happens is that during strong African wind events we only detect the arrival of species of a certain size that arrive in large numbers and which are usually migratory.

\subsubsection{Conclusion}

In February 2020 there was an unprecedented invasion of the vagrant emperor dragonfly (Anax ephippiger), which reached as far as the island of El Hierro, the westernmost island of the Canary archipelago. With respect to the red-veined darter (Sympetrum fonscolombii), the arrival of a large number of individuals was recorded during the February 2020 dust outbreak, but in much smaller numbers than Anax ephippiger. In the February 2020 dust episode, very few specimens of the Desert locust (Schistocerca gregaria) arrived; one of the locust species that swarms after the rainy season in arid areas of Africa. No individuals of the Painted Lady were observed - a butterfly which makes extensive, multigenerational circular migrations from tropical Africa to Europe and vice versa, because it does not coincide with its time of passage through the African zone off the Canary Islands.

\subsubsection{References}

Boudot J.P. \& V. Kalkman, 2015: Atlas of the European dragonflies and damselflies.

Talavera, G., C. Bataille, D. Benyamini, M. Gascoigne-Pees, R. Vila, 2018: Round-trip across the Sahara: Afrotropical Painted Lady butterflies recolonize the Mediterranean in early spring, Biology Letters 20180274 http://dx.doi.org/10.1098/rsbl.2018.0274 


\subsection{I mpact in the media and social networks}

R. del Campo-Hernández

\subsubsection{Introduction}

The episode of airborne desert dust that occurred in the Canary I slands between

22- 24 February 2020 had a great impact in the media and social networks at a local, national and even international scale. The spectacular nature of the images, the fact that the episode coincided with the dates of the famous Canary Islands Carnival, whose events had to be suspended at certain times and locations, as well as the temporary interruption of air traffic, are most likely the reason for the ample coverage the episode had in the media.

\subsubsection{Incidence on Twitter}

Twitter is a microblogging social network that allows its users to read and post short messages (currently up to a maximum of 280 characters) along with still images and short videos. In September 2019 it had a total of 328 million users, many of whom use the social network to keep up to date with current issues.

One of the ways that Twitter has to organize content is through the use of popular hashtags, or tags, consisting of a word or set of words joined and marked at the beginning with the 'hashtag or number' symbol (For example, \#calima). The use of hashtags allows you to search for tweets on a specific topic, and with certain computer tools, you can see the impact that this topic has on the social network. When the impact is very high, it is said that the topic is a trend or trending topic.

To study the impact on Twitter of the airborne dust episode that occurred in the Canary I slands between 22-24 February 2020, the use of two hashtags on these dates is analysed: \#CalimaCanarias and \#Calima. Both were widely used by Twitter users. The hashtag \#AlertaCalima was also used, although to a lesser extent.

Table 8.8.1 shows the position of the hashtags in the daily ranking based on the time that each hashtag was a trend during the episode, and the hours it remained as such in Spain, according to the trend analysis portal on the social network Twitter Trendinalia Spain. We can observe that the hashtags \#Calima and \#CalimaCanarias, in particular, had a great impact and were distributed unevenly throughout the three days the episode lasted. They were, for several hours, a trending topic for the whole of Spain.

Table 8.8.1. Position of hashtags in the daily ranking based on the time that each hashtag was a trend during the episode, and the hours it remained as such in Spain

\begin{tabular}{lllllll}
\hline & 22 February 2020 & 23 February 2020 & \multicolumn{2}{l}{ 24 February 2020 } \\
\hline Hashtag & $\begin{array}{l}\text { Position in } \\
\text { ranking }^{1}\end{array}$ & $\begin{array}{l}\text { Time as } \\
\text { trending } \\
\text { topic } \\
\text { (HH:MM) }\end{array}$ & $\begin{array}{l}\text { Position in } \\
\text { ranking }\end{array}$ & $\begin{array}{l}\text { Time as } \\
\text { trending } \\
\text { topic } \\
\text { (HH:MM) }\end{array}$ & $\begin{array}{l}\text { Position in } \\
\text { ranking }\end{array}$ & $\begin{array}{l}\text { Time as } \\
\text { trending } \\
\text { topic } \\
\text { (HH:MM) }\end{array}$ \\
\hline \#Calima & 13 & $10: 20$ & 47 & $06: 50$ & $\begin{array}{l}\text { Does not } \\
\text { appear }\end{array}$ & - \\
\#CalimaCanarias & $\begin{array}{l}\text { Does not } \\
\text { appear }\end{array}$ & - & 12 & $11: 15$ & 12 & $09: 45$ \\
\#AlertaCalima & $\begin{array}{l}\text { Does not } \\
\text { appear }\end{array}$ & - & 347 & $00: 15$ & 156 & $02: 35$ \\
\hline
\end{tabular}

${ }^{1}$ Source: https://www.trendinalia.com/twitter-trending-topics/spain/spain-200224.html 
Another approach to examine the scope of the episode is by analysing the total number of daily tweets posted on Twitter with a certain tag over time. For this purpose, the online tool Trendsmap was used, and the results are shown in Figure 8.8.1.

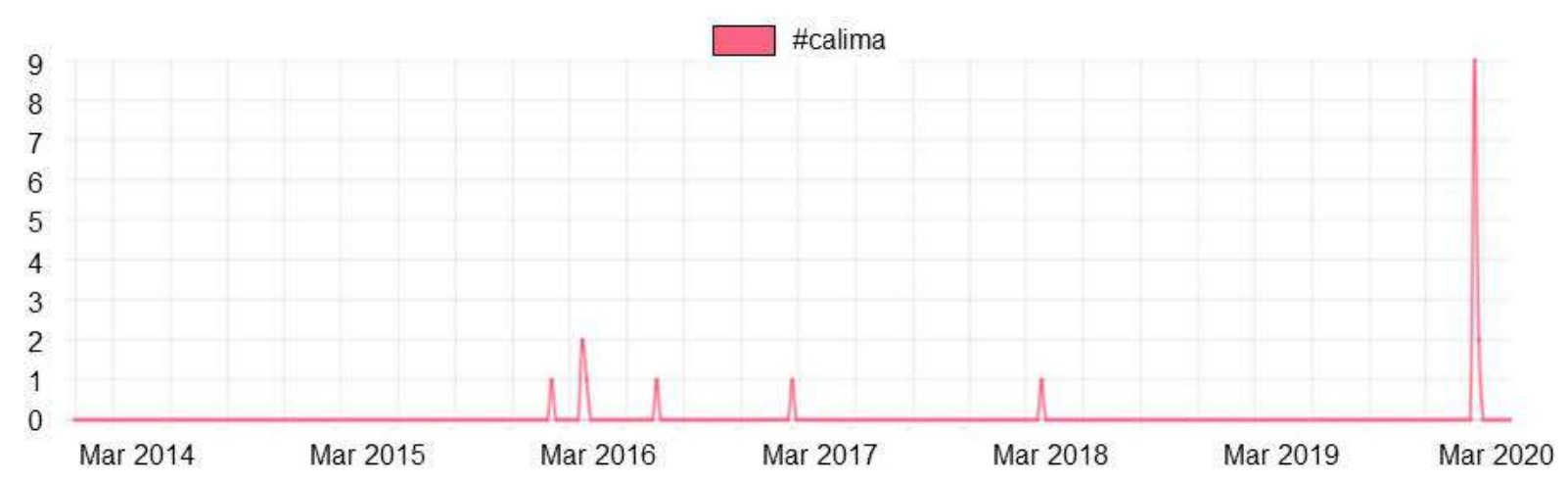

Figure 8.8.1. Total number of daily tweets posted on Twitter with \# calima hashtag March 2014-March 2020

Source: https://www.trendsmap.com/historical?q=\%23Calima

The graph represents the proportion of tweets that include a certain tag with respect to the total tweets published on a day on a global scale. The peak of tweets containing this tag is clearly observed during the episode at the end of February 2020 and is much higher than for other dust episodes occurring in recent years.

Something very similar happens with the \#CalimaCanarias tag, although in this case the proportion with respect to the total number of tweets is three times lower than that of the \#calima tag and it is most likely it was the first time it was used massively. However, the large increase in tweets with this hashtag during the episode is evident (Figure 8.8.2).

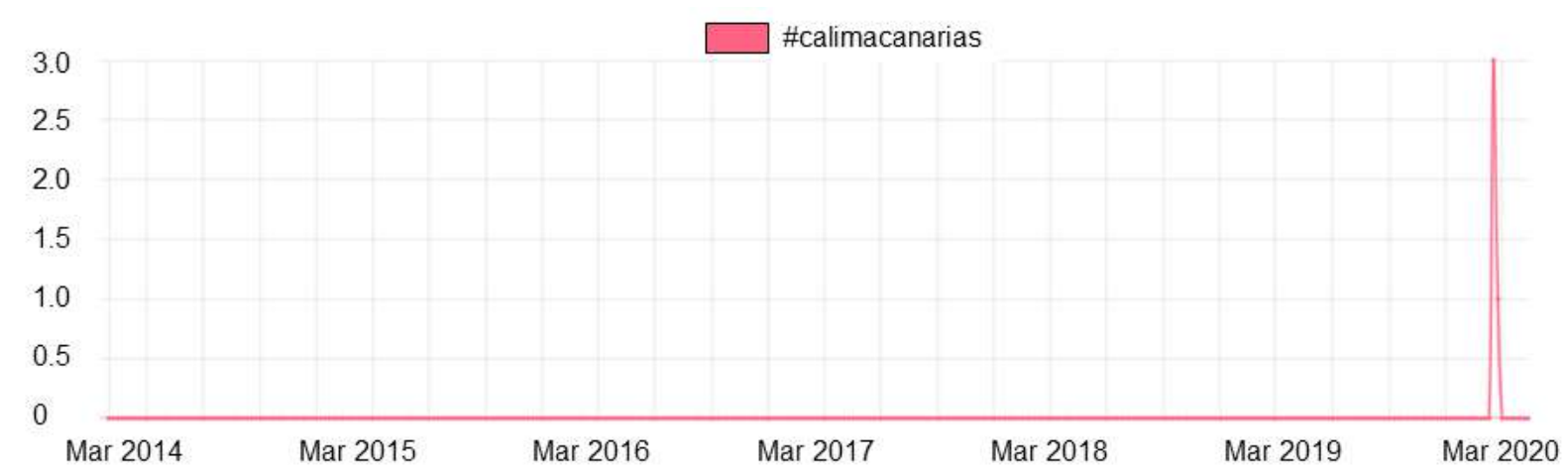

Figure 8.8.2. Total number of daily tweets posted on Twitter with \# calimacanarias hashtag March 2014-March 2020

Source: https://www.trendsmap.com/historical

In fact, the social network was flooded with tweets of spectacular images of the episode, shared by residents, tourists and the media. Some examples are shown in Figure 8.8.3. 

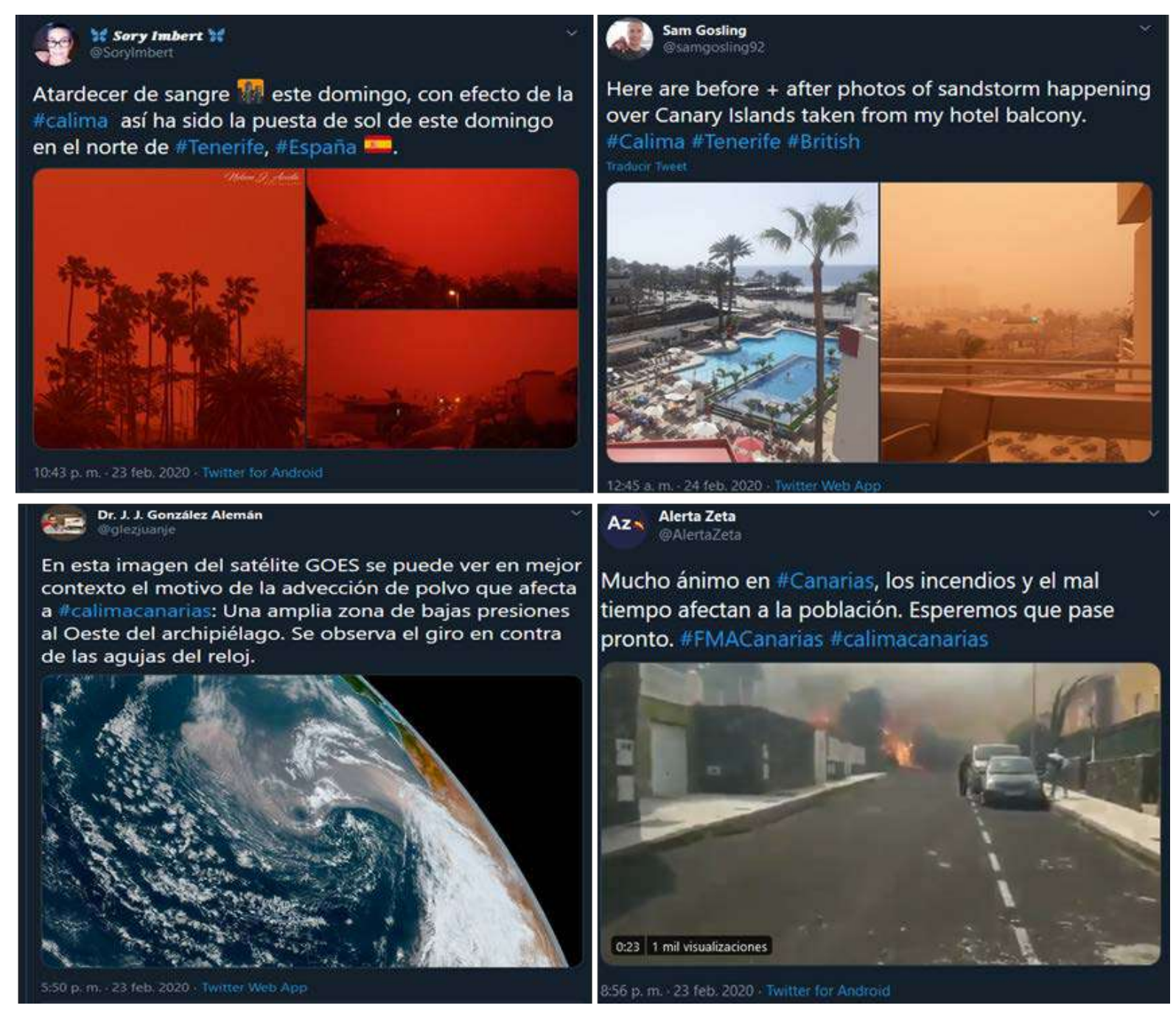

Figure 8.8.3. I mages of the 22- 24 February 2020 dust outbreak on Twitter

Many tweets contained images of the sky at sunset, especially on 23 February 2020, others showed the extent of reduced visibility that occurred within a few hours. Some users chose satellite images showing the dust advection very clearly, while other users focused on the consequences beyond reduced visibility, such as fires exacerbated by the wind, high temperatures and low relative humidity.

\subsubsection{Incidence in the media}

The Meteorological and Climatological Information Area of AEMET collects daily, from Monday to Friday, links to news related to weather and the climate in a bulletin published on its website. The bulletin is divided into several sections: "Weather, climate and society";

"Atmosphere, natural resources and impacts"; "Climate change and ecological transition"; and "The weather around the world".

News items related to the 22-24 February 2020 dust outbreak appeared in the news bulletins published on the AEMET website on 24 and 25 February 2020 (as 23 February was Sunday). These newsletters are no longer available for viewing, as they are replaced on a weekly basis.

The news items related to the dust outbreak were found in the first two sections; in the first (weather, climate and society) were the news items that reported the dust episode itself, and in the second (atmosphere, natural resources and impacts) were the news items related to the impacts of the episode (interruption of air traffic or fires, for example). 
Table 8.8.2 shows the number of news items related to the 22-24 February 2020 dust outbreak that appeared in the aforementioned sections of the news bulletins published on the AEMET website on 24 and 25 February. Altogether, almost two thirds of the news items referred to the episode, which is a very high percentage.

Table 8.8.2. Number of news items related to the 22- 24 February 2020 dust outbreak that appeared in the AEMET news bulletins

\begin{tabular}{lccc}
\hline Date of bulletin & $\begin{array}{c}\text { Number of news } \\
\text { items related to } \\
\text { dust outbreak }\end{array}$ & $\begin{array}{c}\text { Total number of news } \\
\text { items }\end{array}$ & $\begin{array}{c}\% \text { news items } \\
\text { related to dust } \\
\text { outbreak }\end{array}$ \\
\hline 24 February 2020 & 33 & 52 & $63 \%$ \\
25 February 2020 & 13 & 19 & $68 \%$ \\
Total & 46 & 71 & $65 \%$ \\
\hline
\end{tabular}

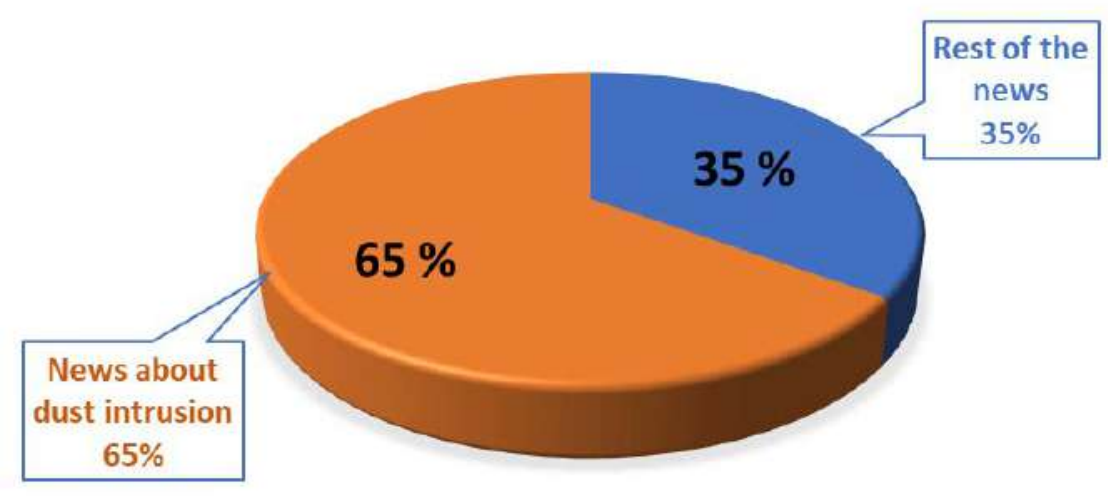

Figure 8.8.4. Proportion of news items related to the 22- 24 February 2020 desert dust outbreak in news bulletins published on the AEMET website on 24 and 25 February 2020

Some examples of the news items related to the 22-24 February 2020 dust outbreak that appeared in local, national and international media are shown in Figures 8.8.5 to 8.8.7. 


\section{Canarias, en imágenes y vídeos \\ Desde hoy sabado se esta registrando un episodio fuerte de calima que se polvo africano en el ambiente seran imponantes y reduciran la visibilidad de anamo de ansos}

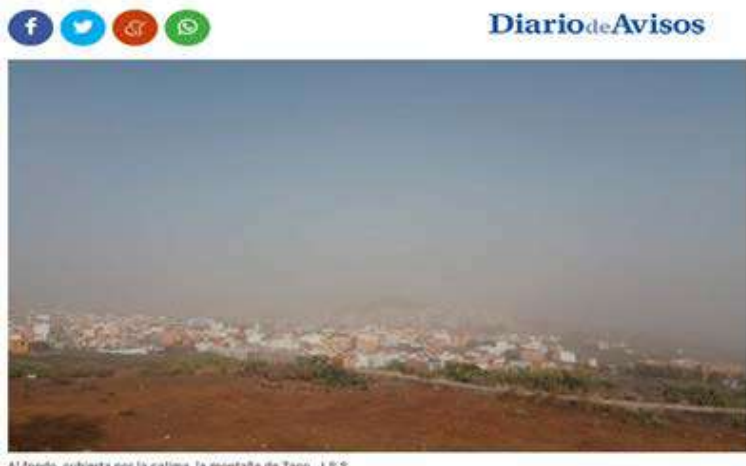

Figure 8.8.5. I mages of the 22- 24 February 2020 dust outbreak published in local and national media. Left: Diario de Avisos, a local newspaper (Santa Cruz de Tenerife province). Right: El País, a national newspaper in Spain.
El episodio de calima de Canarias bate récords de temperatura

El fenómeno, que comenzará a remitir esta tarde y que el martes se dará por concluido, tiene opecones de ser histórico

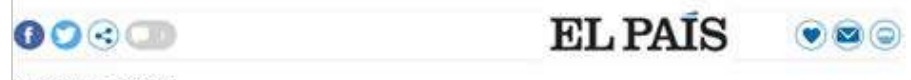

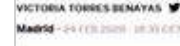

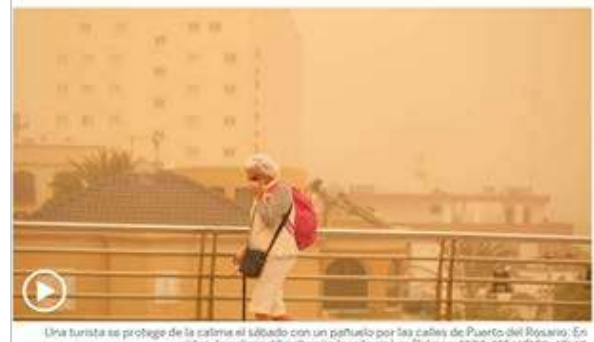

SUSCRIPCIÓN

IUMIITAD

$\left.\begin{array}{c}\text { PRaMer } \\ \text { MES }\end{array}\right]$

$10^{\mathrm{c} / \mathrm{mes}}$
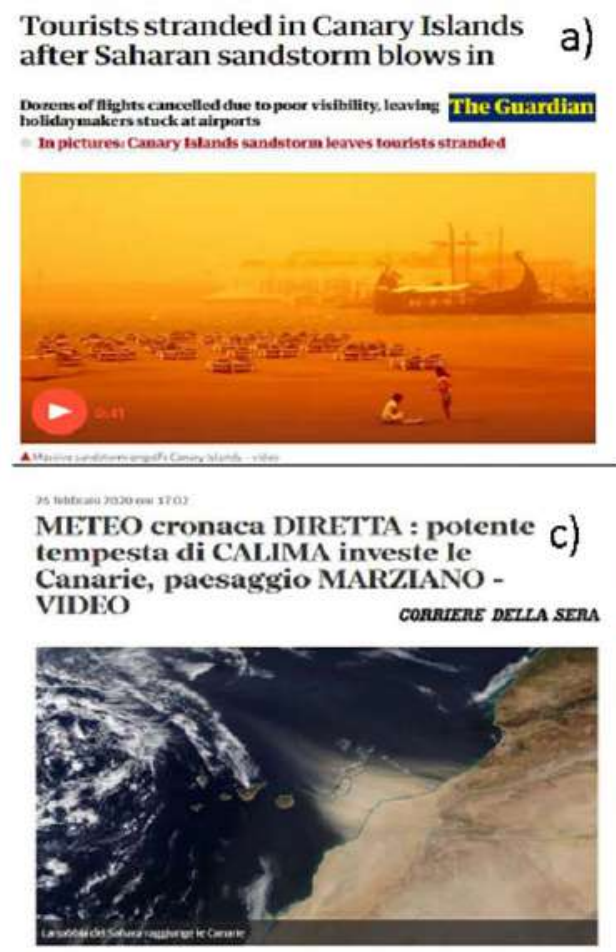

a) Le trafic reprend dans trois aéroports des iles Canaries après une tempête de sable parteriero onecNip LE TIGARO
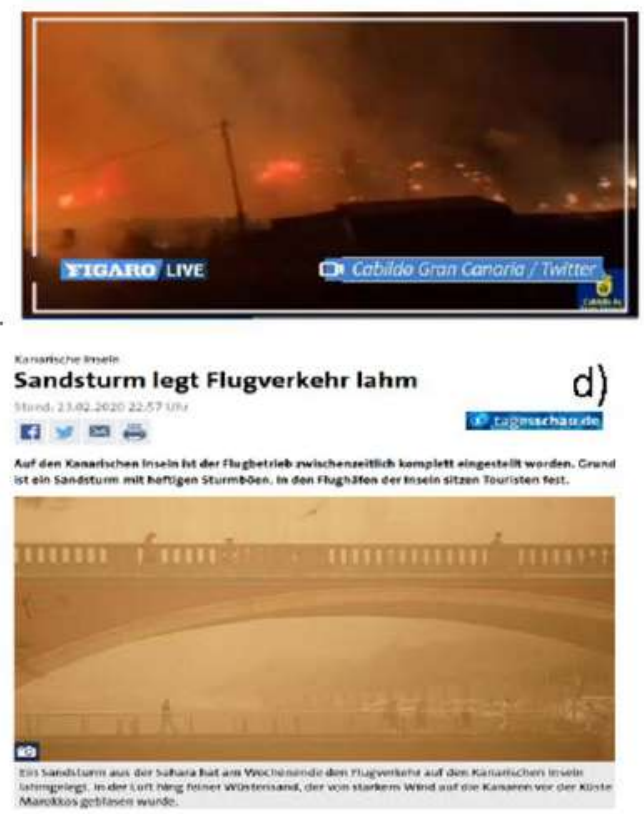

Figure 8.8.6. I mages of the 22- 24 February 2020 dust outbreak published in international media. (a) The Guardian (UK); (b) Le Figaro (France); (c) Corriere della Sera (I taly);

(d) Tagesschau (Germany) 


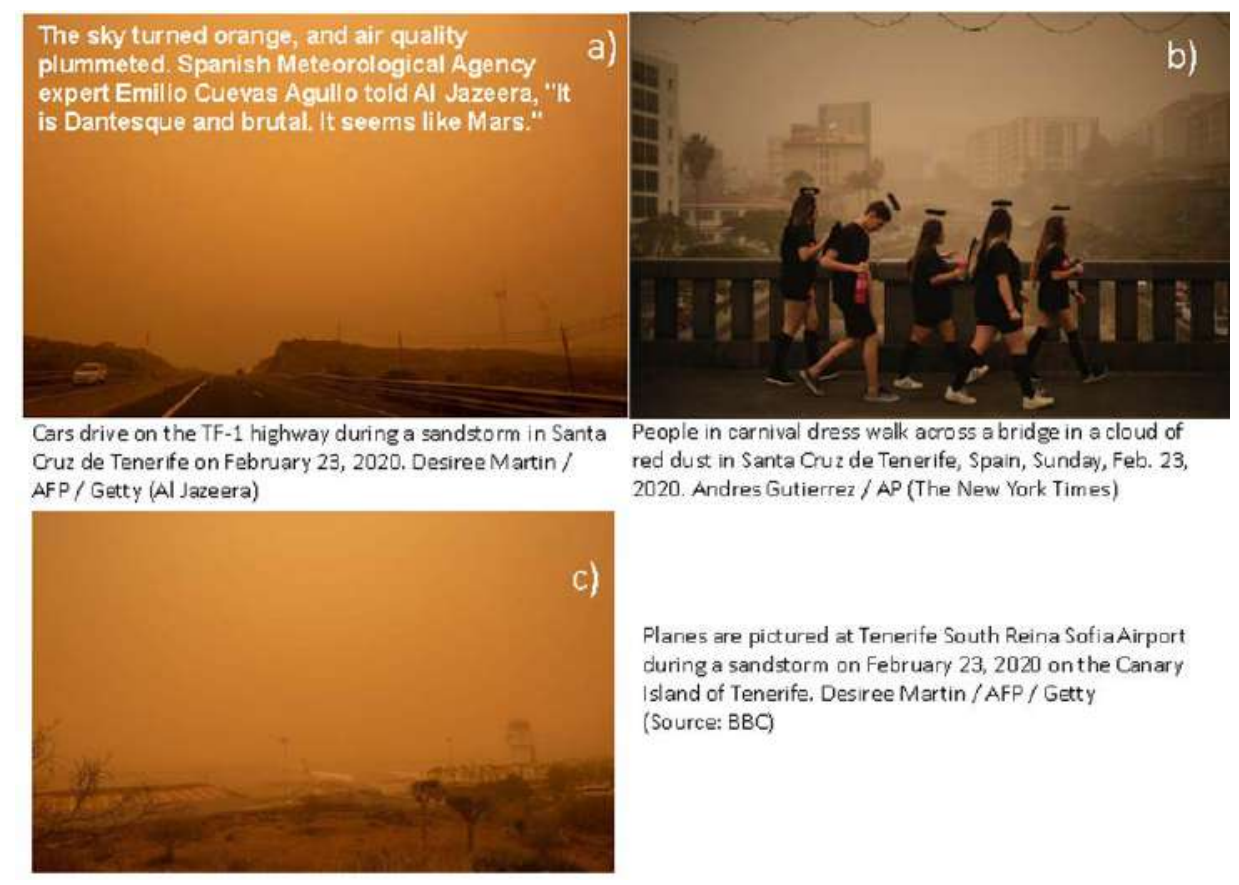

Figure 8.8.7. I mages of the 22-24 February 2020 dust outbreak published in international media: (a) Al Jazeera (Arab countries); (b) The New York Times (USA); (c) BBC (UK)

\subsubsection{Conclusions}

The 22-24 February 2020 dust outbreak has been the most widely reported dust episode in the Spanish media in its history. The severe impact on the operations of the eight Canarian airports, which were closed for hours, caused by this dust outbreak, and its concurrence with the famous Carnivals of Santa Cruz de Tenerife and Las Palmas de Gran Canaria, with a huge influx of national and foreign tourists to the archipelago, explains the extensive publicity given to it by the media from all over the world. The enormous development of social networks multiplied the effect of spreading the news about the impacts of this huge dust outbreak. 
In this report we have undertaken a comprehensive study of the exceptionally severe dust outbreak that affected the Canary archipelago between 22-24 February 2020. It is a unique study for its unprecedented intensity and its associated impacts in different socio-economic sectors.

The 22-24 February 2020 dust outbreak was reported extensively in local, national and international media, especially because of the closure of airports and the enormous problems caused to tens of thousands of tourists who suffered the cancellation of their flights. The dust episode also had a huge impact on Twitter. The long-term aerosol observations $\left(\mathrm{PM}_{10}\right.$, groundbased AOD, satellite borne AOD, and horizontal visibility as a proxy of suspended dust) confirmed that the dust outbreak that occurred between 22-24 February 2020 was the most intense dust episode so far recorded in the Canary Islands.

This dust outbreak, like most outbreaks affecting the Canary Islands that take place in winter, was caused by a very deep cut-off low that became detached from the mid-latitudes circulation and was located in the vicinity of the Canary Islands archipelago, causing very intense winds (around $90 \mathrm{~km} \mathrm{~h}^{-1}$ at $1500 \mathrm{~m}$ a.s.l.) over the western Sahara that transported mineral dust to the Canary archipelago within a relatively short distance. Two weeks earlier, on 4 February 2020, another intense dust episode had already taken place, a type of episode observed usually in winter every 2 or 3 years and which normally affect low altitudes of some islands of the archipelago. Winter dust outbreaks in the Canary Islands are often associated with the presence of cut-off lows, deep-lows or deep troughs located in the vicinity of the Canary archipelago, which can cause rain or snowfall on peaks of the islands of higher orography along with the presence of mineral dust. The air quality stations of the Canary I slands recorded three peaks of $\mathrm{PM}_{10}$ and $\mathrm{PM}_{2.5}$ concentrations on 22, 23 and 24 February 2020, with extremely high $\mathrm{PM}_{10}$ and $\mathrm{PM}_{2.5}$ hourly concentrations, which exceeded 3000 and $1000 \mathrm{mg} \mathrm{m}^{-3}$, respectively, during the largest peak recorded on 23 February 2020. This three-day dust event resulted in severe reductions in horizontal visibility to a few hundred meters, with visibility reduced to $100 \mathrm{~m}$ in some points of the archipelago for short periods of time, as observed, for example, in the Santa Cruz de Tenerife port.

Analysis of the chemical composition of aerosols measured during the dust outbreak shows that from 22 to 25 February 2020 most of the aerosol consisted of mineral dust (>95\%). Different optical properties of the dust were characterized. The AOD at $500 \mathrm{~nm}$ reached values of 3.11 at sea level, and 0.84 at $2400 \mathrm{~m}$ altitude (23 February 2020). The AE values were very low $(<0.4)$, and close to zero during 23 February, indicating that the dust particles were of a considerable size (up to $6 \mu \mathrm{m}$ ) due to the geographical proximity of their sources located in the western Sahara. The Micro Pulse Lidar recorded an abnormally high Saharan Air Layer (5 km) for this type of winter dust outbreak whose vertical extension does not usually exceed $2.5 \mathrm{~km}$. The observed increase of AOD in the atmosphere led to an increase in the radiative forcing. The daily radiative forcing increased by $41 \%\left(-17.48 \mathrm{~W} \mathrm{~m}^{-2}\right.$ on 22 February to $-42.72 \mathrm{~W} \mathrm{~m}^{-2}$ on 23 February) in the case of global radiation, and by $67 \%$ for direct radiation $\left(-116.94 \mathrm{~W} \mathrm{~m}^{-2}\right.$ on 22 February to $-175.01 \mathrm{~W} \mathrm{~m}^{-2}$ on 23 February).

The desert dust outbreak was well predicted (the spread but also the vertical distribution) by the BDFC MONARCH model, especially for the easternmost islands, delaying the entry of the dust intrusion into Tenerife and forecasting a lower intensity on this island than observed. A week before this dust outbreak took place, the SDS-WAS NAMEE RC had just finished implementing a new product of probabilistic prediction of dust outbreaks for the Canary Islands (based on the SDS-WAS multi-model ensemble) that included EPS-Meteograms of PM $_{10}$ for the Canary Islands air quality stations. With this information, and with the outputs of the dust models of the SDS-WAS Regional Centre, and those of the MONARCH operational model, it was realized that the Canary I slands were facing an exceptional, unprecedented dust episode, much more intense than any dust episode recorded to date. Therefore, it was very fortunate that the SDS-WAS NAMEE RC could alert the AEMET Canary I slands weather prediction and surveillance group to this dust outbreak and also the population directly through social networks. Probabilistic products, used experimentally for the first time in this event, 
demonstrated to be a very useful tool because they are able to summarize the information provided by a set of models, which are very difficult to understand separately, and at the same time provide an objective value of the probability of the event and its maximum value.

The 22-24 February 2020 dust outbreak impacted, unsurprisingly, the health of the population of the Canary archipelago as it took place at low altitudes where most of the population is concentrated. Studies carried out in the two main cities of the Canary Islands, Las Palmas de Gran Canaria and Santa Cruz de Tenerife, indicate that, despite the effectiveness of weather alerts and early warning systems, which prevented part of the population from being exposed to exceptional $\mathrm{PM}_{10}$ levels during the Saharan dust episode of 22-24 February 2020, our results suggest that there were hospital admissions attributable to this episode. Around $70 \%$ of the excess hospital admissions recorded during the first trimester of 2020, attributable to dust, corresponded only to this episode.

Another important impact of this intrusion was on the air operations of airports due to the unprecedented reduction in visibility recorded in the eight Canary Islands airports, with a minimum visibility of $400 \mathrm{~m}$ being recorded at Gran Canaria Airport. For the first time in history, all airports in the archipelago, and their airspace, were closed for a few hours. This resulted in the cancellation of 1000 flights throughout the Canary Islands, which involved an estimated cost of at least 17,650,000 euros, and a major disruption for tens of thousands of passengers who were trapped on the islands for at least two days.

The solar photovoltaic energy production sector was also negatively affected by this severe dust event. On 23 February 2020, production was reduced by $52 \%$ and on 24 February by $72 \%$ compared to normal production. However, this was not the only impact of dust intrusion. Due to the intense dust deposition in the photovoltaic modules, the performance of the installation decreased from $96 \%$ under pre-dust intrusion conditions, to $75 \%$ after the dust intrusion. This situation continued for almost a month until precipitation cleaned the modules. It is estimated that this dust event caused an economic cost in the Canary Islands solar photovoltaic energy production system of one million euros.

Some ecological impacts were identified as:

a drastic decrease in the concentration of pollens and fungal spores,

vagrant bird species ( 80 specimens of Desert Wheatear Oenanthe deserti and about 20 I sabelline Wheatears Oenanthe isabellina), and

invertebrates (vagrant emperor dragonfly and red-veined darter) for the most part typical of northwest Africa reached the islands due to the intense jet that transported the dust to the Canary Islands.

Dust storms are not considered, even today, to be adverse weather events by national weather services and WMO, and perhaps this is why they have not been analysed in detail neither in operational areas of meteorology, nor in academic and scientific fields until relatively recently. Dust storm observation and prediction has developed decades behind conventional weather observation and prediction, and this is also the case with the assessment and quantification of dust storm impacts. Currently we know that severe dust storms cause significant damage in many sectors that directly affect the lives of citizens in large regions of the world (northern Africa, the Middle East and Asia), causing high economic costs. There are sectors where dust storms are known to have a significant impact, but assessment is still difficult because of a lack of available tools.

We hope that this report will be useful for professionals working in the areas of weather prediction observation, in air quality and in atmospheric research, but also for decision makers, managers and stakeholders for different socio-economic sectors who may be greatly affected by these dust storms. This case study can help them become familiar with the effects of these phenomena and their consequences. 


\section{E. Cuevas, C. Milford and S. Basart}

The 22-24 February 2020 dust outbreak was followed by another dust episode of severe intensity a few months later, in June 2020, that while it did not greatly affect the Canary Islands, did have an effect further south and right across the North Atlantic. Every year, dust from the Sahara Desert blows off from Africa and crosses the Atlantic, but most years the dust plume is not as massive or as persistent as that produced in June 2020. This enormous dust plume and event of June 2020 has been nicknamed "Godzilla".

In fact, "Godzilla" was really a series of large dust episodes that originated in the south of the Sahara and Sahel, practically throughout the whole month of J une 2020, which were transported over the Atlantic to the Caribbean and Central America. It has undoubtedly, been the most severe and long-lasting set of dust episodes ever recorded over the Atlantic Ocean since continuous satellite records began. According to the NOAA Atlantic Oceanographic and Meteorological Laboratory (AOML), the dust plume was around $60-70 \%$ dustier than an average dust outbreak. Currently hundreds of researchers from several countries are studying the "Godzilla" dust event with different types of data and from different perspectives and approaches.

2020 has been, without a doubt, a completely anomalous year in terms of dust outbreaks over the North Atlantic. It has also been a year in which numerous climatological and adverse meteorological events records have been broken, circumstances that are explainable in the climate change scenario in which we find ourselves. Most likely, the unprecedented episodes of dust transport that we are already starting to register are connected to two direct consequences of climate change: the change of tropical circulation related to an expansion towards the poles of the Hadley cell, and the change of extratropical circulation, manifested by a shift towards the poles of the zone of high westerly winds in the middle latitudes (Reichler, 2009).

At the regional level, direct feedback between dust and climate are stronger by approximately an order of magnitude near the main regions of origin than everywhere else. This suggests that it could play an important role in the configuration of future climates in North Africa, the Sahel, the Mediterranean region or, the Middle East and Central Asia (Kok et al., 2018), and therefore in Saharan dust outbreaks over the North Atlantic. Shao et al. (2013) indicated that the global dust trend is largely driven by the dominance of the North African dust source, and that under the present climate, the global dust trend is determined by the climate systems governing the Atlantic and North African regimes. Moreover, they found that for North Africa, a direct dust-climate feedback is apparent. A recent study using the highest-resolution continuous climate record ever published, based on ultrahigh resolution glacio-chemical records (Clifford et al., 2019), revealed stronger Saharan dust storms during past warming periods. This same study predicts that a warming planet will make dust storms more intense in the Mediterranean and the Atlantic.

All of these results indicate that northern Africa's dust sources will be, or are already being, greatly affected by climate change. We cannot claim a cause-and-effect relationship between climate change and the dust episode analysed in this report, but it is quite possible that this anomalous February 2020 dust episode and the extraordinary "Godzilla" J une 2020 dust event have occurred as a result of changes in atmospheric processes that could be taking place due to climate change. Evaluating the impact these extraordinary dust episodes have on socioeconomic and environmental activities in as much details as possible is necessary to assess and quantify the impact that climate change could have through dust outbreaks. 
Clifford, H. M., N.E. Spaulding, A.V Kurbatov, A. More, E.V. Korotkikh, S.B. Sneed, M. Handley, K.A. Maasch, C.P. Loveluck, J. Chaplin, M. McCormick, and P.A. Mayewski, 2019: A 2000 year Saharan dust event proxy record from an ice core in the European Alps. Journal of Geophysical Research: Atmospheres, 124, 12.882-12.900. https://doi.org/10.1029/2019J D030725.

Kok, J.F., D.S. Ward, N.M. Mahowald, A.T. Evan, 2018: Global and regional importance of the direct dust-climate feedback. Nat. Commun., 9, 241, https: //www. nature.com/articles/s41467-017-02620-y.

Reichler, T, 2009: Changes in the Atmospheric Circulation as Indicator of Climate Change. In Trevor M. Letcher, editor: Climate Change: Observed impacts on Planet Earth, The Netherlands, pp. 145-164, ISBN: 978-0-444-53301-2.

Shao, Y., M. Klose, K.-H. Wyrwoll, 2013: Recent global dust trend and connections to climate forcing, J. Geophys. Res. Atmos., 118, https://agupubs.onlinelibrary. wiley.com/doi/full/10.1002/jgrd.50836 
The authors would like to thank all those who have participated in obtaining the results in this report for their important contributions. In addition, we express our sincere gratitude to the many public and private institutions that have participated in the preparation of this multidisciplinary report.

We acknowledge the use of imagery provided by services from NASA's GIBS, part of NASA's EOSDIS. We would also like to acknowledge the inDust COST Action (CA162020) which is a network that seeks to develop specific services to help in the mitigation of sand and dust storm impacts.

This work has been carried out in the framework of the WMO Sand and Dust Storm Warning Advisory and Assessment System, which is part of two key WMO research programmes, the GAW Programme and the World Weather Research Programme (WWRP). The authors of the report express their appreciation to O. Tarasova of WMO Secretariat for the additional technical comments provided on the report.

Back cover images:

Photographs taken from the Santa Cruz de Tenerife Observatory of I zaña Atmospheric Research Centre towards the Santa Cruz de Tenerife harbour.

Top photo: 19 November 2020. Bottom photo: 23 February 2020 (Ramon Ramos). 


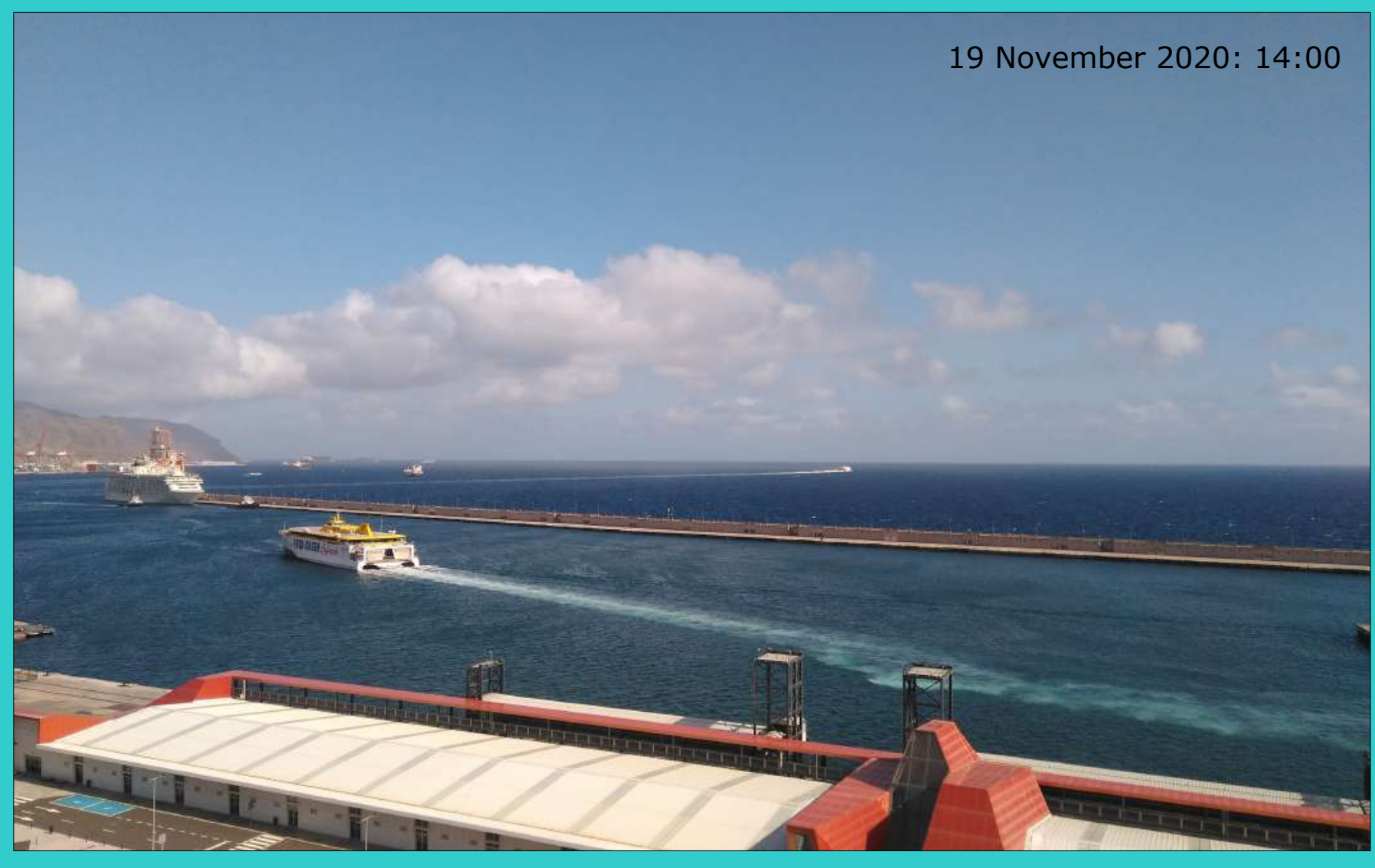

23 February 2020: 17:22

For more information, please contact: Izaña Atmospheric Research Center Calle La Marina, 20, Planta 6 Santa Cruz de Tenerife Tenerife, 38001, Spain http://izana.aemet.es 